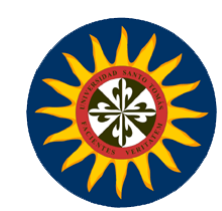

Universidad Santo Tomas

Facultad de Ciencias Económicas

Maestría en Economía

Enseñanza del Modelo Keynesiano para Estudiantes de Pregrado

Una Aproximación Diagramática

Jesús Ricardo Acosta Vesga

Katherine Corredor Quintero

Bogotá D.C., Colombia

2017 
Universidad Santo Tomas

Facultad de Ciencias Económicas

Maestría en Economía

Enseñanza del Modelo Keynesiano para Estudiantes de Pregrado

Tesis presentada como requisito parcial para optar al título de: Magister en Ciencias

Económicas con énfasis en Investigación Económica.

Director:

PhD. Economía, Dr. Gustavo Junca

Bogotá D.C., Colombia 


\section{Contenido}

pág.

1. Justificación

2. Planteamiento del Problema

2.1 Pregunta de investigación

3. Objetivos

3.1 Objetivo General

3.2 Objetivos Específicos

4. Enseñanza pluralista un enfoque heterodoxo

4.1 Estado del arte

4.2 Marco teórico.

5.1 Uso del diagrama para la enseñanza

5.2 Descripción del modelo

5.3. Diagrama de ilustración del modelo

6. Diseñó y aplicación del modelo diagramático 


\section{ENSEÑANZA DEL MODELO KEYNESIANO}

6.3 Evaluación estadística de la descripción del modelo

5. Conclusiones

6. Recomendaciones

Referencias 
ENSEÑANZA DEL MODELO KEYNESIANO

\section{Índice de Tablas}

pág.

Tabla 1. Matriz de categorización de autores económicos, según el enfoque y la relación con el problema de la construcción de modelos económicos

Tabla 2. Teoría General de la Ocupación el interés y el Dinero

Tabla 3. Análisis Lógico

Tabla 4. Análisis lógico aplicando solución con instrumentos de política fiscal

Tabla 5. Convenciones de los datos a estudiar sobre el taller desarrollado por los

estudiantes de la asignatura de Macroeconomía I en el año 2016

Tabla 6. Análisis estadístico de las respuestas dadas por los estudiantes a los que se

aplicó el taller y a los que respondieron de forma tradicional.

Tabla 7. Análisis estadístico con variaciones

Tabla 8. Análisis Estadístico de la Investigación 
ENSEÑANZA DEL MODELO KEYNESIANO

Índice de Ilustraciones

pág.

Ilustración 1. Aghion y Howitt Modelo de Innovación y Crecimiento

Ilustración 2. Contribución del proyecto a las líneas de investigación modelo de ejecución propuesto.

Ilustración 3. Modelo keynesiano con economía cerrada

Ilustración 4. Modelo keynesiano con economía cerrada en equilibrio

Ilustración 5. Modelo diagramático keynesiano con movimiento de las variables afectadas 58

Ilustración 6. Modelo Diagramático Keynesiano en Equilibrio $\quad 59$

Ilustración 7. Modelo Diagramático Keynesiano con Aplicación De Política Fiscal $\quad 60$

Ilustración 8. Modelo Keynesiano tradicional $\quad 61$

Ilustración 9. Modelo keynesiano forma tradicional $\quad 62$

Ilustración 10. Número de estudiantes que participaron en la investigación 64

Ilustración 11. Respuestas Correctas E Incorrectas 65

Ilustración 12. Medidas de tendencia central que nos muestran que el modelo es pertinente 68

Ilustración 13. Medidas de tendencia central de la forma tradicional 68 


\section{Resumen}

El presente estudio pretende resaltar la importancia de la enseñanza del modelo Keynesiano como una aproximación diagramática para estudiantes de pregrado. El campo de interés está centrado en la educación de la economía específicamente en la utilización de modelos y diagramas que permiten desarrollar un esquema claro frente a diversas anomalías resultantes y que un estudiante de economía debe interiorizar. Con base en el análisis de los test asignados a un grupo de estudiantes de finanzas y negocios internacionales de la Fundación Universitaria Monserrate, se concluye por parte de los investigadores que el método geométrico resulta eficaz para asimilar conceptos complejos de los modelos económicos, por lo tanto puede ser una herramienta pedagógica poderosa y flexible en este contexto.

Palabras clave: Modelo Keynesiano, aproximación diagramática, educación de la economía, método geométrico, herramienta pedagógica. 


\title{
ENSEÑANZA DEL MODELO KEYNESIANO
}

\begin{abstract}
The present study is intended to highlight how important may be the teaching Keynesian model as a diagrammatic approximation for undergraduate students. The empirical evidence was focused on the economic education, more specifically on the use of models and diagrams which allows students to assimilate and develop a clear schema facing different resultant anomalies. Following the analysis of the test assigned to a financial and international business students group at the university foundation Monserrate, it is likely to conclude that the geometrical method proved to be effective when assimilating complex concepts about economics models; this therefore can be a powerful and flexible pedagogic tool in this context.
\end{abstract}

Keywords: Keynesian model, diagrammatic approximation, economic education, geometrical method, pedagogic tool. 


\section{Justificación}

La educación es un elemento vital pero a su vez complejo en el desarrollo humano.

La complejidad en la enseñanza de fundamentos instaurados en el tiempo presentan esta particularidad debido a la variedad de elementos agregados a la esfera del conocimiento desde diferentes puntos de vista, estos deben ser aceptados como propios para permitir su comprensión.

En el estudio y enseñanza de la economía resulta evidente que no todos los estudiantes se apegan fácilmente a una comprensión definitiva de elementos teóricos como modelos macroeconómicos, esto es el resultado de falencias en el proceso educativo, el cual no tiene en cuenta en algunos casos, como la diversidad a la que se enfrenta el conocimiento. Este estudio representa esencialmente una de las complicaciones más comunes en el aprendizaje de la economía, se resalta como ejemplo una de las complejidades que aquejan a los estudiantes de este campo al instaurarse en los modelos keynesianos con propiedad, dicha situación resulta en algunos casos siendo un proceso más que complejo ya que no todos pueden evidenciar un esquema claro mediante las meras formulaciones. Se pretende de este modo y mediante el uso de teorías de apoyo en la educación económica como lo es el pluralismo el cual respeta y fomenta el debate y el escepticismo sano, ya que el monismo no lo hace. El pluralismo es consistente con el ideal de una educación universitaria, y es una parte intrínseca del desarrollo intelectual (Sen, 1981).

De este modo se entrevé una necesidad y una solución a este problema del cual ha sido posible desarrollar una aproximación diagramática, que genera posibilidades para una mejor comprensión a nivel espacial, para aquellos estudiantes de economía, que efectúan su educación mediante procesos más visuales. (Salazar, 2012) 
Se efectuó un test de macroeconomía en estudiantes de finanzas y negocios internacionales de la Fundación Universitaria Monserrate con lo cual se generaron evidencias claras de dicha necesidad y efectividad en el desarrollo de dicha aproximación diagramática. 


\section{Planteamiento del Problema}

La mayoría de nosotros hemos optado por estudiar economía con el fin de adquirir una comprensión profunda de los fenómenos económicos que enfrentan los ciudadanos de hoy en día. Pero la enseñanza que se ofrece, sobre de la teoría neoclásica, clásica y keynesiana, no suele responder a esta expectativa.

Esto dio lugar a movimientos globales para la reformar de enseñanza de la economía, con el objetivo de cambiar la educación tradicional o monista conductista y hegemónico en favor del pluralismo, aprendizaje a partir de diversos puntos de vista y de todo el espectro ideológico de las ciencias sociales opuestas. (Reardon, 2009)

Los modelos económicos utilizados actualmente por profesionales y estudiantes, presentan elementos importantes para el entendimiento en el análisis de anomalías. Tales características facilitan notablemente el trabajo brindando una imagen más clara de posibles relaciones y consecuencias, que afectan a la economía de un país. Muchos aprendices que actualmente se enfrentan a este campo de las ciencias sociales, pueden encontrar una amplia gama de herramientas en formulas desarrolladas y planteadas anteriormente por eruditos en el tema como lo es Keynes y sus modelos macroeconómicos.

De alguna forma este gran conocimiento adquirido a través de los años puede resultar poco complaciente en algunos casos. Vale precisar que en muchos claustros alrededor del mundo, la comprensión de elementos teóricos se enfatiza solo en este aspecto y deslegitimiza las facultades y necesidades de quienes lo adquieren perdiendo libertad en la proliferación de nuevos elementos, así entonces "El mundo", argumentó Bacon (2000), "no debe ser concertado a los estrechos límites de la comprensión (como lo ha sido hasta 
ahora), pero el entendimiento debe ser liberado y debe ampliarse para tener la imagen del mundo, ya que se encuentra para ser".

La decisión por estudiar economía en muchos casos se arraiga a la comprensión de los fenómenos presentes en ella y los cuales deben ser diariamente enfrentados por la sociedad. El dilema resultante en algunos casos, se instaura en un pequeño grupo de estudiantes poco tomados en cuenta por la comunidad educativa, que equivocadamente no perciben uno de los elementos más estudiados en la enseñanza, como lo es la teoría de las inteligencias múltiples.

La enseñanza de la economía se debe realizar de manera integral o pluralista donde el estudiante adquiere más campo de acción para la toma de decisiones, y no de forma conductita o monista que no le da la oportunidad de abrir su conocimiento. Todo esto está relacionado con la reestructuración de la enseñanza de la economía para resolver los diferentes problemas económicos.

\subsection{Pregunta de investigación}

¿Cómo puede la educación en economía reestructurarse para resolver los problemas económicos? 


\section{Objetivos}

\subsection{Objetivo General}

Implementar el modelo keynesiano como una aproximación diagramática para los estudiantes de pregrado.

\subsection{Objetivos Específicos}

- Desarrollar un elemento diagramático del modelo keynesiano en cuatro cuadrantes.

- Identificar la necesidad de esta herramienta en estudiantes de pregrado.

- Implementar el material didáctico en estudiantes de pregrado para verificar su eficacia dentro del proceso de toma de decisiones. 


\section{Enseñanza pluralista un enfoque heterodoxo}

\subsection{Estado del arte}

En la educación se deben tener en cuenta algunos aspectos que nos llevan al mejoramiento de la misma tal, como es el pluralismo (filosóficamente significa que es una doctrina en oposición al monismo o conductismo, afirma que hay múltiples o infinitas afirmaciones, o tipos de realidades económicas). El cual es necesario para la innovación y el avance científico (Hodgson, 1999), esto resulta de vital importancia en cualquier campo de la educación, puesto que permite afianzar una apropiada y segura evolución de la enseñanza, visto esto en el contexto de la educación en economía, se puede obtener confianza, para registrar un paso, hacia una economía más dinámica, con profesionales mejor preparados y motivados.

Ahora bien, una clara definición de pluralismo según (Vromen, 2007) es similar a otros múltiples conceptos, facetas como la democracia y la igualdad, rica en significado, pero que carecen de una definición universalmente aceptada. De hecho, el "pluralismo significa que acepta, reconoce y tolera la existencia de diferentes posiciones o pensamientos diferentes y para diferentes personas". Se puede evidenciar entonces una aceptabilidad y una facilidad en el acoplamiento de conceptos, con el fin de brindar un entorno positivo a la enseñanza. Son diversos los modelos en economía y más aún las formulas contenidas para ejercer un desarrollo propio de distintas situaciones, en las cuales un método pluralista en la enseñanza de la economía ayudaría a su mejor comprensión.

Ocasionalmente resulta fácil reinventar equívocamente la comprensión sobre el pluralismo, Reardon (1995). Describe, que, si bien, por una parte, el pluralismo acepta la 
legitimidad de otros enfoques en sus propios términos, el pluralismo es perfectamente coherente con el argumento. De esta forma, resulta imprescindible resaltar esta demostración, en el propio enfoque que es preferible a otros en términos de un criterio propio, sabiendo que ningún enfoque puede reclamar la verdad, la esencia del pluralismo y argumentando en contra de las alternativas, porque han asumido demostrablemente lo malo - la esencia del monismo( es que acepta un solo enfoque como verdadero).

Las postulaciones críticas, frente a determinados aspectos de la economía, pueden llegar a ser relevantes, siempre y cuando se respeten los principios, dando cabida a la diversidad conceptual. El no establecer un ejercicio crítico constructivista, resultaría como la antítesis del pluralismo, de lo cual, se asume que la antítesis del pluralismo es el monismo (reconoce un solo principio como fundamento de todo lo existente). (Diccionario Filosófico Marxista , 1946)

Pedagogía monista, mediante, la exclusión de la discusión de alternativas y deslegitimiza su existencia, es equivalente al proselitismo, y por desgracia "los estudiantes que están haciendo proselitismo, no pueden respetar puntos de vista alternativos y por lo tanto, no pueden trabajar juntos para resolver los problemas" (Reardon. 1995, p. 91). Es importante destacar el trabajo del pluralismo en la enseñanza de la economía, puesto que esta respeta, fomenta el debate y el escepticismo sano, el monismo no lo hace. El pluralismo es consistente con el ideal de una educación universitaria, y "es una parte intrínseca del desarrollo intelectual" (Reardon, 2009)

El cambio es un aspecto, que pocas veces se asume fácilmente por las personas, resulta igualmente complicado para los economistas ortodoxos, integrar elementos nuevos como el pluralismo en el ámbito profesional. No es más que una simple norma de 
comportamiento que rige a este grupo de individuos a plasmar su rechazo frente a esta nueva postura, por otra parte es de suponer, que los economistas heterodoxos integran de una mejor forma al pluralismo pero establece, que esto es una simplificación engañosa, de los economistas heterodoxos "a menudo promueven sus propias ideas y métodos de cómo superar a los demás y no abrazan el pluralismo" (Holcombe 2008, p. 52, tomado de Reardon 1995: 91). Después de todo, "disciplinas son como tribus, que tienen una cultura específica y hábitos específicos, normas y reglas, y no aceptan fácilmente los extraños" (weehuizen 2007, p. 165, tomado de Reardon 1995: 91).

Simplificando un poco lo planteado anteriormente resulta factible afirmar que lo importante, más que establecer una comparación entre economistas pluralistas y heterodoxos, en realidad se trata de que la educación de la economía logre adoptar de manera constructivista métodos pluralistas sin dar relevancia a las ideologías.

No en todos los ámbitos se presume que los ortodoxos tengan un desinterés al cambio. De igual forma es posible afirmar que la ortodoxia se ha vuelto más pluralismo, especialmente a nivel metodológico. Diane Coyle (2007), escribe evidentemente que la economía ya no es el monolito que una vez fue: "los académicos que trabajan en las fronteras de la economía, con firmeza han dejado atrás el reduccionismo que mira hacia adentro, que, efectivamente, a veces caracterizan a la disciplina en el pasado. (p 3-4, tomado de Reardon (1995).

Por desgracia, como Coyle (2007), ella se lamenta, "que los economistas "no" enseñamos lo que predicamos" (p. 250), tomado de Reardon (1995, p. 91). Este es un típico error que se asume constantemente en la educación de la economía, donde educadores ortodoxos presumen de una verdad absoluta, en cuanto a las teorías adoptadas 
por ellos, sin tener en cuenta la evolución y proliferación de nuevos conocimientos y situaciones en el mundo. También coinciden en que al menos, pedagógicamente la corriente económica principal está lejos de ser plural: esto resulta ser un problema para los nuevos economistas que surgen, que quieren adoptar nuevas ideas, para asimilar con mayor claridad las perspectivas que cada día van surgiendo. "Por desgracia, la enseñanza de la economía en la licenciatura, se ha quedado atrás lo que es ampliamente entendido por los principales economistas. El modelo neoclásico convencional se enseña, a menudo como si fuera el único enfoque en el campo" (XVII - XVIII, tomado de Reardon 1995: 91).

Es imprescindible que el nuevo economista pretenda generar una asociación entre las distintas doctrinas y la aparición de nuevas teorías, que refresquen el campo de acción y den mayor claridad para desentrañar diversos problemas.

Para establecer un ejemplo más claro sobre este tema seria indispensable dirigir la mirada al libro de Hermann (2007), la economía institucional y el psicoanálisis: ¿Cómo pueden colaborar para una mejor comprensión de la dinámica individual en la sociedad? Si bien es un título extenso, es evidente que su teoría traiciona, su objetivo institucional el cual se beneficiaría teniendo en cuenta los conceptos psicoanalíticos, con el fin de ayudar a arrojar luz más profunda en lo psicológico y en un aspecto más individual de las dinámica institucionales; en relación con esto, por otro lado, la teoría psicoanalítica en su aplicación a los problemas sociales de las consideraciones de conceptos institucionales, tendrían como fin ayudar a aclarar el lado institucional y colectivo en base a la dinámica psicológica. (2007, Tomado de Reardon 1995, p. 91).

Sería un error tratar de infundir en los recientes educadores que asimilen y sean 
conscientes de la diversidad de herramientas, que se le podrían dar a un estudiante a partir de la vinculación de nuevos conceptos, para que este pueda ejercer un trabajo más confiable e enriquecido. En su lugar, lo que debería pretender el pluralismo en teoría es infundir humildad y una curiosidad respetuosa sobre puntos de vista alternativos.

Los elementos que han sido creados en el pasado por respetados economistas y quienes son considerados como los padres de la misma, son de vital importancia y no se puede perder el vínculo con esta valiosa información. Por otra parte el uso excesivo de estos elementos de la economía tradicional, ha hecho un enorme perjuicio a la educación, al pretender que la economía se basa en hechos irrefutables, sin áreas pendientes de acuerdo. Por esta razón las nuevas generaciones deberían trabajar por un pluralismo respetuoso en el que permitan reciclar y crear elementos que sean necesarios.

Luego de haber generado conciencia hacia un nuevo enfoque pluralista se debería definir la estrategia más adecuada, con metodologías pedagógicas enfatizadas al contexto actual. Es indispensable entonces la creación de una guía para aquellos interesados en la enseñanza, desde una perspectiva pluralista, lógica, independientemente de la ideología de que se trate.

De este modo se establecen las siguientes definiciones a tener en cuenta para tal fin: (Reardon, 1995, p. 91)

(a) Para proporcionar sugerencias prácticas a los profesores dispuestos a poner en práctica pluralismo en el aula.

(b) Para aumentar la influencia pedagógica de la economía pluralista reduciendo al mismo tiempo la hegemonía del monismo en cualquier nivel.

(c) Para aumentar el pensamiento crítico en la economía. 
(d) Para aumentar el interés de los estudiantes en la economía.

Es factible encontrar quienes se preocupaban por establecer una economía pluralista, que protegiera elementos como la economía política, desde un punto de vista más diversificado, optando por una expansión de conceptos en la misma a través de la necesidad del pluralismo en la educación económica. Una de estas postulaciones la hace Edward Fullbrook, (Reardon 1995) quien hace una acusación mordaz al fracaso de la profesión económica de predecir, comprender y tomar posesión de la actual crisis financiera y argumenta que "Nunca una profesión ha traicionado la confianza de la sociedad tan agudamente y nunca ha estado tan desesperada en una reforma fundamental" (p. 91). Es evidente entonces que persiste una necesidad por mejorar las características de la educación de la economía dado a la escasez de herramientas de apoyo como conceptos verídicos que aporten a la realidad.

Se define que nuestros libros de texto, cursos que inculcan conceptos erróneos sobre cómo funciona la economía, por tanto dice que hay que reformar el sistema educativo de la misma para evitar los desastres en la toma de decisiones futuras. (Reardon, 1995, p. 91)

Guerrien, (tomado de Reardon, 1995, p. 91) autor principal de la petición francesa y Sophie Jallais, argumentan que, para que las semillas del pluralismo germinen, es necesario despejar los residuos adecuados del pensamiento monista, que desafortunadamente se enseña como inevitablemente cierto, algo para ser analizado críticamente. Este es un paso importante pero a menudo pasado por alto en la implementación del pluralismo: Demuestran cómo, con los conceptos hasta ahora apreciados del comercio, competencia perfecta e imperfecta y racionalidad no les 
quedaron claros.

El cambio en la enseñanza de la economía debe ser algo necesario de generar en este momento, y cada aspecto que estimule una evolución en la misma debe ser estudiado, respetado y adoptado de ser necesario. Marshall (1946) escribió en el prefacio de su octava edición:

La principal preocupación de la economía es, por lo tanto, con los seres humanos que son impulsados, para el bien y el mal, a cambiar y progresar. Así, la idea central de la economía, aun cuando sus fundamentos son los únicos en discusión, debe ser la de la fuerza viva y el movimiento. (1920 XV, tomado de Reardon 1995, p. 91)

Uno de los factores que puede afectar el desarrollo económico óptimo, se ve claramente expuesto en el uso de tácticas directamente relacionadas con algunas ideologías clásicas. Son en estas situaciones las que por un mal entendimiento de las mismas ideologías y/o por un mal manejo al integrarlas, dentro de un contexto actual, terminan por derivar la economía y el mismo desarrollo educativo de esta, hacia una problemática difícilmente irreversible. Esta situación es visible en el análisis que se hace de los principios económicos más vendidos por Makin, (tomado de Reardon 1995, p. 91) quien como presidente, del consejo de asesores económicos del presidente Bush, el cual estuvo involucrado directamente en la ingeniería del desastre actual, el encuentra el texto culpable del neoplatonismo, (sostenido como verdades básicas evidentes de las cuales todo se deduce), técnicas excesivas de intimidación y apelación, todas diseñadas para proselitismo en lugar de educar.

No obstante es importante retomar que las teorías de la economía clásica, no son ni deben ser optadas, como inadecuadas en su totalidad, pues son la base de la economía 
actual. Es deber de los educadores como emisores del conocimiento asumir responsable y críticamente su rol en el campo educativo, para implementar correctamente el pluralismo, de igual forma es deber de los estudiantes exigir una educación basada en la integración de teorías sin límites conceptuales.

Un ejemplo claro de la situación expuesta anteriormente se ve en el siguiente extracto:

Después de leer la petición de los estudiantes de la Universidad de Notre Dame, me conmovió su apremiante y apasionado pedido de la reforma de la educación económica para comprender mejor nuestro mundo rápidamente cambiante. (Editado por Reardon 1995, p. 91)

Estos estudiantes propulsaron la crítica constructiva a un nivel muy importante en la economía moderna, una economía cuya pretensión es de crecer en conceptos acorde con el desarrollo de la sociedad, además de estimular este proceso adecuadamente.

Es evidente que estos estudiantes lograron aportar un cambio en el pensamiento de su maestro y de aquellos que se relacionan con el caso. Esto no es ajeno a muchos economistas a nivel mundial, que seguramente se han preguntado por este mismo cambio propuesto aquí y el cual solo pretende una buena integración de saberes, como se muestra a continuación; su argumento pluralista no es para reemplazar una hegemonía con otra, sino “para permitir una comprensión más rica y más profunda de la economía tradicional”, lo que constituye un verdadero pluralismo. El aprendizaje de la economía como los estudiantes normalmente la ven, es decir de una manera instrumental, esta desprovista de una rica comprensión de la evolución histórica de los conceptos y sus implicaciones”. (Editado por Reardon 1995, p. 91) 
Este es un ejercicio que puede llevar tiempo de asimilar pero es indispensable asumir adecuadamente un pensamiento más liberal y permisivo en el cual se deje a un lado la doctrina elitista monista.

Bernard Guerrien, autor principal de la petición francesa y Sophie Jallais argumentan que, para las semillas del pluralismo germinen, es necesario despejar los residuos canónicos del pensamiento monista, que desafortunadamente se enseña como inevitablemente cierto, algo para ser analizado críticamente. Este es un paso importante pero a menudo pasado por alto, en la implementación del pluralismo: Demuestran cómo, con los conceptos hasta ahora apreciados del comercio, competencia perfecta e imperfecta y racionalidad, no les quedaron claros. (Editado por Reardon 1995, p. 91)

Es posible encontrar diferentes puntos de vista en cuanto a lo planteado anteriormente, pero es de resaltar la economía por sí misma, no justifica el mal uso de la comprensión de ella misma, por el contrario genera un campo propicio con situaciones que estimulan a la creatividad para la solución de problemas en la sociedad. Así entonces es posible evidenciarlo en la siguiente afirmación; La principal preocupación de la economía es, por lo tanto, con los seres humanos que son impulsados, para el bien y el mal, a cambiar y progresar. Así la idea central de la economía, aun cuando sus fundamentos son los únicos en discusión, debe ser la de la fuerza viva y el movimiento. (1946 (1920): XV, tomado de Reardon 1995, p. 91)

Al centrarse estrictamente en el equilibrio del curso de los principios de la economía tradicional se ignora el paso del tiempo. Esto, según David trigo en el capítulo 7, enseña a los estudiantes a pensar que el tiempo no importa, ni tampoco el camino hacia el equilibrio: "los estudiantes pueden aprender una falsa dinámica interpretativa habilidad 
de sus libros de texto o instructores, pero tal conocimiento puede ser un cosa peligrosa si promueve el malentendido de la dinámica económica y las expectativas ingenuas sobre el ritmo y el camino de los resultados a largo plazo”. (Editado por Reardon, 1995, p. 91)

De acuerdo con Irene Van Staveren en el capítulo 8 la economía tradicional sufre tres deficiencias:

(a) La suposición de que la macroeconomía es simplemente una agregación de micro fenómeno.

(b) El aumento gradual de la complejidad tópica, que afortunadamente sacrifica efectos realistas y la interrelación entre agentes económicos.

(c) La inclusión de un conjunto predecible de temas centrales: inflación, crecimiento, ciclos económicos, desempleo, dinero, intereses y comercio, etc., omitiendo temas importantes sobre externalidades, desequilibrios, riesgos, inestabilidad, y el medio ambiente. Staveren sugiere reestructurar el programa para enfatizar estos temas críticos, omitidos e interrelacionados. (Editado por Reardon, 1995, p. 91)

En lugar de estudiar las firmas reales, los estudiantes en microeconomía tradicional, estudian los beneficios hipotéticos de equilibrio y las condiciones de producción bajo diferentes estructuras de la industria. Aunque se reconocen los cambios del equilibrio existente y se hacen comparaciones entre los equilibrios, "este precio de equilibrio nos interesa, no en cómo el mercado llega a este equilibrio o cómo puede cambiar durante largos períodos de tiempo" (Varían 3005, p. 3, énfasis en original, tomado de Reardon 1995, p. 91). El énfasis de equilibrio se remonta a la envidia física del siglo XIX, donde la búsqueda de las condiciones de equilibrio de esto y aquélla surgió en una época muy enamorada por la ciencia, sobre todo de la física newtoniana. El método 
en gran parte del enfoque- de la economía se desarrolló como si estuviera estudiando las fuerzas cambiantes muy lentamente y previsiblemente de la naturaleza, en lugar de los procesos rápidos, caóticos e inciertos de la sociedad. (Dowd, 2004, p 134, tomado de Reardon 1995, p. 91)).

Champlin y Wiens - Tuers, alude que hasta la primera mitad del siglo XX, la economía del trabajo era pluralista, con los institucionalistas y los marxistas contribuyendo activamente. Lamentablemente, Champlin y Wiens - Tuers, señalan que la economía laboral contemporánea "no es sólo un curso que utiliza la microeconomía; Es la microeconomía”. (Editado por Reardon, 1995, p. 91). De hecho, la economía laboral tradicional utiliza bloques neoclásicos: maximización de la utilidad, oferta y demanda, isocuantas, productividad marginal, equilibrio y competencia perfecta. Los estudiantes expuestos a la economía tradicional, se matriculan en cursos de división superior con equipaje sesgado. Como un ejemplo, dado que la competencia perfecta es el ideal, cualquier intervención institucional, como el salario mínimo o los sindicatos sólo puede distorsionar los resultados de otro modo benéfico.

La historia es una parte primordial en todos los aspectos, pero lo es aún más para la economía política; Por lo tanto, una visión dinámica del crédito y las finanzas es fundamental para su teoría y política fundamental. Los sucesivos cambios institucionales están incrustados en la teoría, por lo que el conocimiento se vuelve relevante para los cambios en la economía real. El análisis es histórico ya que las diferentes fases de evolución se delimitan a través del tiempo, ya que la histéresis (describe la dependencia que tiene la llamada tasa natural de desempleo con su trayectoria en el tiempo, y para el análisis de la relación entre el tipo de cambio y comercio exterior) (Diccionario Filosófico 
Marxista , 1946) y la dependencia del camino afectan la economía. De este modo vemos como hilaba la historia de forma incesante y natural en cada hecho de la vida, siendo de este modo un elemento primordial de información dispuesta al análisis, que la economía debe aprovechar para un determinado estudio.

\subsection{Marco teórico.}

Los modelos keynesianos son un vivo ejemplo de las estructuras económicas que un día fueron innovadoras, luego refutadas y por ultimo reinstauradas. La re vinculación de conceptos en la economía se dan por la necesidad que surge en determinada situación, la deflación en el desempleo es lo que da vida nuevamente a Keynes (1936), ya que la respuesta a esta situación se encuentra en la siguiente formula.

Desempleo y $\quad$ Dg $\quad C=C(Y d-T) \quad I=I(Y, r) \quad G \quad X=X\left(P^{X}, T c\right)$

deflación

En ocasiones aunque los modelos resulten ser significantes para una situación cotidiana, resulta aún para algunos un tanto complicado el asimilar estos conceptos presentados con formulaciones que limitan su visón y no los sitúa en un plano espacial. Los diagramas presentados para plasmar dichas situaciones instauran mayor seguridad en su asimilación, por su parte (Blau \& Lloyd, 2010) señalan que las figuras y diagramas también se han utilizado en economía para las funciones de investigación de análisis de alto nivel, tales como el descubrimiento de los resultados y la demostración de pruebas, así como para la pedagogía. No está mal adquirir las matemáticas necesarias en determinado modelo pero sería de gran ayuda para mejorar aspectos tales como la intuición en la economía el brindar un acercamiento a al mismo modelo con la ayuda de un diagrama de cuatro cuadrantes, siendo este el foco para visualizar atentamente el trabajo desarrollado con una amplia comprensión. 
Para fomentar aún más el uso de diagramas como herramienta pedagógica, Ramsden (2003, p.86) sostiene que el aprendizaje efectivo, y la enseñanza que facilita este tipo de aprendizaje, se conceptualiza mejor como un cambio en la forma en que los alumnos van a entender el mundo que les rodea. Ciertamente esto permite ampliar la perspectiva y enfocarse aún más en el proceso lo cual genera un entendimiento efectivo y no solo como el entendimiento de datos relacionados.

El acceso a una estructura subyacente es algo factible con este método y una de las características clave de la enseñanza eficaz. Un claro ejemplo del uso espacial en la enseñanza de economía se presenta en la utilización del muy conocido diagrama (Solow, 1956), Blaug y Lloyd (2010, p.5) señalan que las figuras y diagramas también se han utilizado en economía para las funciones de investigación de análisis de alto nivel, tales como el descubrimiento de los resultados y la demostración de pruebas, así como para la pedagogía.

Minsky (2008), Presentan un modelo de innovación y crecimiento en cuatro cuadrantes el cual influye ciertamente en nuestra representación diagramática, este modelo resulta trascendental para lograr arraigar conceptos clave en los estudiantes. Es importante tener en cuenta esta concepción del tiempo en el modelo. Las variables clave se determinan conjuntamente por las relaciones funcionales que se muestran en las expresiones (1), (2), (3) y (4), que se presentan a continuación (Aghion \& Howitt, 1997): $Y=A x^{a}$

$$
\begin{aligned}
& x_{t}=\left(\frac{\alpha^{2}}{w_{t}}\right)^{\frac{1}{(1-\alpha)}} \\
& W_{t}=\lambda \frac{\gamma \widetilde{\pi}\left(w_{t}+1\right)}{\gamma+\lambda n_{t}+1} \\
& n_{t}=N-\bar{x}\left(w_{t}\right)
\end{aligned}
$$


En el desarrollo de nuestro diagrama de cuatro cuadrantes, vamos a dejar a un lado la ecuación (1) y la producción en el sector de bienes final (que en última instancia será la variable de interés) y volver a estos aspectos del modelo posteriores. Por el momento, nuestra atención se centrará en las ecuaciones (2), (3) y (4) y las cuatro variables endógenas dentro de estas ecuaciones: $\mathrm{Xt}, \omega \mathrm{t}, \mathrm{y}$ nt $\mathrm{n}_{\mathrm{t}+1}$. La ecuación (2) representa la demanda de mano de obra en el sector de bienes intermedios en función del salario productividad ajustada. Esta relación se muestra en el tercer cuadrante (abajo a la derecha) de la figura 1 , donde ¿xt empleo es una función decreciente de la tasa de salario? $\mathrm{T}$ la productividad ajustada. La ecuación (4) es la condición de equilibrio para el mercado de trabajo en general y esto se muestra en el cuadrante IV de la figura 1 como una línea recta con pendiente menos uno en el espacio $\left(\mathrm{x}_{\mathrm{t}}, \mathrm{n}_{\mathrm{t}}\right)$. Debido a que el mercado laboral es competitivo, todas las transacciones en el mercado de trabajo se producen al mismo precio de mercado. Con la oferta de trabajo agregada igual a $\mathrm{N}$, la tasa de salario $\mathrm{W}_{\mathrm{T}}$ la productividad ajustada será, por lo tanto, será determinado por la ecuación (4). (Aghion \& Howitt, 1997)

La curva de arbitraje de la investigación (A) está disminuyendo por lo tanto en el futuro cantidad de mano de obra empleada debido a que el valor de hacer la siguiente innovación es: 


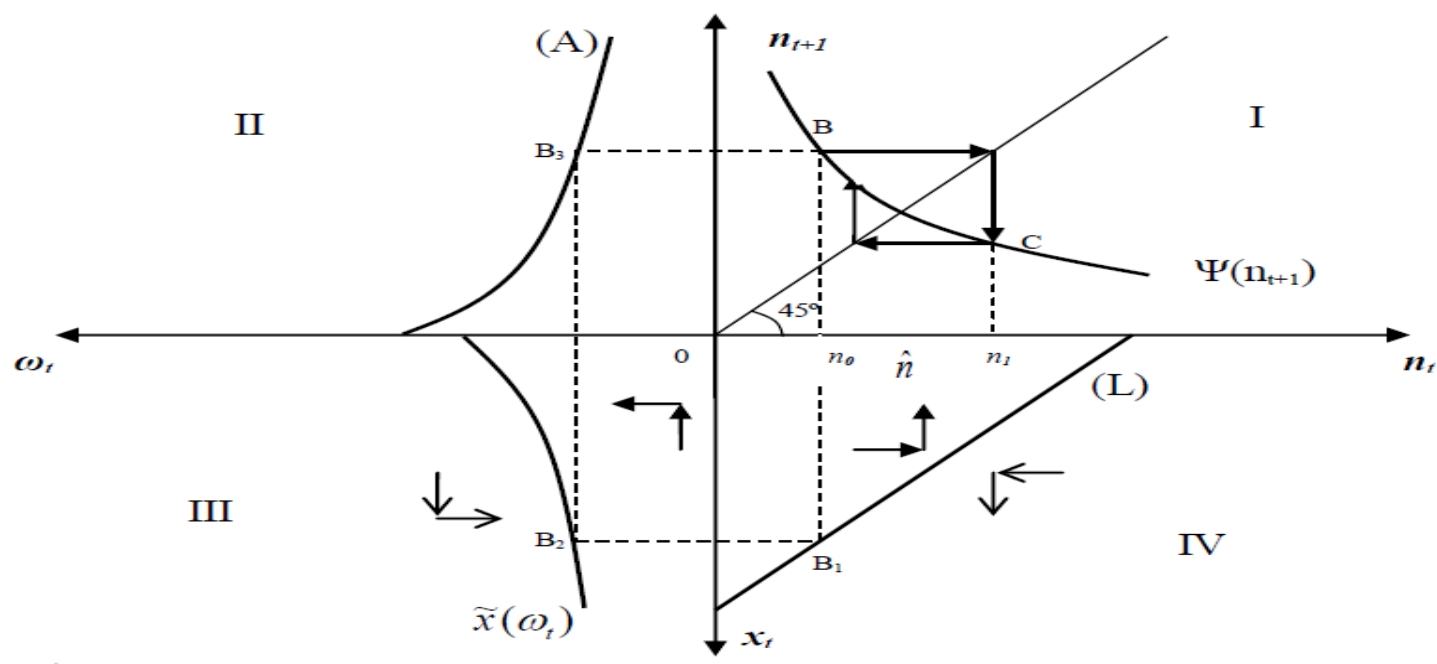

Ilustración 1. Aghion y Howitt Modelo de Innovación y Crecimiento

Disminución en el futuro cantidad de investigación. El valor de hacer la siguiente innovación está disminuyendo en la probabilidad de la innovación $\lambda n_{t+1}$ (en el caso de tecnología de investigación lineal), donde $\lambda$ es un parámetro que indica la productividad del sector de la investigación. En consecuencia, el salario corriente disminuye también. La condición de arbitraje de investigación (A) regula la dinámica de la economía a lo largo de sus sucesivas innovaciones. Las inversiones óptimas en las innovaciones son determinadas por esta condición y rigen la dinámica de la economía. Observe que la pendiente negativa de la curva correspondiente a (A) refleja la suma de dos elementos, la influencia de un efecto de destrucción creativa, y el impacto de dos efectos de equilibrio general, con repercusiones para la pendiente de la relación funcional entre la investigación en dos períodos sucesivos en el primer cuadrante. Los efectos de equilibrio general de los salarios sobre los beneficios creados por la investigación actual y del nivel de empleo en la industria de los salarios se añaden al siguiente análisis.

En la sección anterior del papel derivamos esta relación implícita en la forma de expresión (5), que también se reproduce a continuación. (Aghion \& Howitt, 1997) 
$n t=N-\left(\frac{\left(\frac{\lambda y(1-\alpha)}{\alpha}\right)(N-n t+1)^{\alpha}}{\gamma+\lambda n t+1}\right)^{\wedge}\left(\frac{1}{\alpha-1}\right)$

Esta es la curva de la relación de la ecuación (5) y su relación negativa entre la mano de obra empleada en la investigación actual y el futuro nos dice que una mayor cantidad de investigaciones futuras desalentará la investigación actual. Una mayor cantidad de investigaciones futuras disminuirá el beneficio marginal de una unidad de trabajo de investigación (a través de la influencia de un efecto de destrucción creativa y el impacto de un efecto de equilibrio general), lo que implicará un salario corriente más baja (con el fin de restablecer la igualdad entre el costo marginal de la investigación y el beneficio marginal de la investigación tomada de la ecuación de arbitraje de investigación).

Económicamente, podemos pensar en este resultado en términos de maximización del agente y la previsión perfecta. Versión Minsky (2008) de schumpeteriano del modelo de abstracción de elementos tales como la incertidumbre acerca de los futuros esfuerzos de investigación y utiliza estas herramientas modernas de agente de la maximización y la previsión perfecta.

Conclusión del modelo Minsky (2008), modelo de innovación y crecimiento.

En este trabajo se ha argumentado que el método geométrico es muy eficaz para lograr que los conceptos clave a través de los estudiantes y proporcionar explicaciones claras de las ideas complejas en modelos económicos. Por lo tanto puede ser una herramienta pedagógica poderosa y flexible incluso para enseñar a los estudiantes graduados. Hemos utilizado estos principios para desarrollar un diagrama que ilustra las características clave de (Minsky, 2008), modelo de crecimiento endógeno, a través de la destrucción creativa. 
Tabla 1.

Matriz de categorización de autores económicos, según el enfoque y la relación con el problema de la construcción de modelos económicos.

\begin{tabular}{|c|c|c|c|}
\hline $\begin{array}{c}\text { Categorías y } \\
\text { Autores } \\
\end{array}$ & $\begin{array}{c}\text { Teoría } \\
\text { Económica } \\
\end{array}$ & $\begin{array}{c}\text { Modelo } \\
\text { Económico } \\
\end{array}$ & $\begin{array}{c}\text { Aplicación del } \\
\text { Modelo } \\
\end{array}$ \\
\hline \multirow[t]{25}{*}{ Jhon Hicks } & Introdujo el principio & IS - LM, la curva & Muestra la relación \\
\hline & de compensación y el & descendiente de la & entre inversión \\
\hline & Análisis transversal. & IS representa el & ahorros y liquidez \\
\hline & (Forstater, 2008) & equilibrio en el & monetaria. A medida \\
\hline & El esquema IS-LM es & mercado de bienes, & que la inversión \\
\hline & presentado & Mientras que la & aumenta la curva IS, \\
\hline & inicialmente por Hicks & curva ascendiente & se desplaza hacia la \\
\hline & en 1937. & LM representa el & derecha, \\
\hline & Posteriormente sufre & equilibrio en el & conduciendo a tipos \\
\hline & diversas & mercado monetario. & de interés más altos y \\
\hline & modificaciones. Entre & El punto de & a la expansión \\
\hline & ellas, las más & intersección entre & económica. \\
\hline & importantes. Fueron & ambas curvas & (Forstater, 2008) \\
\hline & las de 1957 y 1981 . A & señala el equilibrio & Entonces, según \\
\hline & lo largo de este medio & general entre ambos & Hicks, el trabajo de \\
\hline & siglo Hicks & mercados. & Keynes \\
\hline & consolidado & (Forstater, 2008) & representa \\
\hline & "método & Hicks comienza la & ruptura. Es, más \\
\hline & equilibrio". Su reciente & exposición & bien, la continuación \\
\hline & escepticismo frente al & mostrando cuál es la & y "cualificación" de \\
\hline & modelo original de & clásica & los análisis clásicos. \\
\hline & 1937 no significa que & "típica". & La demostración de \\
\hline & haya renunciado a la & Inicialmente, & hipótesis \\
\hline & lógica neoclásica. Por & análisis es de corto & constituye \\
\hline & el contrario, gracias a & plazo. Los supuesto & objetivo final del \\
\hline
\end{tabular}




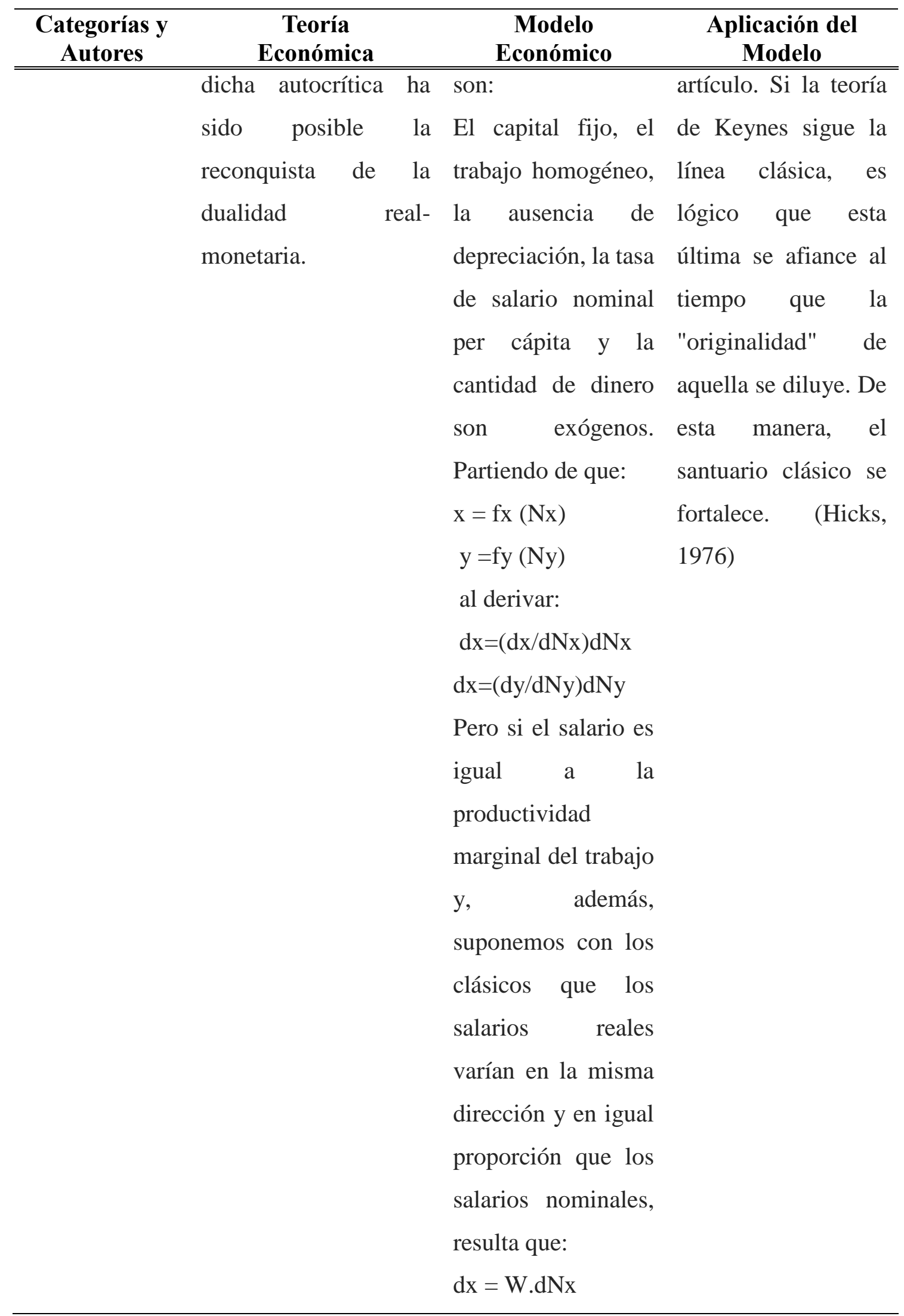




\begin{tabular}{|c|c|c|c|}
\hline \multirow[t]{2}{*}{$\begin{array}{c}\text { Categorías y } \\
\text { Autores } \\
\end{array}$} & $\begin{array}{c}\text { Teoría } \\
\text { Económica }\end{array}$ & $\begin{array}{c}\text { Modelo } \\
\text { Económico }\end{array}$ & \multirow[t]{2}{*}{$\begin{array}{c}\text { Aplicación del } \\
\text { Modelo }\end{array}$} \\
\hline & & dy=W.dNy $\quad$ y $\quad$ el & \\
\hline & & ingreso obtenido en & \\
\hline & & cada sector sería & \\
\hline & & igual a: & \\
\hline & & $\mathrm{Ix}=\mathrm{Wx}(\mathrm{d} N \mathrm{~N} / \mathrm{dx}$ & \\
\hline & & $\mathrm{Iy}=\mathrm{Wy}(\mathrm{d}$ Ny / dy) & \\
\hline & & El ingreso total será & \\
\hline & & igual a: & \\
\hline & & $1=\mathrm{Ix}+\mathrm{Iy}$ & \\
\hline & & $1=\mathrm{Wx}(\mathrm{d} N \mathrm{x} / \mathrm{dx})$ & \\
\hline & & + Wy (d Ny / dy) & \\
\hline & & Posteriormente, & \\
\hline & & Hicks introduce la & \\
\hline & & ecuación & \\
\hline & & cuantitativa de & \\
\hline & & Cambridge, de & \\
\hline & & acuerdo con la cual & \\
\hline & & la cantidad de & \\
\hline & & dinero está & \\
\hline & & relacionada con el & \\
\hline & & ingreso. 1) $\mathrm{M}=\mathrm{Ki}$ & \\
\hline & & La inversión, o el & \\
\hline & & ingreso en el sector & \\
\hline & & que produce bienes & \\
\hline & & capital, & \\
\hline & & dependerán de la & \\
\hline & & tasa de interés. & \\
\hline & & 2) $\mathrm{Ix}=\mathrm{C}(\mathrm{i})$ & \\
\hline & & Y, finalmente: & \\
\hline
\end{tabular}




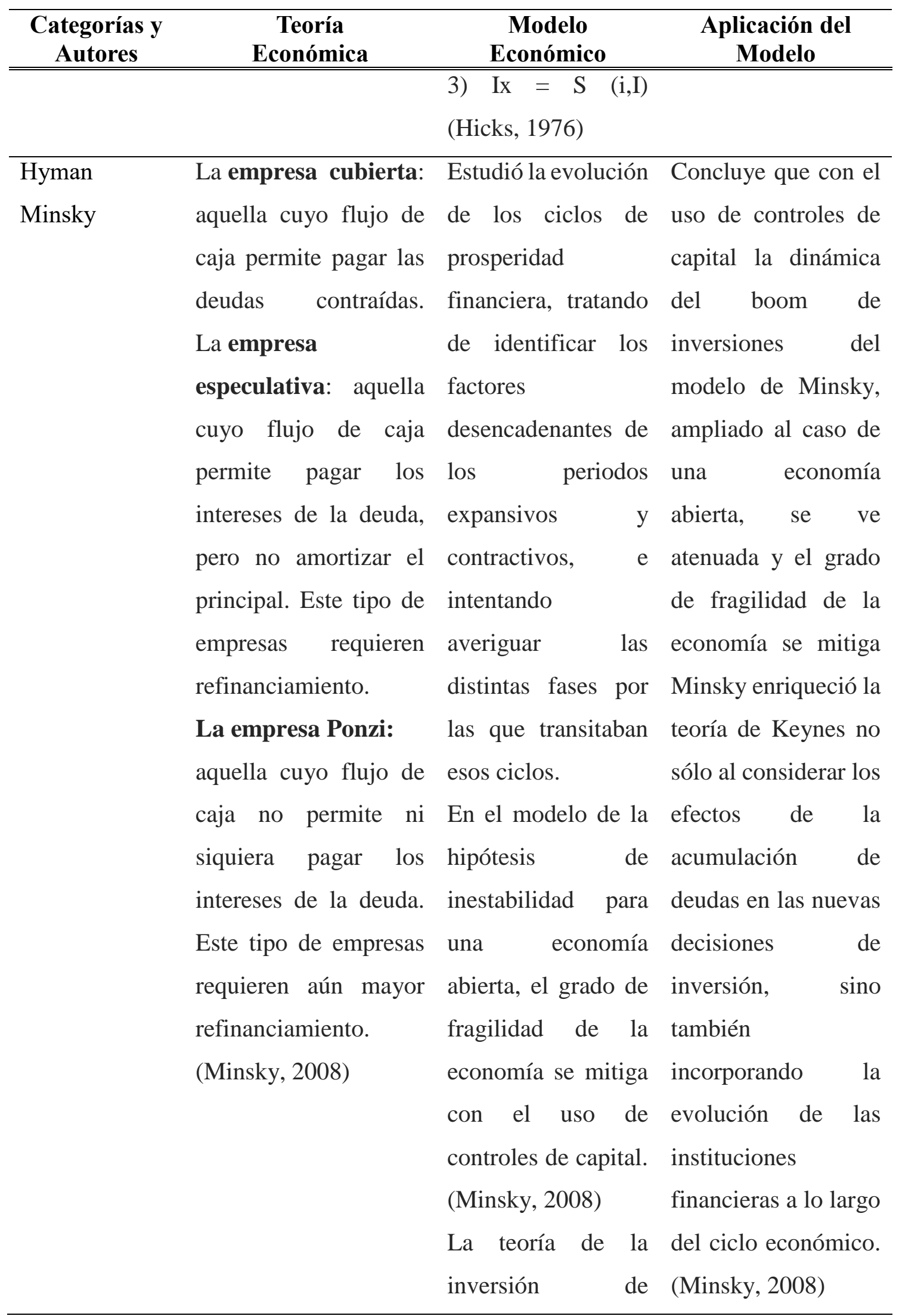




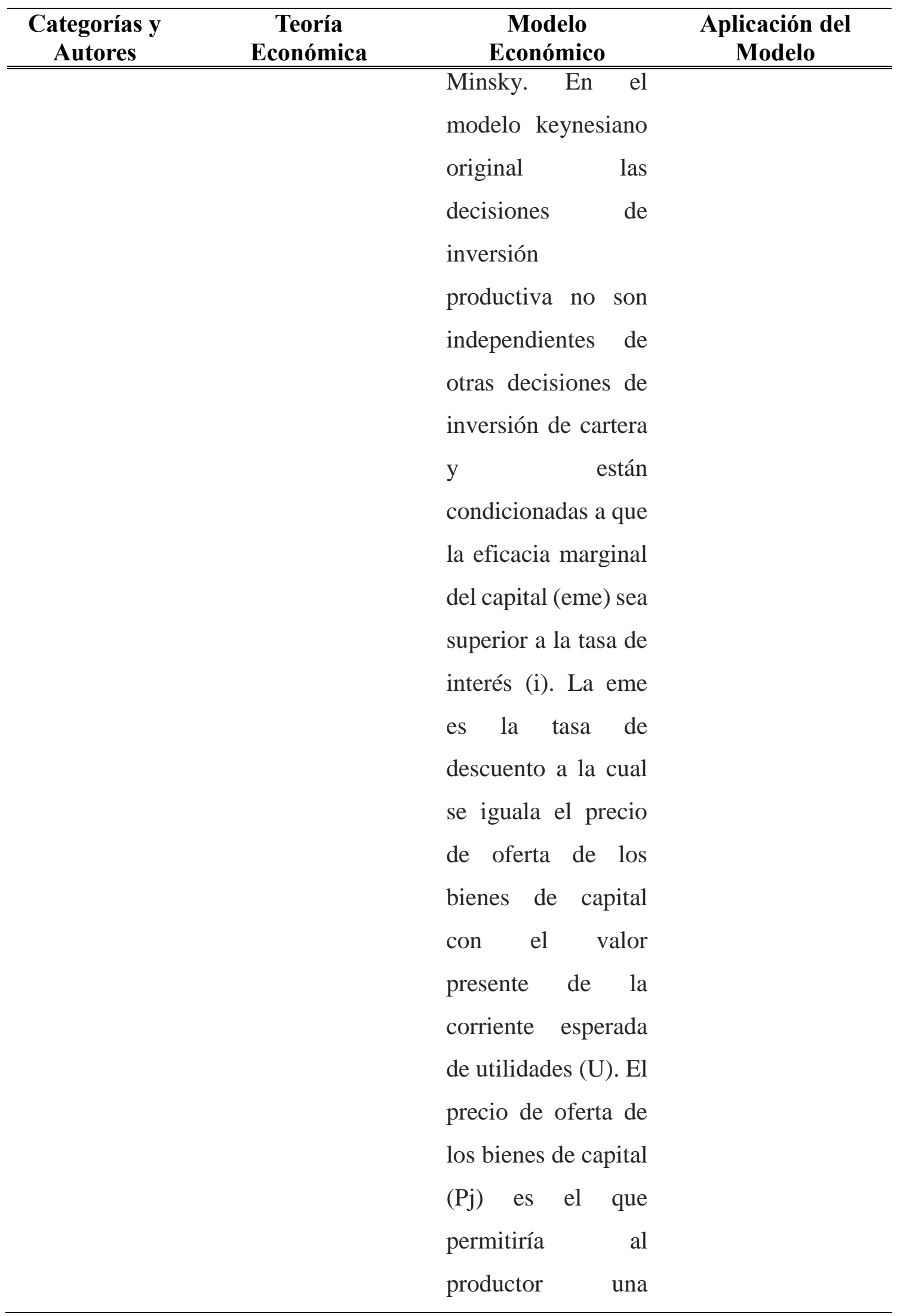




\begin{tabular}{|c|c|c|c|}
\hline \multirow[t]{30}{*}{$\begin{array}{c}\text { Categorías y } \\
\text { Autores } \\
\end{array}$} & $\begin{array}{c}\text { Teoría } \\
\text { Económica }\end{array}$ & $\begin{array}{c}\text { Modelo } \\
\text { Económico }\end{array}$ & $\begin{array}{l}\text { Aplicación del } \\
\text { Modelo }\end{array}$ \\
\hline & & ganancia normal $\mathrm{y}$ & \\
\hline & & lo mantendría en su & \\
\hline & & actividad & \\
\hline & & productiva. & \\
\hline & & consecuencia: & \\
\hline & & (Uieme $)=P f$ & \\
\hline & & Por efecto de la & \\
\hline & & competencia, la & \\
\hline & & corriente esperada & \\
\hline & & de utilidades tiende & \\
\hline & & a decrecer a medida & \\
\hline & & que aumenta la & \\
\hline & & inversión; & \\
\hline & & contrario sucede & \\
\hline & & con el precio de & \\
\hline & & oferta de los bienes & \\
\hline & & de capital. Por tanto, & \\
\hline & & existen tendencias & \\
\hline & & que conducen a un & \\
\hline & & equilibrio, el cual no & \\
\hline & & obstante, puede ir & \\
\hline & & acompañado del & \\
\hline & & subempleo. & \\
\hline & & modificar la esencia & \\
\hline & & del argumento de & \\
\hline & & Keynes, en el & \\
\hline & & sentido de que la & \\
\hline & & inversión depende & \\
\hline & & de la diferencia & \\
\hline
\end{tabular}




\begin{tabular}{|c|c|c|c|}
\hline \multirow[t]{30}{*}{$\begin{array}{c}\text { Categorías y } \\
\text { Autores } \\
\end{array}$} & $\begin{array}{c}\text { Teoría } \\
\text { Económica }\end{array}$ & $\begin{array}{c}\text { Modelo } \\
\text { Económico }\end{array}$ & $\begin{array}{l}\text { Aplicación del } \\
\text { Modelo }\end{array}$ \\
\hline & & entre la eficacia & \\
\hline & & marginal del capital & \\
\hline & & y la tasa de interés, & \\
\hline & & Minsky aborda el & \\
\hline & & análisis desde una & \\
\hline & & perspectiva similar & \\
\hline & & a la de Brainard $y$ & \\
\hline & & Tobin: $\quad(\mathrm{W}$. & \\
\hline & & C.Brainard. & \\
\hline & & J.Tobin, mayo de & \\
\hline & & 1968) Vincula & \\
\hline & & ambas variables por & \\
\hline & & medio de la & \\
\hline & & diferencia entre la & \\
\hline & & valuación de las & \\
\hline & & empresas en el & \\
\hline & & mercado financiero & \\
\hline & & y el precio de oferta & \\
\hline & & de los bienes de & \\
\hline & & capital. & \\
\hline & & definimos $\mathrm{Pk}$ como & \\
\hline & & la valuación de & \\
\hline & & capital en el & \\
\hline & & mercado financiero & \\
\hline & & e igual a la corriente & \\
\hline & & esperada & \\
\hline & & utilidades & \\
\hline & & capitalizada a la tasa & \\
\hline & & de interés (i), $\mathrm{Pk}=$ & \\
\hline
\end{tabular}




\begin{tabular}{|c|c|c|c|}
\hline \multirow[t]{17}{*}{$\begin{array}{c}\text { Categorías y } \\
\text { Autores } \\
\end{array}$} & $\begin{array}{c}\text { Teoría } \\
\text { Económica } \\
\end{array}$ & \begin{tabular}{|c|} 
Modelo \\
Económico \\
\end{tabular} & $\begin{array}{c}\text { Aplicación del } \\
\text { Modelo } \\
\end{array}$ \\
\hline & & (U/i) tendríamos & \\
\hline & & que, para Keynes, la & \\
\hline & & inversión & \\
\hline & & procedería hasta que & \\
\hline & & eme $=i$, es decir, & \\
\hline & & hasta que $\mathrm{Pk}=\mathrm{Pf}$. & \\
\hline & & Minsky y Tobin & \\
\hline & & prefieren expresar la & \\
\hline & & inversión como & \\
\hline & & función de $(\mathrm{PkPf}>\mathrm{y}$ & \\
\hline & & no en términos de & \\
\hline & & (emc-i) como hizo & \\
\hline & & Keynes. & \\
\hline & & C.Brainard. & \\
\hline & & J.Tobin, mayo de & \\
\hline & & 1968) & \\
\hline \multirow{13}{*}{$\begin{array}{l}\text { Alfred } \\
\text { Marshall }\end{array}$} & Fue uno de los & Introdujo el método & Análisis estático del \\
\hline & fundadores de la & estático de análisis & equilibrio parcial, es \\
\hline & economía neoclásica, & del equilibrio & la forma de como \\
\hline & su principal obra & parcial, & determino el precio \\
\hline & principios de economía & examinaba & de mercado de una \\
\hline & en 1890, se le & comportamiento de & empresa concreta a \\
\hline & considera el fundador & empresas & través de \\
\hline & de la teoría de la oferta & particulares. & intersección de las \\
\hline & y la demanda. & El coloco en el & fuerzas \\
\hline & Desarrollo la teoría de & centro de la & contrapuestas de la \\
\hline & competencia perfecta & demostración del & oferta y la demanda. \\
\hline & de los mercados e & razonamiento & Las "tijeras" \\
\hline & íntegro en un análisis & económico & Marshall, con sus \\
\hline
\end{tabular}




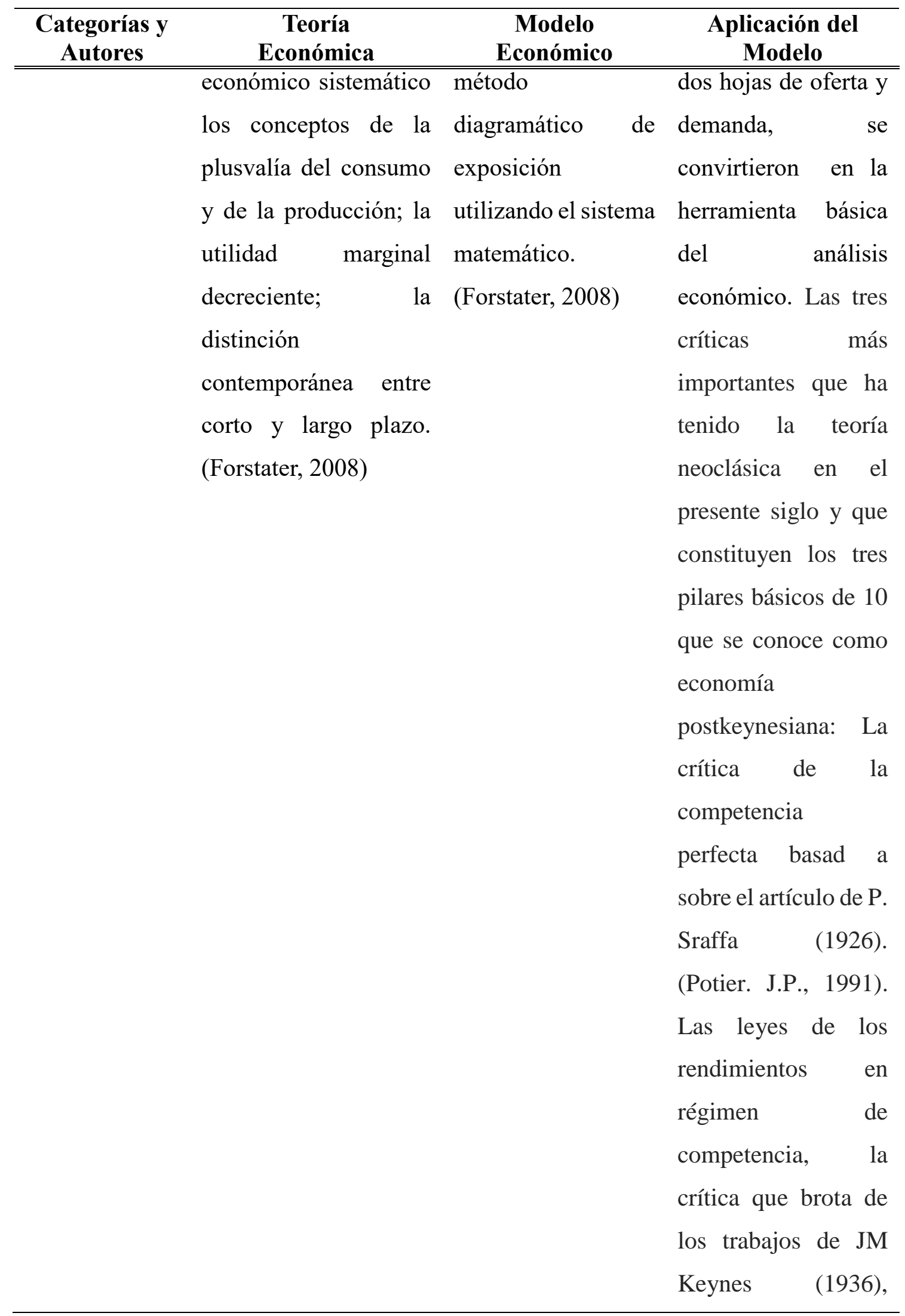




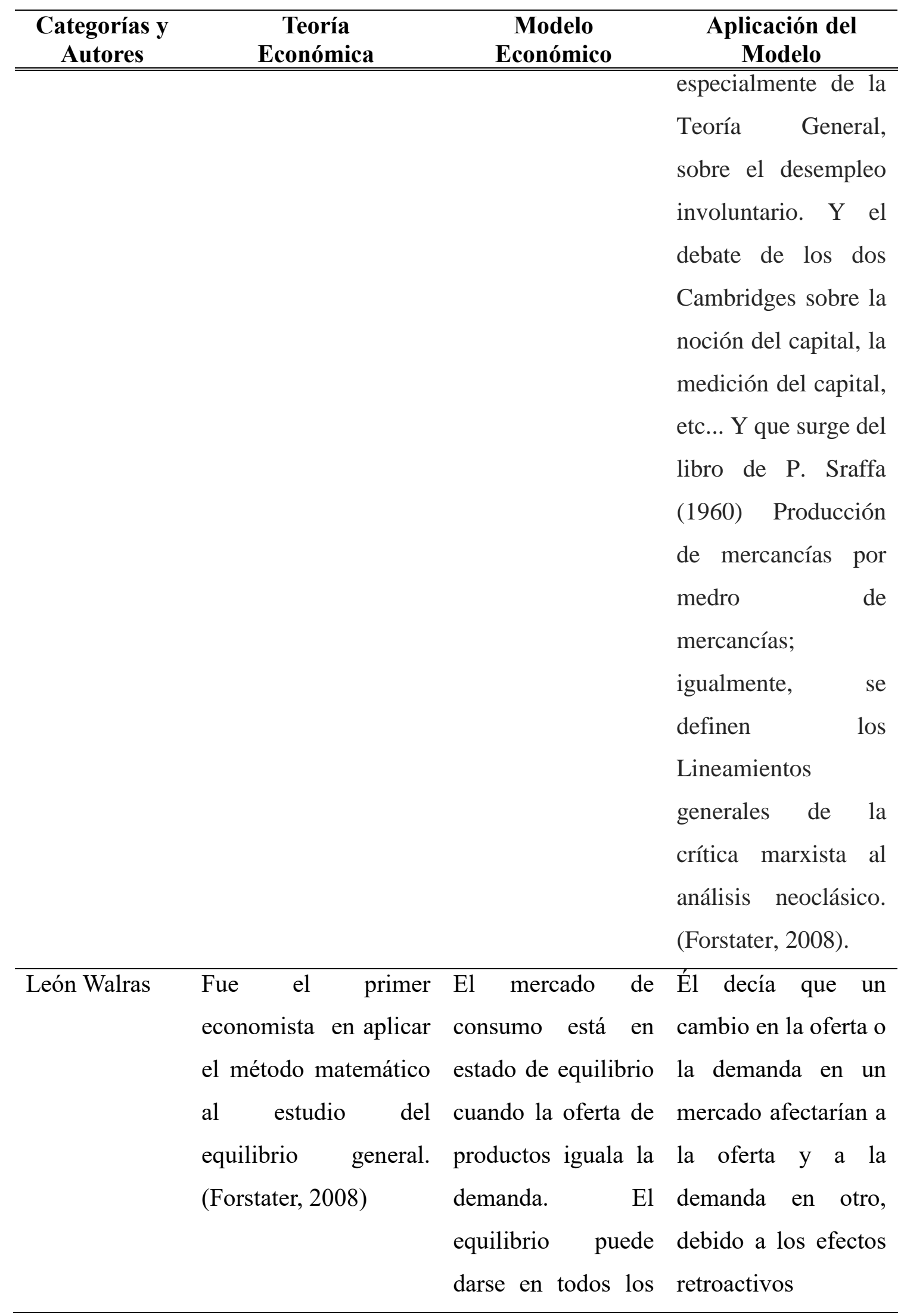




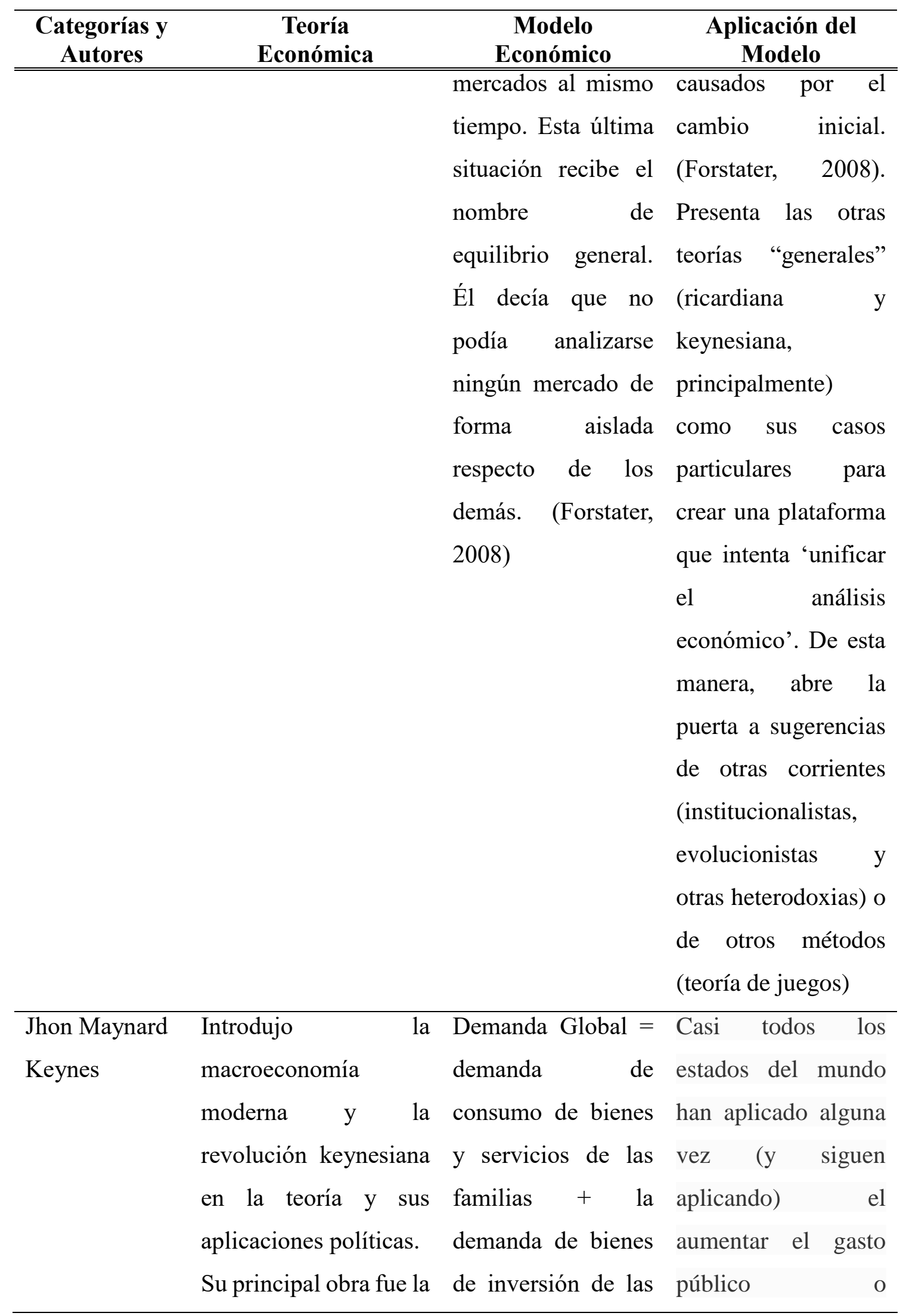




\begin{tabular}{|c|c|c|c|}
\hline \multirow[t]{28}{*}{$\begin{array}{c}\text { Categorías y } \\
\text { Autores } \\
\end{array}$} & $\begin{array}{c}\text { Teoría } \\
\text { Económica }\end{array}$ & $\begin{array}{c}\text { Modelo } \\
\text { Económico }\end{array}$ & $\begin{array}{c}\text { Aplicación del } \\
\text { Modelo }\end{array}$ \\
\hline & Teoría general de la & empresas + la & disminuirlo, \\
\hline & ocupación el interés y & demanda del sector & también \\
\hline & el dinero en el año & público a través del & utilizado \\
\hline & 1936. & gasto público + la & impuestos \\
\hline & Planteo una visión & demanda de los & mejorar la situación \\
\hline & alternativa & mercados & económica. \\
\hline & capitalismo como una & internacionales & (Forstater, 2008) \\
\hline & economía & través de & Uno de los aportes \\
\hline & producción monetaria & exportaciones. $\mathrm{La}$ & keynesianos \\
\hline & y rechazo la separación & política keynesiana & significativos, a la \\
\hline & tradicional entre & por excelencia seria & teoría econ6mica \\
\hline & factores monetarios $y$ & aquella que se & moderna, es el de que \\
\hline & reales. Para Keynes el & encamina a utilizar & decisiones \\
\hline & dinero es real y las & la política fiscal & econ6micas se toman \\
\hline & variables monetarias & (cobro de impuestos & en condiciones de \\
\hline & afectan a $\quad$ los & y gasto de gobierno) & incertidumbre. \\
\hline & rendimientos reales, & como & Ignorancia. Frente al \\
\hline & esto condujo a tener & herramienta & futuro. En \\
\hline & una aproximación & fuera capaz de & horizonte de tiempo \\
\hline & entre el ahorro y la & asistir a la demanda & histórico. \\
\hline & inversión que rechaza & agregada. (Keynes, & Contingente $y$ sin \\
\hline & el modelo de fondos de & 1936) & leyes. (Keynes, \\
\hline & crédito y plantea & & 1936) \\
\hline & teorías alternativas & & \\
\hline & para la determinación & & \\
\hline & de ambos. (Forstater, & & \\
\hline & 2008) & & \\
\hline Joseph & Fue uno de los grandes & Las fluctuaciones & Schumpeter se ocupa \\
\hline Schumpeter & teóricos del desarrollo & económicas & entonces de delimitar \\
\hline
\end{tabular}




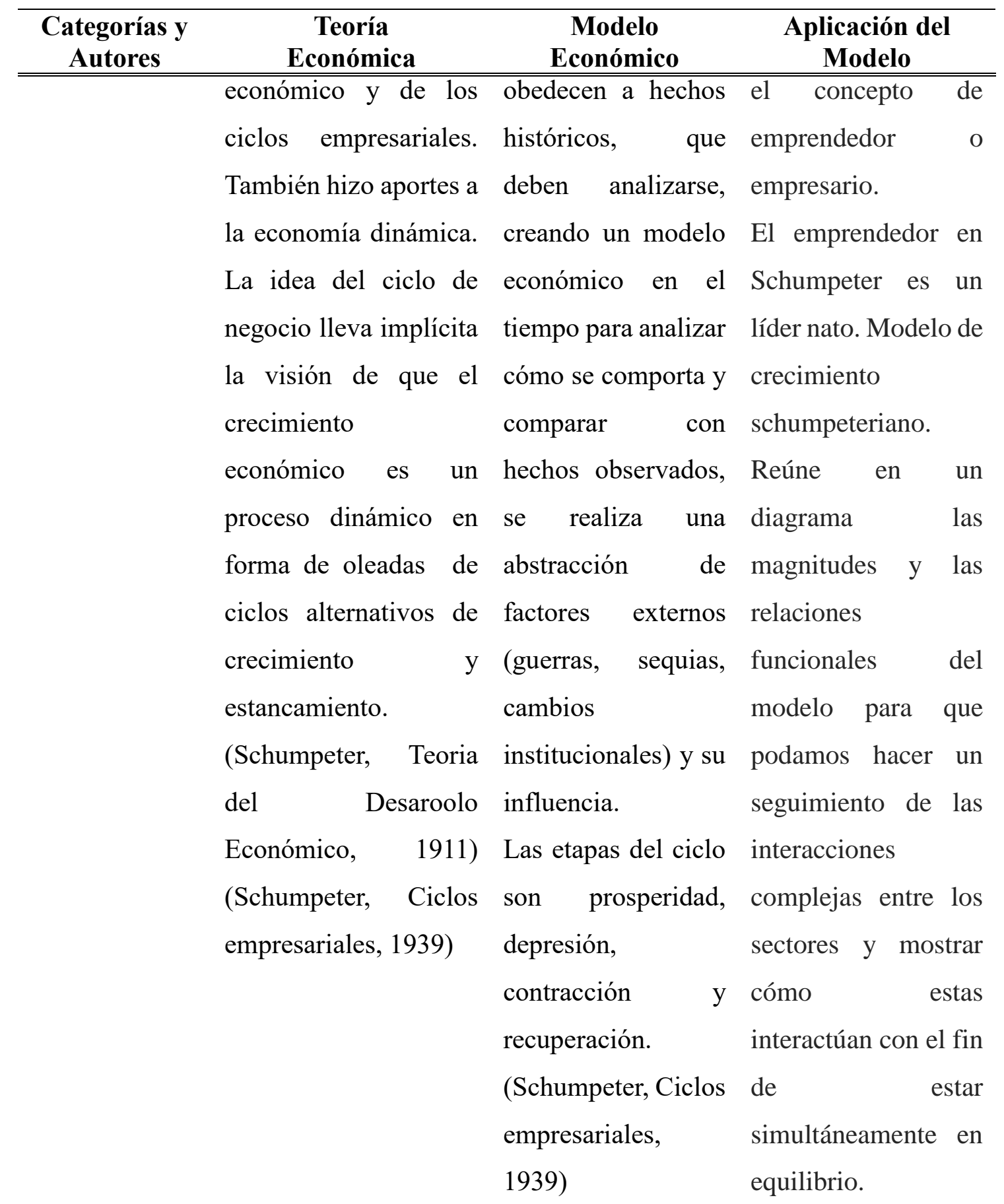

(Forstater, 2008)

\begin{tabular}{llll}
\hline Aghion $\&$ & Es técnicamente & Este modelo se & Es una herramienta \\
Howitt. & complejo y un primer & puede ver como pedagógica poderosa \\
& paso para generar el formado por cuatro $\mathrm{y}$ flexible incluso \\
& tipo de diagrama que & variables clave y para enseñar a los \\
\hline
\end{tabular}




\begin{tabular}{|c|c|c|c|}
\hline \multirow[t]{2}{*}{$\begin{array}{c}\text { Categorías y } \\
\text { Autores } \\
\end{array}$} & $\begin{array}{c}\text { Teoría } \\
\text { Económica } \\
\end{array}$ & \begin{tabular}{c|c|} 
Modelo \\
Económico \\
\end{tabular} & $\begin{array}{c}\text { Aplicación del } \\
\text { Modelo }\end{array}$ \\
\hline & hará que el modelo sea & $\begin{array}{lll}\text { cuatro } & \text { relaciones }\end{array}$ & estudiantes \\
\hline & $\begin{array}{l}\text { más accesible a los } \\
\text { estudiantes graduados }\end{array}$ & $\begin{array}{l}\text { funcionales. Las } \\
\text { cuatro variables }\end{array}$ & $\begin{array}{lr}\text { graduados. } & \text { Hemos } \\
\text { utilizado } & \text { estos }\end{array}$ \\
\hline & es el desarrollo de una & clave son: el & principios \\
\hline & versión simplificada & volumen de bienes & desarrollar \\
\hline & del modelo en cuatro & finales producidos, & diagrama que ilustra \\
\hline & cuadrantes. (Aghion \& & $\mathrm{y}_{\mathrm{t}}$; el volumen de & las características \\
\hline & Howitt, 1997) & bienes intermedios & clave de (Aghion \& \\
\hline & & producidos, $\mathrm{X}_{\mathrm{t}} ; \mathrm{el}$ & Howitt, 1997) \\
\hline & & salario & \\
\hline & & productividad & \\
\hline & & ajustados, $\mathrm{w}_{\mathrm{t}}$; y la & \\
\hline & & cantidad de mano de & \\
\hline & & obra actualmente & \\
\hline & & empleado en el & \\
\hline & & sector de la & \\
\hline & & investigación y el & \\
\hline & & desarrollo, $\quad \mathrm{n}_{\mathrm{t}}$. & \\
\hline & & (Aghion \& Howitt, & \\
\hline & & 1997) & \\
\hline
\end{tabular}

5. Enseñanza del Modelo

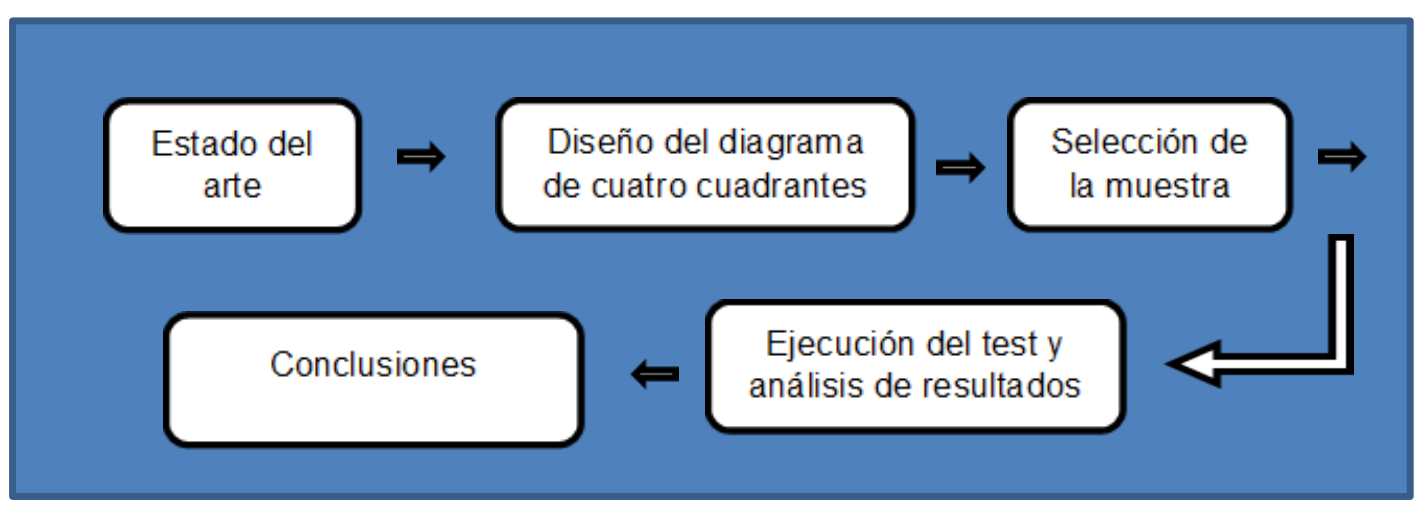


Ilustración 2. Contribución del proyecto a las líneas de investigación modelo de ejecución propuesto.

\subsection{Uso del diagrama para la enseñanza}

El producto diagramático desarrollado en el presente estudio es una mejor contribución a las líneas de investigación en el campo de la economía, para garantizar una efectiva absorción del conocimiento de forma generalizada, de esta forma se garantiza una reducción en la falta de comprensión de las situaciones casuísticas expuestas en los modelos económicos por parte de los docentes a los estudiantes, que generan diferentes formas de entendimiento.

A continuación se expone el producto del presente estudio.

Modelo keynesiano para estudiantes de pregrado una aproximación diagramática Postulados de (Keynes, 1936).

Los postulados de la teoría clásica aplicados a la teoría keynesiana, solo son aplicables a un caso especial, y no en general por que las condiciones que supone son un caso extremo de todas las posiciones posibles de equilibrio.

a. El salario es igual al producto marginal del trabajo.

b. La utilidad del salario, cuando se usa determinado volumen de trabajo, es igual a la desutilidad marginal de ese mismo volumen de ocupación.

c. El principio de la demanda efectiva, nos explica que el Ingreso Total o la Renta Total, es la suma del consumo agregado y la inversión agregada.

d. La expectativa como elemento determinante de la producción y la ocupación, donde toda producción tiene por fin ultimo la satisfacción de algún consumidor.

e. Ingreso, ahorro e inversión.

f. La propensión marginal a consumir, la suma que se gasta en consumir medida 
en unidades de salario (Co), con el ingreso en términos de unidades de salario (Y), correspondiente a un nivel dado de ocupación (L). Keynes acepto este postulado de los clásicos: La igualdad entre el salario real y el producto marginal del trabajo, Este proviene simplemente de la condición de primer orden de la maximización de beneficios por parte de empresas que operan en competencia atomística y que, en consecuencia, toman como dados precios y salarios y maximizan, sujetas a una restricción tecnológica (dada por la función de producción).

f.1. Un cambio en la unidad de salario.

f.2. Un cambio en la diferencia entre el ingreso y el ingreso neto.

f.2.1. Cambios imprevistos en el valor de los bienes de capital, no considerados al calcular el ingreso neto.

f.2.2. Cambios en la tasa de descuento del futuro, es decir en la relación de cambio entre bienes presentes y futuros.

f.2.3. Cambios en la política fiscal.

f.2.4. Cambios en las expectativas acerca de la relación entre el nivel presente y futuro del ingreso.

f.2.5. El multiplicador entre los ingresos y la inversión.

f.2.6. La eficiencia marginal del capital.

f.2.7. Expectativas a largo plazo.

f.2.8. Teoría general de la tasa de interés.

f.2.9. Incentivos para la liquidez.

f.2.10. Propiedades esenciales del interés y el dinero. (Keynes. J. M., teoría general de la ocupación el interés y el dinero, 2000, pág. 15 - 260). 


\subsection{Descripción del modelo}

A continuación se definen las variables así:

$Y=$ producto

$L=$ Nivel de ocupación

$K=$ Cantidad de capital físico, humano o equivalentes.

$W=$ Salario minimo

$P=$ Nivel general de precios (precios del bien y)

$$
\begin{aligned}
& C=\text { Consumo Privado } \\
& \begin{aligned}
G=\text { Gasto del gobierno } \\
T=\text { Valor real de los impuestos. } \\
r=i \text { Tasa de interés. }
\end{aligned}
\end{aligned}
$$

$M=$ Cantidad nominal de dinero o masa monetaria. (Fernandez, 1996)

La masa monetaria (M), es la totalidad del dinero en circulación en la economía.

Comprende tanto, el efectivo en manos del público, monedas y billetes bancarios, así como aquellos activos emitidos por las instituciones financieras que por su elevada liquidez y escaso riesgo, pueden ser considerados dinero o cuasidineros (tarjeta de crédito, tarjeta débito, cheque, letra, factura, Cds't, Cdt).

A continuación se detallan los activos que pueden ser considerados como integrantes de la masa monetaria, desde la acepción más restrictiva (denominada Mo), que incluye únicamente los activos plenamente líquidos, billetes y monedas, a las más amplias (M1, M2 y M3), que tienen en cuenta otros activos con elevada liquidez y escaso riesgo que por tanto pueden ser considerados dinero.

$$
S_{m}=\text { Oferta monetaria. }
$$


$m_{0}=$ Sería la definición más restrictiva de masa monetaria. Incluiría la totalidad de billetes y monedas en manos del público. Se trata pues del efectivo en circulación en la economía. El efectivo constituye un activo para los agentes económicos que lo posee y un pasivo.

$m_{1}=$ Comprende el efectivo más los saldos que se pueden convertir inmediatamente en dinero o que pueden movilizarse para realizar pagos y transferencias, es decir, los depósitos a la vista.

$m_{2}=$ Además de la $m_{1}$, incorpora los depósitos con un plazo de hasta dos años así como los depósitos disponibles con preaviso de hasta tres meses. Estos últimos se caracterizan por ser depósitos de ahorro en los que el tenedor, para disponer de sus fondos, tiene que esperar un período determinado previo aviso.

$m_{3}=$ Incluiría demás todos los valores negociables emitidos por el sector de instituciones financieras monetarias residentes, esto es, cesiones temporales, participaciones en fondos del mercado monetario e instrumentos del mercado monetario y valores distintos de acciones hasta dos años. Se trata de activos financieros sustitutos próximos de los depósitos debido a su elevado grado de liquidez y reducido riesgo.

$\frac{m}{p}=$ oferta real de dinero.

$m_{r}=$ demanda de dinero especulativo y preventivo

$m_{y}=$ demanda de dinerotransaccional.

Las siguientes ecuaciones resumen apropiadamente, la estructura del modelo keynesiano cerrado. (Fernandez Riva, 1996)

$$
Y=Y\left(L, K^{*}\right) ; Y_{L}>0 ; Y_{L L}<0
$$

(2) $\frac{W}{P}=Y_{L}$ 
(3) $\quad W=W^{*}$

(4) $\quad Y=C+I+G$

$$
Y=P_{S} * Q_{d}
$$

$$
C=C(Y-T) ; \quad O<C_{Y-T}<1
$$

$$
I=I(r, Y)+I^{*} ; \quad I_{r}<0 ; I_{Y}>0
$$

(7) $\quad m=m_{0}, m_{1}, m_{2}, m_{3}$

(8) $\quad S m=S m(m, r)$

$$
\frac{w}{p}=m(r, Y) ; m r<0 ; m y>0
$$

Ahora vamos a explicar cada una de las ecuaciones así:

(a) Ecuación: se basa en la función de producción, que se asocia con la productividad marginal del trabajo $(\mathrm{L})$, y el capital $\left(\mathrm{K}^{*}\right)$, son positivos pero decrecientes y que el producto marginal de un factor aumenta cuando aumenta la cantidad disponible del otro factor. Por consiguiente se supone que el stock de capital es fijo (*).

Un componente de la demanda agregada es la inversión; que representa aumento del stock de capital; en la práctica la hipótesis es justificada teniendo en cuenta que en el corto plazo la inversión es una fracción relativamente pequeña del stock de capital previamente acumulado. (Fernández, 1996, Págs. 42 -61).

(b) Ecuación: Es la demanda agregada por servicios de Trabajo, para cualquier nivel de salario donde los empresarios estarían dispuestos a contratar los servicios de trabajo hasta el punto en que el valor nominal del producto marginal del trabajo (PY) se hace igual al salario nominal para cada mercado de trabajo. La demanda de trabajo depende de forma inversa del salario real. (Keynes. J. M., teoría general de la ocupación el interés y el dinero, 2000, pág. 58) 
(c) Ecuación: Nos indica que la oferta de trabajo depende directamente del salario real. El mercado de trabajo supone que el salario nominal es rígido, para que los salarios reales caigan será necesario que aumenten los precios y el comportamiento del consumidor depende de las circunstancias económicas. la concepción keynesiana de la estructura macroeconómica hace posible suponer que el nivel de producción y en empleo en una sociedad capitalista moderna es inherentemente inestable y que, en usencia de intervención estatal, la situación de nuevo empleo será la excepción y no la regla. La hipótesis de una rigidez en los salarios nominales hará posible, en el sistema keynesiano. (Keynes. J. M., teoría general de la ocupación el interés y el dinero, 2000, pág. 50)

(d) Ecuación: Nos muestra la relación de equilibrio entre la oferta total de bienes y servicios o ingreso neto global debe ser igual a la demanda agregada cuyos componente en la economía cerrada serian el consumo privado de los hogares (C), la inversión de los hogares (I), y el gasto del gobierno (G), debe observarse que esta ecuación no implica nada sobre el nivel de producción del cual se lograra el equilibrio. Esta ecuación la podemos expresar de la siguiente forma reemplazando las anteriores en ella y nos queda así:

$$
\begin{aligned}
& Y=C(Y-T)+I(Y, r)+I *+g \\
& D g=C+I+G+x \quad \text { O la demanda efectiva global que nos lleva a que: } \\
& Y=C+I+G+X \quad \text { ECUACION DE (Keynes, 1936) } \\
& D g=C+I+G+X P \\
& \mathrm{Dg}=\mathrm{C}+\mathrm{I}+\mathrm{G}+\mathrm{EXP} .
\end{aligned}
$$


Tabla 2

Keynes. J.M., Teoría General de la Ocupación el interés y el Dinero

\begin{tabular}{cccccc}
\hline $\begin{array}{c}\text { Desempleo } \\
\text { Deflación }\end{array}$ & $\mathrm{Dg}$ & $\mathrm{C}=\mathrm{c}(\mathrm{yd}-\mathrm{T})$ & $\mathrm{I}=\mathrm{I}(\mathrm{y}, \mathrm{r})$ & $\mathrm{G}$ & $\mathrm{X}=\mathrm{X}\left(\mathrm{P}^{\mathrm{x}}, \mathrm{Tc}\right)$ \\
\hline Inflación & $\mathrm{Dg}$ & $\mathrm{C}=\mathrm{c}(\mathrm{yd}-\mathrm{T})$ & $\mathrm{I}=\mathrm{I}(\mathrm{y}, \mathrm{r})$ & $\mathrm{G}$ & $\mathrm{X}=\mathrm{X}\left(\mathrm{P}^{\mathrm{x}}, \mathrm{Tc}\right)$ \\
\hline
\end{tabular}

(Keynes. J. M., teoría general de la ocupación el interés y el dinero, 2000, pág. 58)

Esta identidad: $Y=P_{S} * Q_{d}$, Nos presenta la relación de equilibrio del mercado de bienes y servicios que también está dado por el precio (Ps) de los bienes y servicios y la cantidad demandada de los mismos (Qd). (Nicholson, 2008)

(e) Ecuación: indica que el consumo privado depende directamente del ingreso disponible, (Y - T). (Javier Fernández Riva, modelos clásico y keynesianos, 1996, pág. 10)

(f) Ecuación: Keynes aducía que la inversión depende de la eficiencia marginal del capital, concepto que involucraba no solamente el retorno objetivo de la inversión en relación con el costo de los fondos sino también las expectativas de los inversionistas sobre ese retorno, expectativas que podrían tener un carácter bastante subjetivo y que, probablemente, serian bastante inestables en el corto plazo. También nos dice que la inversión depende directamente de las tasas de interés y de los ingresos como inversión especulativa y una inversión transaccional y hay una inversión exógena de forma forzosa que se debe exigir a los empresarios en colaboración para mejorar la economía y quitarle esa volatilidad de la misma inversión.

(g) Es una identidad que nos muestra los componentes de la masa monetaria que tenemos en el mundo y que está compuesta por todos los billetes y monedas ósea el flujo de efectivo en cuentas corrientes más los cuasidineros que son los títulos valores más 
fácilmente convertibles en efectico ( entre ellos están el cheque, la letra, factura, las tarjetas débito y crédito, y los certificados de depósito a término tanto de ahorros como de cuenta corriente. $m_{0}=$ Sería la definición más restrictiva de masa monetaria. Incluiría la totalidad de billetes y monedas en manos del público. Se trata pues del efectivo en circulación en la economía. $\mathrm{m}_{1}=$ Comprende el efectivo más los saldos que se pueden convertir inmediatamente en dinero o que pueden movilizarse para realizar pagos y transferencias, es decir, los depósitos a la vista. $\mathrm{m}_{2}=$ Además de la $\mathrm{m}_{1}$, incorpora los depósitos con un plazo de hasta dos años así como los depósitos disponibles con preaviso de hasta tres meses. Estos últimos se caracterizan por ser depósitos de ahorro en los que el tenedor, para disponer de sus fondos, tiene que esperar un período determinado previo aviso. $\mathbf{m}_{3}=$ Incluiría demás todos los valores negociables emitidos por el sector de instituciones financieras monetarias residentes, esto es, cesiones temporales, participaciones en fondos del mercado monetario e instrumentos del mercado monetario y valores distintos de acciones hasta dos años. Se trata de activos financieros sustitutos próximos de los depósitos debido a su elevado grado de liquidez y reducido riesgo. (Banco República de Colombia, 2003)

(h) Ecuación muestra la oferta monetaria que está en función de la cantidad ofertada de dinero y las tasas de interés y estas variables son directamente proporcionales a la oferta es decir entre más cantidad de dinero demande el público más será la tasa de interés que cobren los bancos eso es debido al riesgo y a la incertidumbre de que los cuentas habientes demandantes de dinero retornen el mismo a estas instituciones financieras. (Keynes, 1936).

(i) Nos muestra la condición de equilibrio de la oferta real de dinero (M/p), que 
es igual a la demanda real de dinero o liquidez, también hay demanda de dinero para especulación y otra por motivo de precaución que son las formas por las cuales Keynes decía que la gente demanda dinero. Lo que nos lleva al equilibrio del mercado monetario. (Fernandez Riva, 1996)

A continuación vemos el modelo que se va a enseñar a los estudiantes y el cual tienen que aplicar para dar solución a la problemática, donde en primer lugar el estudiante diagramara el modelo keynesiano cerrado en equilibrio y luego diagramara el modelo keynesiano cerrado mostrando las variables que se afectan y luego dan la solución.

\subsection{Diagrama de ilustración del modelo}

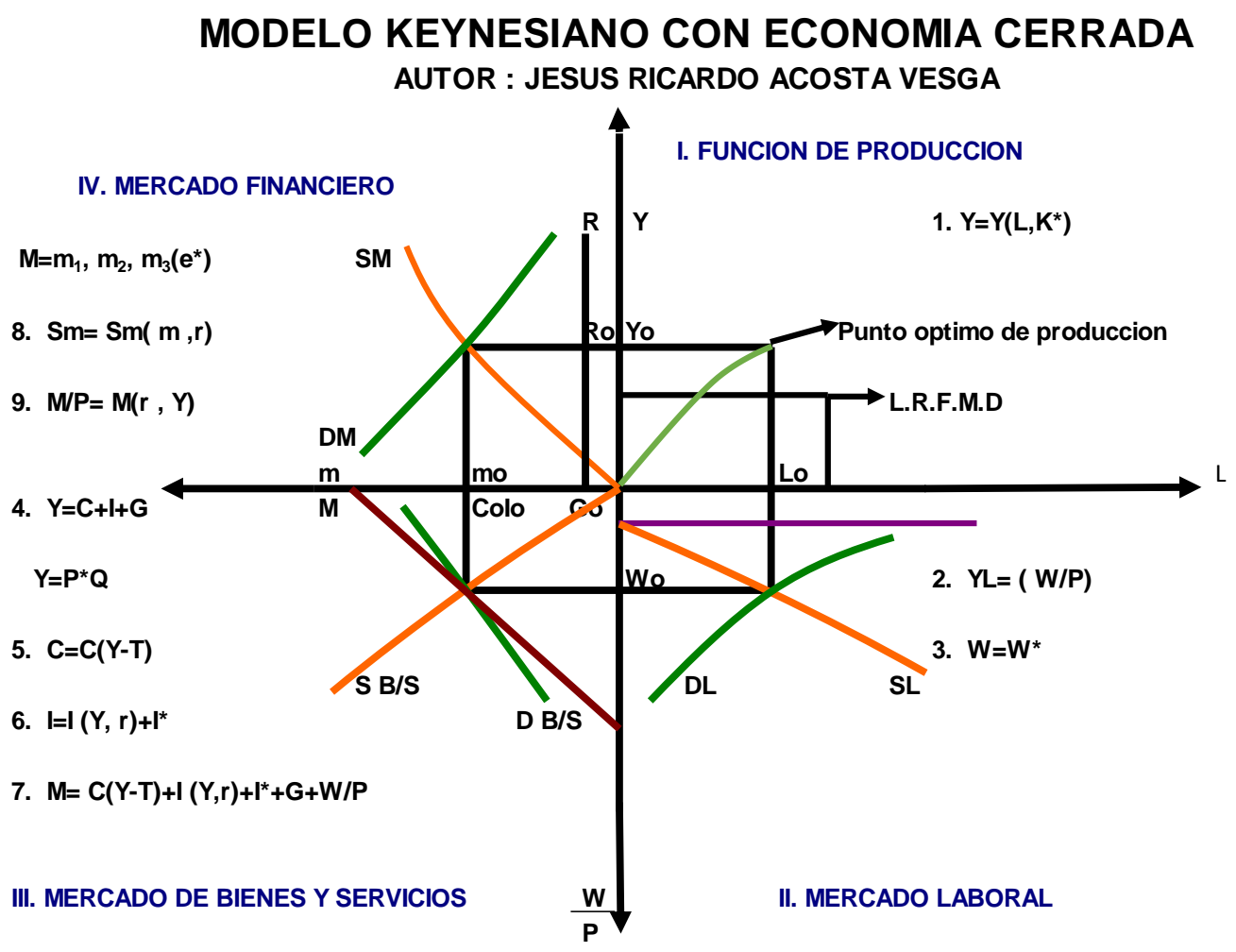

Ilustración 3. Modelo keynesiano con economía cerrada 


\section{Diseñó y aplicación del modelo diagramático}

\subsection{Metodología}

Seleccionamos dos grupos de estudiantes de la Facultad de Administración y Economía de los programas de Finanzas y Negocios Internacionales y del Programa de Administración y Economía, de la Fundación Universitaria Monserrate, de la asignatura de Macroeconomía I, donde un grupo era de 4 estudiantes y el otro grupo de 10 estudiantes, donde al primer grupo se les enseño de la forma tradicional de la macroeconomía y al otro grupo se le enseño con la aplicación del modelo diagramático Keynesiano Cerrado, con el fin aplicar un test, en el cual evidenciaríamos aspectos positivos o negativos sobre los métodos de aprendizaje de la macroeconomía. Para el periodo 2016 - 2. En dos secciones de dos (2) horas cada una.

\subsection{Explicación del modelo diagramático Keynesiano Cerrado.}

En primer lugar se diseñó un diagrama de cuatro cuadrantes donde todos sus cuadrantes son positivos: utilizamos esta perspectiva pedagógica para desarrollar un enfoque geométrico para ilustrar el modelo Keynesiano cerrado una aproximación diagramática de equilibrio general. Reunimos en un diagrama las magnitudes y las relaciones funcionales del modelo para que podamos hacer un seguimiento de las interacciones de simples a complejas entre los cuadrantes, donde se observa en el primer cuadrante la función de producción, donde se especifica la máxima producción que se puede elaborar con una cantidad determinada de insumos. Aquí podemos incluir tres conceptos importantes de producción: producto total, medio y marginal, se comienza por calcular el producto físico total, el cual designa la cantidad la cantidad total de producción que se obtiene en unidades físicas. 
El producto total responde a medida que se incrementa la cantidad de trabajo. El producto marginal es el producto adicional que se fabrica con una unidad adicional de ese insumo mientras que los otros permanecen constantes. Ahora miremos el producto medio que es igual a la producción total dividida en la cantidad total de los insumos. (Samuelson \& Nordhaus, 2006).en este cuadrante también podemos observar la famosa ley de economía, la ley de los rendimientos físico marginales decrecientes, donde la producción se disminuye cuando aumenta una unidad de trabajo manteniendo la capacidad de producción constante.

Luego en el segundo cuadrante tenemos el mercado laboral, donde los estudiantes, deben tener conocimiento de los tipos de contratos que existen en Colombia y los tipos de desempleo, que hay, el trabajo es un factor abstracto de la producción en donde los trabajadores son personas que desean buenos trabajos y salarios elevados para poder adquirir los bienes que desean, aquí vemos el salario real por medio del cual se puede medir el poder adquisitivo de los empleado de una hora de trabajo o los salarios monetarios divididos entre el costo de vida. La demanda de trabajo está dada por la productividad marginal en un momento dado y con un determinado nivel de tecnología donde existe una relación entre la cantidad de trabajo y la cantidad de producción de acuerdo con la ley de los rendimientos decrecientes, cada unidad de trabajo añadirá una cantidad cada vez menor de producción. Ahora vemos que la oferta de trabajo está dada a las horas que la población desea trabajar en actividades redituables donde hay tres elementos claves como son las horas del trabajador, la participación de la fuerza laboral y la inmigración.

Donde a medida que los salarios aumentan, los trabajadores laboran menos horas, 
la diferencia que existe en los trabajos está dada, por las competencias que posean cada uno de los trabajadores, por ello, para cualquier cargo el salario debe ser rígido, lo que hace que el empleado sea más productivo y los aumentos deben ser por ley o por ascenso del empleado. Los sindicatos desempeñan un papel importante puesto que luchan por los intereses de sus afiliados donde cada día son menos los afiliados y estos luchan atraves de las convenciones colectivas presentando a las empresas un pliego de peticiones donde se aplica la negociación de la caja de Edgeworth, es un instrumento gráfico empleado en economía para representar el intercambio de dos bienes entre dos personas o agentes económicos. Se utiliza con frecuencia en el marco del equilibrio general para ayudar a encontrar el equilibrio competitivo de un sistema simple.

Donde lo que gana uno lo pierde el otro. en el tercer cuadrante tenemos el mercado de bienes y servicios en el cual manejaremos todo lo relacionado con la oferta y la demanda agregada, también manejaremos el presupuesto y es en donde obtenemos los ingresos y realizamos los egresos, luego en el cuatro cuadrante manejaremos el mercado monetario o financiero, donde entraremos a manejar la oferta y la demanda de dinero que necesita la economía donde vamos a ver que la gente demanda dinero según Keynes por tres motivos como son el motivo transaccional, el especulativo y deprecación. Luego mostraremos cómo interactúa cada variable en cada sector con el fin de mostrar en primer lugar el problema que lo dibuja el estudiante y luego se busca poner el modelo en equilibrio.

Esperamos que sea de utilidad a los estudiantes de pregrado y para los docentes que este material les sirva como una herramienta que maneja una nueva metodología de forma lógica heterodoxa pluralista que mejore el análisis y el pensamiento de los mismos 
partiendo de movimientos simples a hacerlos de forma compleja cada vez explicando el movimiento de cada variable.

El diseño del instrumentó se aplicó a los estudiantes aparecen en el anexo N. 1.

6.2.1 Análisis descriptivo del comportamiento de las variables. Para este análisis veremos solo dos ejemplos.

Ejemplo N.1. ¿Señor gerente general, como se ve afectada su empresa cuando el banco de la república decide aumentar la tasa de interés de política monetaria?

Al subir las tasas de interés, aumenta la inversión, aumentan los ingresos, lo que hace que aumente el ingreso disponible a su vez origina un aumento del presupuesto esto origina un aumento en la masa monetaria, luego aumenta la cantidad real de dinero, lo que hizo que aumentara el dinero especulativo y el dinero de transacción todo esto origino una expansión monetaria.

Tabla 3.

Análisis Lógico

\begin{tabular}{|c|c|c|c|c|c|c|c|c|c|c|c|c|c|c|}
\hline & \multicolumn{14}{|c|}{ Variables endógenas } \\
\hline $\mathbf{R}$ & $\mathbf{Y}$ & $\mathbf{L}$ & $\mathbf{W}$ & $\frac{W}{P}$ & $\mathbf{y}$ & $\mathbf{C}$ & $\begin{array}{l}\mathbf{y}- \\
T\end{array}$ & I & $\mathbf{M}$ & $\mathbf{m}$ & Sm & $\frac{m}{P}$ & $m_{r}$ & $m_{y}$ \\
\hline & & & & & & & & & & & & & & \\
\hline
\end{tabular}

Primero partimos con él modelo en equilibrio como sigue: 


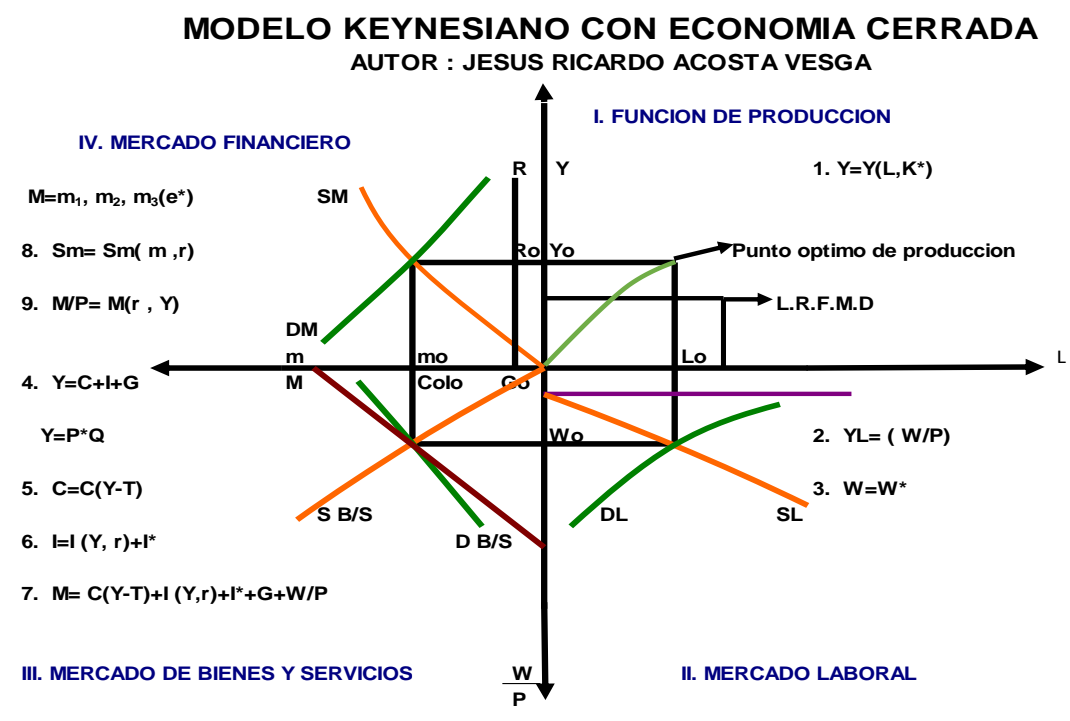

Ilustración 4. Modelo keynesiano con economía cerrada en equilibrio

\section{MODELO KEYNESIANO CON ECONOMIA CERRADA AUTOR : JESUS RICARDO ACOSTA VESGA}

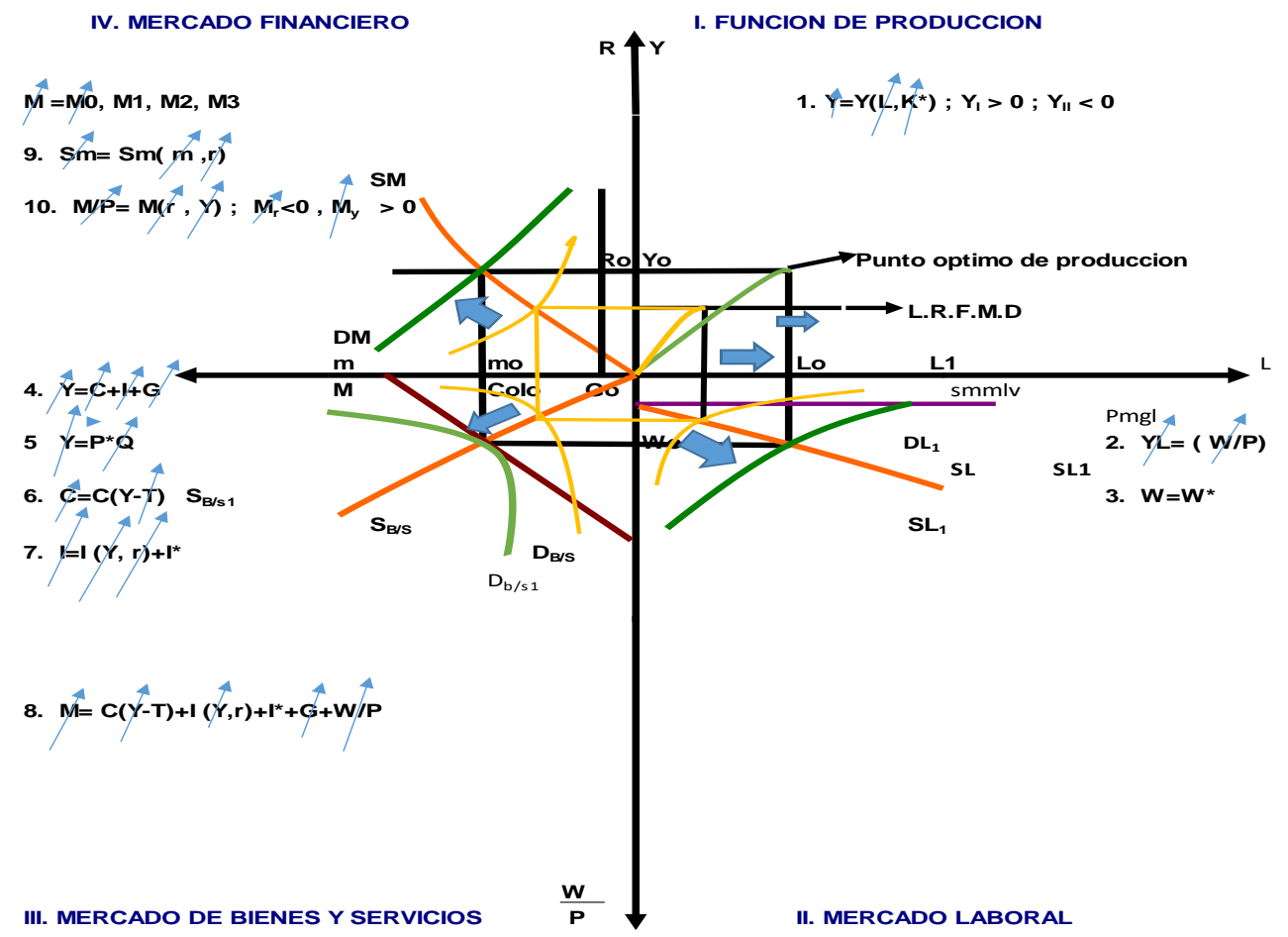

Ilustración 5. Modelo diagramático keynesiano con movimiento de las variables afectadas La solución como se observa en el grafico las flechas indican el movimiento de las variables hacia arriba mostrando que aumentaron y crearon una 
expansión monetaria, como gerente la solución es aumentar (política Fiscal), los impuestos para reducir esa expansión y así volver al equilibrio.

Ejemplo N.2. Utilizando el diagrama del modelo Keynesiano Cerrado con todas las ecuaciones, analice que pasa cuando aumenta el consumo de los hogares.

Cuando aumenta el consumo indica que aumentaron los ingresos lo que hace que se incrementé la inversión y se haga una expansión monetaria en la economía.

Tabla 4.

Análisis lógico aplicando solución con instrumentos de política fiscal

\begin{tabular}{|c|c|c|c|c|c|c|c|c|c|c|c|c|c|c|}
\hline & \multicolumn{14}{|c|}{ Variables endógenas } \\
\hline $\mathbf{R}$ & $\mathbf{Y}$ & $\mathbf{L}$ & W & $\frac{W}{P}$ & $\mathbf{y}$ & $\mathrm{C}$ & $y-T$ & I & M & m & Sm & $\frac{m}{P}$ & $m_{r}$ & $\boldsymbol{m}_{y}$ \\
\hline & & & & & & & & & & & & & & \\
\hline
\end{tabular}

\section{MODELO KEYNESIANO CON ECONOMIA CERRADA AUTOR : JESUS RICARDO ACOSTA VESGA}

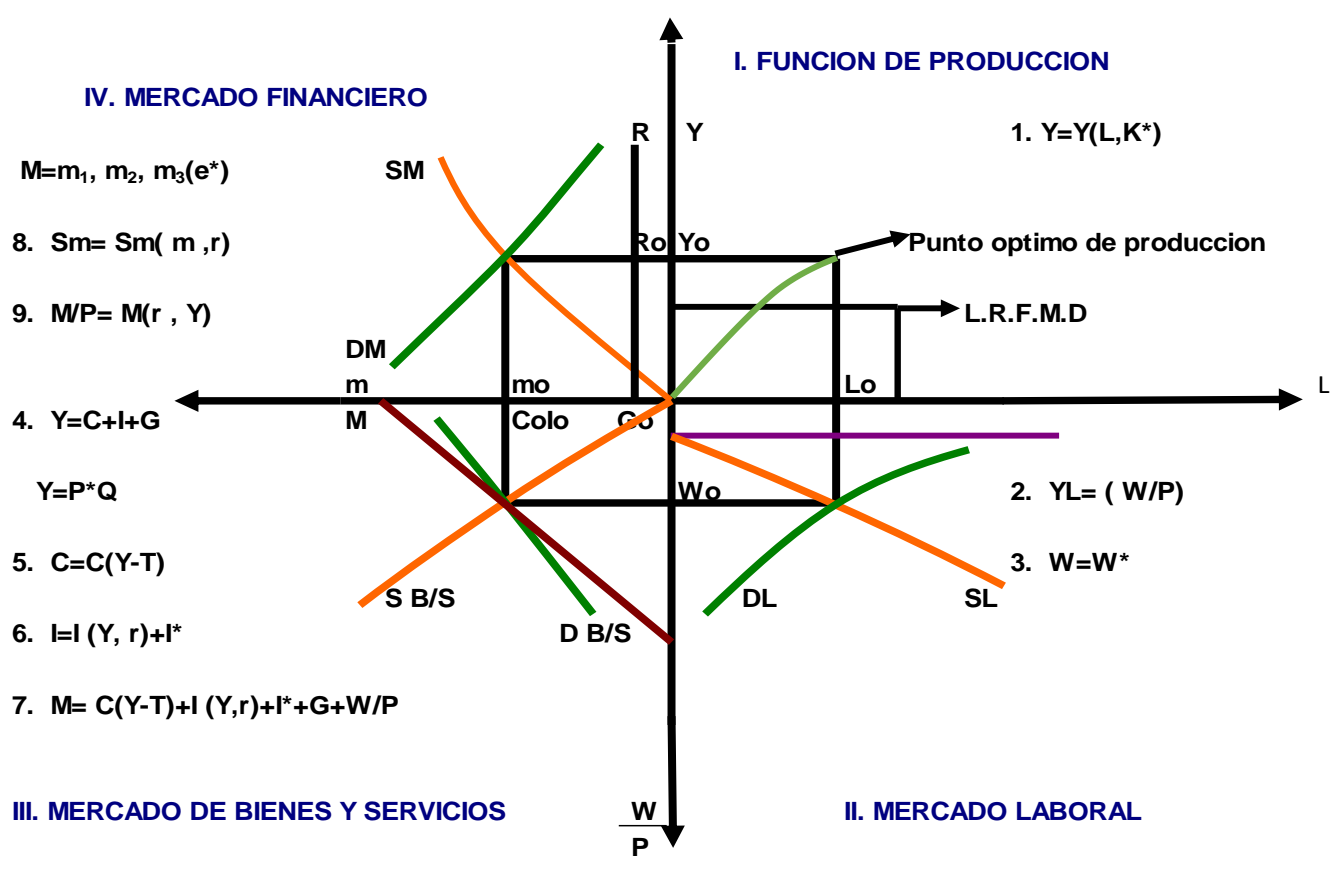

Ilustración 6. Modelo Diagramático Keynesiano en Equilibrio 


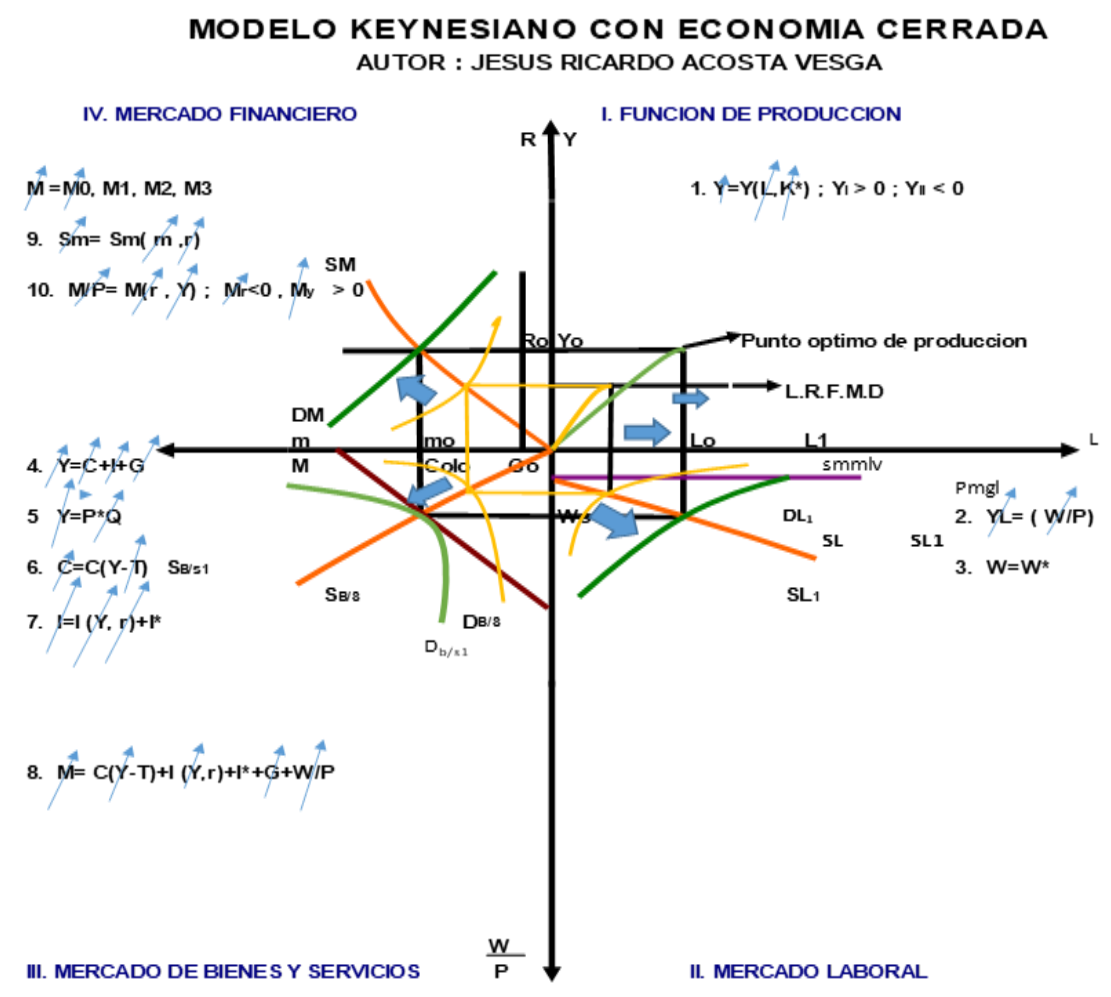

Ilustración 7. Modelo Diagramático Keynesiano con Aplicación De Política Fiscal

La solución: Para volver al punto de equilibrio debemos aumentar los impuestos y con esto reducimos la liquidez qué existe en la economía y así volvemos al punto de equilibrio la economía.

Nota: El resto de soluciones del instrumento se encuentran en los anexos.

\subsubsection{Solución del instrumento de la forma tradicional de la enseñanza de la}

\section{economía.}

Ejemplo N.1. ¿Señor gerente general como se ve afectada la empresa cuando el banco de la republica decide aumentar la tasa de interés como instrumento de la política monetaria? 


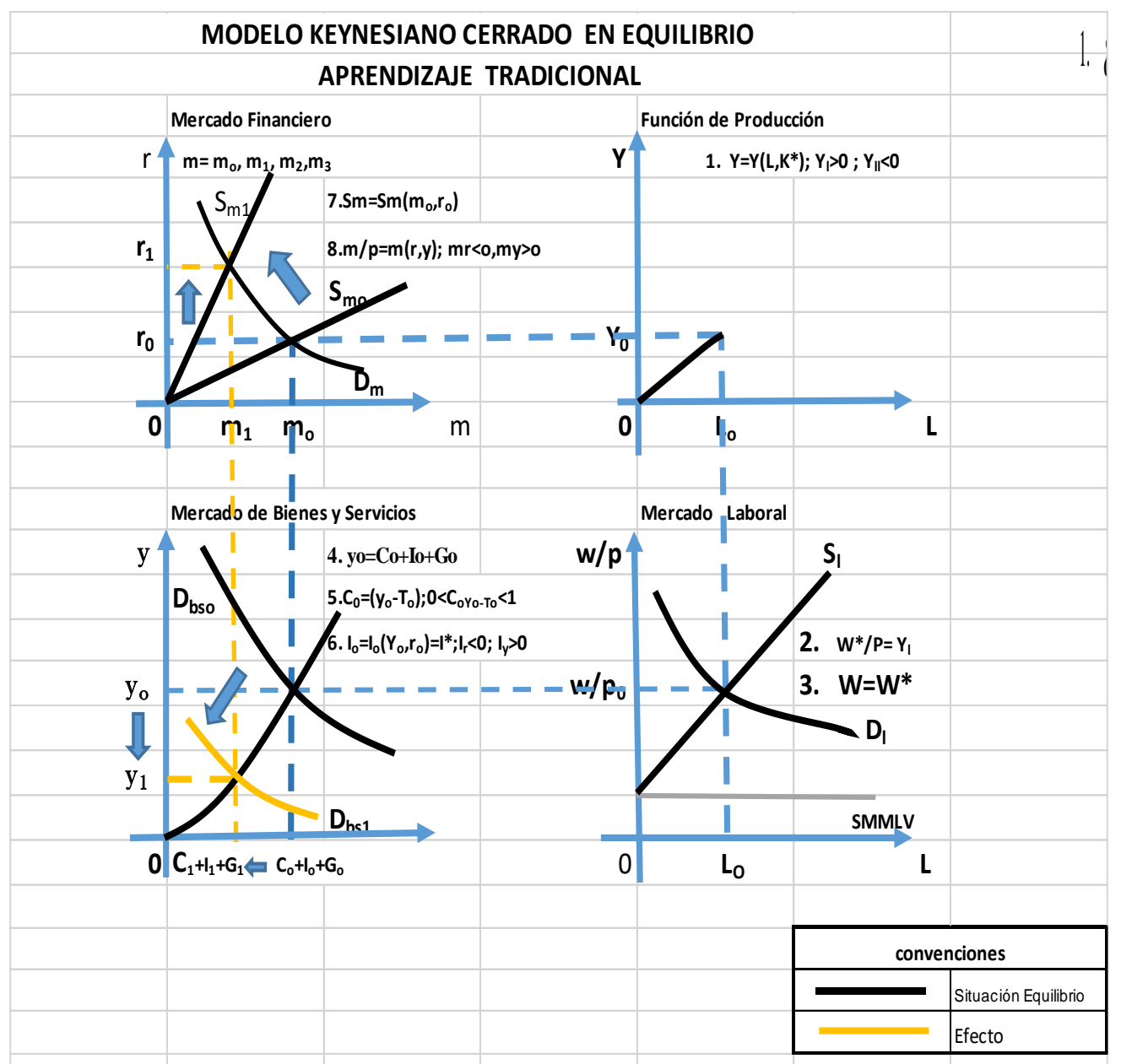

Ilustración 8. Modelo Keynesiano tradicional

Como se observa en el modelo keynesiano partimos de un situación de equilibrio y luego analizamos la variable afectada en este caso la tasa de interés que aumento lo cual hace que disminuya el ingreso disponible lo que hace disminuir el ingreso total en el mercado de bienes y servicios mientras que en el mercado monetario se afecta porque se reduce la demanda monetaria por el costo de los intereses. La función de producción y el mercado laboral no se ven afectados por la tasa de interés por que permanecen ceteris paribus.

Ejemplo.N.2. ¿Utilizando el modelo keynesiano cerrado con todas las ecuaciones que pasa cuando aumenta el consumo de los hogares? 


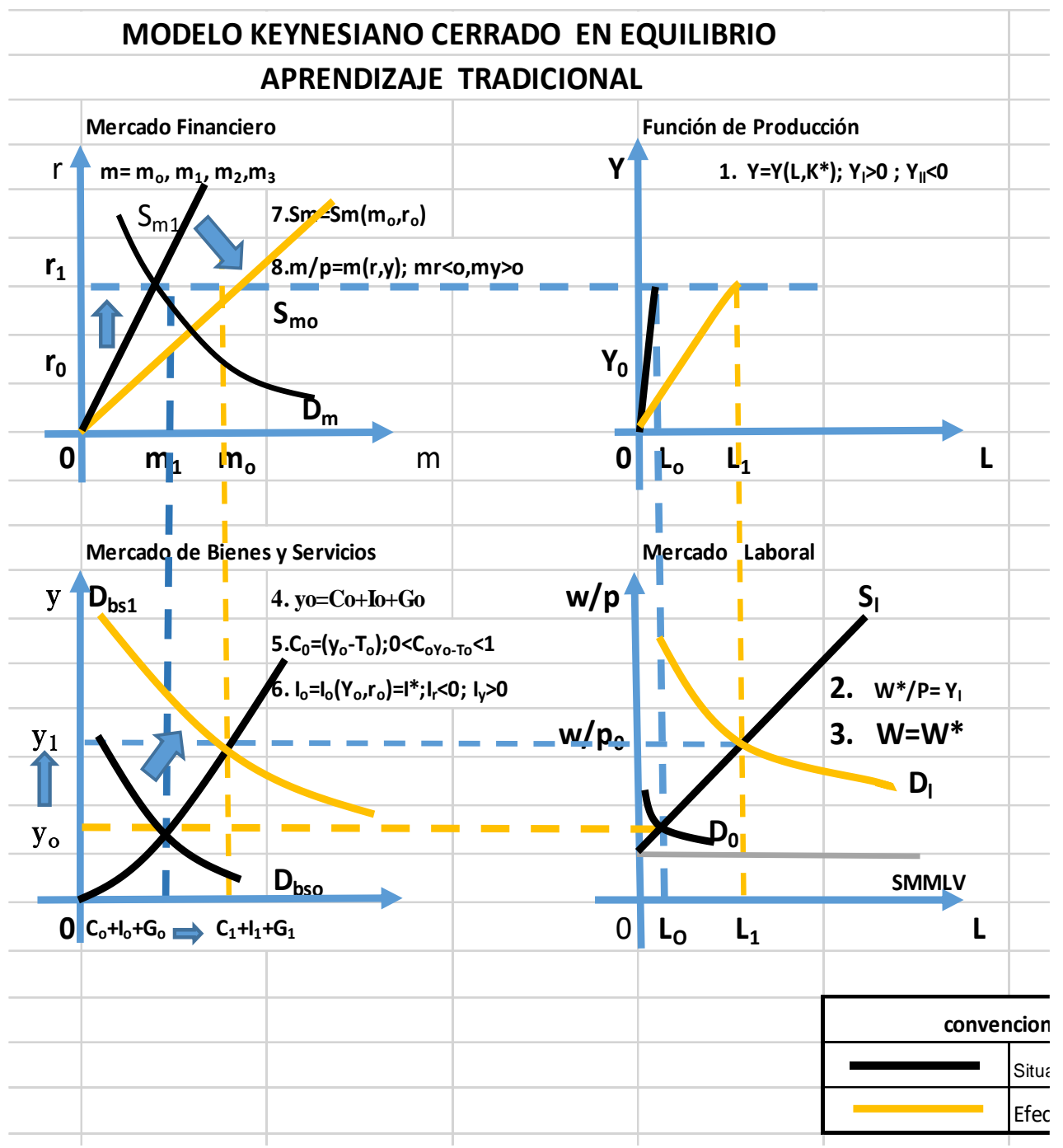

Ilustración 9. Modelo keynesiano forma tradicional

Partimos de una situación de equilibrio en todos los cuadrantes y analizamos la variable afectada en este caso fue el consumo delos hogares, que se dio por un aumento en los ingresos y esto hace que toda la economía se incremente. 


\subsection{Evaluación estadística de la descripción del modelo}

Tabla 5.

Convenciones de los datos a estudiar sobre el taller desarrollado por los estudiantes de la asignatura de Macroeconomía I en el año 2016

Convenciones:

\begin{tabular}{|l|l|l|}
\hline Preg. & $\Rightarrow$ & Preguntas \\
\hline Ne & $\Rightarrow$ & Número de estudiantes \\
\hline $\mathrm{Cm}$ & $\Rightarrow$ & Con Modelo \\
\hline $\mathrm{Sm}$ & $\Rightarrow$ & Sin Modelo \\
\hline Rccm & $\Rightarrow$ & Respuesta correcta con Modelo \\
\hline Ricm & $\Rightarrow$ & Respuesta incorrecta con Modelo \\
\hline Rcsm & $\Rightarrow$ & Respuesta correcta sin Modelo \\
\hline Rism & $\Rightarrow$ & Respuesta Incorrecta sin Modelo \\
\hline Vrcmrc & $\Rightarrow$ & Variación relativa con modelo respuesta correcta \\
\hline Vrcmri & $\Rightarrow$ & Variación relativa con modelo respuesta incorrecta \\
\hline Vracmrc & $\Rightarrow$ & Variación relativa acumulada con modelo respuesta correcta \\
\hline Vracmri & $\Rightarrow$ & Variación relativa acumulada con modelo respuesta incorrecta \\
\hline Vrsmrc & $\Rightarrow$ & Variación relativa sin modelo respuesta correcta \\
\hline Vrsmri & $\Rightarrow$ & Variación relativa sin modelo respuesta incorrecta \\
\hline Vracmrc & $\Rightarrow$ & Variación relativa acumulada con modelo respuesta correcta \\
\hline Vrasmri & $\Rightarrow$ & Variación relativa acumulada con modelo respuesta incorrecta \\
\hline Vasmrc & $\Rightarrow$ & Variación absoluta sin modelo respuesta correcta \\
\hline Vasmri & $\Rightarrow$ & Variación absoluta sin modelo respuesta incorrecta \\
\hline Vacmrc & $\Rightarrow$ & Variación absoluta con modelo respuesta correcta \\
\hline Vacmri & $\Rightarrow$ & Variación absoluta con modelo respuesta incorrecta \\
\hline Vacmrca $\Longrightarrow$ & Variación absoluta con modelo respuesta correcta acumulada \\
\hline vasmria & $\Rightarrow$ & Variación absoluta sin modelo respuesta incorrecta acumulada \\
\hline vasmrca & $\Rightarrow$ & Variación absoluta sin modelo respuesta correcta acumulada \\
\hline Vasmria & $\Rightarrow$ & Variación absoluta sin modelo respuesta incorrecta acumulada \\
\hline
\end{tabular}

Para el procesamiento de los datos se le dio nombre a las variables a desarrollar Tabla 6.

Análisis estadístico de las respuestas dadas por los estudiantes a los que se aplicó el taller 
y a los que respondieron de forma tradicional.

\begin{tabular}{|c|c|c|c|c|c|c|c|c|c|c|c|c|c|c|c|c|c|c|c|c|c|}
\hline \multicolumn{22}{|c|}{ ANALISIS ESTADISTISTICO DE LAS EVALUACIONES PRACTICADAS A LOS ESTUDIANTES } \\
\hline PREG. & $\mathrm{Ne}$ & $\mathrm{cm}$ & $\mathrm{sm}$ & $\mathrm{rccm}$ & ricm & rcsm & rism & VRCM R & VRCM RI & vracmrc & vracmri & VRSM RC & dVRSM RI & VRAsmbc & VRASM RI & VASM RC & VASM RI & VACM RC & VACM RI & VACM RCA & VACM RIA \\
\hline 1 & 14 & 10 & 4 & 8 & 2 & 1 & 3 & 0,08 & 0,02 & 0,08 & 0,02 & 0,01 & 0,03 & 0,01 & 0,03 & 1 & 1 & 2 & 8 & 2 & 8 \\
\hline 2 & 14 & 10 & 4 & 10 & 0 & 0 & 4 & 0,1 & 0 & 0,18 & 0,02 & 0 & 0,04 & 0,01 & 0,04 & 0 & 0 & 0 & 10 & 2 & 18 \\
\hline 3 & 14 & 10 & 4 & 10 & 0 & 0 & 4 & 0,1 & 0 & 0,28 & 0,02 & 0 & 0,04 & 0,01 & 0,05 & 0 & 0 & 0 & 10 & 2 & 28 \\
\hline 4 & 14 & 10 & 4 & 10 & 0 & 0 & 4 & 0,1 & 0 & 0,38 & 0,02 & 0 & 0,04 & 0,01 & 0,06 & 0 & 0 & 0 & 10 & 2 & 38 \\
\hline 5 & 14 & 10 & 4 & 6 & 4 & 0 & 4 & 0,06 & 0,04 & 0,44 & 0,06 & 0 & 0,04 & 0,01 & 0,07 & 0 & 0 & 4 & 6 & 6 & 44 \\
\hline 6 & 14 & 10 & 4 & 6 & 4 & 2 & 2 & 0,06 & 0,04 & 0,5 & 0,1 & 0,02 & 0,02 & 0,03 & 0,1 & 2 & 2 & 4 & 6 & 10 & 50 \\
\hline 7 & 14 & 10 & 4 & 5 & 5 & 0 & 4 & 0,05 & 0,05 & 0,55 & 0,15 & 0 & 0,04 & 0,03 & 0,13 & 0 & 0 & 5 & 5 & 15 & 55 \\
\hline 8 & 14 & 10 & 4 & 10 & 0 & 1 & 3 & 0,1 & 0 & 0,65 & 0,15 & 0,01 & 0,03 & 0,04 & 0,17 & 1 & 1 & 0 & 10 & 15 & 65 \\
\hline 9 & 14 & 10 & 4 & 10 & 0 & 0 & 4 & 0,1 & 0 & 0,75 & 0,15 & 0 & 0,04 & 0,04 & 0,21 & 0 & 0 & 0 & 10 & 15 & 75 \\
\hline 10 & 14 & 10 & 4 & 10 & 0 & 0 & 4 & 0,1 & 0 & 0,85 & 0,15 & 0 & 0,04 & 0,04 & 0,25 & 0 & 0 & 0 & 10 & 15 & 85 \\
\hline TOTALES & 14 & 100 & 40 & 85 & 15 & 4 & 36 & 0,85 & 0,15 & 4,66 & 0,84 & 0,04 & 0,36 & 0,23 & 1,11 & 4 & 4 & 15 & 85 & 84 & 466 \\
\hline
\end{tabular}

Esta tabla muestra la de distribución de frecuencias de acuerdo a la calificación obtenida por los estudiantes y a cada una de las respuestas se les dio una calificación 1, y 0 , si era buena o mala la respuesta, tanto a los que se les aplico el instrumento con modelo, como también a los que respondieron de la forma tradicional. Donde se observa que los respondieron con el modelo keynesiano de una aproximación diagramática obtuvieron un $85 \%$ de respuestas buenas, mientras que los que respondieron de forma tradicional obtuvieron solamente el $10 \%$ de respuestas buenas.

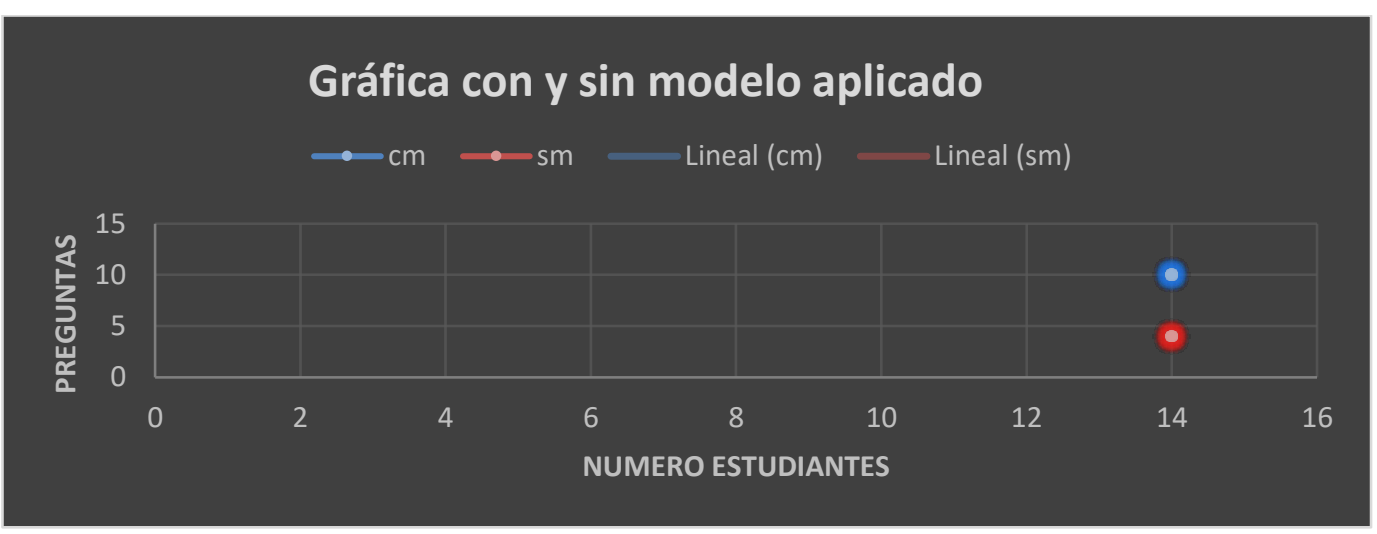

Ilustración 10. Número de estudiantes que participaron en la investigación

Esta ilustración nos muestra el número de los estudiantes que participaron en la solución al test que se les aplico con modelo fueron los azules que indican Diez (10) 
participantes y sin modelo fueron los de rojo, que fueron cuatro (4) participantes.

Tabla 7.

Análisis estadístico con variaciones

\begin{tabular}{|c|c|c|c|c|c|c|c|c|c|c|c|}
\hline \multicolumn{12}{|c|}{$\begin{array}{l}\text { ANALISIS ESTADISTISTICO CON VARIACION RELATIVA CON } \\
\text { MODELO Y SIN MODELO }\end{array}$} \\
\hline Preg. & $\mathrm{Ne}$ & $\mathbf{c m}$ & sm & VRCM & VRCM & vracmr & vracmri & VRSMR & VRSMRI & VRASM & VRASMF \\
\hline 1 & 14 & 10 & 4 & 0 & 0,14 & 0,01 & 0,28 & 0,01 & 0,04 & 0,01 & 0,04 \\
\hline 2 & 14 & 10 & 4 & $\mathrm{o}$ & 0,14 & 0,03 & 0,42 & 0,1 & 0,04 & 0,11 & 0,15 \\
\hline 3 & 14 & 10 & 4 & o & 0,14 & 0,06 & 0,56 & 0,1 & 0,04 & 0,21 & 0,36 \\
\hline 4 & 14 & 10 & 4 & 0 & 0,14 & 0,1 & 0,7 & 0,1 & 0,04 & 0,31 & 0,67 \\
\hline 5 & 14 & 10 & 4 & 0,1 & 0,14 & 0,15 & 0,84 & 0,1 & 0,04 & 0,41 & 1,08 \\
\hline 6 & 14 & 10 & 4 & 0,1 & 0,14 & 0,21 & 0,98 & 0,1 & 0,04 & 0,51 & 1,59 \\
\hline 7 & 14 & 10 & 4 & 0,1 & 0,14 & 0,28 & 1,12 & 0,1 & 0,04 & 0,61 & 2,2 \\
\hline 8 & 14 & 10 & 4 & 0,1 & 0,14 & 0,36 & 1,26 & 0,1 & 0,04 & 0,71 & 2,91 \\
\hline 9 & 14 & 10 & 4 & 0,1 & 0,14 & 0,45 & 1,4 & 0,1 & 0,04 & 0,81 & 3,72 \\
\hline 10 & 14 & 10 & 4 & 0,1 & 0,14 & 0,55 & 1,54 & 0,1 & 0,04 & 0,91 & 4,63 \\
\hline TOTALES & 14 & 100 & 40 & 0,6 & 1,4 & 2,2 & 9,1 & 0,91 & 0,4 & 4,6 & 17,35 \\
\hline
\end{tabular}

En esta tabla se puede observar que la variación relativa con la aplicación del instrumento con modelo los datos fueron más agrupados $(0.6 \%)$ y se obtuvieron respuestas correctas más consistentes, mientras que los datos sin modelo arrojaron datos más dispersos en la variación relativa de un 0,91\%.

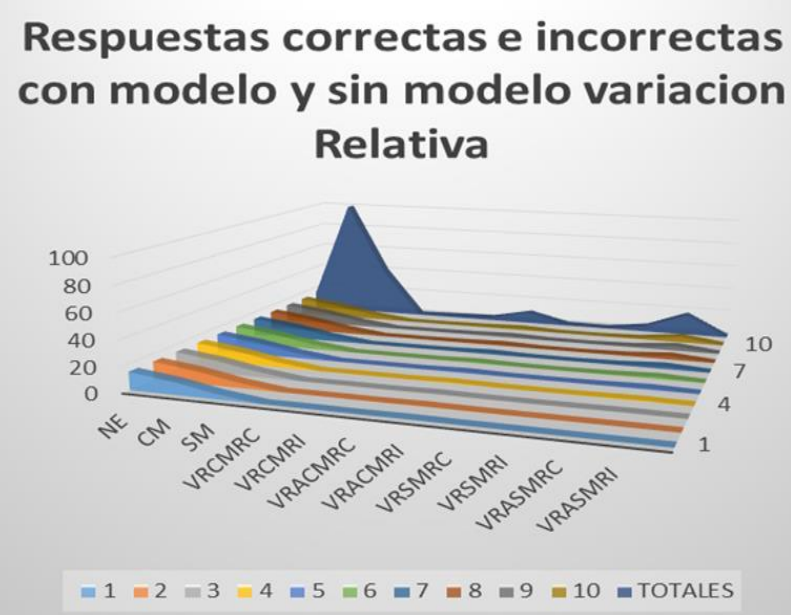

Ilustración 11. Respuestas Correctas E Incorrectas

En esta ilustración se observa que el número total de participantes en la aplicación del instrumento fueron 14 donde a 10 se les enseño la aproximación diagramática del 
modelo Keynesiano en cuatro (4) cuadrantes mientras que a los 4 participantes restantes se les enseño la macroeconomía de la forma tradicional, demostrando así que a los estudiantes que se les enseño el modelo dieron mejores resultados mostrando una mejor comprensión de la economía, sus variables y comportamiento económico.

Tabla 8.

Análisis Estadístico De La Investigación

\begin{tabular}{|c|c|c|c|c|c|c|c|c|c|}
\hline Preg. & $\mathrm{Ne}$ & $\mathbf{c m}$ & $\mathbf{s} \mathbf{m}$ & VASM & VASMI & VACM & VACMRI & VACMRCA & VACMRIA \\
\hline 1 & 14 & 10 & 4 & 1 & 1 & 2 & 8 & 2 & 8 \\
\hline 2 & 14 & 10 & 4 & o & o & o & 10 & 2 & 18 \\
\hline 3 & 14 & 10 & 4 & O & O & O & 10 & 2 & 28 \\
\hline 4 & 14 & 10 & 4 & O & o & O & 10 & 2 & 38 \\
\hline 5 & 14 & 10 & 4 & o & o & 4 & 6 & 6 & 44 \\
\hline 6 & 14 & 10 & 4 & 2 & 2 & 4 & 6 & 10 & 50 \\
\hline 7 & 14 & 10 & 4 & $\mathbf{O}$ & O & 5 & 5 & 15 & 55 \\
\hline 8 & 14 & 10 & 4 & 1 & 1 & O & 10 & 15 & 65 \\
\hline 9 & 14 & 10 & 4 & o & 0 & o & 10 & 15 & 75 \\
\hline 10 & 14 & 10 & 4 & O & o & O & 10 & 15 & 85 \\
\hline TOTAL & 14 & 100 & 40 & 4 & 4 & 15 & 85 & 84 & 466 \\
\hline
\end{tabular}

En esta tabla se puede apreciar la variación absoluta que nos deja ver que las respuestas correctas con modelo fueron de un $85 \%$, mientras que de la forma tradicional solo se obtuvo un $10 \%$ de 40 preguntas respondieron 4 buenas. 
Tabla 9.

Medidas De Tendencia Central

\begin{tabular}{|l|l|}
\hline media aritmetica $\mathrm{cm}$ & $=$ \\
\hline media aritmetica $\mathrm{sm}$ & $=$ \\
\hline varianza cm & $=$ \\
\hline varianza sm & $=$ \\
\hline Desviacion estandar cm & $=$ \\
\hline Desviacion estandar $\mathrm{sm}$ & $=$ \\
\hline mediana cm & $=$ \\
\hline Mediana sm & $=$ \\
\hline Moda Cm & $=$ \\
\hline Moda Sm & $=$ \\
\hline
\end{tabular}

\begin{tabular}{|r|}
\hline \multicolumn{1}{|c|}{$\mathrm{RC}$} \\
\hline 6,07 \\
\hline 0,29 \\
\hline 6,96 \\
\hline 1,50 \\
\hline 2,64 \\
\hline 1,27 \\
\hline 6,00 \\
\hline 2,00 \\
\hline 10,00 \\
\hline 1,00 \\
\hline
\end{tabular}

\begin{tabular}{|r|}
\hline \multicolumn{1}{|c|}{$\mathrm{Ri}$} \\
\hline 1,07 \\
\hline 2,57 \\
\hline 2,88 \\
\hline 0,94 \\
\hline 1,70 \\
\hline 1,27 \\
\hline 4,00 \\
\hline 3,00 \\
\hline 4,00 \\
\hline 4,00 \\
\hline
\end{tabular}

\begin{tabular}{|l|l|}
\hline Desviacion estandar $\mathrm{cm}$ & $=$ \\
\hline Desviacion estandar $\mathrm{sm}$ & $=$ \\
\hline
\end{tabular}

\begin{tabular}{|c|}
\hline $\mathrm{Rc}$ \\
\hline 2,64 \\
\hline 1,27 \\
\hline
\end{tabular}

\begin{tabular}{|c|}
\hline$R i$ \\
\hline 1,70 \\
\hline 0,97 \\
\hline
\end{tabular}

Observando las medidas de tendencia central se puede demostrar que los datos obtenidos nos muestran que dio mejores resultados las respuestas de los estudiantes a quienes se le enseño el modelo mientras que los estudiantes que vieron la macroeconomía de forma tradicional no obtuvieron resultados satisfactorios.

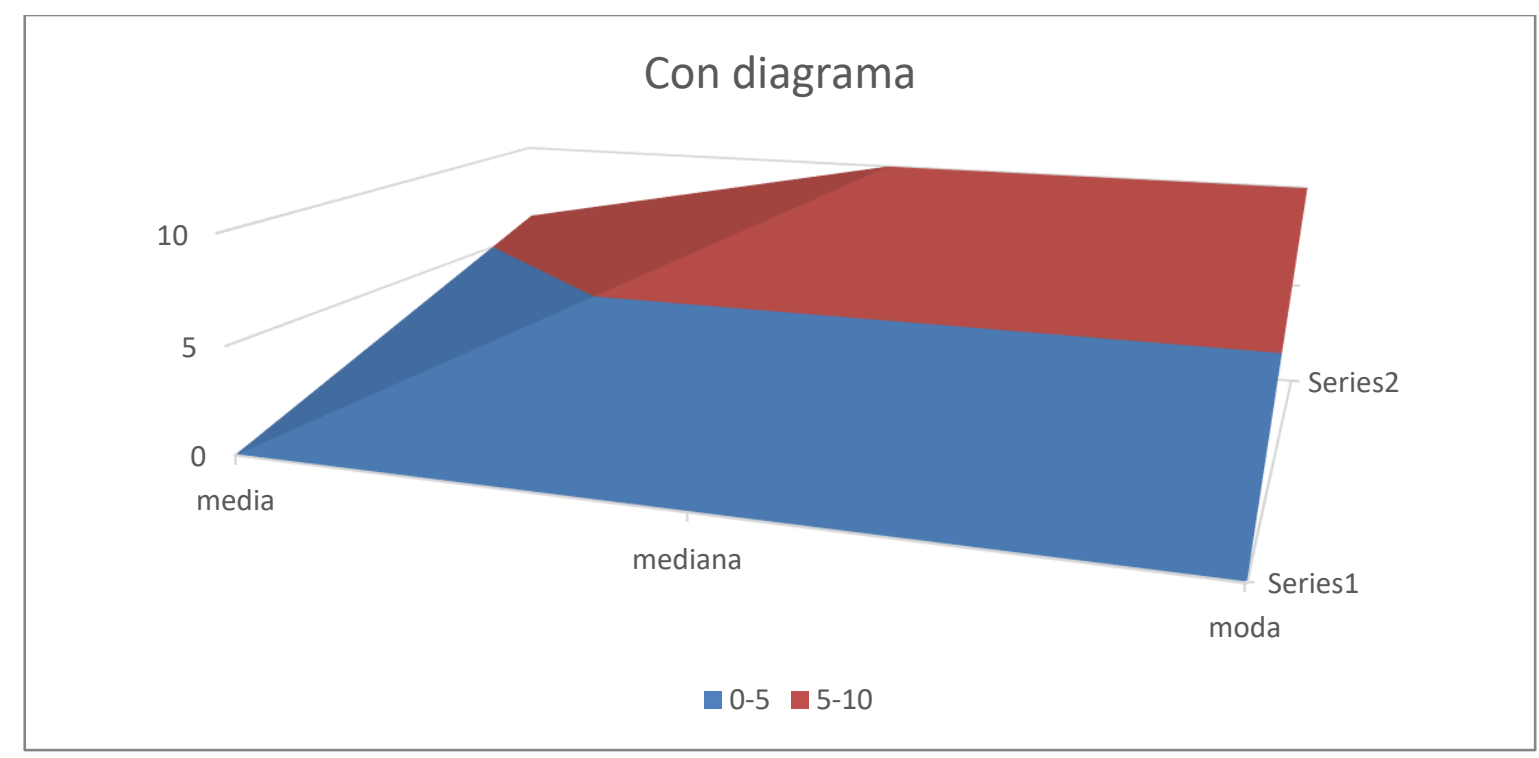


Ilustración 12. Medidas de tendencia central que nos muestran que el modelo es pertinente

Este grafico de la tabla con diagrama nos muestra que es simétrica hacia la derecha donde la mediana y la moda son iguales siendo este valor el que corresponde un máximo.

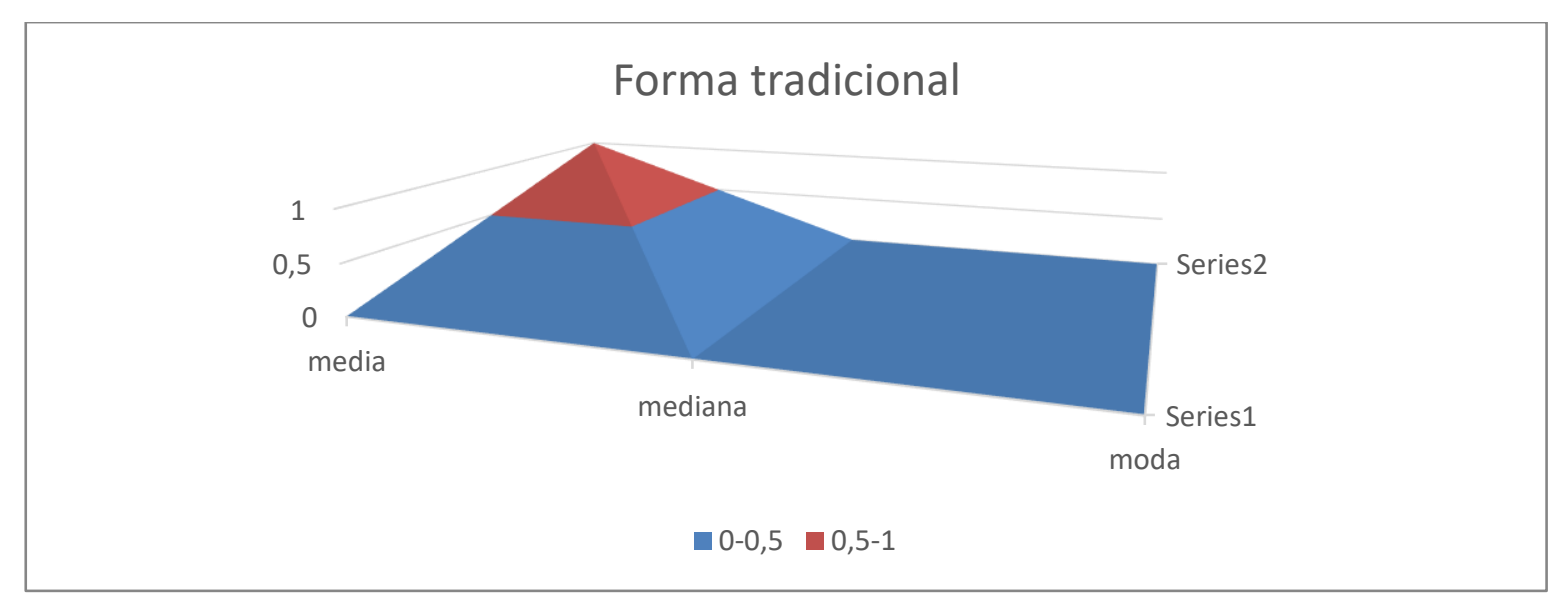

Ilustración 13. Medidas de tendencia central de la forma tradicional

En estas medidas se puede observar que las respuestas incorrectas son menores demostrando así que el modelo mejora el nivel de comprensión y aprendizaje de los estudiantes.

En cuanto a estos datos se puede observar que a los estudiantes que se les enseño la macroeconomía de la forma tradicional su nivel de comprensión fue menor y se evidencia la dificultad en el aprendizaje.

El experimento se realizó con dos cursos de la Fundación Universitaria Monserrate, de la facultad de finanzas y comercio exterior en la asignatura de Macroeconomía, donde a uno de los cursos se le enseño el diagrama del modelo keynesiano cerrado, durante el transcurso de un semestre que equivale a cuatro meses ( 16 semanas), partiendo desde el 28 de julio del 2016 al 2 de diciembre de 2016 , con una 
intensidad horaria de cuatro horas semanales, para un total de horas presenciales de 64 horas y horas externas trabajadas por parte de los estudiantes mínimo 2 horas en casa, durante el mismo tiempo, que serían un total de 32 horas, para un gran total trabajado por los estudiantes tanto en el aula como en la casa de 96 horas.

El curso al que se impartió el modelo, poseía una población de 10 estudiantes, y el otro curso se le enseño el modelo de la forma tradicional, donde habían solo 4 estudiantes que trabajaron el mismo tiempo (96 Horas), donde se obtuvieron las estadísticas arriba observadas, de las cuales podemos concluir que :

Los estudiantes a los cuales se enseñó el modelo keynesiano en cuatro cuadrantes presentaron más respuestas correctas donde los datos de tendencia central son muy coherentes a la media que es 6 y la mediana y la moda son 10

De acuerdo al análisis de estadísticos descriptivos mostrado en las tablas y gráficas previamente analizadas, se puede evidenciar que, para la muestra de estudiantes de la Fundación Universitaria Monserrate, de la escuela de Economía, la aplicación del modelo keynesiano de 4 cuadrantes ayuda a obtener una mejora significativa del aprendizaje de los conceptos que soportan la teoría económicas, sus aplicaciones y relaciones.

Las medidas de tendencia central son claras al demostrar que el número de respuestas correctas para los estudiantes en los que se aplicó el modelo de prueba son mayores que en el grupo que no tuvo esta característica. El porcentaje respuesta correcta fue del $85 \%$.

El puntaje general obtenido para los estudiantes en los que no se aplicó el modelo tiende a ser significativamente más bajo que en los que sí. Obteniendo un porcentaje del $4 \%$ 
Lo anterior, teniendo en cuenta que el nivel académico de los estudiantes es homogéneo, constituye una evidencia estadística de las bondades del modelo en el mejoramiento de los procesos de enseñanza-aprendizaje. 


\section{Conclusiones}

En el esfuerzo de reestructurar la educación en economía para resolver los problemas económicos, situando a sus estudiantes en un campo de mayor comodidad en donde se obtenga una recepción más clara de los conceptos, se ha optado por implementar el modelo keynesiano como una aproximación diagramática para los estudiantes de pregrado.

En un esfuerzo por mejorar la calidad de la información que el estudiante debe afrontar y teniendo en cuenta que no todos poseen la destreza de percibir los conceptos de forma clara, se instauro este modelo como una herramienta pedagógica de la cual se pudo determinar que en gran medida permitía mejorar la obtención de datos desde un plano más visual y didáctico puesto que se desarrollaba mediante un elemento diagramático del modelo keynesiano en cuatro cuadrantes instaurando así una base que los estudiantes tomaron no solo como un elemento funcional si no que la identificaron como una herramienta necesaria para el proceso.

Es importante determinar la importancia que pudiera tener un modelo de este tipo en el marco educativo de un estudiante de economía. La eficiencia de este modelo se vio evidenciada con resultados obtenidos con base en el análisis de los test asignados a un grupo de estudiantes de finanzas y negocios internacionales de la Fundación Universitaria Monserrate. Por este hecho se reafirma por parte de los investigadores que el método geométrico resulta eficaz para asimilar conceptos complejos de los modelos económicos, por lo tanto puede ser una herramienta pedagógica poderosa y flexible en este contexto Implementar el material didáctico en estudiantes de pregrado para verificar su eficacia.

La hipótesis aquí planteada demuestra en diferentes campos de evaluación como 
las asignadas en el proceso, una nueva e importante forma de reestructurar la educación en economía, siendo además aceptada como indispensable por los mismos estudiantes quienes fueron participes del método planteado.

La implementación del modelo keynesiano como una aproximación diagramática para los estudiantes de pregrado se desarrolló teniendo en cuenta los procesos pertinentes para tal fin. En primer lugar se diseñó un diagrama de cuatro cuadrantes donde todos sus cuadrantes son positivos: se utilizó esta perspectiva pedagógica para desarrollar un enfoque geométrico donde se ilustrara el modelo Keynesiano cerrado en una aproximación diagramática de equilibrio general. Esto permitió en la práctica desarrollar en los estudiantes un mejor entendimiento del proceso generando en ellos un vínculo más didáctico con el modelo. Como paso a seguir los estudiantes fueron instruidos a reunir en un diagrama las magnitudes y las relaciones funcionales del modelo para que pudieran hacer un seguimiento de las interacciones de simples a complejas entre los cuadrantes, donde se observa en el primer cuadrante la función de producción, especificando la máxima producción que se puede elaborar con una cantidad determinada de insumos. El experimento se realizó con dos cursos de la Fundación Universitaria Monserrate, de la facultad de finanzas y comercio exterior en la asignatura de Macroeconomía, donde a uno de los cursos se le enseño el diagrama del modelo keynesiano cerrado, durante el transcurso de un semestre que equivale a cuatro meses ( 16 semanas), partiendo desde el 28 de julio del 2016 al 2 de diciembre de 2016, con una intensidad horaria de cuatro horas semanales, para un total de horas presenciales de 64 horas y horas externas trabajadas por parte de los estudiantes mínimo 2 horas en casa, durante el mismo tiempo, que serían un total de 32 horas, para un gran total trabajado por los estudiantes tanto en el aula como en 
la casa de 96 horas.

En los datos obtenidos de primer y segundo test se observa que el número total de participantes en la aplicación del instrumento fueron 14 donde a 10 se les enseño la aproximación diagramática del modelo Keynesiano en cuatro (4) cuadrantes mientras que a los 4 participantes restantes se les enseño la macroeconomía de la forma tradicional, demostrando así que a los estudiantes que se les enseño el modelo dieron mejores resultados mostrando una mejor comprensión de la economía, sus variables y comportamiento económico.

De esto se indica que el modelo se instaura con éxito en los estudiantes a los que se les impartió la enseñanza del modelo estando un paso adelante del método de enseñanza tradicional de la macroeconomía.

El curso al que se impartió el modelo, poseía una población de 10 estudiantes, y el otro curso se le enseño el modelo de la forma tradicional, donde habían solo 4 estudiantes que trabajaron el mismo tiempo (96 Horas), donde se obtuvieron las estadísticas observadas en el trabajo, de las cuales podemos concluir que :

Los estudiantes a los cuales se enseñó el modelo keynesiano en cuatro cuadrantes presentaron más respuestas correctas donde los datos de tendencia central son muy coherentes a la media que es 6 y la mediana y la moda son 10 .

De acuerdo al análisis de estadísticos descriptivos mostrado en las tablas y gráficas previamente analizadas, se puede evidenciar que, para la muestra de estudiantes de la Fundación Universitaria Monserrate, de la escuela de Economía, la aplicación del modelo keynesiano de 4 cuadrantes ayuda a obtener una mejora significativa del aprendizaje de los conceptos que soportan la teoría económicas, sus aplicaciones y relaciones. 
Las medidas de tendencia central son claras al demostrar que el número de respuestas correctas para los estudiantes en los que se aplicó el modelo de prueba son mayores que en el grupo que no tuvo esta característica. El porcentaje respuesta correcta fue del $85 \%$.

El puntaje general obtenido para los estudiantes en los que no se aplicó el modelo tiende a ser significativamente más bajo que en los que sí. Obteniendo un porcentaje del $4 \%$

Lo anterior, teniendo en cuenta que el nivel académico de los estudiantes es homogéneo, constituye una evidencia estadística de las bondades del modelo en el mejoramiento de los procesos de enseñanza-aprendizaje.

Teniendo como referencia el desarrollo practico que se llevó a cabo con estudiantes de macroeconomía, como se ha especificado anteriormente y teniendo en cuenta los aciertos obtenidos en la implementación y recepción de comentarios por parte de la muestra, es posible resaltar el éxito del modelo, obteniendo el resultado esperado, demostrando que mejora el aprendizaje de la economía de forma práctica como un elemento didáctico.

Vale resaltar que para tal fin fue de gran importancia la investigación bibliográfica aplicada al trabajo de la cual se obtuvo información importante para la construcción de este modelo y el desarrollo pleno y exitoso del mismo, dejando así una marca positiva para la comunidad educativa de economía en general, siendo los estudiantes de macroeconomía los más beneficiados.

Como se pudo observar en el análisis estadístico, el modelo si mostro resultado esperado, demostrando que mejora el aprendizaje de la economía de forma práctica. 


\section{Recomendaciones}

Para poder aplicar el modelo primero se debe iniciar por el aprendizaje de las variables, luego se debe continuar con el aprendizaje de las ecuaciones, después se deben analizar los movimientos de cada una de las variables y sus implicaciones en cada uno de los mercados, y así se logra una mayor comprensión del modelo, con sus movimientos. 


\section{Referencias}

Aghion, P., \& Howitt, P. (1997). Teoria Del Crecimiento Endogeno. Estados Unidos: Universidad de Harvard.

Bacon, F. (2000). El nuevo Organon. Cambridge: Cambridge University Press.

Banco República de Colombia. (2003). Introducción al análisis el Caso Colombiano. Bogotá. D.C.: Banco República de Colombia.

Blau, M., \& Lloyd, P. (2010). Figuras y Diagramas Famosos en la Economía. Minesota: Lishing.

Chou, Y.-L. (1969). Análisis Estadistico. México: Nueva editorial Interamericana, S. A.

Fernandez Riva, J. (1996). Apuntes De Clase Modelos Clasico y Keynesiano. Bogotá: Universidad de los Andes, Centro de estudios sobre Desarrollo Economico.

Forstater, M. (2008). Pequeñas Grandes Ideas. Economía. Barcelona - España: Printed in Singapur .

Hicks, J. (1976). Ensayos sobre la teoria Monetaria. Una sugerencia para simplificar la teoria monetaria 1935. Barcelona: Ariel.

Hodgson, G. (1999). Evolution and Institutions. . Cheltenham, UK: Edward Elgar.

Keynes, J. (1936). Teoria General de la ocupación, el interés y el dinero. New York: Harcourt.

Minsky, H. (2008). La Estabilización de una Economía Inestable. Estados Unidos: McGraum-Hill.

Nicholson, W. (2008). Teoria Microeconómica. Mexico. D.F.: Cengage Learning Editores, S.A. 
Potier. J.P., P. S. (1991). Un ensayo biográfico. Un ensayo biográfico. Londres: Routledge.

Reardon, J. (2009). The Handbook of Pluralist Economics Education . New York: Routledge.

Salazar Pulido, W. (2012). Alta Redacción. Bogotá. D.C.: Net Educativa.

Samuelson, P., \& Nordhaus, W. (2006). Economía. Mexico D.F.: McGraw - Hill Companies, Inc.

Schumpeter, J. (1911). Teoria del Desaroolo Económico. Estados Unidos: Universidad de Harvard.

Schumpeter, J. (1939). Ciclos empresariales. Estados Unidos: Harvard.

Sen K., A. (1981). La pobreza y las hambrunas : Un ensayo sobre los derechos y la Privación. OXford: Claredon Press.

Solow, R. (1956). Crecimiento Económico. Quarterly Journal of Economics.

Vromen, J. (2007). "In Praise of Moderate Plurality" in J. Groenewegen. Northampton: Teaching Pluralism in Economics.

W. C.Brainard. J.Tobin. (mayo de 1968). Pitfalls in financial model Building. Americaan Economic. 
Anexos 
Anexo A. Enseñanza del modelo keynesiano para estudiantes de pregrado una aproximación diagramática.

Estudiantes de Macroeconomía II

TEST

\section{Nombre del estudiante:}

\section{Programa:}

Semestre:

Fecha:

Test enfocado al estudio de la enseñanza del modelo Keynesiano cerrado, a través de un diagrama económico, donde su participación, será de vital importancia, para evidenciar su aplicación en la nueva forma de aprender la economía, donde conocerá y aplicara de una forma más didáctica los movimiento de las variables económicas y así poder tomar mejor las decisiones para lograr los correctivos a los fenómenos económicos casuísticos.

A continuación se presentan diez preguntas tipo Saber Pro a las cuales usted primero dibujara la problemática y dará solución utilizando el modelo keynesiano de economía cerrada, evidenciando el movimiento de las variables económicas, para lo cual usted tendrá un rol.

1. ¿Señor gerente general, como se ve afectada su empresa cuando el banco de la república decide aumentar la tasa de interés de política monetaria?

2. ¿Señor gerente financiero, como se ve afectada su empresa cuando el banco de la república decide aumentar el encaje bancario?

3. ¿Señor gerente financiero, como se ve afectada su empresa cuando el banco de la república decide aumentar la emisión de dinero? 
4. ¿Señor gerente de producción, que pasa cuando el gobierno decide aumentar los instrumentos de política fiscal, como se afectan las variables del modelo?

5. Utilizando el diagrama del modelo Keynesiano cerrado con todas las ecuaciones, analice que pasa cuando disminuye la oferta monetaria.

6. Utilizando el diagrama del modelo Keynesiano cerrado con todas las ecuaciones, analice que pasa cuando aumenta el gasto público.

7. Utilizando el diagrama del modelo Keynesiano Cerrado con todas las ecuaciones, analice que pasa cuando aumenta el consumo de los hogares.

8. Utilizando el diagrama del modelo Keynesiano cerrado con todas las ecuaciones, analice que pasa cuando aumenta la inversión.

9. Utilizando el diagrama del modelo Keynesiano cerrado con todas las ecuaciones y analice que pasa cuando disminuye la tasa de interés.

10. ¿Usted cree que el diagrama del modelo le da las herramientas necesarias para conocer de una forma más sencilla la comprensión de la economía?

\section{Respuestas de los estudiantes: al aplicativo}

1. ¿Señor gerente general, como se ve afectada su empresa cuando el banco de la república decide aumentar la tasa de interés de política monetaria?

Al subir las tasas de interés, aumenta la inversión, aumentan los ingresos, lo que hace que aumente el ingreso disponible a su vez origina un aumento del presupuesto esto origina un aumento en la masa monetaria, luego aumenta la cantidad real de dinero, lo que hizo que aumentara el dinero especulativo y el dinero de transacción todo esto origino una expansión monetaria. 


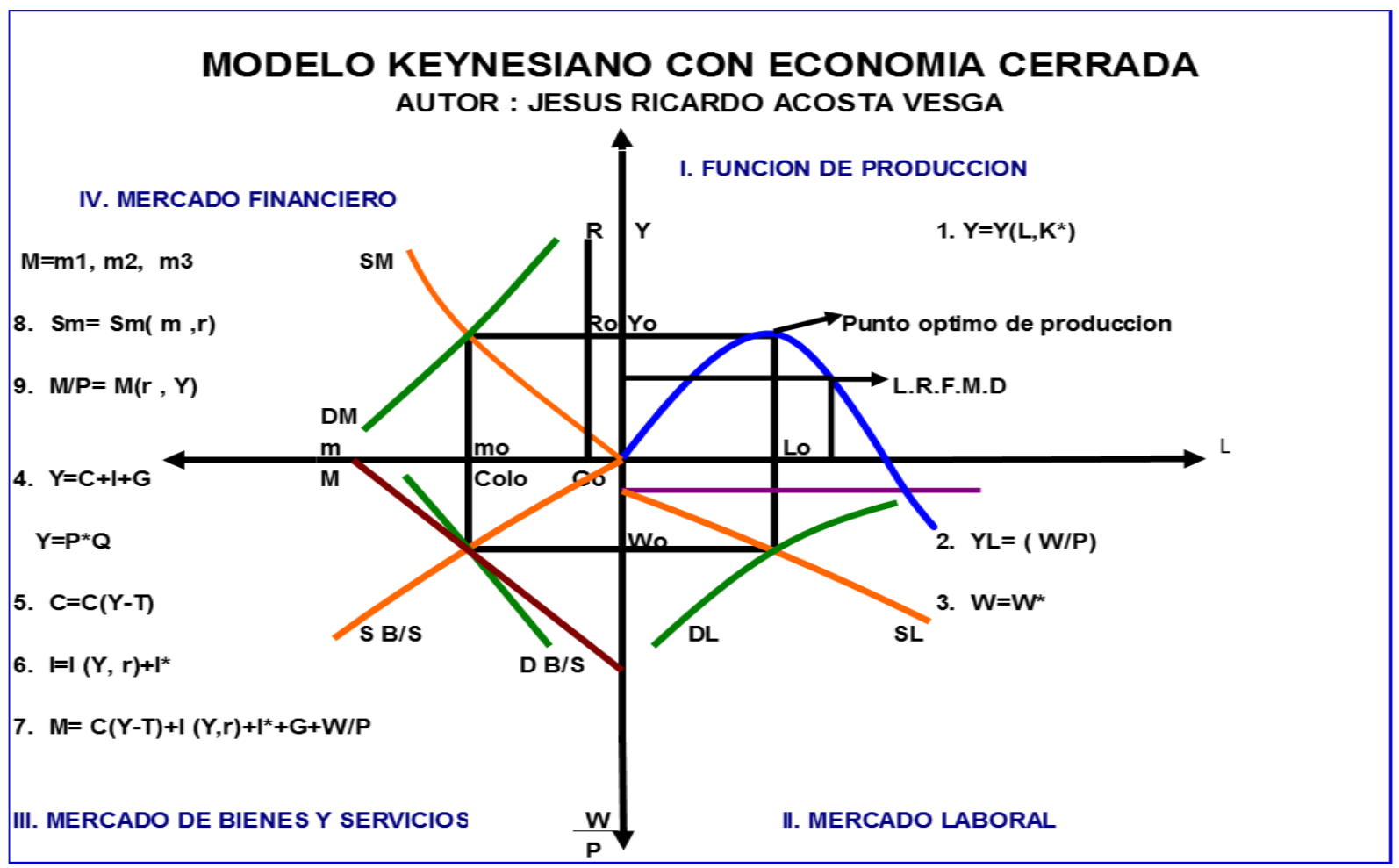

Anexo. Ilustración No. 1. Situación de equilibrio. 
Modelo con movimiento de las variables afectadas.

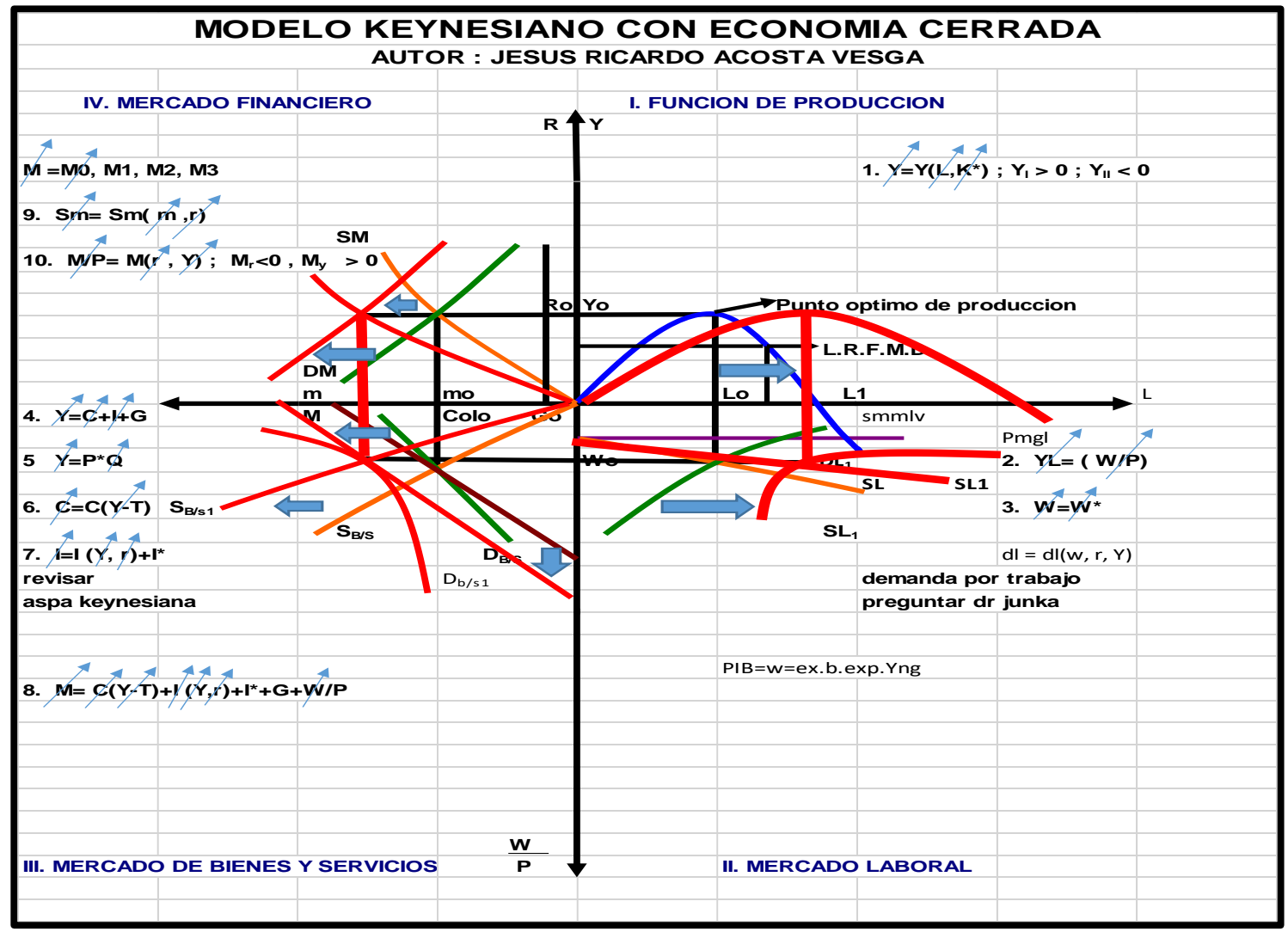

\section{Anexo. Ilustración No. 2. Movimiento de las variables.}

La solución como se observa en el grafico las flechas indican el movimiento de las variables hacia arriba mostrando que aumentaron y crearon una expansión monetaria, como gerente la solución es aumentar la capacidad instalada de la empresa teniendo en cuenta que hay más capital y eso ubica la economía en equilibrio.

2. ¿Señor gerente financiero, como se ve afectada su empresa cuando el banco de la república decide aumentar el encaje bancario?

Al aumentar el encaje bancario, se reduce el la oferta monetaria, disminuyendo el crédito, lo que hace y se reduce la demanda del dinero especulativo y de transacción, y esto origina una caída en el presupuesto y hace bajar los ingresos de la empresa originando una contracción monetaria, la producción y el número de empleados no se ve afectada en el 
corto plazo, ni los salarios nominales y por supuesto tampoco se afecta el salario real.

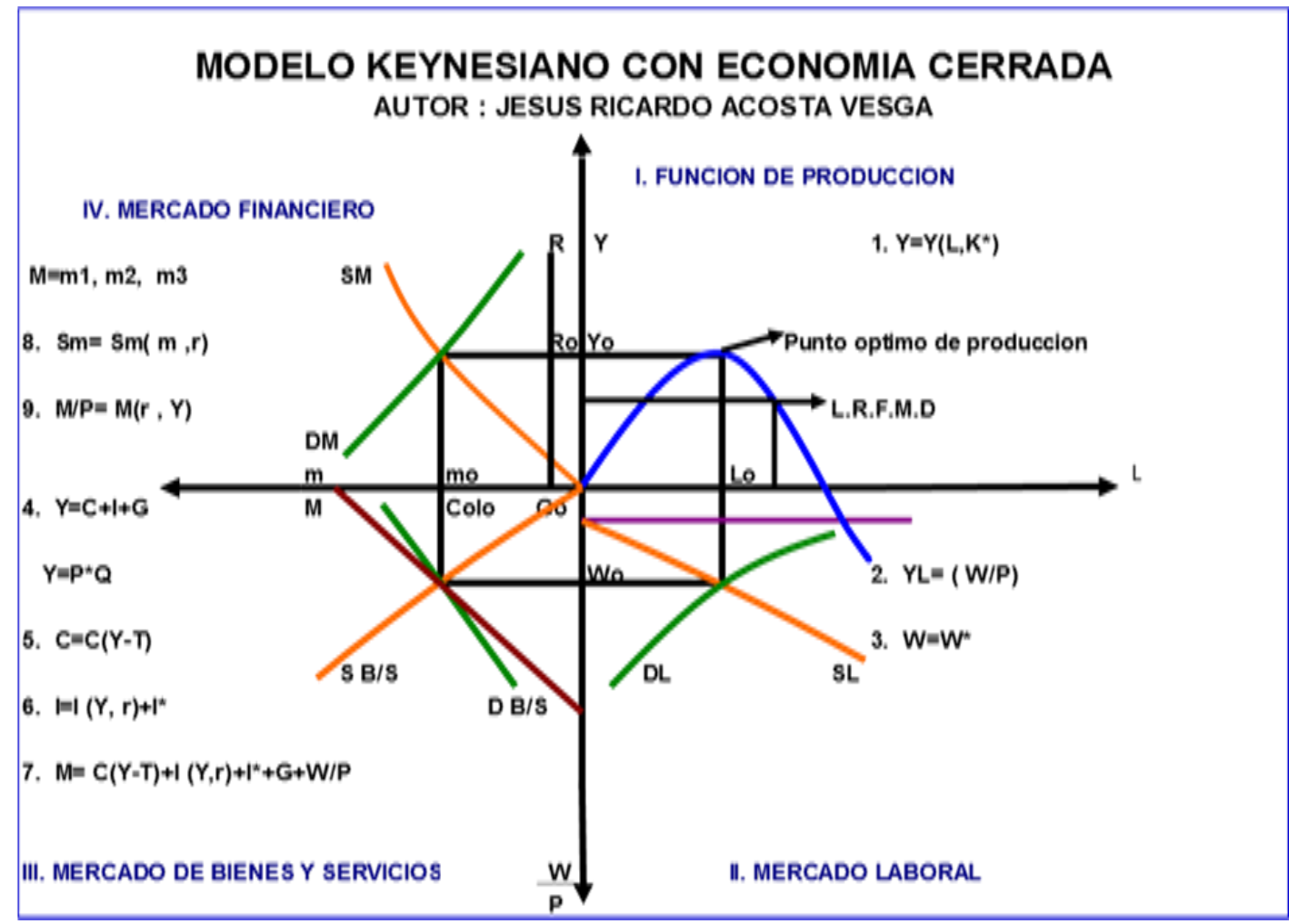

Anexo. Ilustración No. 3. Situación de equilibrio.

Modelo con movimiento de las variables afectadas

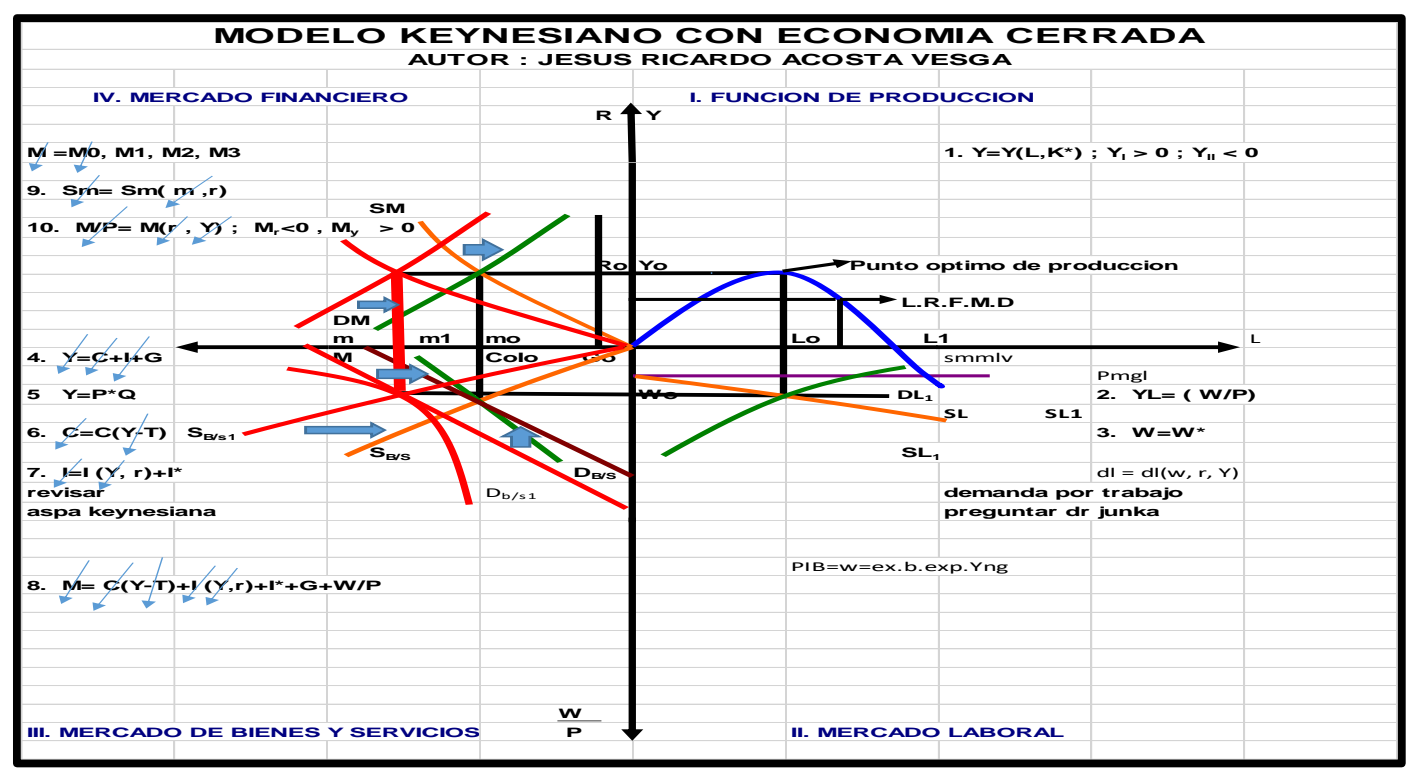

Anexo. Ilustración No. 3. Movimiento de las variables afectadas. 
La solución para colocar el modelo en equilibrio es aumentando el gasto para reactivar la economía, con este aumento se produce un aumento en los ingresos y esto reactiva el consumo, la inversión, el presupuesto y a la vez aumentaría la masa monetaria incentivando de nuevo el crédito y así volveríamos al equilibrio.

3. ¿Señor gerente financiero, como se ve afectada su empresa cuando el banco de la república decide aumentar la emisión de dinero?

Al aumentar la emisión primaria de dinero por parte de Banco de la república, va a existir mayor cantidad de dinero en la economía, lo que ocasiona que se incremente la oferta monetaria y esto hace que aumente el consumo de los hogares, la inversión y el gasto y esto hace a la vez que se aumente el ingreso y se reactive la economía.

Y la economía puede llegar a presentar un sobre calentamiento financiero.

Modelo con movimiento de las variables afectadas

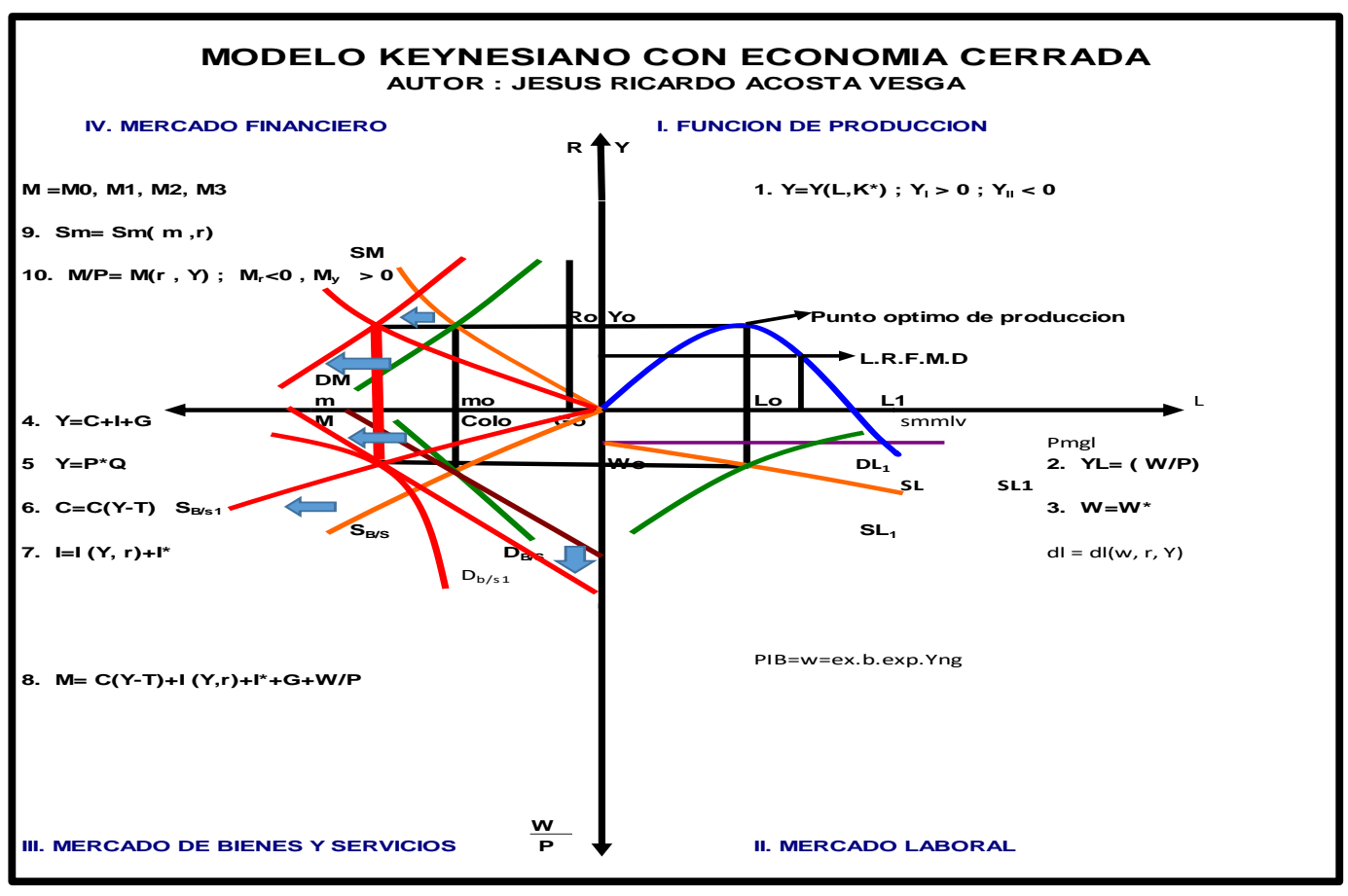

Anexo. Ilustración No. 4. Movimiento de las variables afectadas. 
La Solución: Se debe invertir en la planta de producción para aumentar la capacidad productiva, aumentando la producción el número de empleados y así volver al punto de equilibrio inicial.

4. ¿Señor gerente de producción, que pasa cuando el gobierno decide aumentar los instrumentos de política fiscal, como se afectan las variables del modelo?

La solución: Si se incrementan tanto en gasto como los impuestos en el mismo porcentaje, el uno reduce el poder adquisitivo, como son los impuestos y al aumentar el gasto se mejora el poder adquisitivo y se reactiva la economía devolviendo todo al punto de equilibrio. Lo que indica que el modelo no se vea afectado.

5. Utilizando el diagrama del modelo Keynesiano cerrado con todas las ecuaciones, analice que pasa cuando disminuye la oferta monetaria.

Si disminuye la oferta monetaria, hace que se suban las tasas de interés, lo que hace que se reduzca la inversión por el costo de los intereses, lo mismo pasa con el consumó, el ingreso se reduce y el gasto también, esto puede producir que se baje la producción y exista una contracción en la economía.

\section{Modelo con movimiento de las variables afectadas}




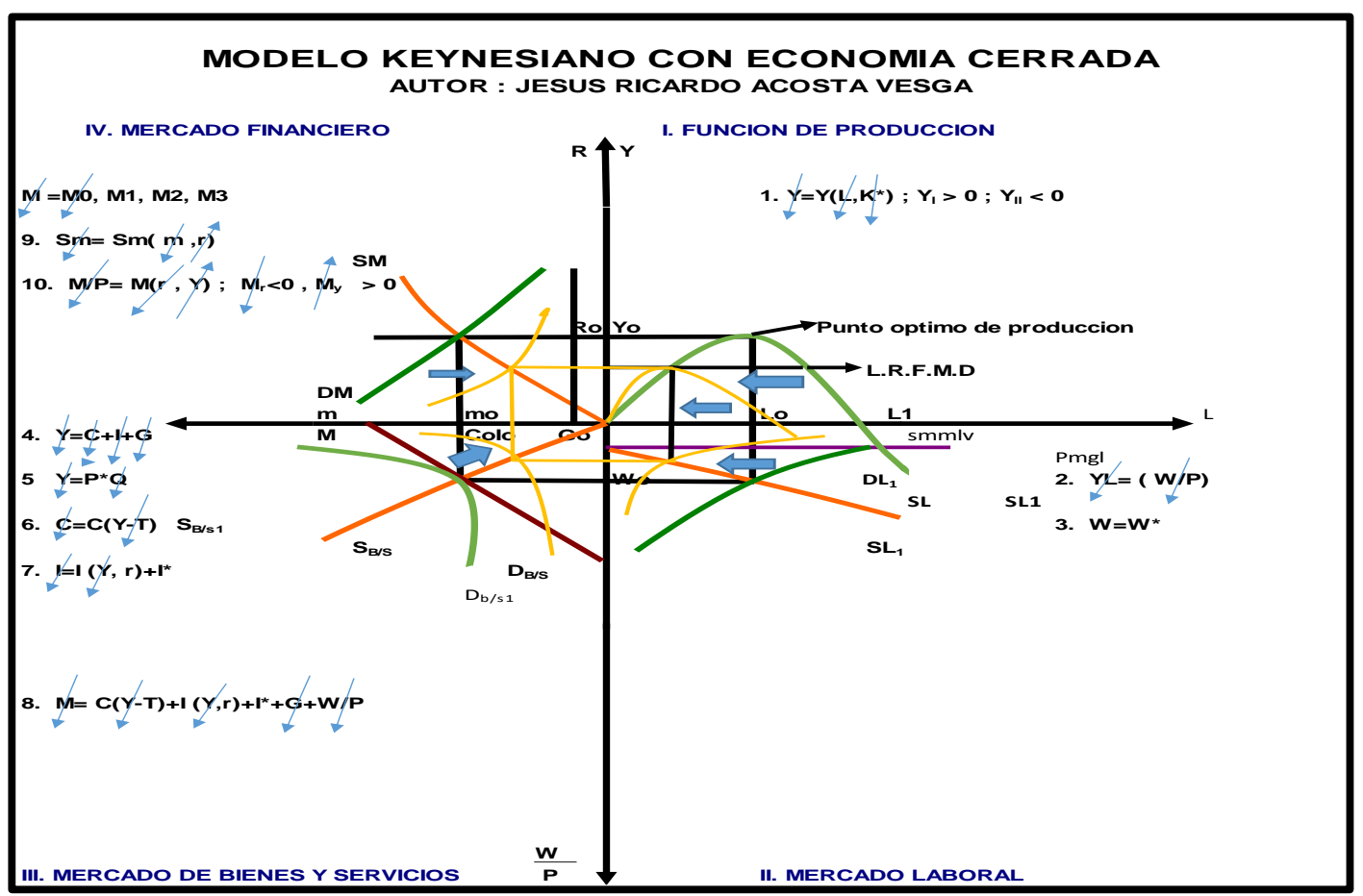

\section{Anexo. Ilustración No. 5. Movimiento de las variables afectadas.}

La Solución: Para este caso hay varias respuestas entre ellas una es incrementar

el gasto público para reactivar la economía y así volver al punto de equilibrio, otra solución sería que el Banco de la Republica, aumentara las emisiones de dinero y así reactivar la economía y volver al punto de equilibrio.

6. Utilizando el diagrama del modelo Keynesiano cerrado con todas las ecuaciones, analice que pasa cuando aumenta el gasto público.

Cuando aumenta el gasto público se reactiva la economía y esto hace que exista una expansión monetaria y hace que la economía crezca. 


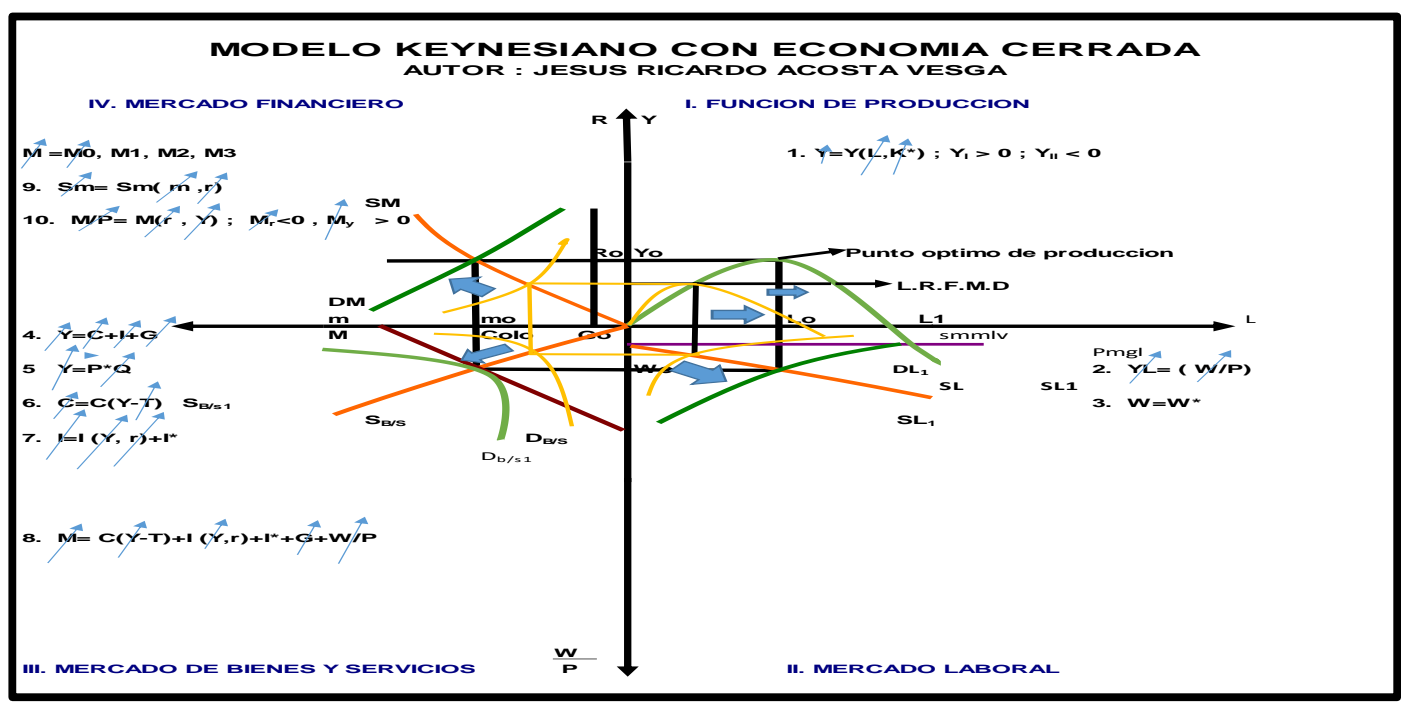

Anexo. Ilustración No. 6. Movimiento de las variables afectadas.

7. Utilizando el diagrama del modelo Keynesiano Cerrado con todas las ecuaciones, analice que pasa cuando aumenta el consumo de los hogares.

Cuando aumenta el consumo indica que aumentaron los ingresos lo que hace que se incrementé la inversión y se haga una expansión monetaria en la economía.

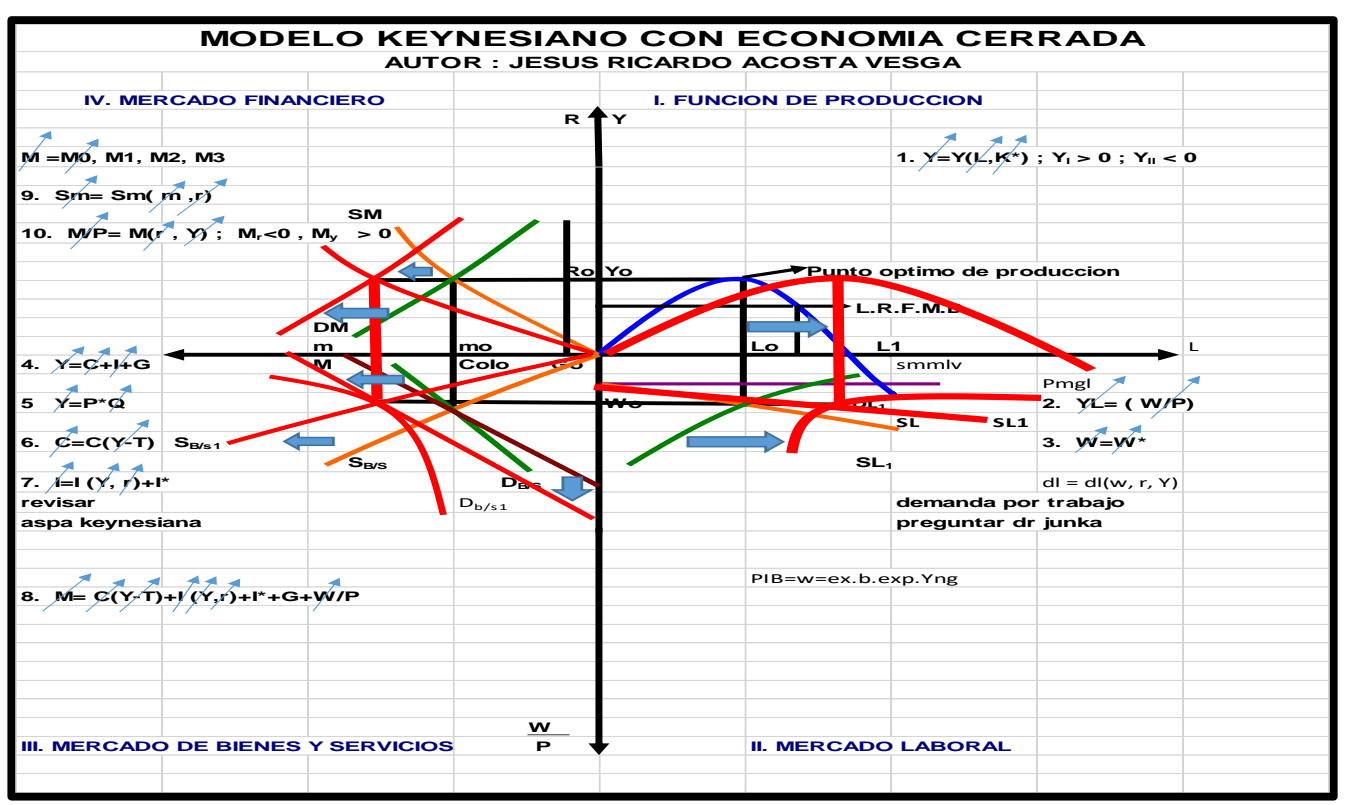

Anexo. Ilustración No. 7. Movimiento de las variables afectadas.

La solución: Para volver 1 punto de equilibrio debemos aumentar los impuestos y 
con esto reducimos la liquidez qué existe en la economía y así volvemos al punto de equilibrio la economía.

8. Utilizando el diagrama del modelo Keynesiano cerrado con todas las ecuaciones, analice que pasa cuando aumenta la inversión.

Si hay un aumento en la inversión es divido a que se incrementaron los ingresos y esto nos lleva a una expansión monetaria.

Modelo con movimiento de las variables afectadas

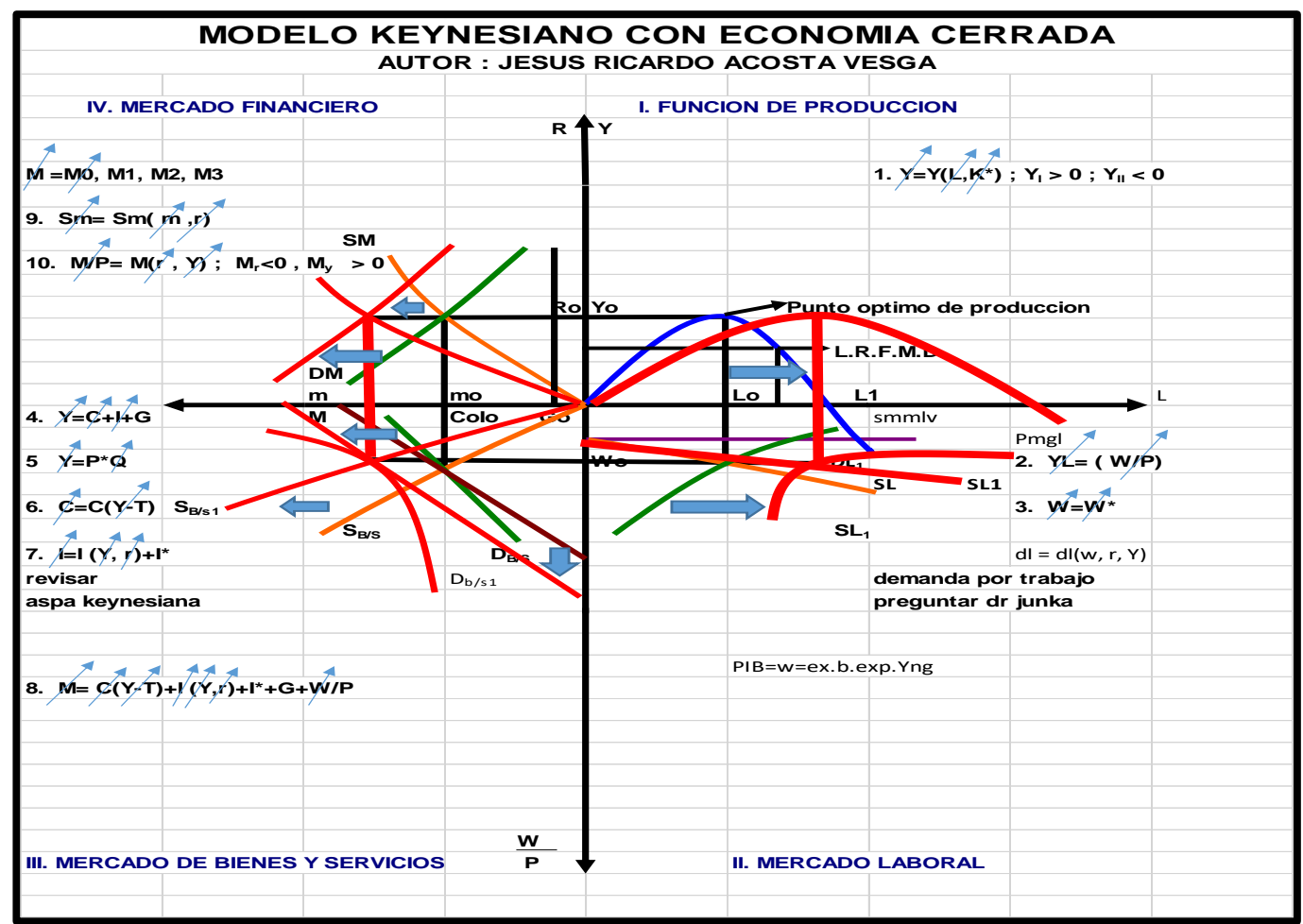

Anexo. Ilustración No. 8. Movimiento de las variables afectadas.

La solución: Para volver 1 punto de equilibrio debemos aumentar los impuestos y con esto reducimos la liquidez qué existe en la economía y así volvemos al punto de equilibrio la economía.

9. Utilizando el diagrama del modelo Keynesiano cerrado con todas las ecuaciones y 
analice que pasa cuando disminuye la tasa de interés.

Si disminuye la tasa de interés esto ocasiona que la gente demande más dinero porque el costo del dinero es más barato y esto reactiva la economía y origina una expansión monetaria.

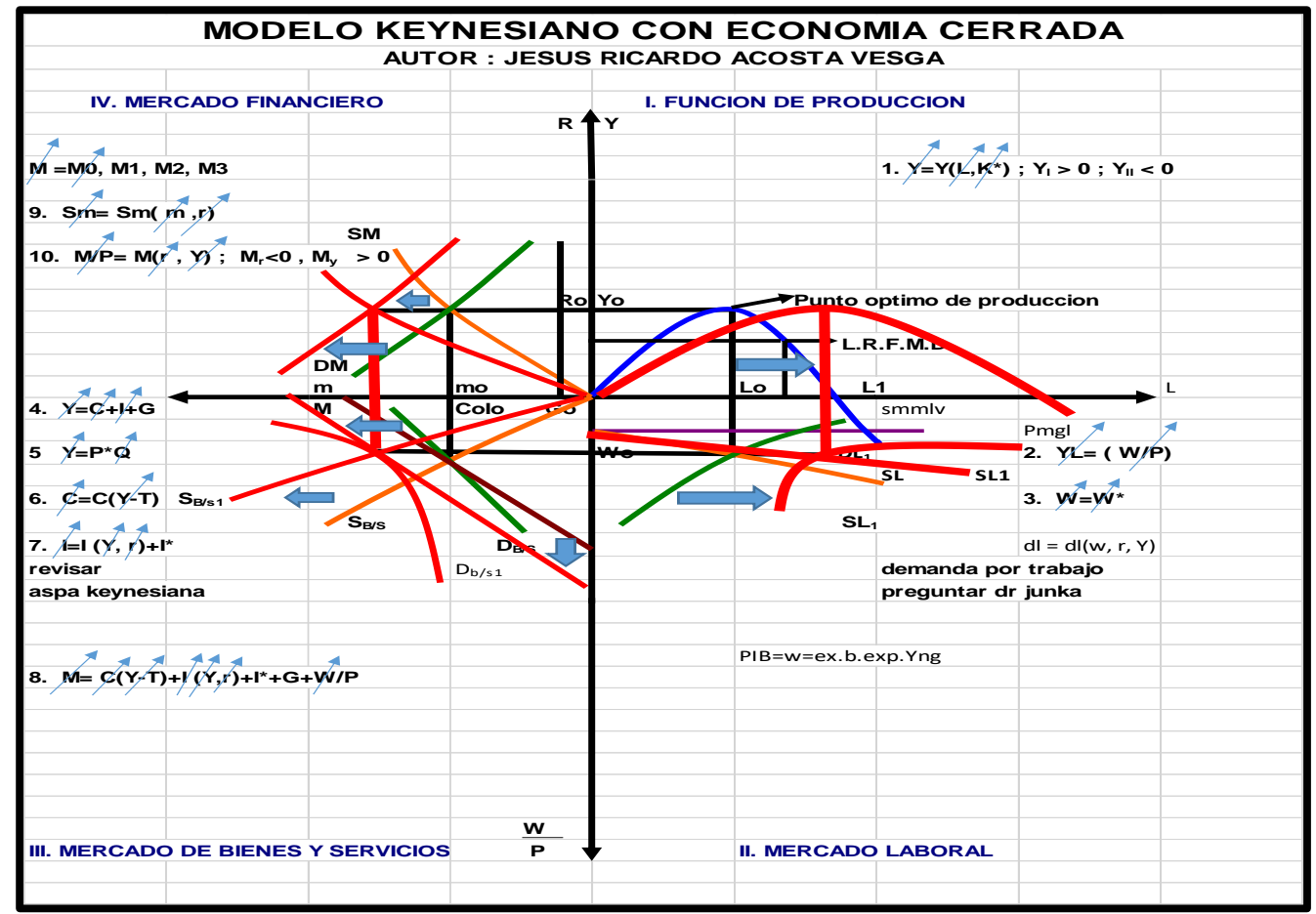

\section{Anexo. Ilustración No. 9. Movimiento de las variables afectadas.}

La solución: Para volver al punto de equilibrio debemos aumentar los impuestos y con esto reducimos la liquidez qué existe en la economía y así volvemos al punto de equilibrio la economía.

10. ¿Usted cree que el diagrama del modelo le da las herramientas necesarias para conocer de una forma más sencilla la comprensión de la economía?

El modelo explica de un forma clara, el comportamiento de las variables, ya que estudiamos ecuación por ecuación y cada una de las variable observando su impacto en la economía, y nos colabora para comprender mejor la economía y nos 
ayuda en el proceso de toma de decisiones

\section{Enseñanza Del Modelo Keynesiano Para Estudiantes De \\ Pregrado Una Aproximación Diagramática}

Asignatura Macroeconomía II

TEST N. 1

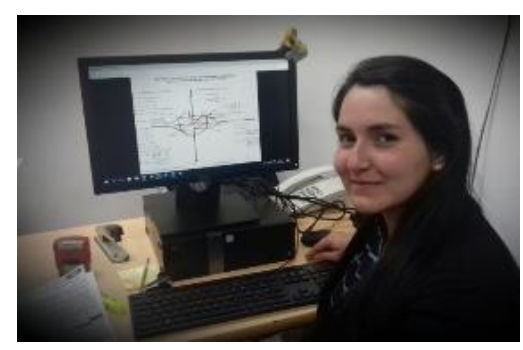

Nombre de estudiante: María F. Herrera Mahecha

\section{Universidad: Monserrate Programa: Finanzas y Negocios Internacionales Semestre:}

8 fecha: D. 21 M noviembre año 2016.

A continuación se presentan diez preguntas tipo Saber Pro a las cuales usted les dará solución utilizando el modelo keynesiano de economía cerrada, evidenciando el movimiento de las variables económicas, para lo cual usted tendrá un rol.

1. ¿Señor gerente general, como se ve afectada su empresa cuando el banco de la república decide aumentar la tasa de interés de política monetaria?

Al subir las tasas de interés, aumenta la inversión, aumentan los ingresos, lo que hace que aumente el ingreso disponible a su vez origina un aumento del presupuesto esto origina un aumento en la masa monetaria, luego aumenta la cantidad real de dinero, lo que hizo que aumentara el dinero especulativo y el dinero de transacción todo esto origino una expansión monetaria. 
Modelo con movimiento de las variables afectadas.

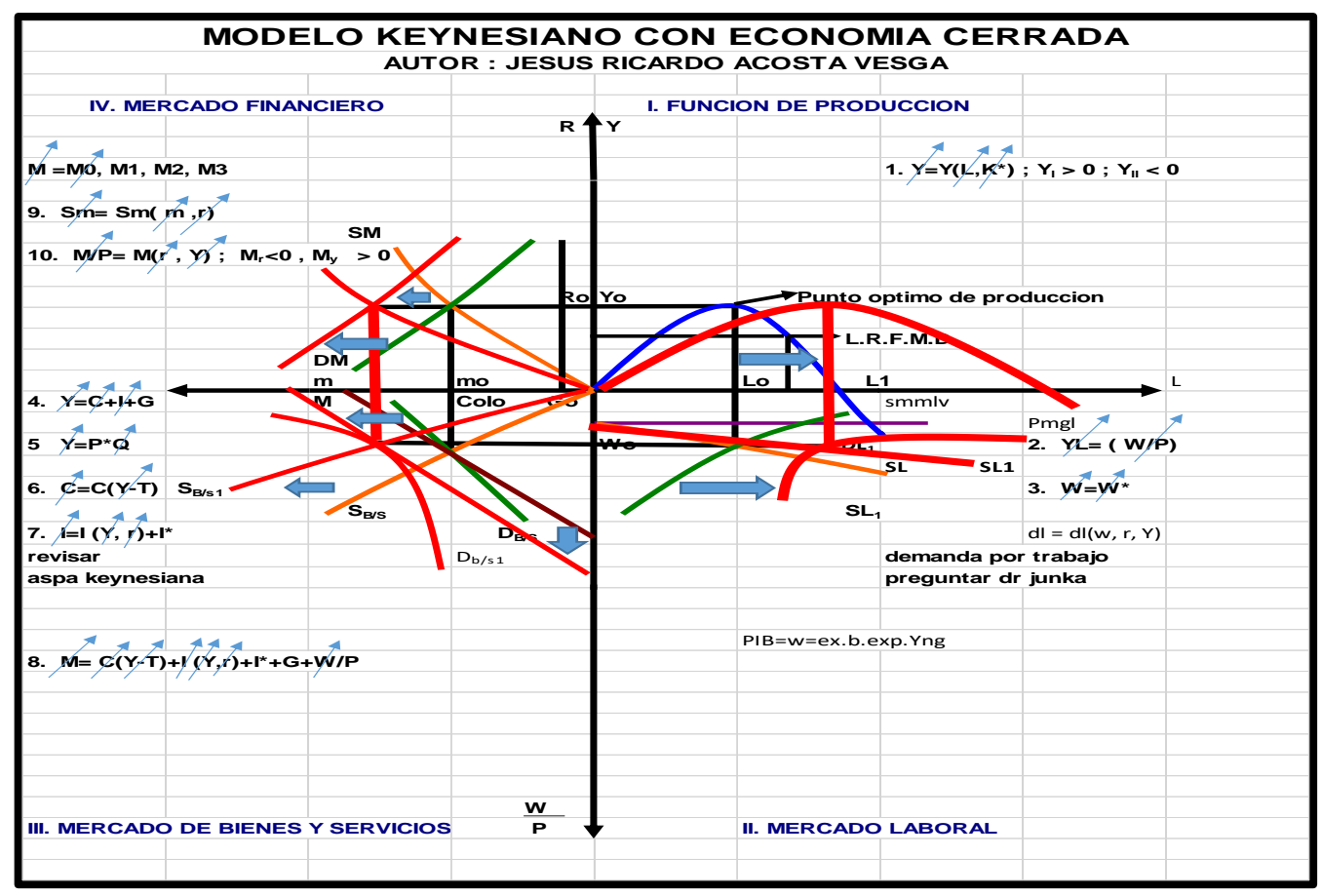

Anexo. Ilustración No. 10. Movimiento de las variables afectadas.

La solución como se observa en el grafico las flechas indican el movimiento de las variables hacia arriba mostrando que aumentaron y crearon una expansión monetaria, como gerente la solución es aumentar la capacidad instalada de la empresa teniendo en cuenta que hay más capital y eso ubica la economía en equilibrio.

2. ¿Señor gerente financiero, como se ve afectada su empresa cuando el banco de la república decide aumentar el encaje bancario?

$\mathrm{Al}$ aumentar el encaje bancario, se reduce el la oferta monetaria, disminuyendo el crédito, lo que hace y se reduce la demanda del dinero especulativo y de transacción, y esto origina una caída en el presupuesto y hace bajar los ingresos de 
la empresa originando una contracción monetaria, la producción y el número de empleados no se ve afectada en el corto plazo, ni los salarios nominales y por supuesto tampoco se afecta el salario real.

Modelo con movimiento de las variables afectadas

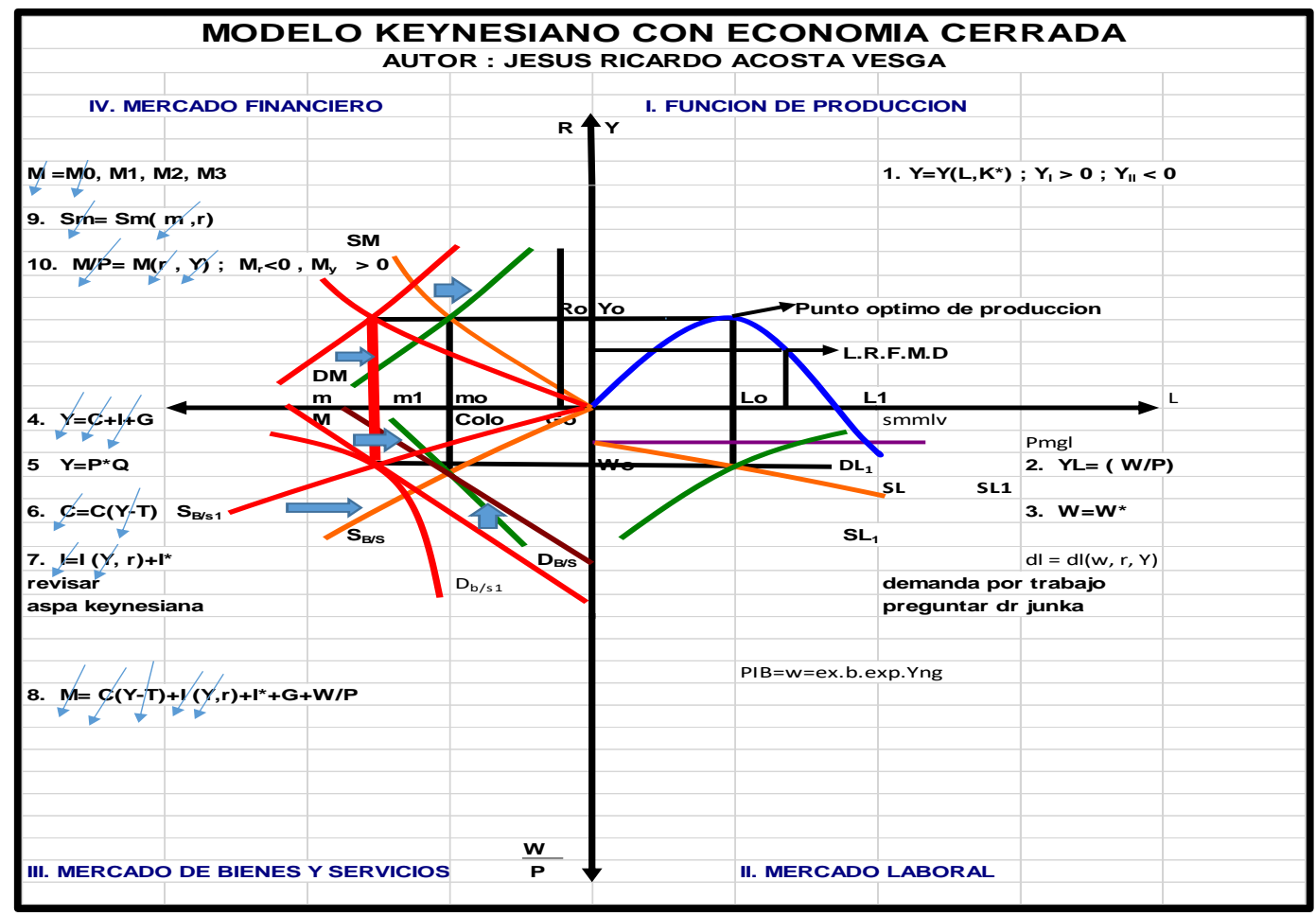

Anexo. Ilustración No. 11. Movimiento de las variables afectadas.

La solución para colocar el modelo en equilibrio es aumentando el gasto para reactivar la economía, con este aumento se produce un aumento en los ingresos y esto reactiva el consumo, la inversión, el presupuesto y a la vez aumentaría la masa monetaria incentivando de nuevo el crédito y así volveríamos al equilibrio.

3. ¿Señor gerente financiero, como se ve afectada su empresa cuando el banco de la república decide aumentar la emisión de dinero?

Al aumentar la emisión primaria de dinero por parte de Banco de la república, va a existir mayor cantidad de dinero en la economía, lo que ocasiona que se 
incremente la oferta monetaria y esto hace que aumente el consumo de los hogares, la inversión y el gasto y esto hace a la vez que se aumente el ingreso y se reactive la economía. Y la economía puede llegar a presentar un sobre calentamiento financiero.

Modelo con movimiento de las variables afectadas

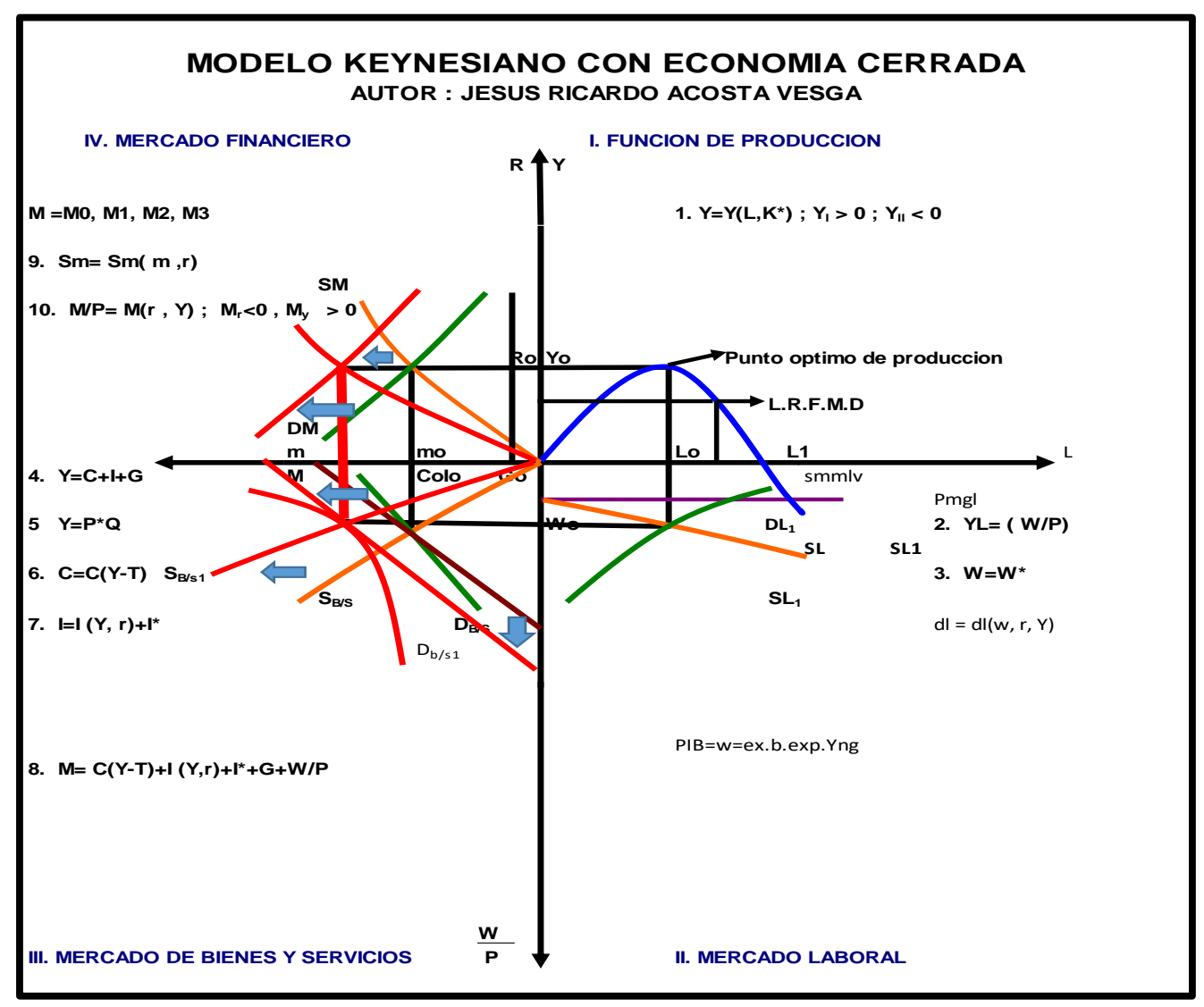

Anexo. Ilustración No. 12. Movimiento de las variables afectadas.

La Solución: Se debe invertir en la planta de producción para aumentar la capacidad productiva, aumentando la producción el número de empleados y así volver al punto de equilibrio inicial.

4. ¿Señor gerente de producción, que pasa cuando el gobierno decide aumentar los instrumentos de política fiscal, como se afectan las variables del modelo? 
La solución: Si se incrementan tanto en gasto como los impuestos en el mismo porcentaje, el uno reduce el poder adquisitivo, como son los impuestos y al aumentar el gasto se mejora el poder adquisitivo y se reactiva la economía devolviendo todo al punto de equilibrio. Lo que indica que el modelo no se vea afectado.

5. Utilizando el diagrama del modelo Keynesiano cerrado con todas las ecuaciones, analice que pasa cuando disminuye la oferta monetaria.

Si disminuye la oferta monetaria, hace que se suban las tasas de interés, lo que hace que se reduzca la inversión por el costo de los intereses, lo mismo pasa con el consumó, el ingreso se reduce y el gasto también, esto puede producir que se baje la producción y exista una contracción en la economía.

\section{Modelo con movimiento de las variables afectadas}

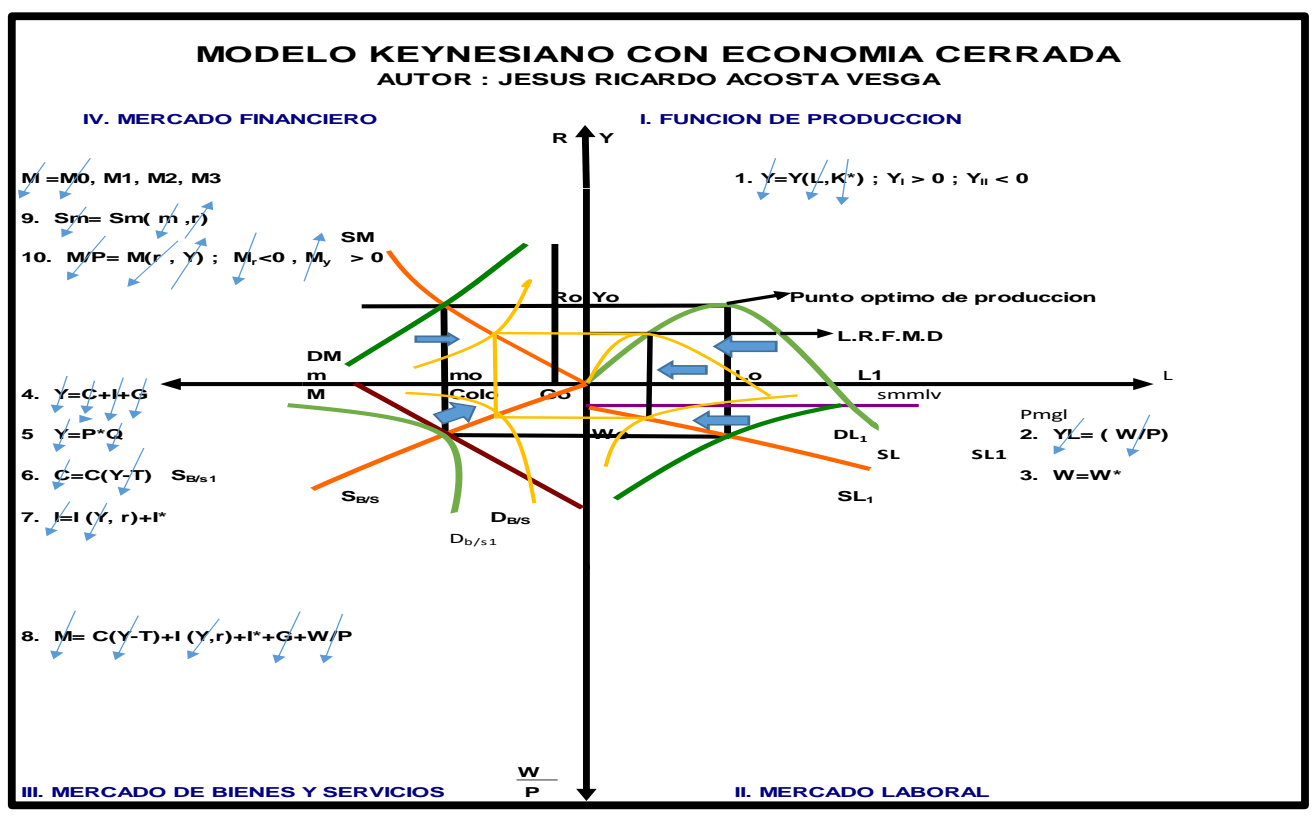

Anexo. Ilustración No. 13. Movimiento de las variables afectadas.

La Solución: Para este caso hay varias respuestas entre ellas una es incrementar el gasto público para reactivar la economía y así volver al punto de equilibrio, otra 
solución sería que el Banco de la Republica, aumentara las emisiones de dinero y así reactivar la economía y volver al punto de equilibrio.

6. Utilizando el diagrama del modelo Keynesiano cerrado con todas las ecuaciones, analice que pasa cuando aumenta el gasto público.

Cuando aumenta el gasto público se reactiva la economía y esto hace que exista una expansión monetaria y hace que la economía crezca.

Modelo con movimiento de las variables afectadas

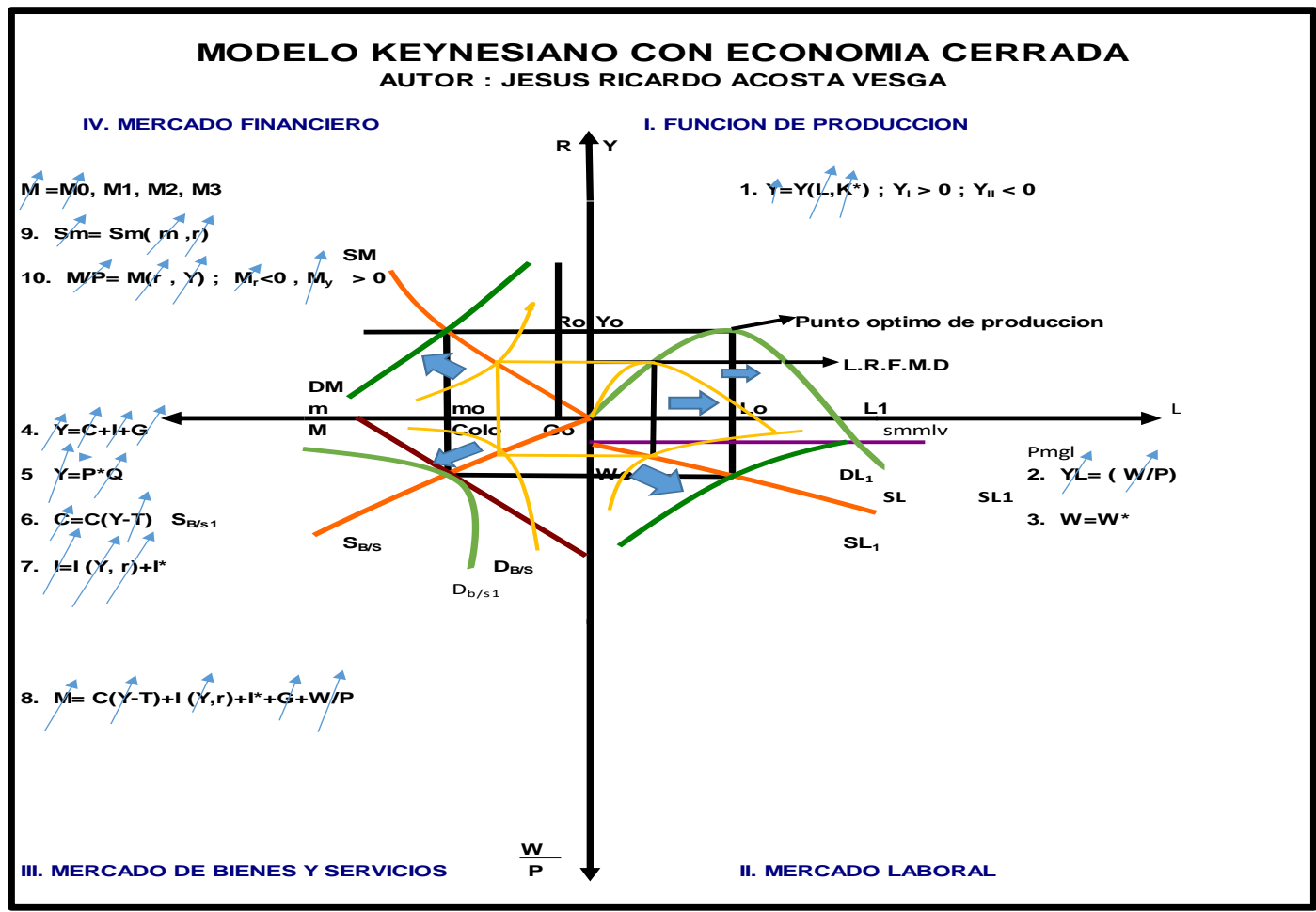

Anexo. Ilustración No. 14. Movimiento de las variables afectadas.

7. Utilizando el diagrama del modelo Keynesiano Cerrado con todas las ecuaciones, analice que pasa cuando aumenta el consumo de los hogares.

Cuando aumenta el consumo indica que aumentaron los ingresos lo que hace que se incrementé la inversión y se haga una expansión monetaria en la economía. 
Modelo con movimiento de las variables afectadas

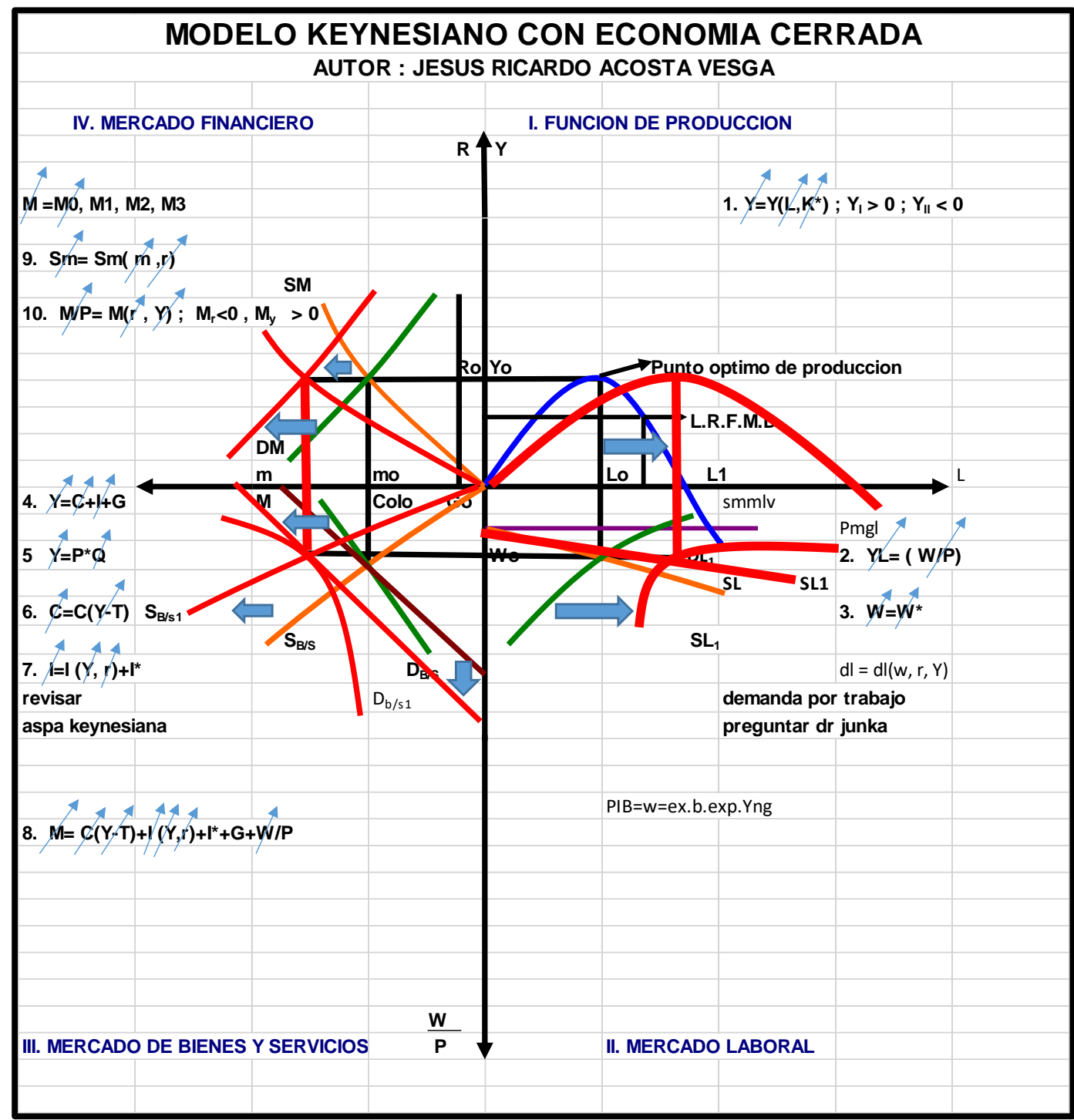

Anexo. Ilustración No. 15. Movimiento de las variables afectadas.

La solución: Para volver 1 punto de equilibrio debemos aumentar los impuestos y con esto reducimos la liquidez qué existe en la economía y así volvemos al punto de equilibrio la economía.

8. Utilizando el diagrama del modelo Keynesiano cerrado con todas las ecuaciones, analice que pasa cuando aumenta la inversión. 
Si hay un aumento en la inversión es divido a que se incrementaron los ingresos y esto nos lleva a una expansión monetaria.

Modelo con movimiento de las variables afectadas

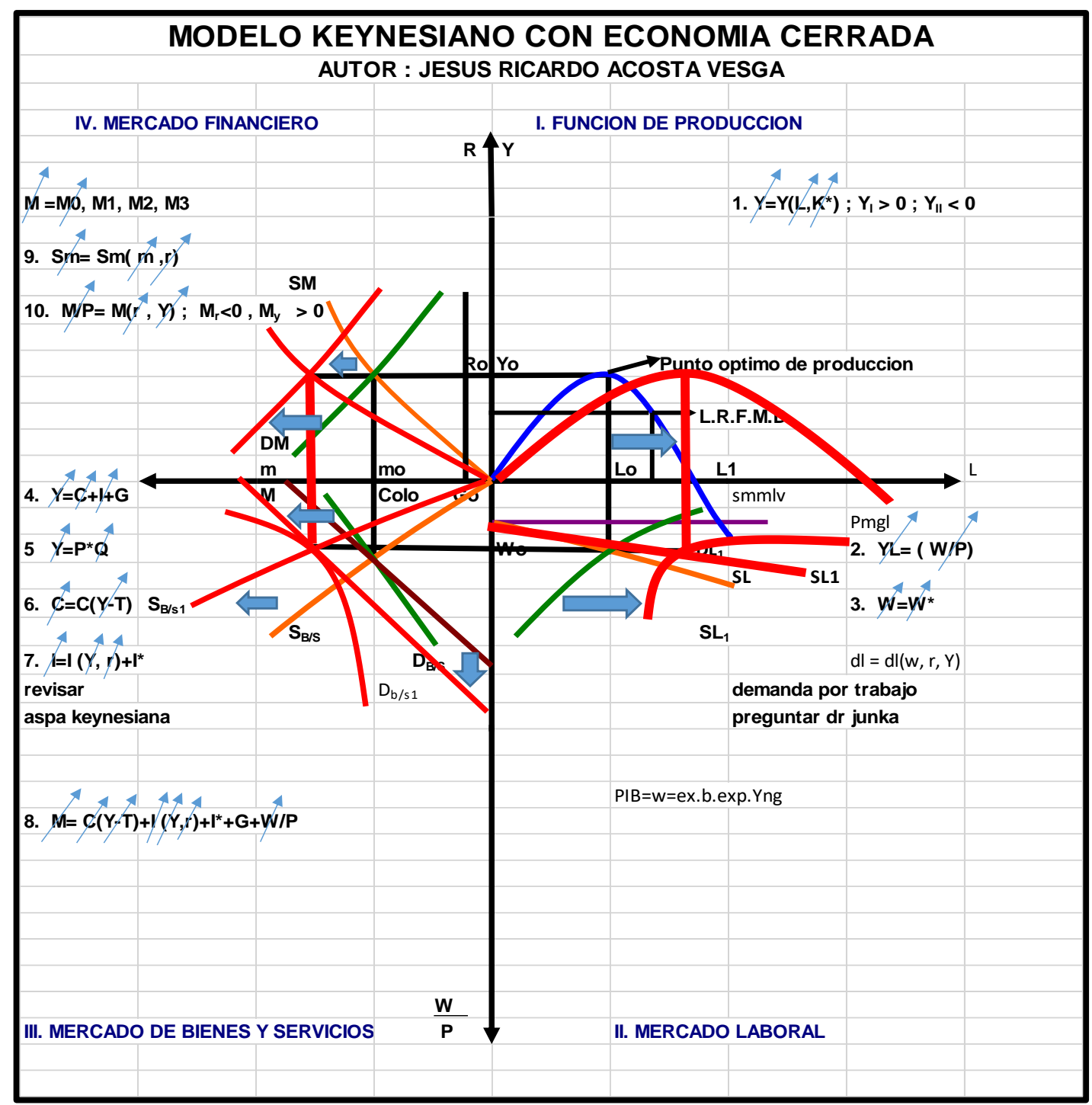

Anexo. Ilustración No. 16. Movimiento de las variables afectadas.

La solución: Para volver 1 punto de equilibrio debemos aumentar los impuestos y con esto reducimos la liquidez qué existe en la economía y así volvemos al punto de equilibrio la economía.

9. Utilizando el diagrama del modelo Keynesiano cerrado con todas las ecuaciones y analice 
que pasa cuando disminuye la tasa de interés.

Si disminuye la tasa de interés esto ocasiona que la gente demande más dinero porque el costo del dinero es más barato y esto reactiva la economía y origina una expansión monetaria.

Modelo con movimiento de las variables afectadas

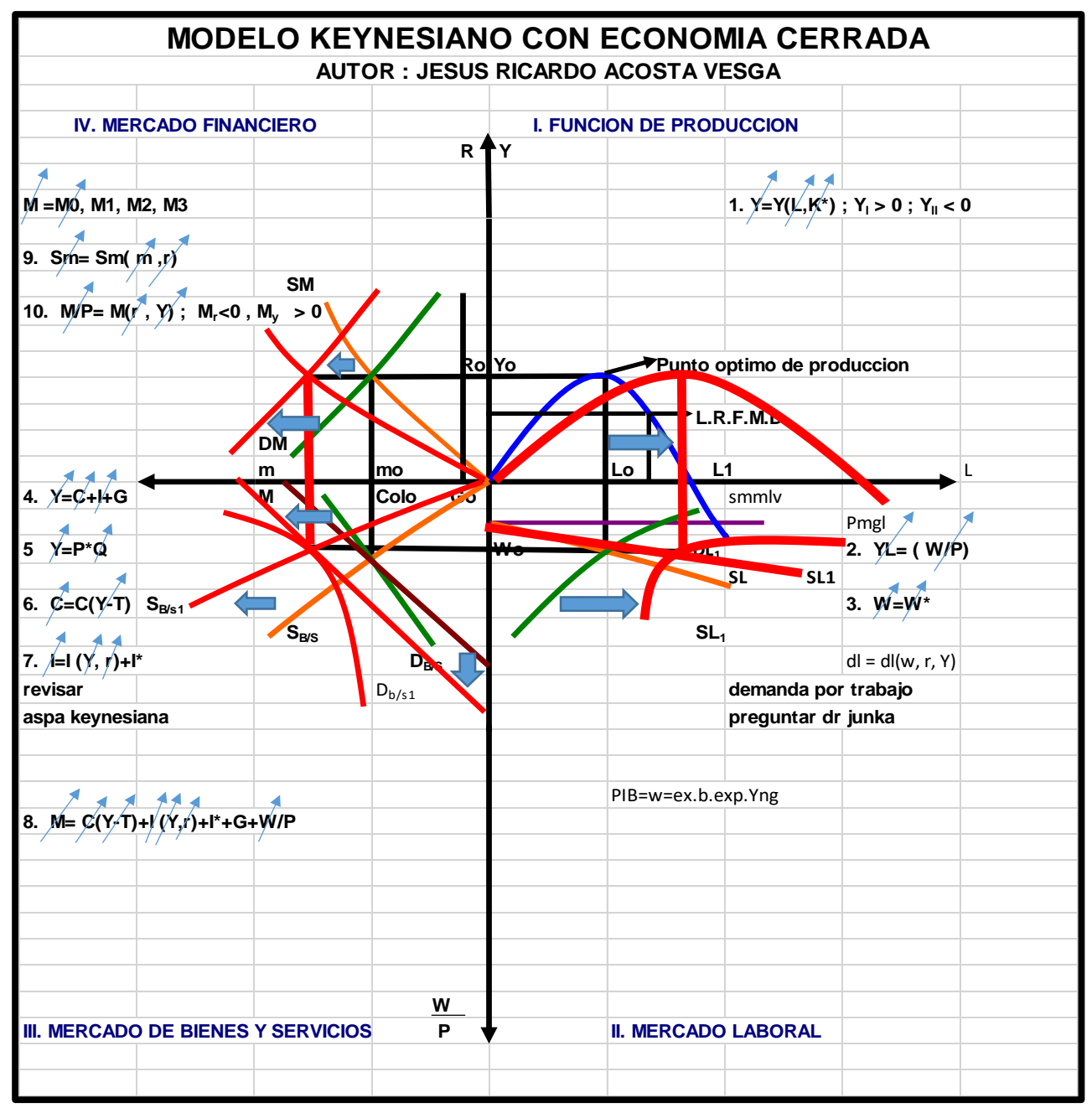

Anexo. Ilustración No. 17. Movimiento de las variables afectadas.

La solución: Para volver al punto de equilibrio debemos aumentar los impuestos y con esto reducimos la liquidez qué existe en la economía y así volvemos al punto de equilibrio la economía. 
10. ¿Usted cree que el diagrama del modelo le da las herramientas necesarias para conocer de una forma más sencilla la comprensión de la economía?

El modelo nos colabora en comprender mejor la economía.

\section{Enseñanza del Modelo Keynesiano para Estudiantes de Pregrado una}

\section{Aproximación Diagramática.}

\section{Asignatura Macroeconomía II}

\section{TEST N. 1}

A continuación se presentan diez preguntas tipo Saber Pro a las cuales usted les dará solución utilizando el modelo keynesiano de economía cerrada, evidenciando el movimiento de las variables económicas, para lo cual usted tendrá un rol.

1. ¿Señor gerente general, como se ve afectada su empresa cuando el banco de la república decide aumentar la tasa de interés de política monetaria?

Al subir las tasas de interés, aumenta la inversión, aumentan los ingresos, lo que hace que aumente el ingreso disponible a su vez origina un aumento del presupuesto esto origina un aumento en la masa monetaria, luego aumenta la cantidad real de dinero, lo que hizo que aumentara el dinero especulativo y el dinero de transacción todo esto origino una expansión monetaria.

Modelo con movimiento de las variables afectadas. 


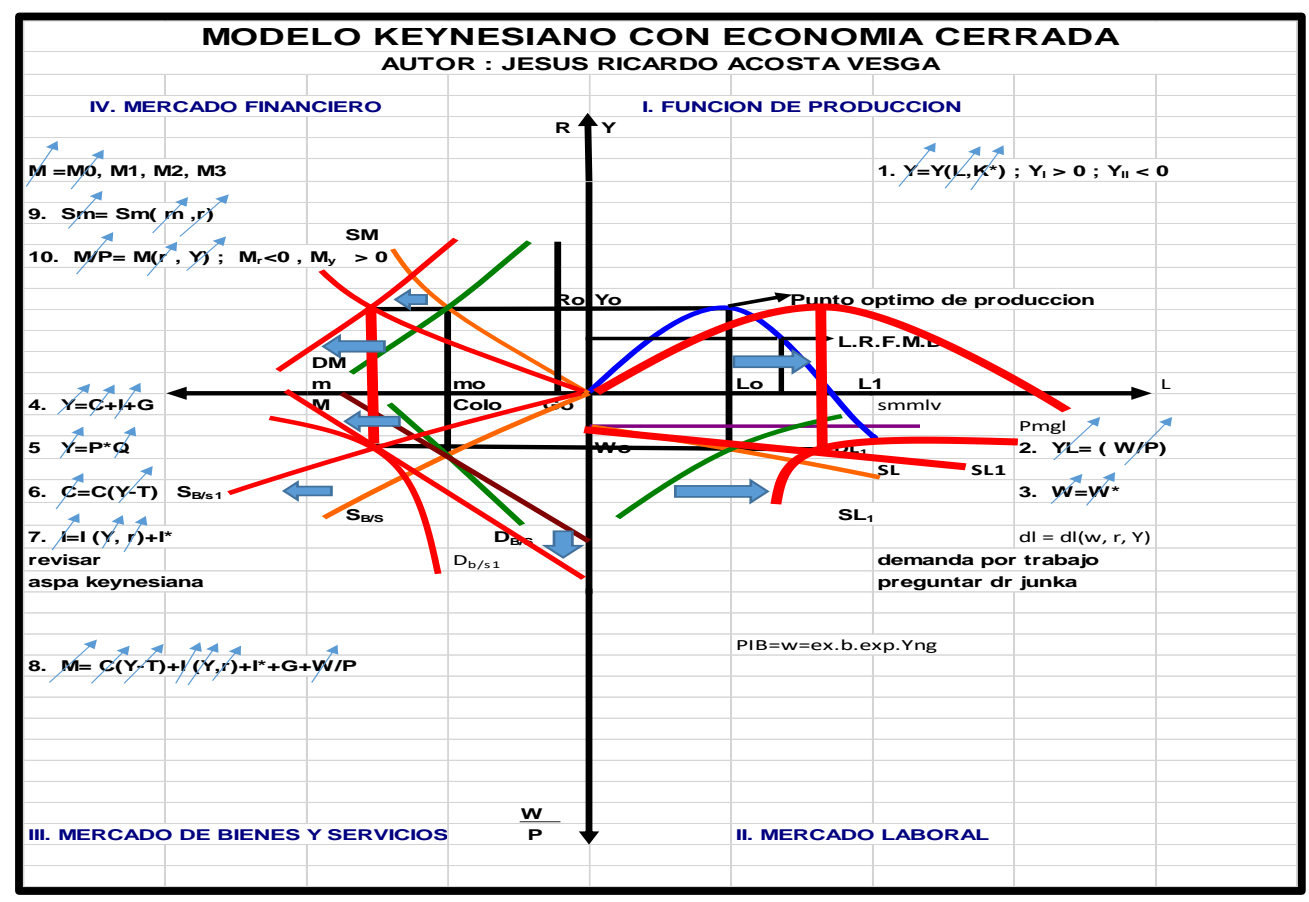

Anexo. Ilustración No. 18. Movimiento de las variables afectadas.

La solución como se observa en el grafico las flechas indican el movimiento de las variables hacia arriba mostrando que aumentaron y crearon una expansión monetaria, como gerente la solución es aumentar la capacidad instalada de la empresa teniendo en cuenta que hay más capital y eso ubica la economía en equilibrio.

2. ¿Señor gerente financiero, como se ve afectada su empresa cuando el banco de la república decide aumentar el encaje bancario?

$\mathrm{Al}$ aumentar el encaje bancario, se reduce el la oferta monetaria, disminuyendo el crédito, lo que hace y se reduce la demanda del dinero especulativo y de transacción, y esto origina una caída en el presupuesto y hace bajar los ingresos de la empresa originando una contracción monetaria, la producción y el número de empleados no se ve afectada en el corto plazo, ni los salarios nominales y por supuesto tampoco se afecta el salario real. 


\section{Modelo con movimiento de las variables afectadas}

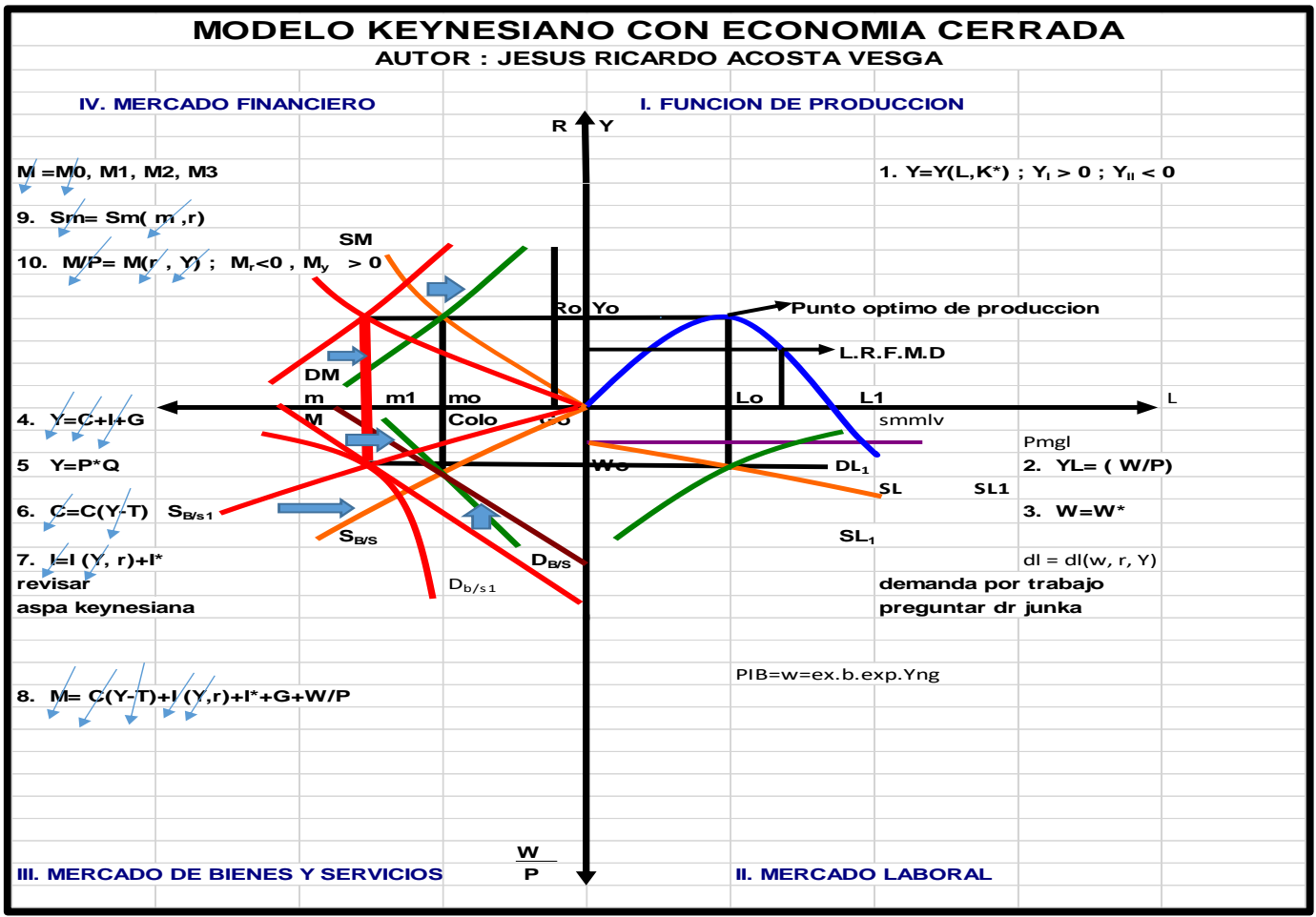

Anexo. Ilustración No. 19. Movimiento de las variables afectadas.

La solución para colocar el modelo en equilibrio es aumentando el gasto para reactivar la economía, con este aumento se produce un aumento en los ingresos y esto reactiva el consumo, la inversión, el presupuesto y a la vez aumentaría la masa monetaria incentivando de nuevo el crédito y así volveríamos al equilibrio.

3. ¿Señor gerente financiero, como se ve afectada su empresa cuando el banco de la república decide aumentar la emisión de dinero?

Al aumentar la emisión primaria de dinero por parte de Banco de la república, va a existir mayor cantidad de dinero en la economía, lo que ocasiona que se incremente la oferta monetaria y esto hace que aumente el consumo de los hogares, la inversión y el gasto y esto hace a la vez que se aumente el ingreso y se reactive la economía. Y la economía puede llegar a presentar un sobre calentamiento 
financiero.

Modelo con movimiento de las variables afectadas

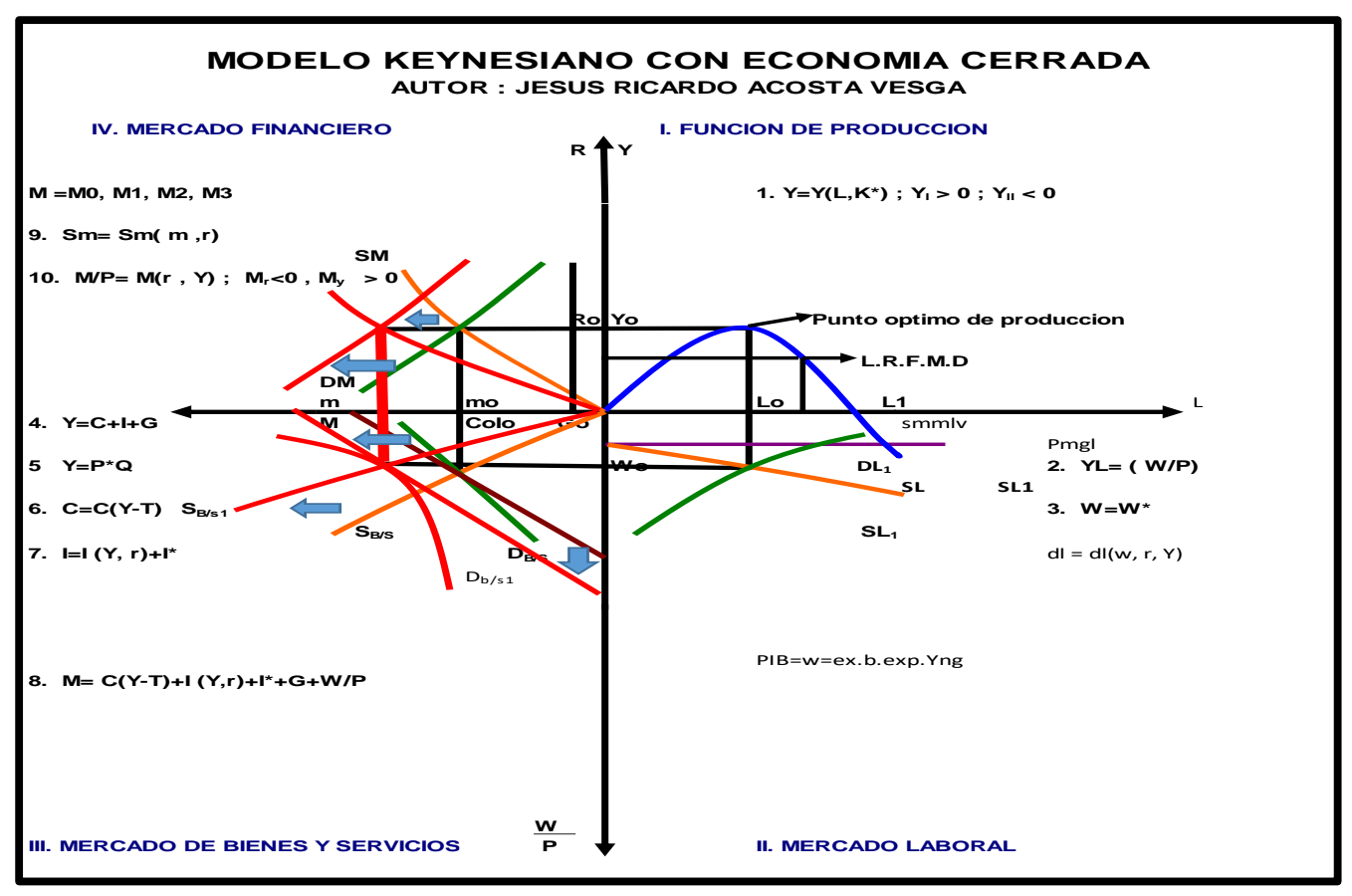

Anexo. Ilustración No. 20. Movimiento de las variables afectadas.

La Solución: Se debe invertir en la planta de producción para aumentar la capacidad productiva, aumentando la producción el número de empleados y así volver al punto de equilibrio inicial.

4. ¿Señor gerente de producción, que pasa cuando el gobierno decide aumentar los instrumentos de política fiscal, como se afectan las variables del modelo?

La solución: Si se incrementan tanto en gasto como los impuestos en el mismo porcentaje, el uno reduce el poder adquisitivo, como son los impuestos y al aumentar el gasto se mejora el poder adquisitivo y se reactiva la economía devolviendo todo al punto de equilibrio. Lo que indica que el modelo no se vea afectado.

5. Utilizando el diagrama del modelo Keynesiano cerrado con todas las ecuaciones, analice 
que pasa cuando disminuye la oferta monetaria.

Si disminuye la oferta monetaria, hace que se suban las tasas de interés, lo que hace que se reduzca la inversión por el costo de los intereses, lo mismo pasa con el consumó, el ingreso se reduce y el gasto también, esto puede producir que se baje la producción y exista una contracción en la economía.

\section{Modelo con movimiento de las variables afectadas}

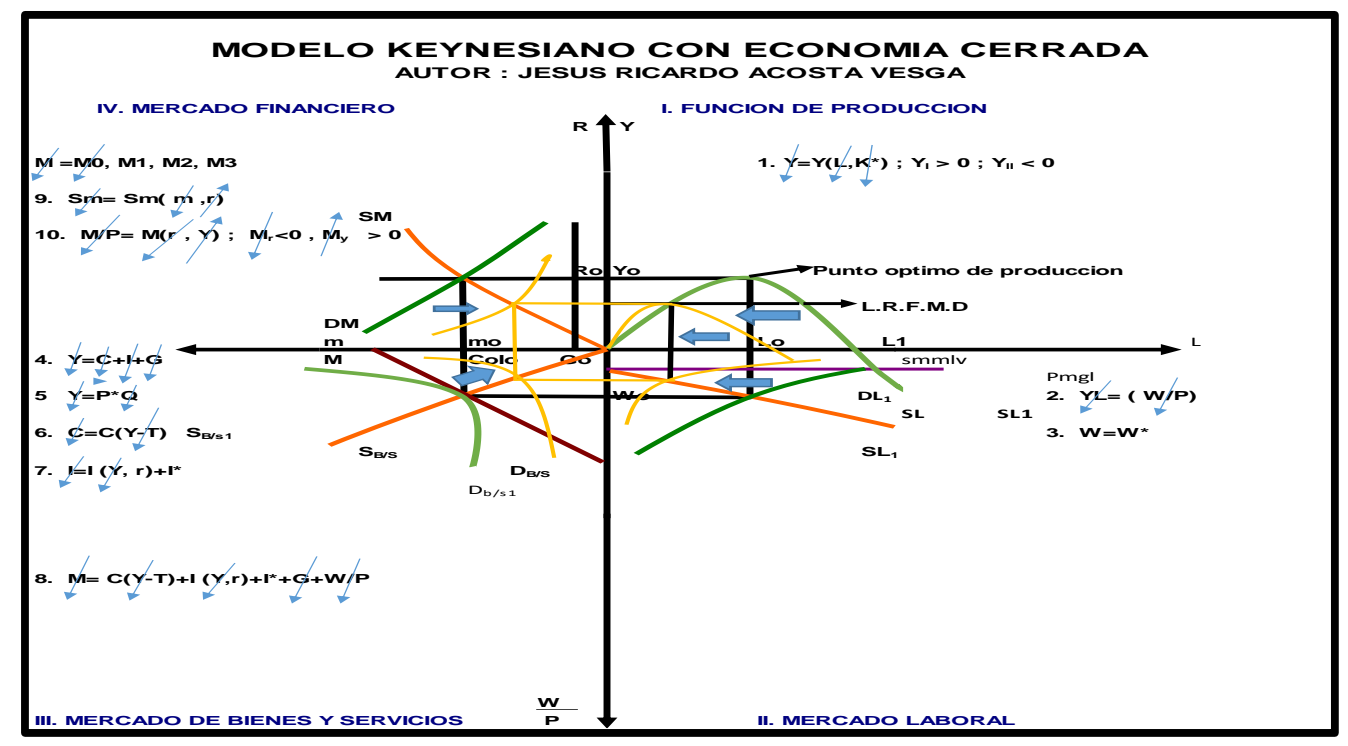

Anexo. Ilustración No. 21. Movimiento de las variables afectadas.

La Solución: Para este caso hay varias respuestas entre ellas una es incrementar el gasto público para reactivar la economía y así volver al punto de equilibrio, otra solución sería que el Banco de la Republica, aumentara las emisiones de dinero y así reactivar la economía y volver al punto de equilibrio.

6. Utilizando el diagrama del modelo Keynesiano cerrado con todas las ecuaciones, analice que pasa cuando aumenta el gasto público.

Cuando aumenta el gasto público se reactiva la economía y esto hace que exista una expansión monetaria y hace que la economía crezca. 
Modelo con movimiento de las variables afectadas

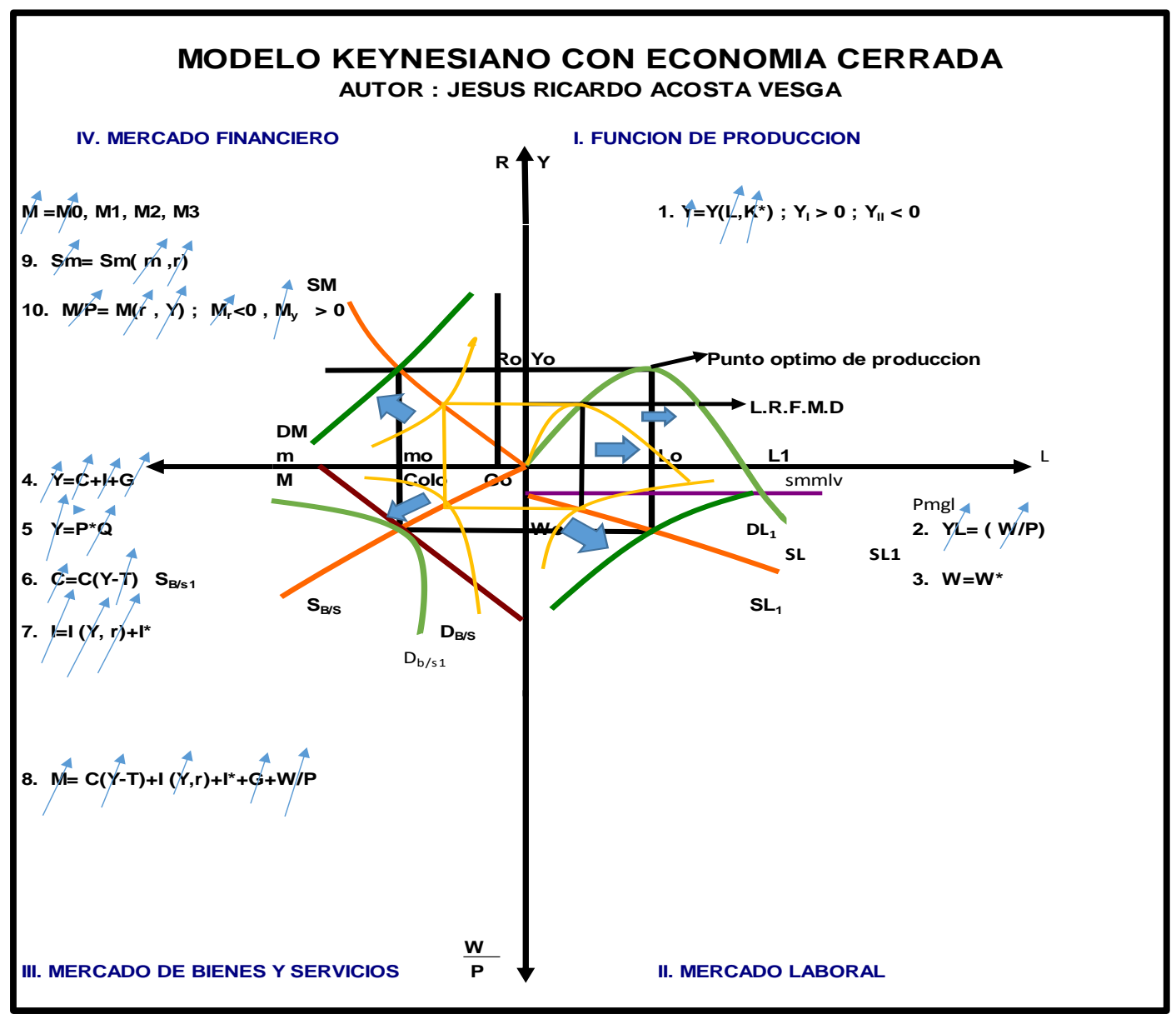

Anexo. Ilustración No. 22. Movimiento de las variables afectadas.

7. Utilizando el diagrama del modelo Keynesiano Cerrado con todas las ecuaciones, analice que pasa cuando aumenta el consumo de los hogares.

Cuando aumenta el consumo indica que aumentaron los ingresos lo que hace que se incrementé la inversión y se haga una expansión monetaria en la economía. Modelo con movimiento de las variables afectadas 


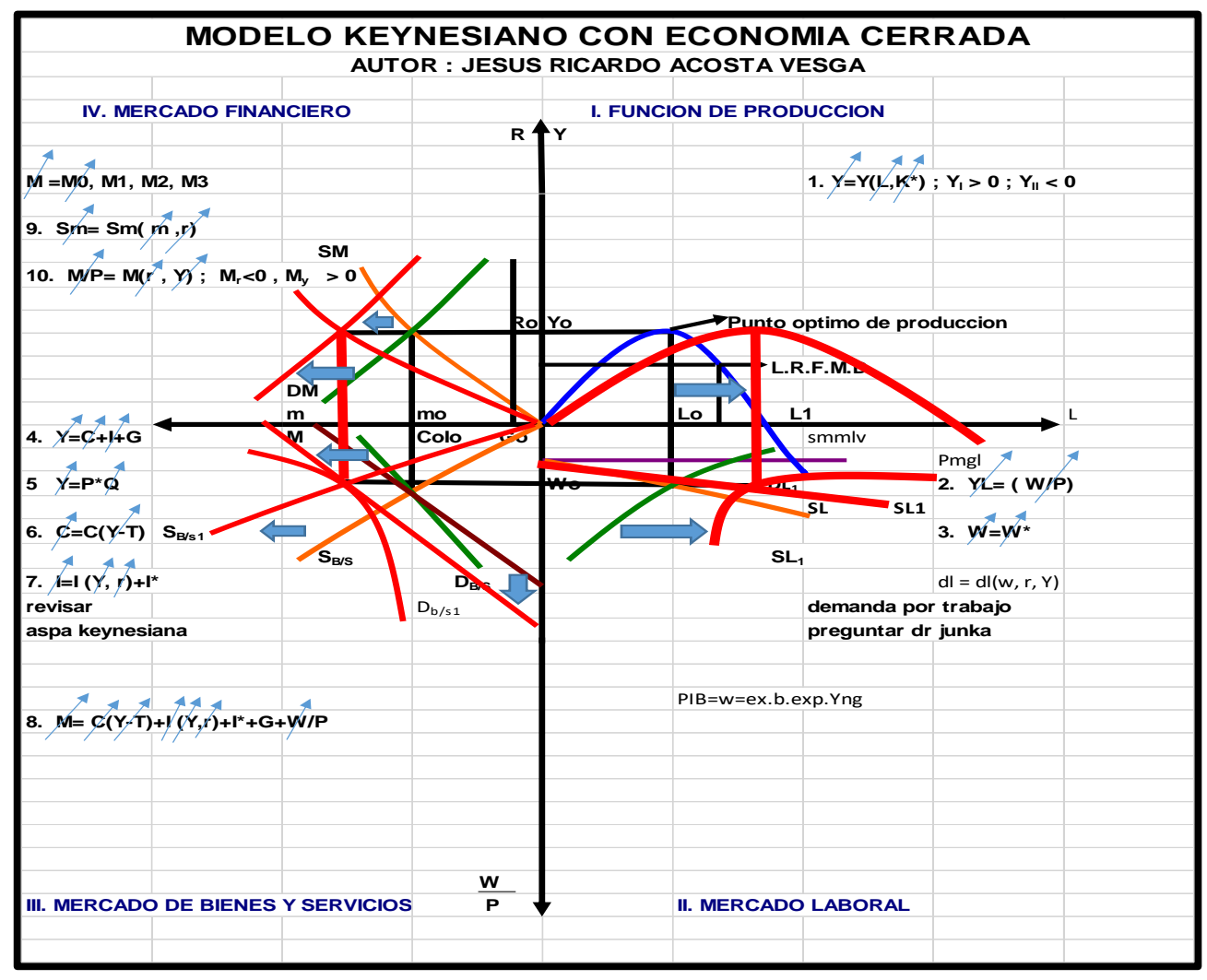

Anexo. Ilustración No. 23. Movimiento de las variables afectadas.

La solución: Para volver 1 punto de equilibrio debemos aumentar los impuestos y con esto reducimos la liquidez qué existe en la economía y así volvemos al punto de equilibrio la economía.

8. Utilizando el diagrama del modelo Keynesiano cerrado con todas las ecuaciones, analice que pasa cuando aumenta la inversión.

Si hay un aumento en la inversión es divido a que se incrementaron los ingresos y esto nos lleva a una expansión monetaria.

Modelo con movimiento de las variables afectadas 


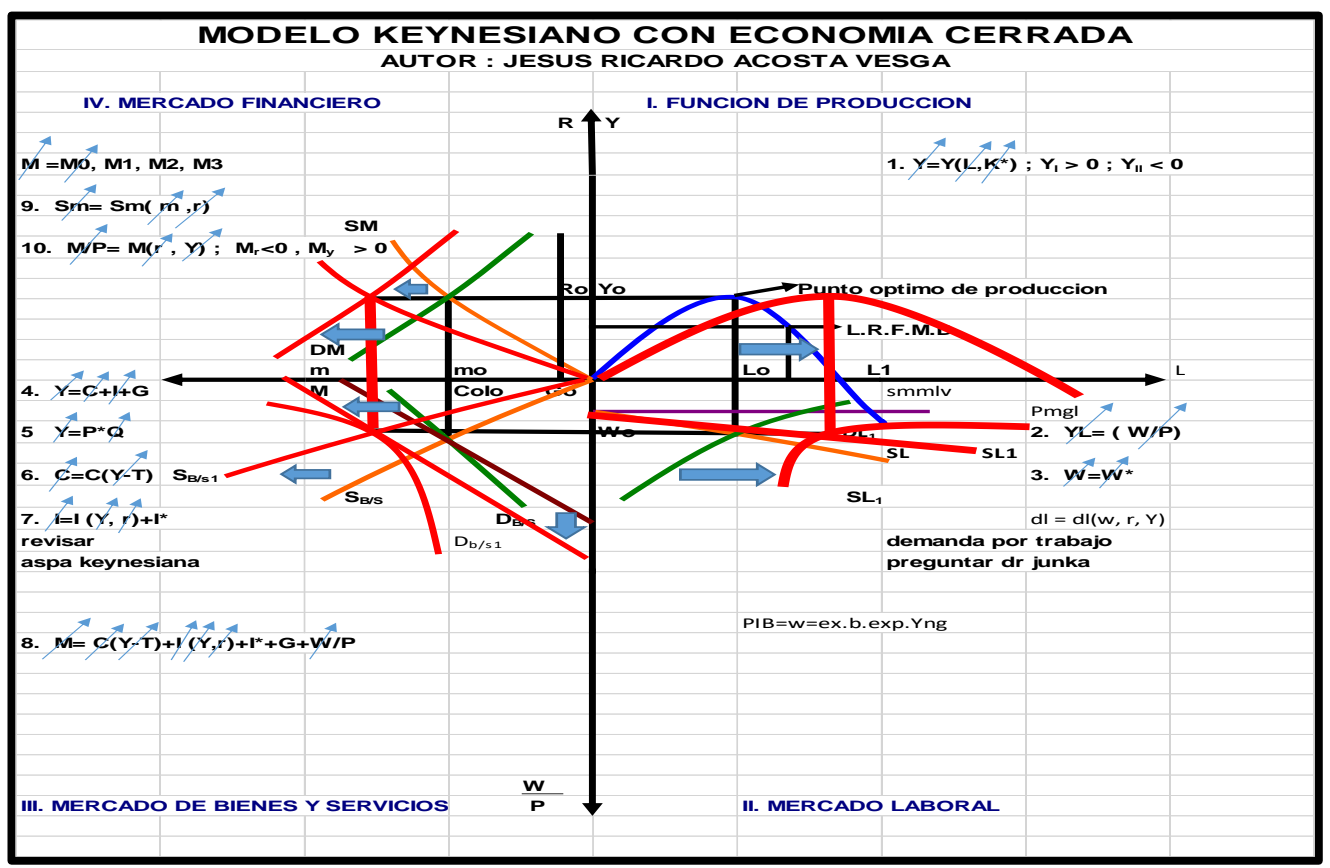

Anexo. Ilustración No. 24. Movimiento de las variables afectadas.

La solución: Para volver 1 punto de equilibrio debemos aumentar los impuestos y con esto reducimos la liquidez qué existe en la economía y así volvemos al punto de equilibrio la economía.

9. Utilizando el diagrama del modelo Keynesiano cerrado con todas las ecuaciones y analice que pasa cuando disminuye la tasa de interés.

Si disminuye la tasa de interés esto ocasiona que la gente demande más dinero porque el costo del dinero es más barato y esto reactiva la economía y origina una expansión monetaria.

Modelo con movimiento de las variables afectadas 


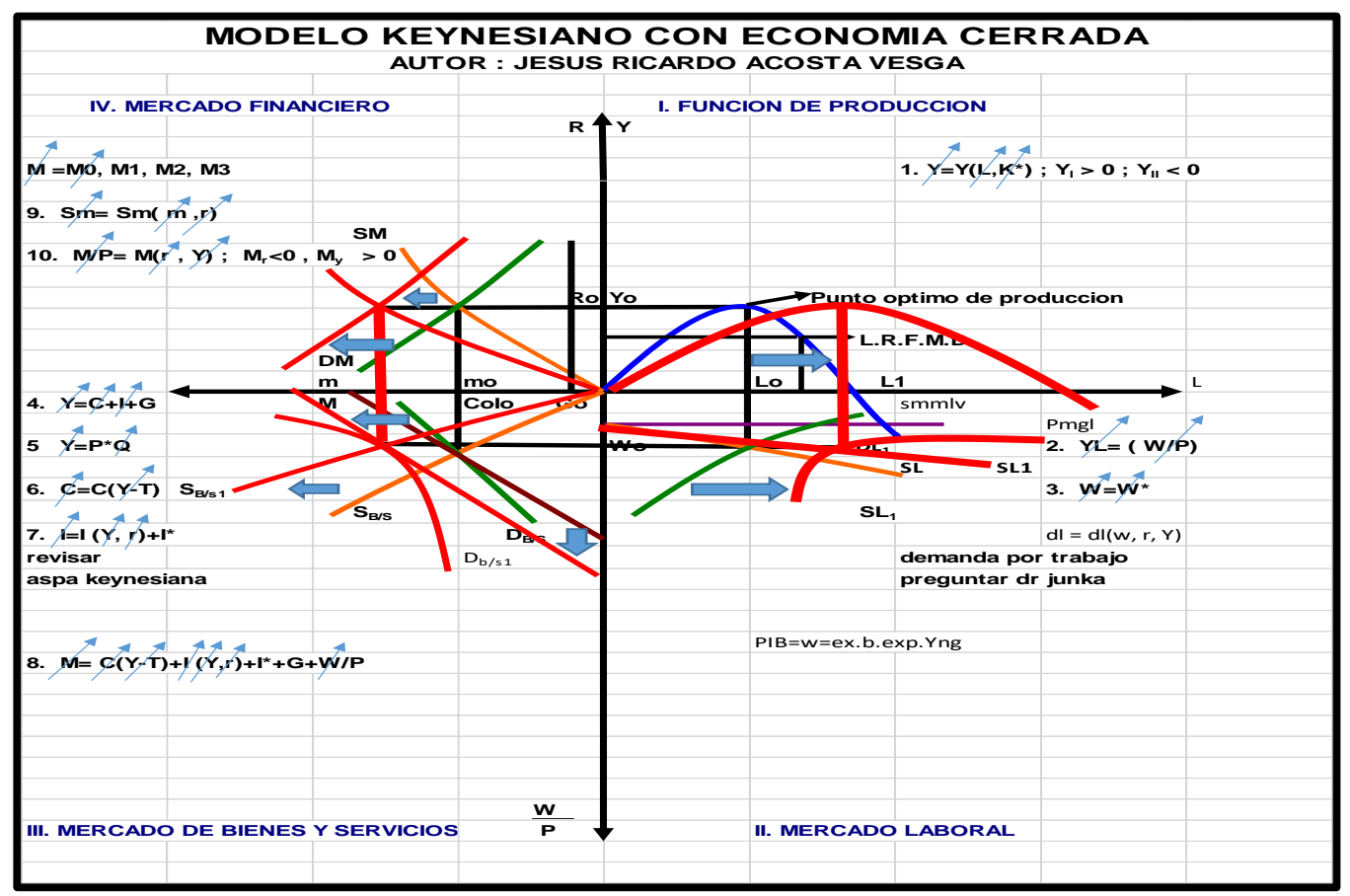

Anexo. Ilustración No. 25. Movimiento de las variables afectadas.

La solución: Para volver al punto de equilibrio debemos aumentar los impuestos y con esto reducimos la liquidez qué existe en la economía y así volvemos al punto de equilibrio la economía.

10. ¿Usted cree que el diagrama del modelo le da las herramientas necesarias para conocer de una forma más sencilla la comprensión de la economía?

El modelo nos ayuda en el proceso de toma de decisiones y a entender cada una de las variables y su comportamiento.

Enseñanza Del Modelo Keynesiano Para Estudiantes De pregrado Una Aproximación Diagramática. Asignatura Macroeconomía II

TEST N. 1

Nombre: Luis Gabriel González Vásquez

Universidad: fundación universitaria Monserrate

Programa: finanzas y negocios 


\section{Fecha: 6/11/2016}

A continuación se presentan diez preguntas tipo Saber Pro a las cuales usted les dará solución utilizando el modelo keynesiano de economía cerrada, evidenciando el movimiento de las variables económicas, para lo cual usted tendrá un rol.

1. ¿Señor gerente general, como se ve afectada su empresa cuando el banco de la república decide aumentar la tasa de interés de política monetaria?

Al subir las tasas de interés, aumenta la inversión, aumentan los ingresos, lo que hace que aumente el ingreso disponible a su vez origina un aumento del presupuesto esto origina un aumento en la masa monetaria, luego aumenta la cantidad real de dinero, lo que hizo que aumentara el dinero especulativo y el dinero de transacción todo esto origino una expansión monetaria.

Modelo con movimiento de las variables afectadas.

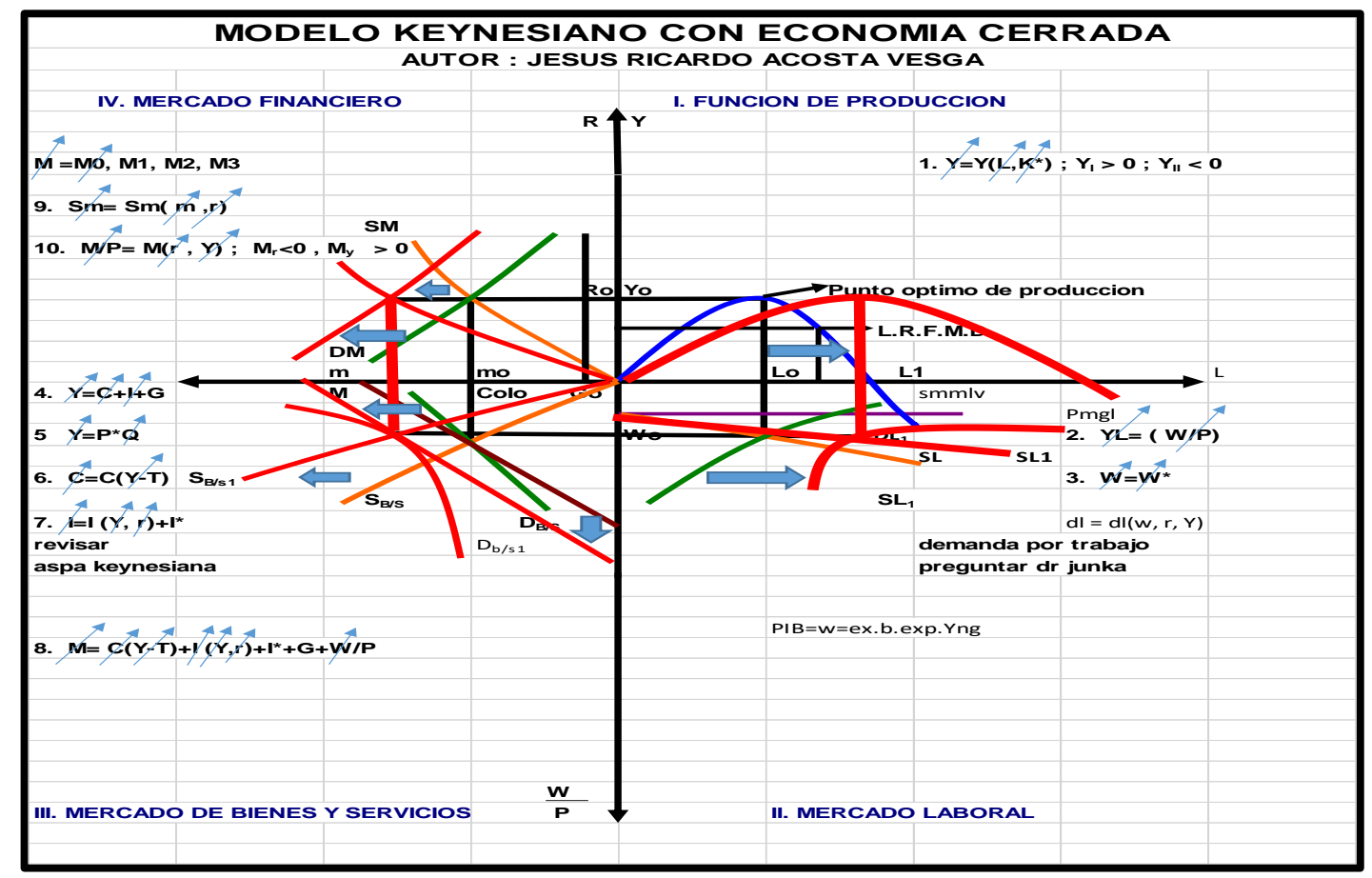

Anexo. Ilustración No. 26. Movimiento de las variables afectadas. 
La solución como se observa en el grafico las flechas indican el movimiento de las variables hacia arriba mostrando que aumentaron y crearon una expansión monetaria, como gerente la solución es aumentar la capacidad instalada de la empresa teniendo en cuenta que hay más capital y eso ubica la economía en equilibrio.

2. ¿Señor gerente financiero, como se ve afectada su empresa cuando el banco de la república decide aumentar el encaje bancario?

$\mathrm{Al}$ aumentar el encaje bancario, se reduce el la oferta monetaria, disminuyendo el crédito, lo que hace y se reduce la demanda del dinero especulativo y de transacción, y esto origina una caída en el presupuesto y hace bajar los ingresos de la empresa originando una contracción monetaria, la producción y el número de empleados no se ve afectada en el corto plazo, ni los salarios nominales y por supuesto tampoco se afecta el salario real.

\section{Modelo con movimiento de las variables afectadas}

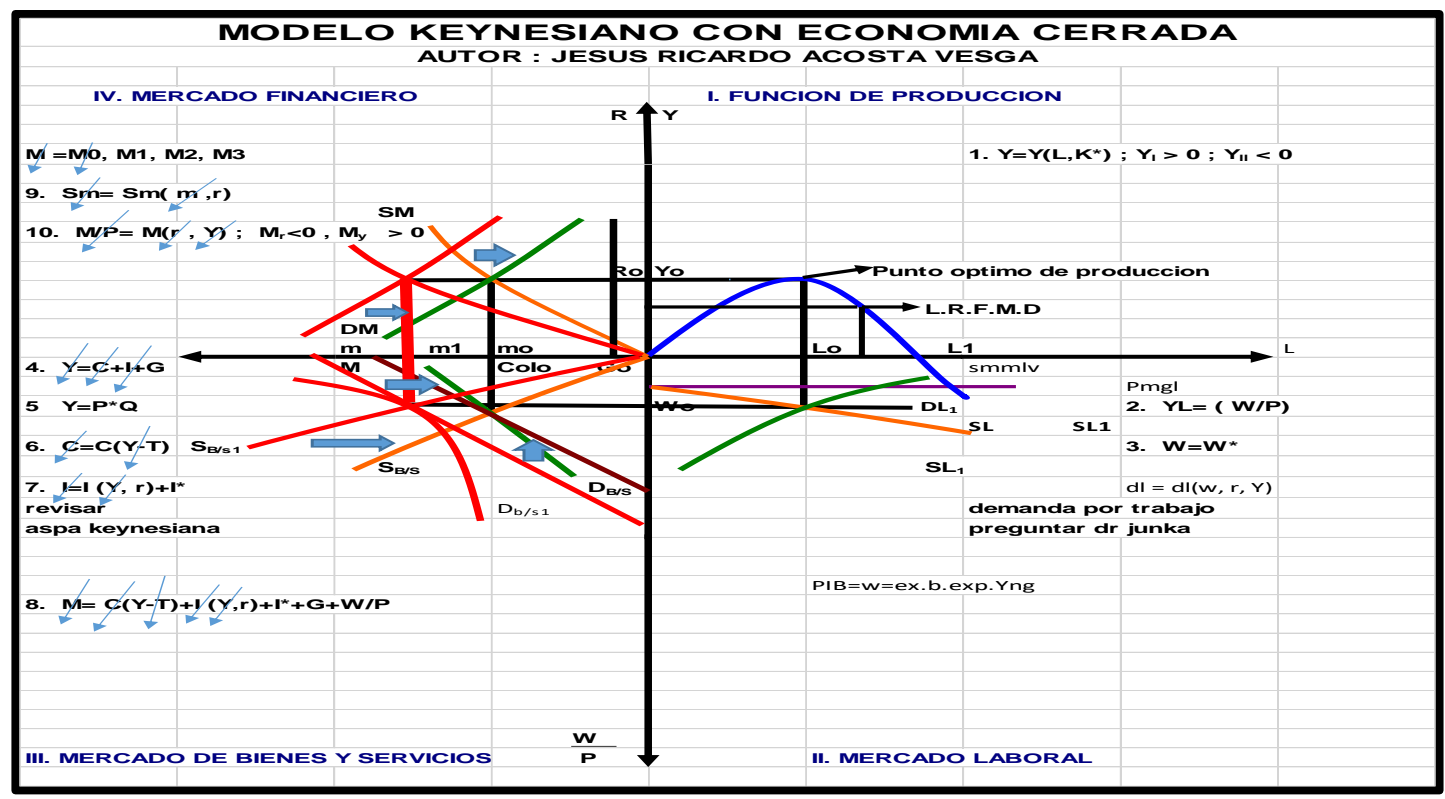

Anexo. Ilustración No. 27. Movimiento de las variables afectadas. 
La solución para colocar el modelo en equilibrio es aumentando el gasto para reactivar la economía, con este aumento se produce un aumento en los ingresos y esto reactiva el consumo, la inversión, el presupuesto y a la vez aumentaría la masa monetaria incentivando de nuevo el crédito y así volveríamos al equilibrio.

3. ¿Señor gerente financiero, como se ve afectada su empresa cuando el banco de la república decide aumentar la emisión de dinero?

Al aumentar la emisión primaria de dinero por parte de Banco de la república, va a existir mayor cantidad de dinero en la economía, lo que ocasiona que se incremente la oferta monetaria y esto hace que aumente el consumo de los hogares, la inversión y el gasto y esto hace a la vez que se aumente el ingreso y se reactive la economía. Y la economía puede llegar a presentar un sobre calentamiento financiero.

\section{Modelo con movimiento de las variables afectadas}

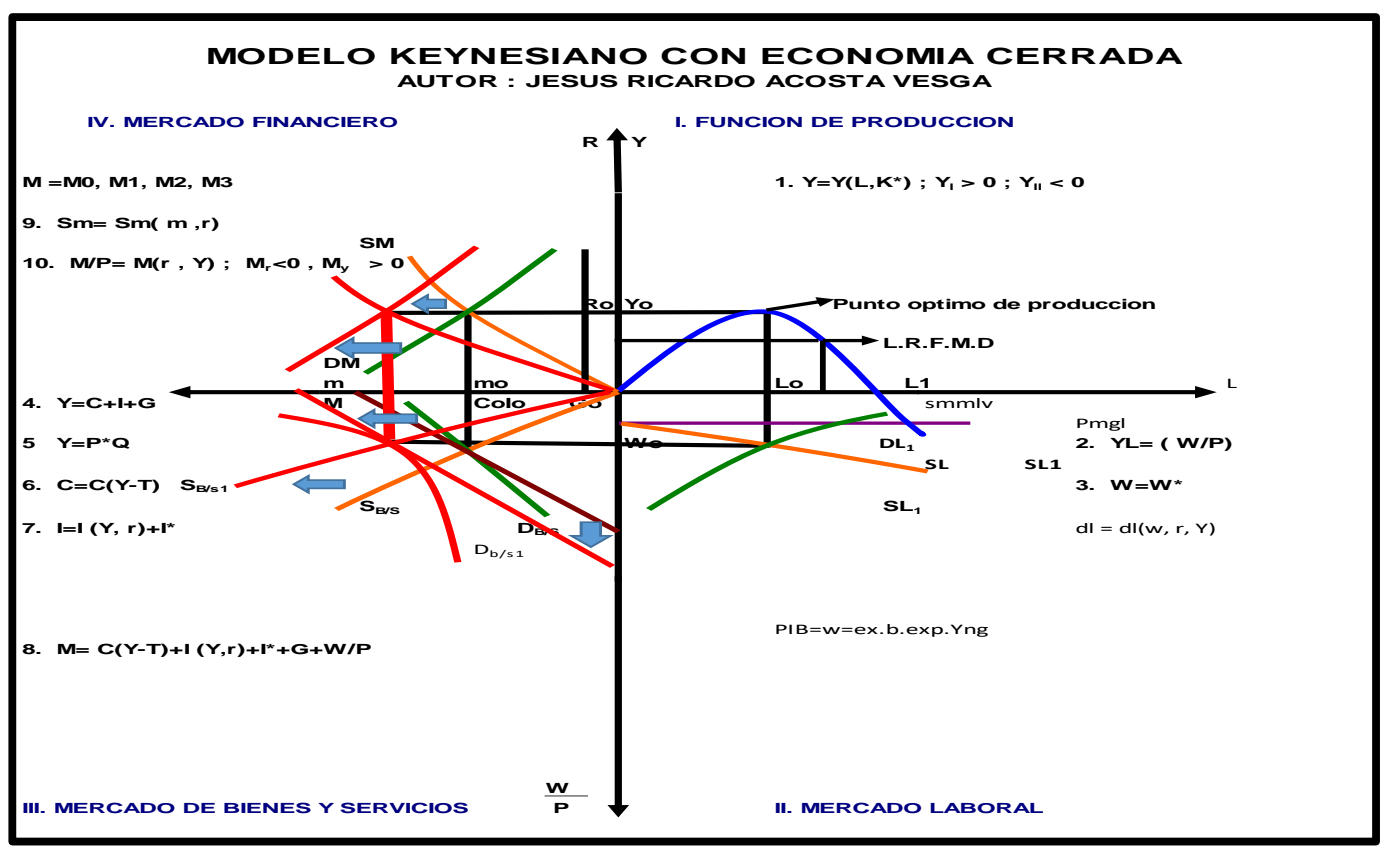

Figura Anexo. Ilustración No. 28. Movimiento de las variables afectadas. 
La Solución: Se debe invertir en la planta de producción para aumentar la capacidad productiva, aumentando la producción el número de empleados y así volver al punto de equilibrio inicial.

4. ¿Señor gerente de producción, que pasa cuando el gobierno decide aumentar los instrumentos de política fiscal, como se afectan las variables del modelo?

La solución: Si se incrementan tanto en gasto como los impuestos en el mismo porcentaje, el uno reduce el poder adquisitivo, como son los impuestos y al aumentar el gasto se mejora el poder adquisitivo y se reactiva la economía devolviendo todo al punto de equilibrio. Lo que indica que el modelo no se vea afectado.

5. Utilizando el diagrama del modelo Keynesiano cerrado con todas las ecuaciones, analice que pasa cuando disminuye la oferta monetaria.

Si disminuye la oferta monetaria, hace que se suban las tasas de interés, lo que hace que se reduzca la inversión por el costo de los intereses, lo mismo pasa con el consumó, el ingreso se reduce y el gasto también, esto puede producir que se baje la producción y exista una contracción en la economía.

Modelo con movimiento de las variables afectadas 


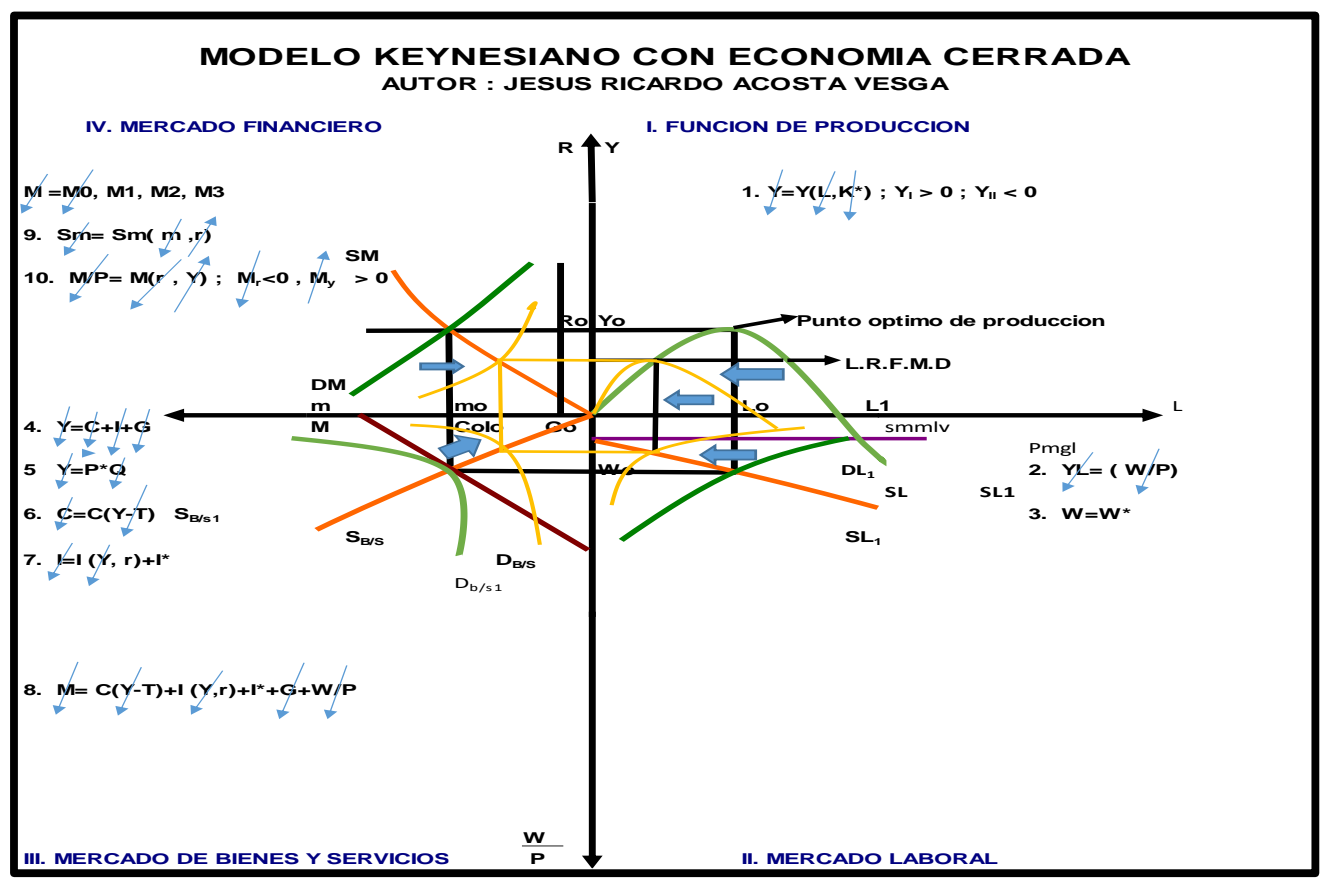

Anexo. Ilustración No. 29. Movimiento de las variables afectadas.

La Solución: Para este caso hay varias respuestas entre ellas una es incrementar el gasto público para reactivar la economía y así volver al punto de equilibrio, otra solución sería que el Banco de la Republica, aumentara las emisiones de dinero y así reactivar la economía y volver al punto de equilibrio.

6. Utilizando el diagrama del modelo Keynesiano cerrado con todas las ecuaciones, analice que pasa cuando aumenta el gasto público.

Cuando aumenta el gasto público se reactiva la economía y esto hace que exista una expansión monetaria y hace que la economía crezca.

Modelo con movimiento de las variables afectadas 


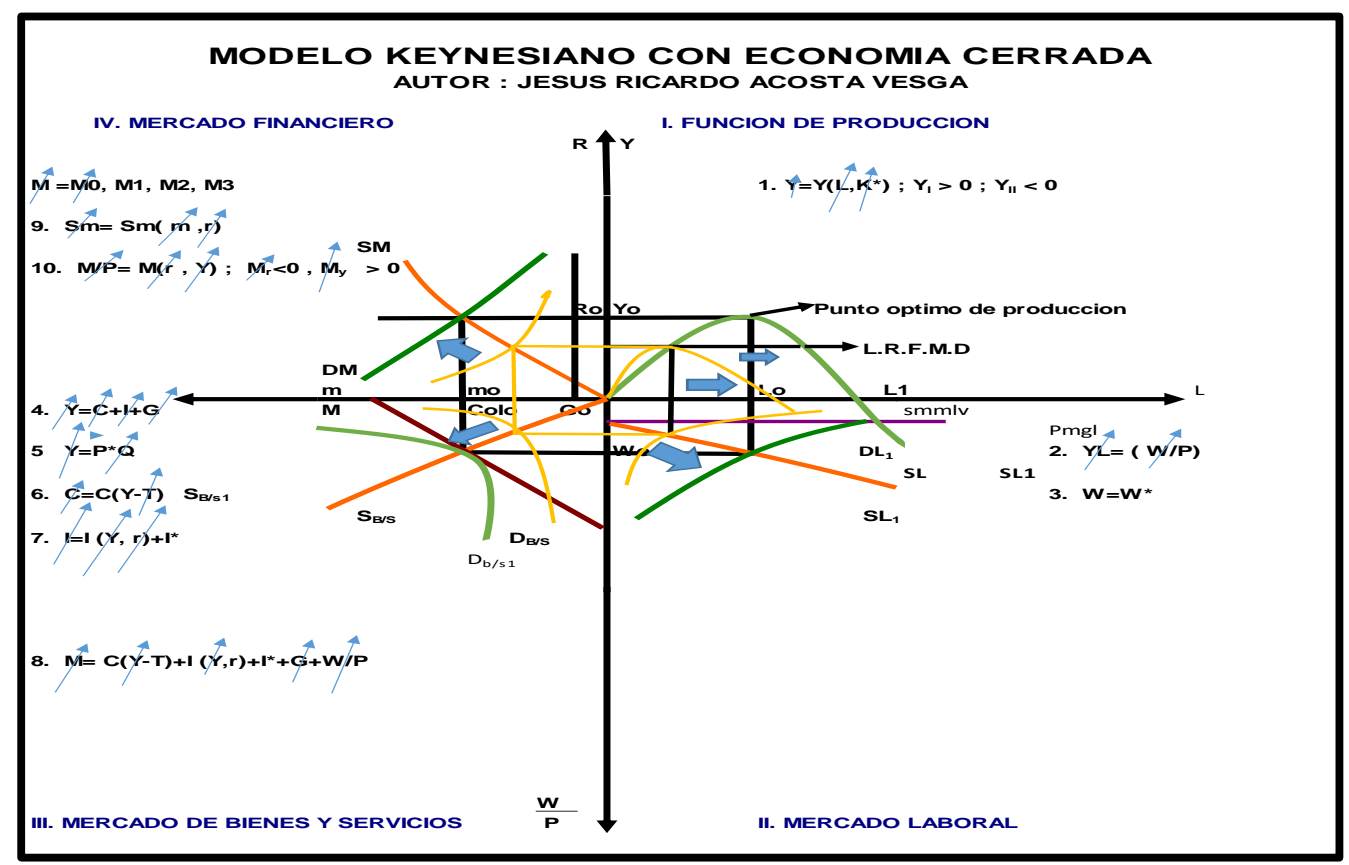

\section{Anexo. Ilustración No. 30. Movimiento de las variables afectadas.}

7. Utilizando el diagrama del modelo Keynesiano Cerrado con todas las ecuaciones analice que pasa cuando aumenta el consumo de los hogares.

Cuando aumenta el consumo indica que aumentaron los ingresos lo que hace que se incrementé la inversión y se haga una expansión monetaria en la economía.

\section{Modelo con movimiento de las variables afectadas}

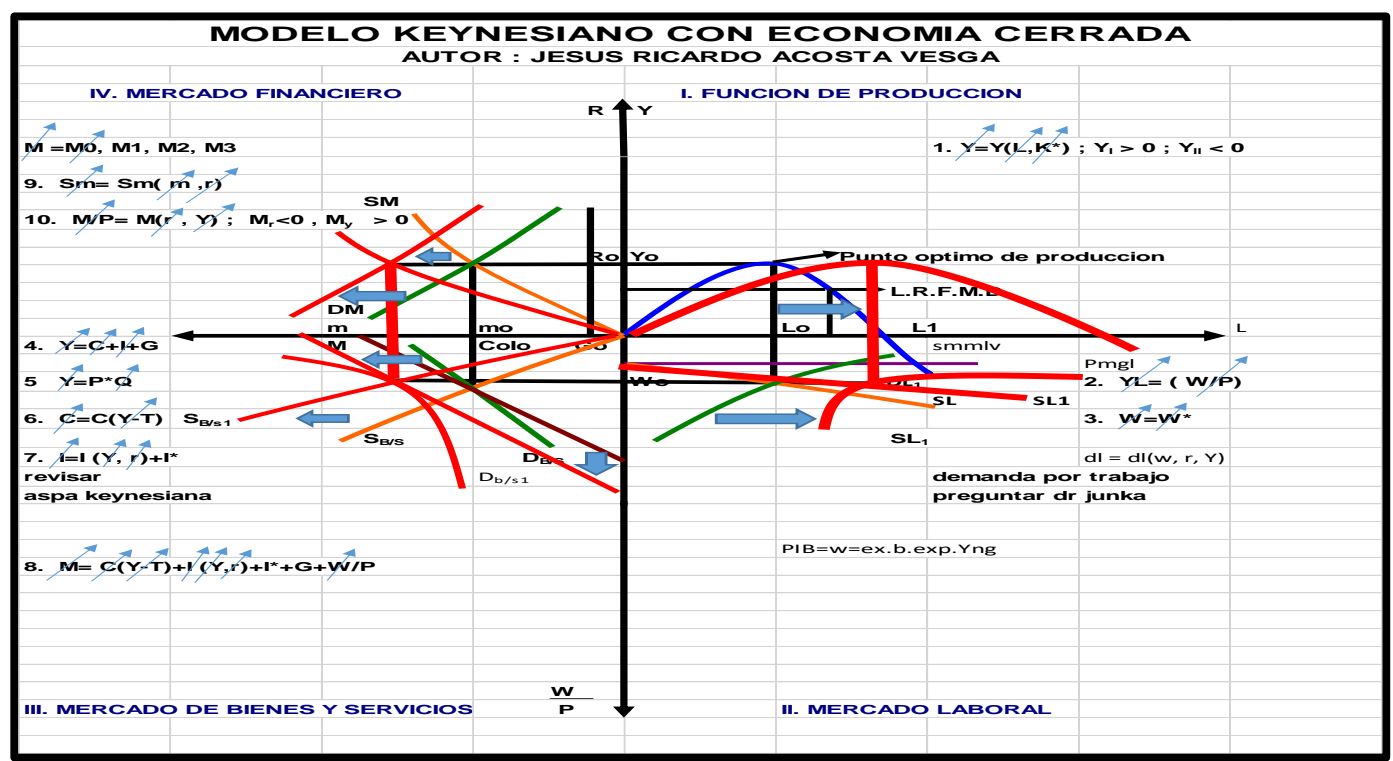


Anexo. Ilustración No. 31. Movimiento de las variables afectadas.

La solución: Para volver 1 punto de equilibrio debemos aumentar los impuestos y con esto reducimos la liquidez qué existe en la economía y así volvemos al punto de equilibrio la economía.

8. Utilizando el diagrama del modelo Keynesiano cerrado con todas las ecuaciones, analice que pasa cuando aumenta la inversión.

Si hay un aumento en la inversión es divido a que se incrementaron los ingresos y esto nos lleva a una expansión monetaria.

Modelo con movimiento de las variables afectadas

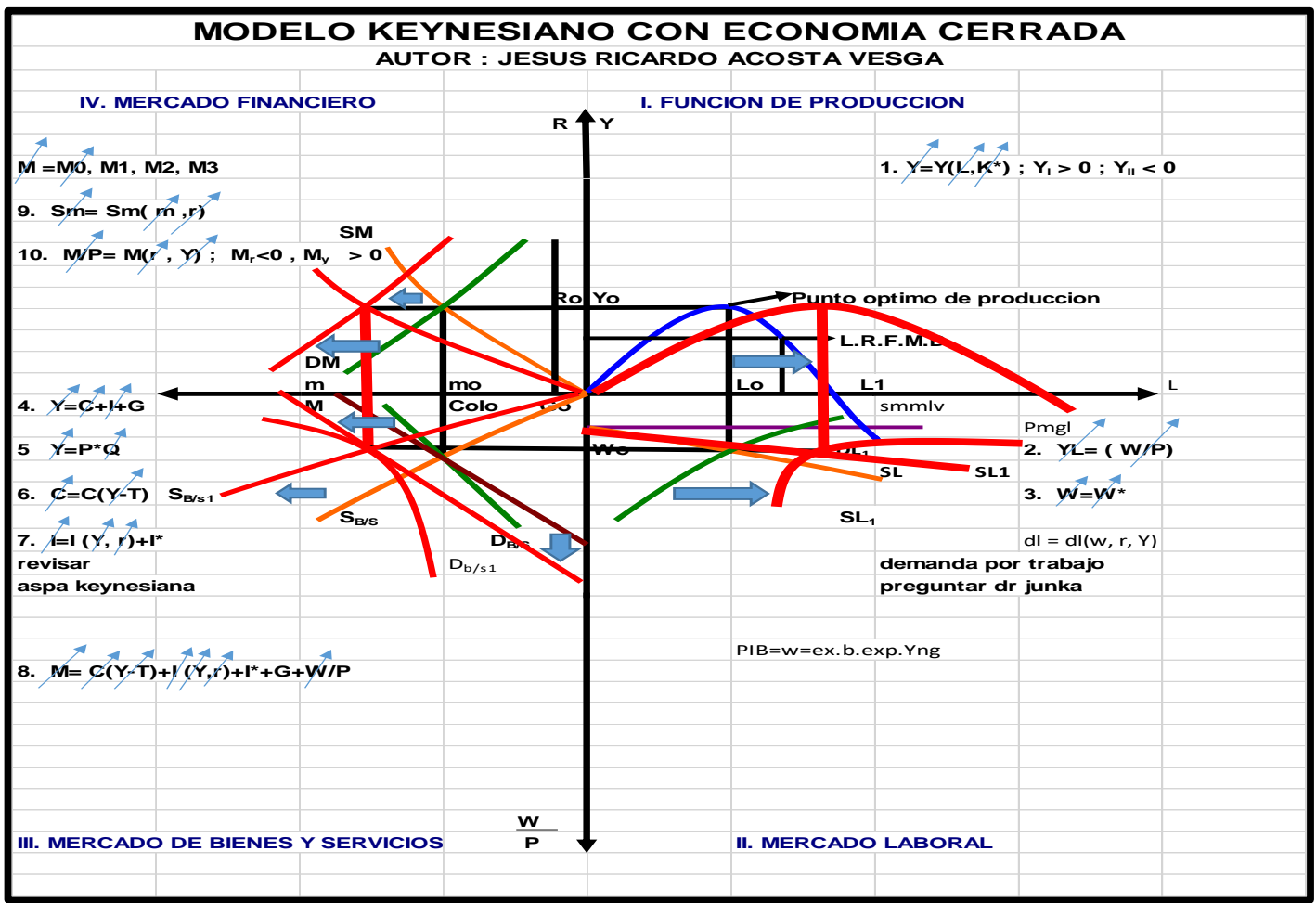

Anexo. Ilustración No. 32. Movimiento de las variables afectadas.

La solución: Para volver 1 punto de equilibrio debemos aumentar los impuestos y con esto reducimos la liquidez qué existe en la economía y así volvemos al punto de equilibrio la economía. 
9. Utilizando el diagrama del modelo Keynesiano cerrado con todas las ecuaciones y analice que pasa cuando disminuye la tasa de interés.

Si disminuye la tasa de interés esto ocasiona que la gente demande más dinero porque el costo del dinero es más barato y esto reactiva la economía y origina una expansión monetaria.

Modelo con movimiento de las variables afectadas

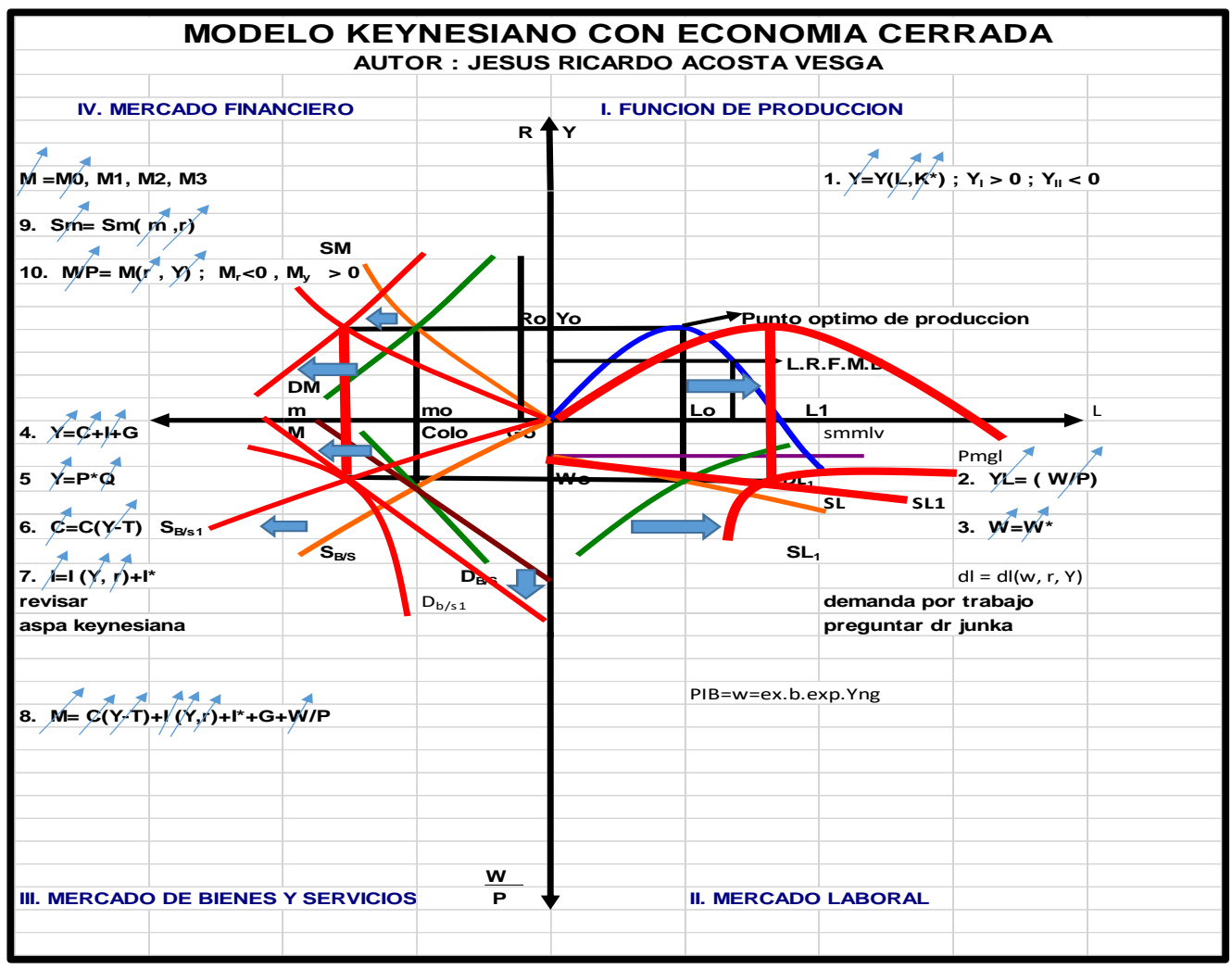

Anexo. Ilustración No. 33. Movimiento de las variables afectadas.

La solución: Para volver al punto de equilibrio debemos aumentar los impuestos y con esto reducimos la liquidez qué existe en la economía y así volvemos al punto de equilibrio la economía.

10. ¿Usted cree que el diagrama del modelo le da las herramientas necesarias para conocer de una forma más sencilla la comprensión de la economía? 
El modelo nos dio las herramientas necesarias en el manejo de las variables económicas y su influencia con el entorno económico.

\section{Enseñanza Del Modelo Keynesiano Para Estudiantes De Pregrado Una Aproximación Diagramática}

Asignatura Macroeconomia II TEST N. 1

Nombre de estudiante: María F. Herrera Mahecha Universidad: Monserrate Programa: Finanzas y Negocios Internacionales Semestre: 8

\section{Fecha: D. 21 M noviembre año 2016.}

A continuación se presentan diez preguntas tipo Saber Pro a las cuales usted les dará solución utilizando el modelo keynesiano de economía cerrada, evidenciando el movimiento de las variables económicas, para lo cual usted tendrá un rol.

1. ¿Señor gerente general, como se ve afectada su empresa cuando el banco de la república decide aumentar la tasa de interés de política monetaria?

Al subir las tasas de interés, aumenta la inversión, aumentan los ingresos, lo que hace que aumente el ingreso disponible a su vez origina un aumento del presupuesto esto origina un aumento en la masa monetaria, luego aumenta la cantidad real de dinero, lo que hizo que aumentara el dinero especulativo y el dinero de transacción todo esto origino una expansión monetaria. 
Modelo con movimiento de las variables afectadas.

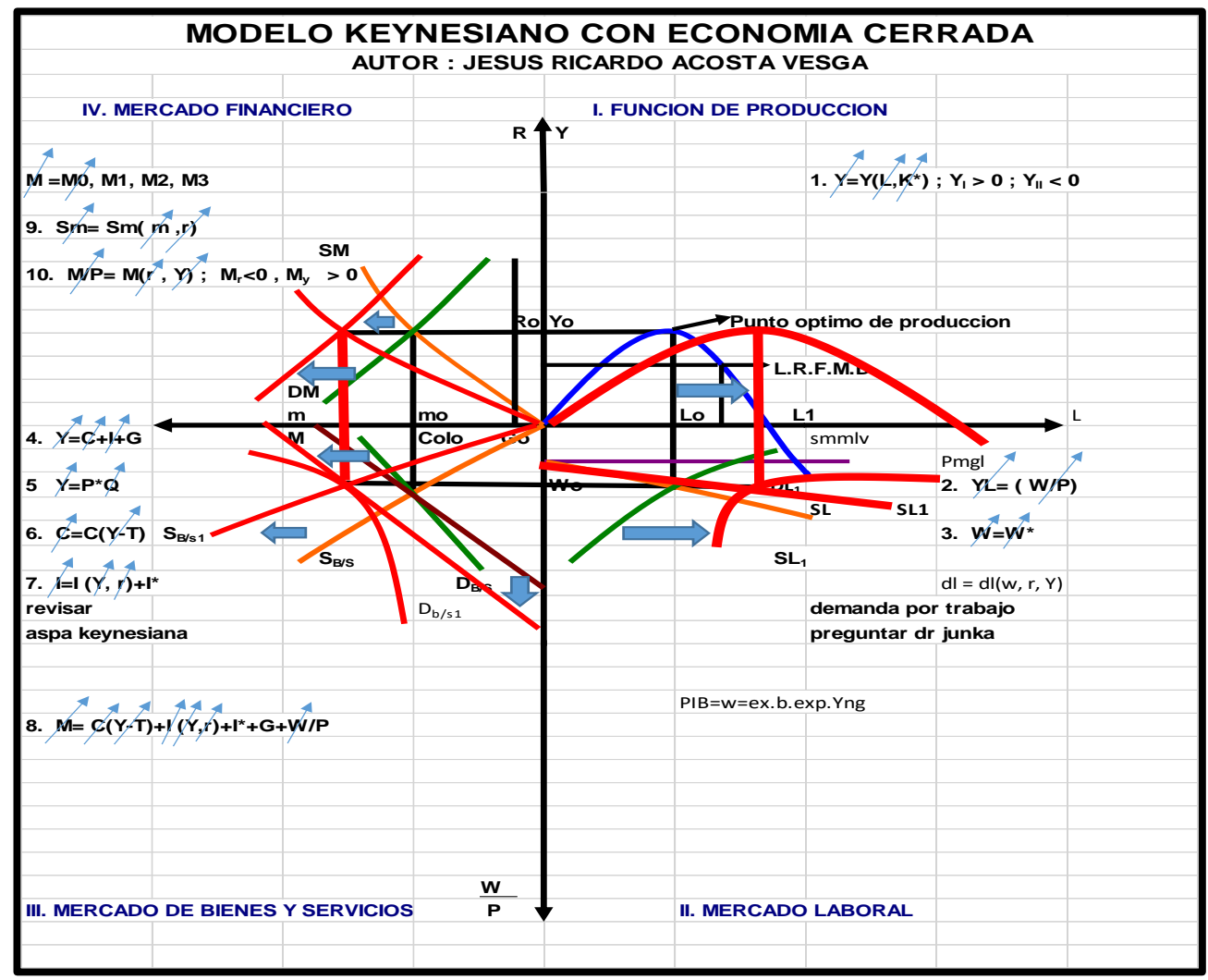

Anexo. Ilustración No. 34. Movimiento de las variables afectadas.

La solución como se observa en el grafico las flechas indican el movimiento de las variables hacia arriba mostrando que aumentaron y crearon una expansión monetaria, como gerente la solución es aumentar la capacidad instalada de la empresa teniendo en cuenta que hay más capital y eso ubica la economía en equilibrio.

2. ¿Señor gerente financiero, como se ve afectada su empresa cuando el banco de la república decide aumentar el encaje bancario?

Al aumentar el encaje bancario, se reduce el la oferta monetaria, disminuyendo el crédito, lo que hace y se reduce la demanda del dinero especulativo y de transacción, y esto origina una caída en el presupuesto y hace bajar los ingresos 
de la empresa originando una contracción monetaria, la producción y el número de empleados no se ve afectada en el corto plazo, ni los salarios nominales y por supuesto tampoco se afecta el salario real.

\section{Modelo con movimiento de las variables afectadas}

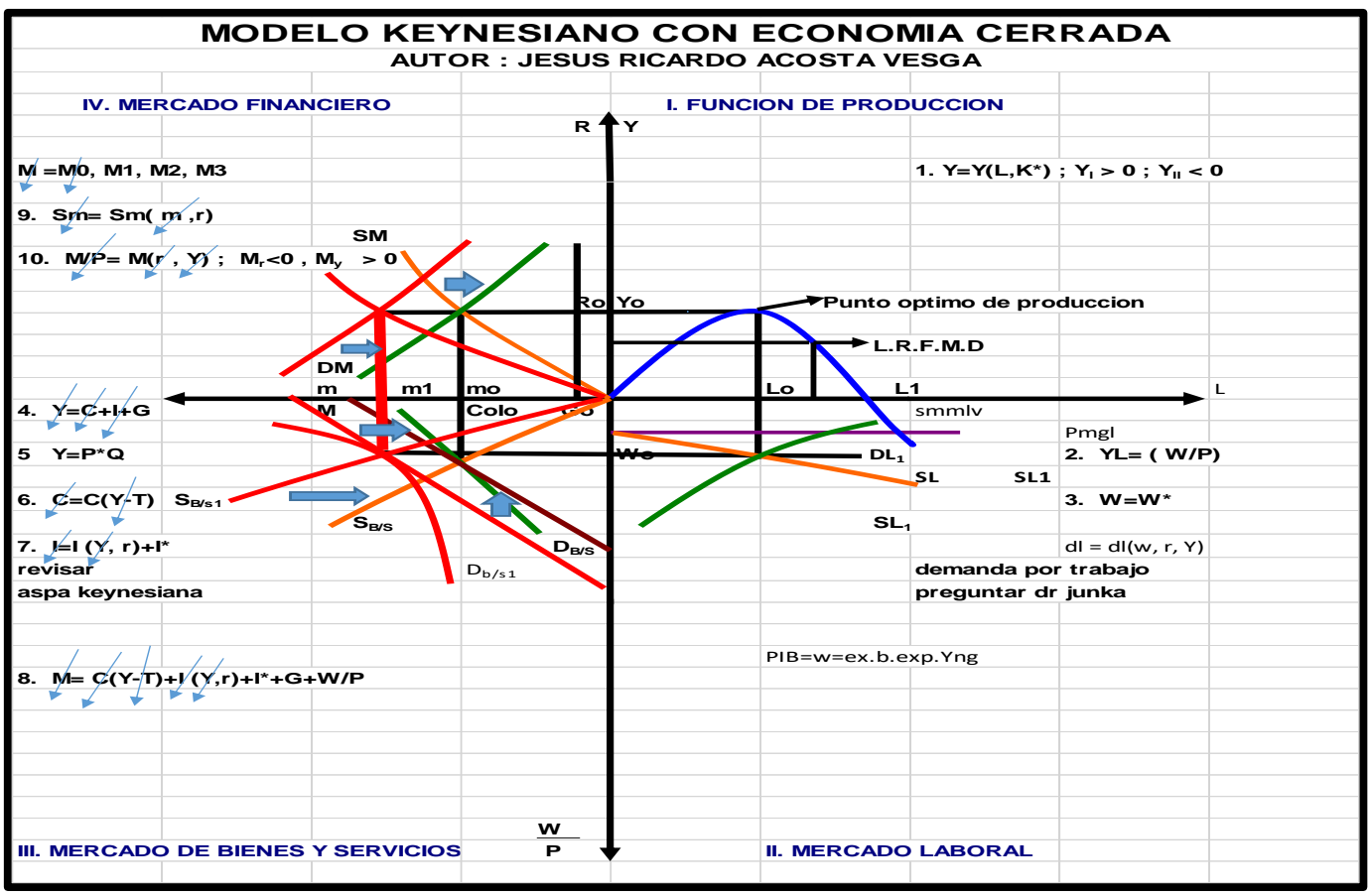

Anexo. Ilustración No. 35. Movimiento de las variables afectadas.

La solución para colocar el modelo en equilibrio es aumentando el gasto para reactivar la economía, con este aumento se produce un aumento en los ingresos y esto reactiva el consumo, la inversión, el presupuesto y a la vez aumentaría la masa monetaria incentivando de nuevo el crédito y así volveríamos al equilibrio.

3. ¿Señor gerente financiero, como se ve afectada su empresa cuando el banco de la república decide aumentar la emisión de dinero?

Al aumentar la emisión primaria de dinero por parte de Banco de la república, va a existir mayor cantidad de dinero en la economía, lo que ocasiona que se incremente la oferta monetaria y esto hace que aumente el consumo de los hogares, 
la inversión y el gasto y esto hace a la vez que se aumente el ingreso y se reactive la economía. Y la economía puede llegar a presentar un sobre calentamiento financiero.

Modelo con movimiento de las variables afectadas

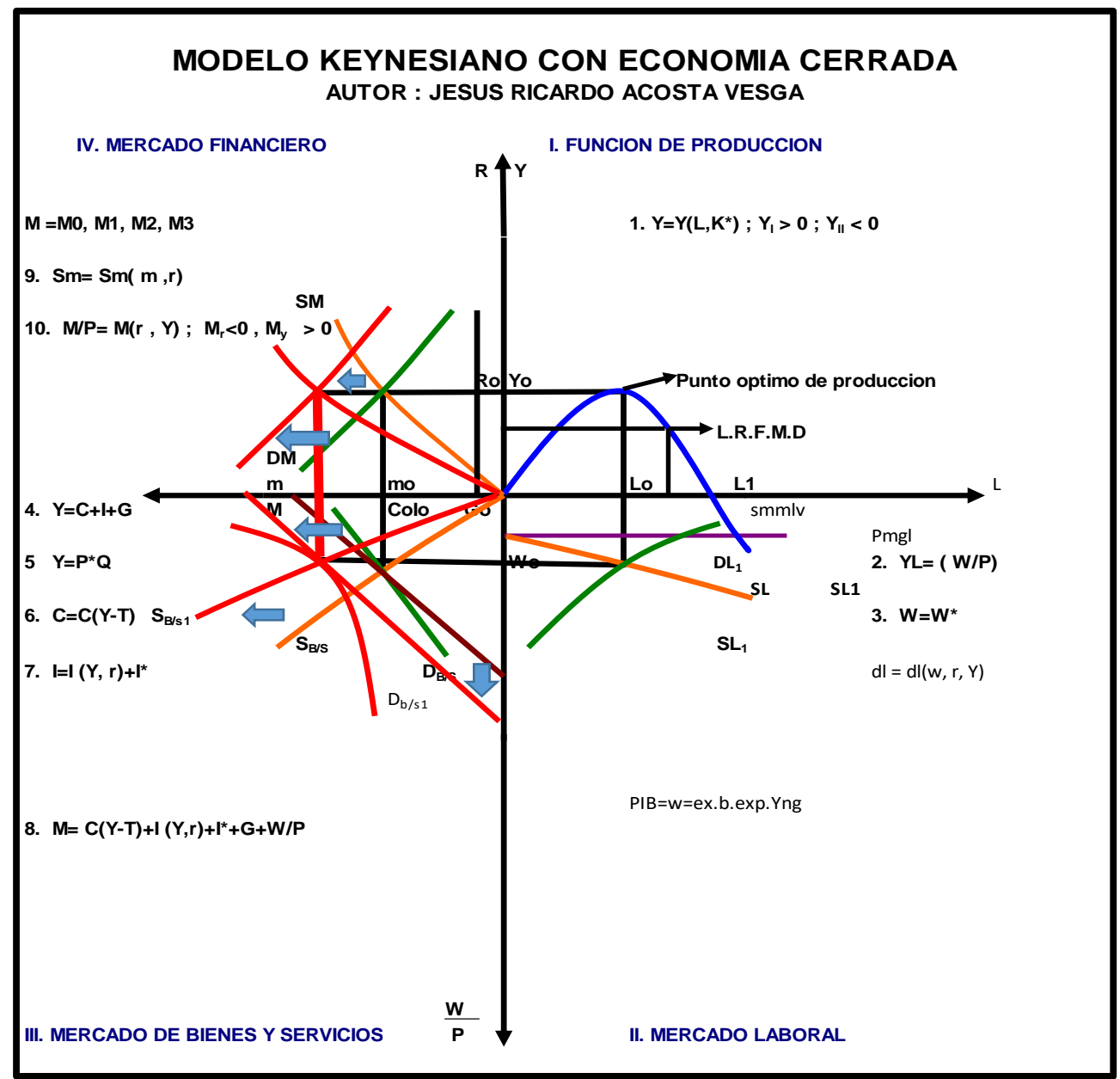

Anexo. Ilustración No. 36. Movimiento de las variables afectadas.

La Solución: Se debe invertir en la planta de producción para aumentar la capacidad productiva, aumentando la producción el número de empleados y así volver al punto de equilibrio inicial.

4. ¿Señor gerente de producción, que pasa cuando el gobierno decide aumentar los instrumentos de política fiscal, como se afectan las variables del modelo? 
La solución: Si se incrementan tanto en gasto como los impuestos en el mismo porcentaje, el uno reduce el poder adquisitivo, como son los impuestos y al aumentar el gasto se mejora el poder adquisitivo y se reactiva la economía devolviendo todo al punto de equilibrio. Lo que indica que el modelo no se vea afectado.

5. Utilizando el diagrama del modelo Keynesiano cerrado con todas las ecuaciones, analice que pasa cuando disminuye la oferta monetaria.

Si disminuye la oferta monetaria, hace que se suban las tasas de interés, lo que hace que se reduzca la inversión por el costo de los intereses, lo mismo pasa con el consumó, el ingreso se reduce y el gasto también, esto puede producir que se baje la producción y exista una contracción en la economía.

\section{Modelo con movimiento de las variables afectadas}

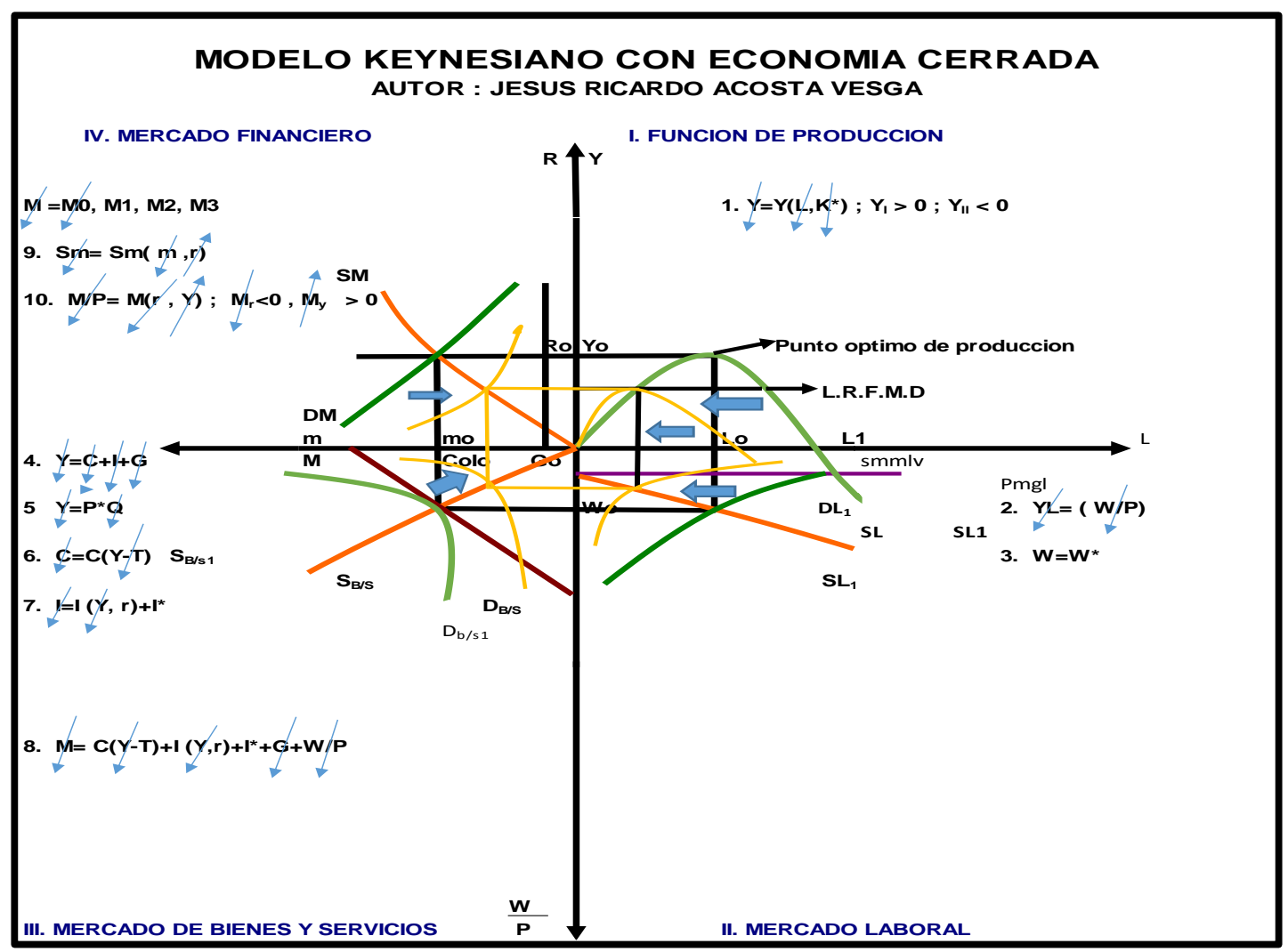


Anexo. Ilustración No. 37. Movimiento de las variables afectadas.

La Solución: Para este caso hay varias respuestas entre ellas una es incrementar el gasto público para reactivar la economía y así volver al punto de equilibrio, otra solución sería que el Banco de la Republica, aumentara las emisiones de dinero y así reactivar la economía y volver al punto de equilibrio.

6. Utilizando el diagrama del modelo Keynesiano cerrado con todas las ecuaciones, analice que pasa cuando aumenta el gasto público.

Cuando aumenta el gasto público se reactiva la economía y esto hace que exista una expansión monetaria y hace que la economía crezca.

Modelo con movimiento de las variables afectadas

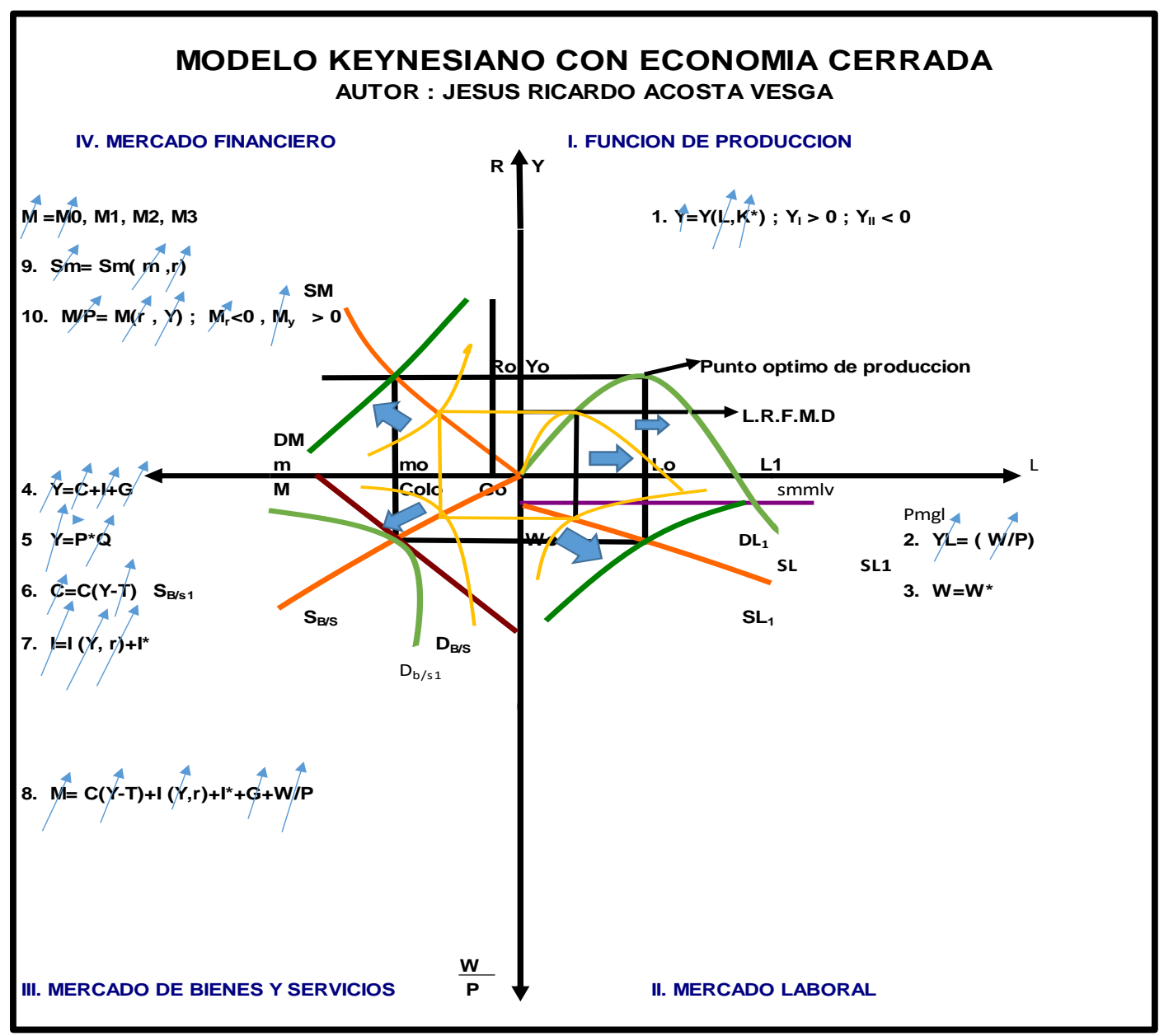


Anexo. Ilustración No. 38. Movimiento de las variables afectadas.

7. Utilizando el diagrama del modelo Keynesiano Cerrado con todas las ecuaciones, analice que pasa cuando aumenta el consumo de los hogares.

Cuando aumenta el consumo indica que aumentaron los ingresos lo que hace que se incrementé la inversión y se haga una expansión monetaria en la economía.

Modelo con movimiento de las variables afectadas

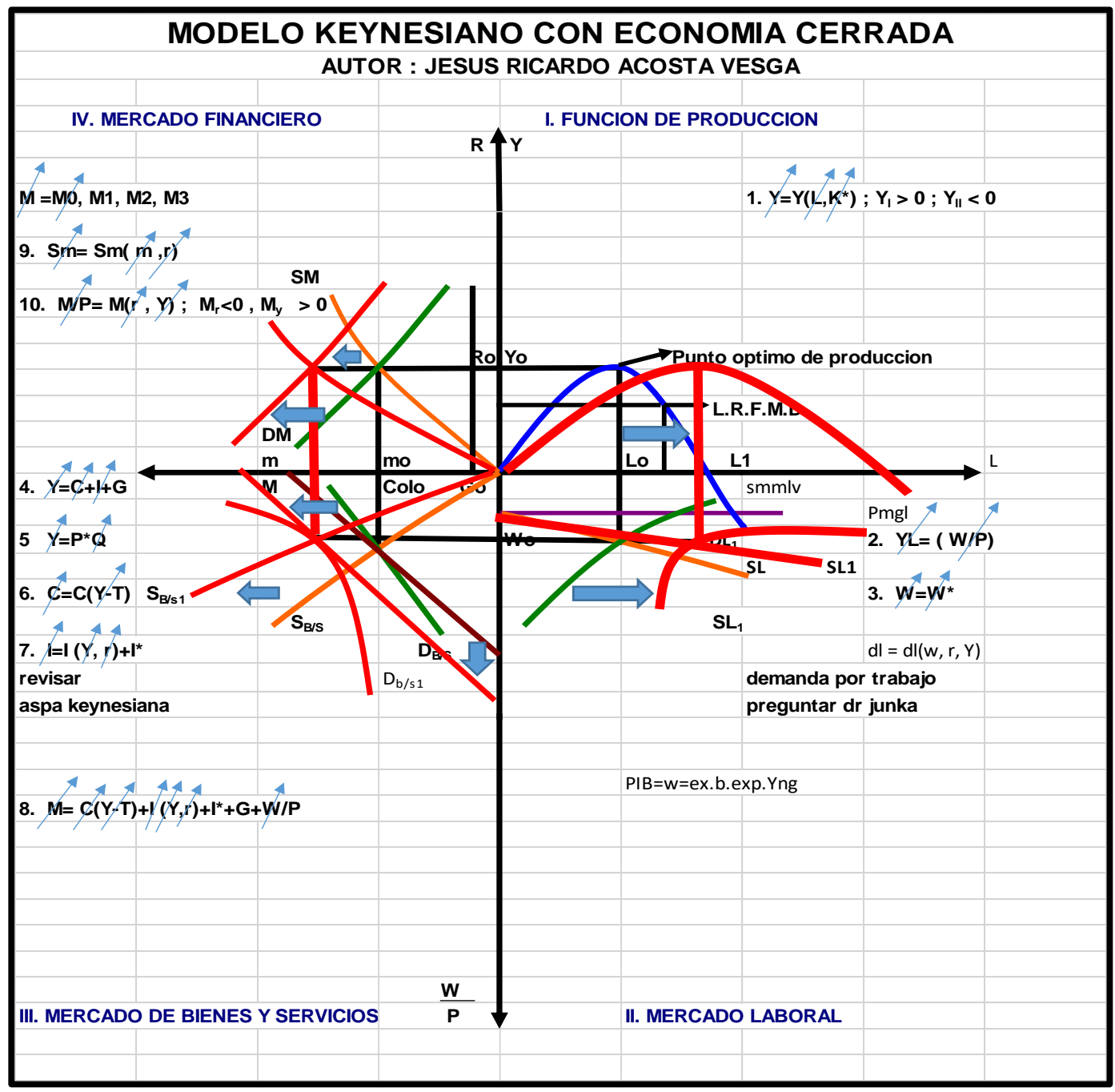

Anexo. Ilustración No. 39. Movimiento de las variables afectadas.

La solución: Para volver 1 punto de equilibrio debemos aumentar los impuestos y con esto reducimos la liquidez qué existe en la economía y así volvemos al punto 
de equilibrio la economía.

8. Utilizando el diagrama del modelo Keynesiano cerrado con todas las ecuaciones, analice que pasa cuando aumenta la inversión.

Si hay un aumento en la inversión es divido a que se incrementaron los ingresos y esto nos lleva a una expansión monetaria.

Modelo con movimiento de las variables afectadas

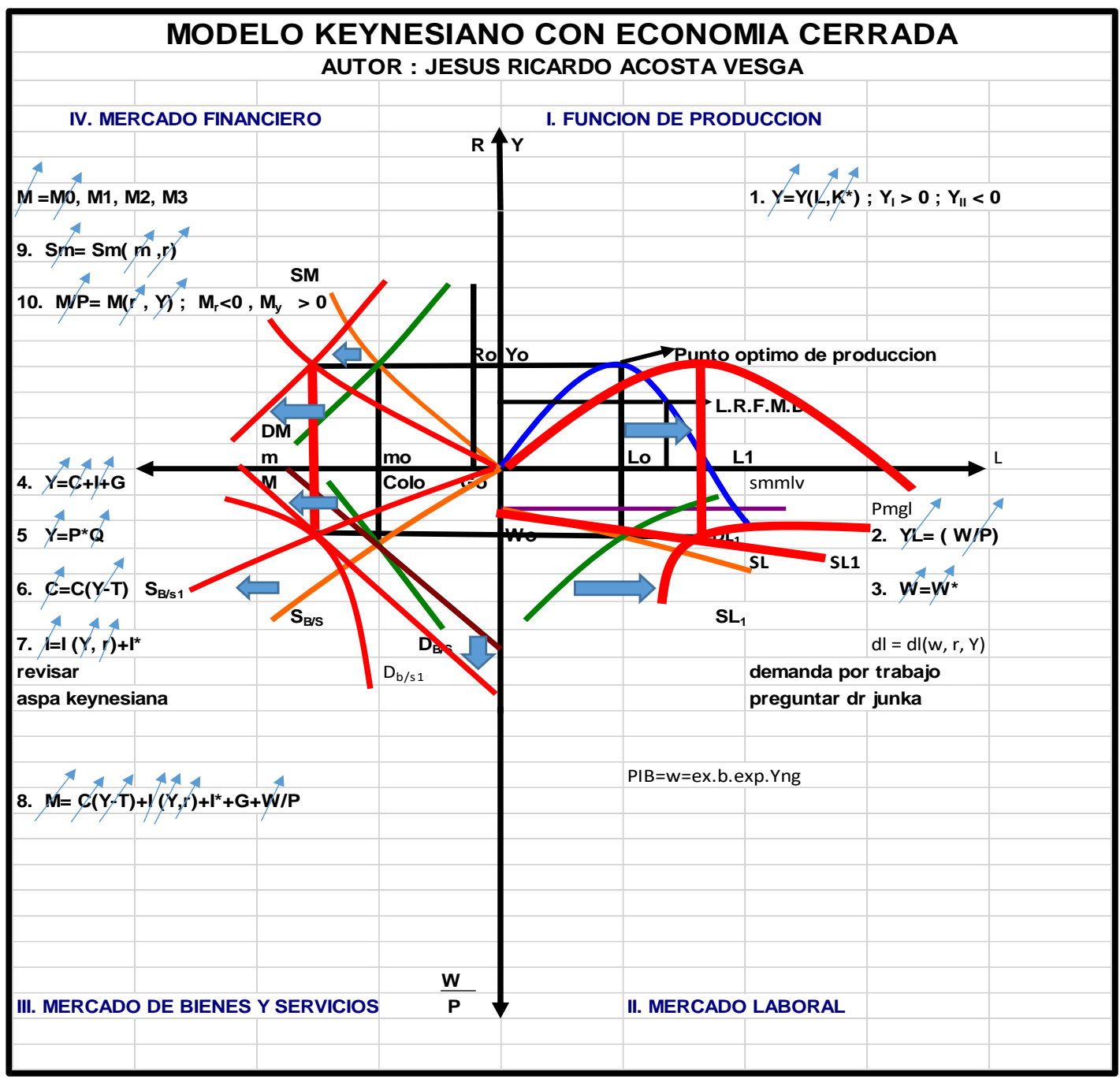

Anexo. Ilustración No. 40. Movimiento de las variables afectadas.

La solución: Para volver 1 punto de equilibrio debemos aumentar los impuestos y con esto reducimos la liquidez qué existe en la economía y así volvemos al punto 
de equilibrio la economía.

9. Utilizando el diagrama del modelo Keynesiano cerrado con todas las ecuaciones y analice que pasa cuando disminuye la tasa de interés.

Si disminuye la tasa de interés esto ocasiona que la gente demande más dinero porque el costo del dinero es más barato y esto reactiva la economía y origina una expansión monetaria.

Modelo con movimiento de las variables afectadas

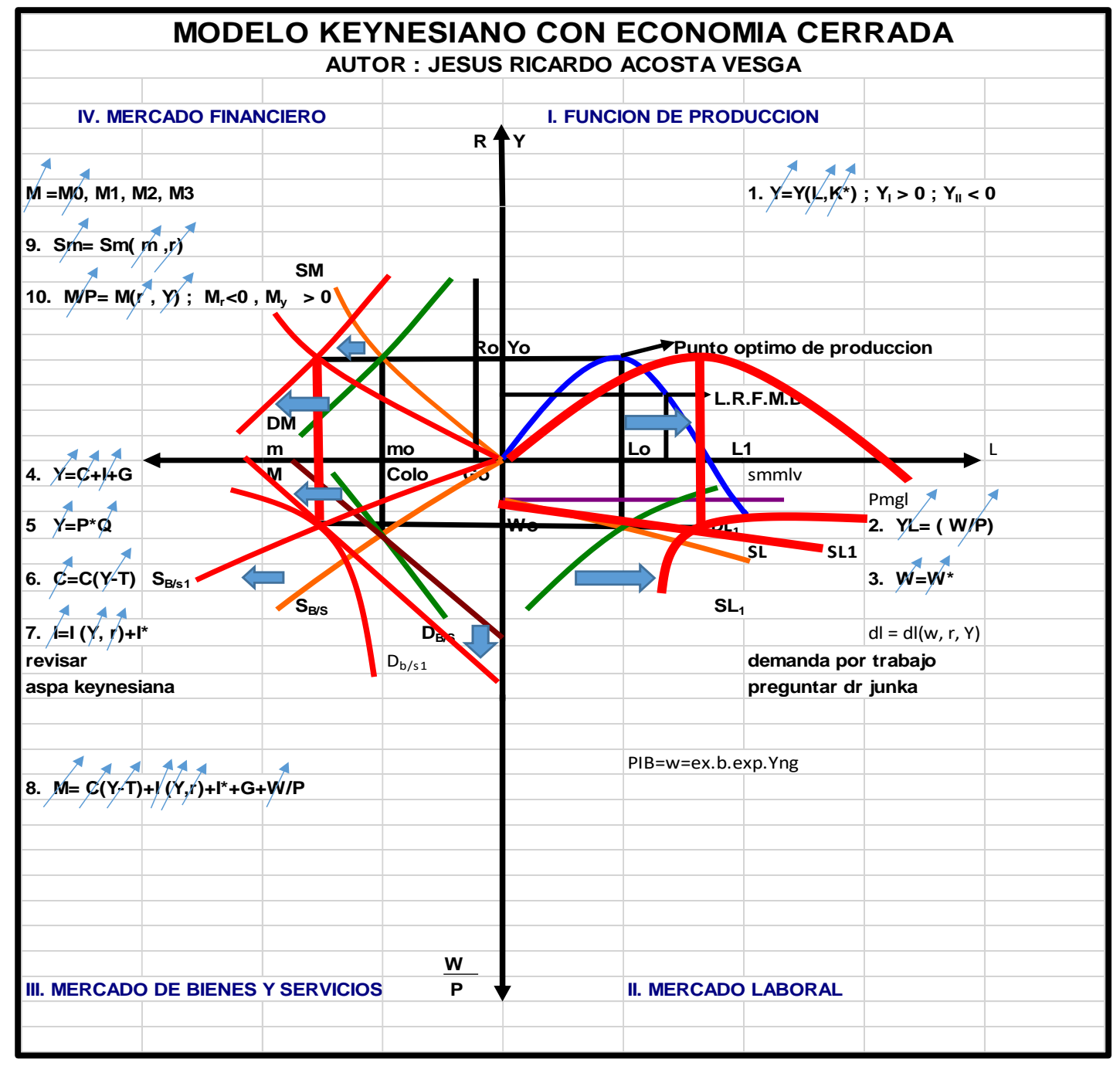

Anexo. Ilustración No. 41. Movimiento de las variables afectadas.

La solución: Para volver al punto de equilibrio debemos aumentar los impuestos 
y con esto reducimos la liquidez qué existe en la economía y así volvemos al punto de equilibrio la economía.

10. ¿Usted cree que el diagrama del modelo le da las herramientas necesarias para conocer de una forma más sencilla la comprensión de la economía?

Explica de forma clara, el comportamiento de las variables, y nos ayuda en el proceso de toma de decisiones.

ENSEÑANZA DEL MODELO KEYNESIANO PARA ESTUDIANTES DE PREGRADO UNA APROXIMACIÓN DIAGRAMATICA

\section{ASIGNATURA MACROECONOMIA II}

\section{TEST N. 1}

$\begin{array}{ccc}\text { Nombre de estudiante: } & \text { _OSCAR VILLAMIL ROZO Universidad: } \\ \text { MONSERRATE_ } & \text { Programa: ___ FNI___Semestre: __ VIII }\end{array}$

fecha: D._21_M_11_ año $\underline{2016}$

A continuación se presentan diez preguntas tipo Saber Pro a las cuales usted les dará solución utilizando el modelo keynesiano de economía cerrada, evidenciando el movimiento de las variables económicas, para lo cual usted tendrá un rol.

1. ¿Señor gerente general, como se ve afectada su empresa cuando el banco de la república decide aumentar la tasa de interés de política monetaria?

Al subir las tasas de interés, aumenta la inversión, aumentan los ingresos, lo que hace que aumente el ingreso disponible a su vez origina un aumento del presupuesto esto origina un aumento en la masa monetaria, luego aumenta la cantidad real de dinero, lo que hizo que aumentara el dinero especulativo y el dinero de transacción todo esto origino una expansión monetaria. 
Modelo con movimiento de las variables afectadas.

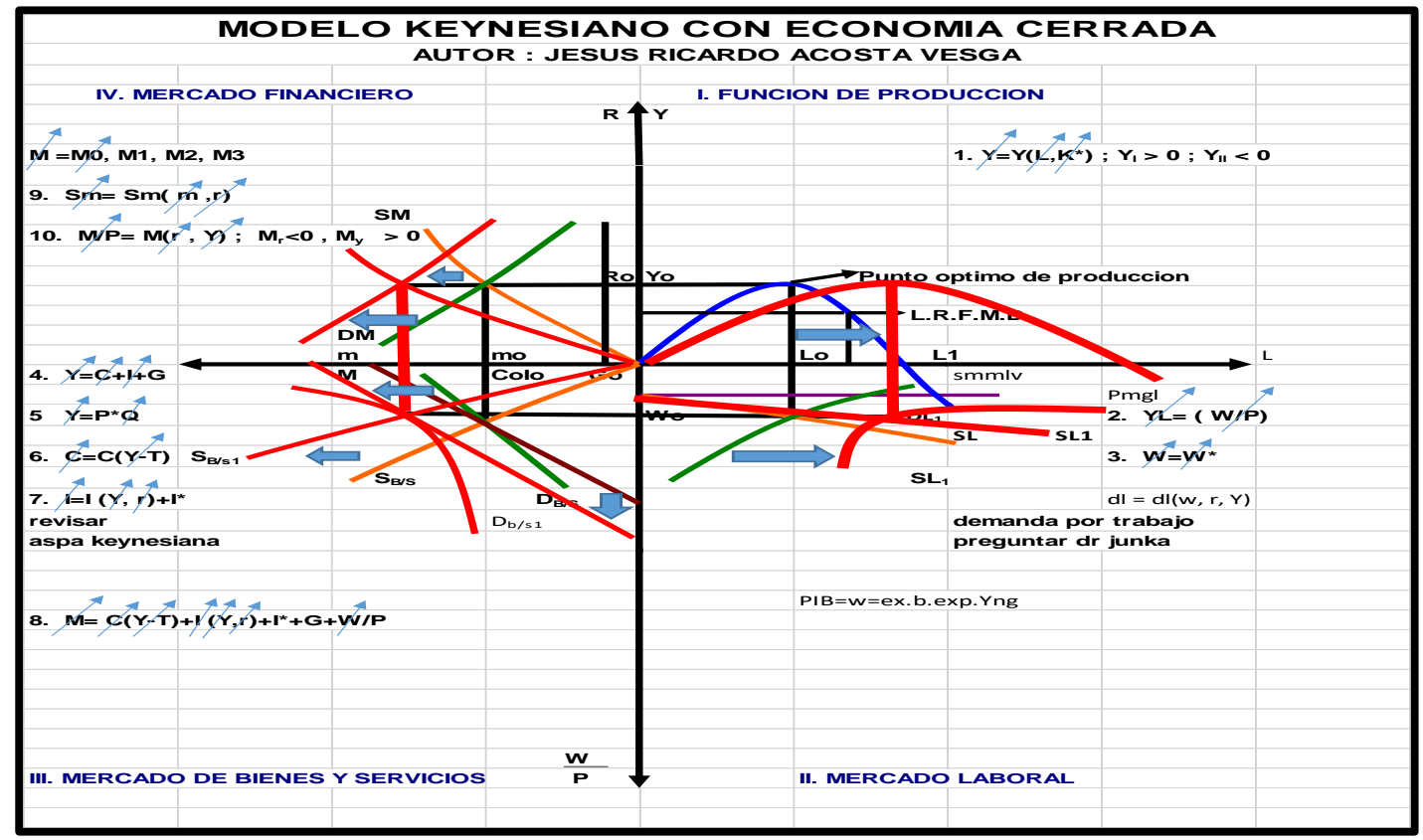

Anexo. Ilustración No. 42. Movimiento de las variables afectadas

La solución como se observa en el grafico las flechas indican el movimiento de

las variables hacia arriba mostrando que aumentaron y crearon una expansión

monetaria, como gerente la solución es aumentar la capacidad instalada de la

empresa teniendo en cuenta que hay más capital y eso ubica la economía en

equilibrio.

2. ¿Señor gerente financiero, como se ve afectada su empresa cuando el banco de la república decide aumentar el encaje bancario?

Al aumentar el encaje bancario, se reduce el la oferta monetaria, disminuyendo el crédito, lo que hace y se reduce la demanda del dinero especulativo y de transacción, y esto origina una caída en el presupuesto y hace bajar los ingresos de la empresa originando una contracción monetaria, la producción y el número de empleados no se ve afectada en el corto plazo, ni los salarios nominales y por 
supuesto tampoco se afecta el salario real.

Modelo con movimiento de las variables afectadas

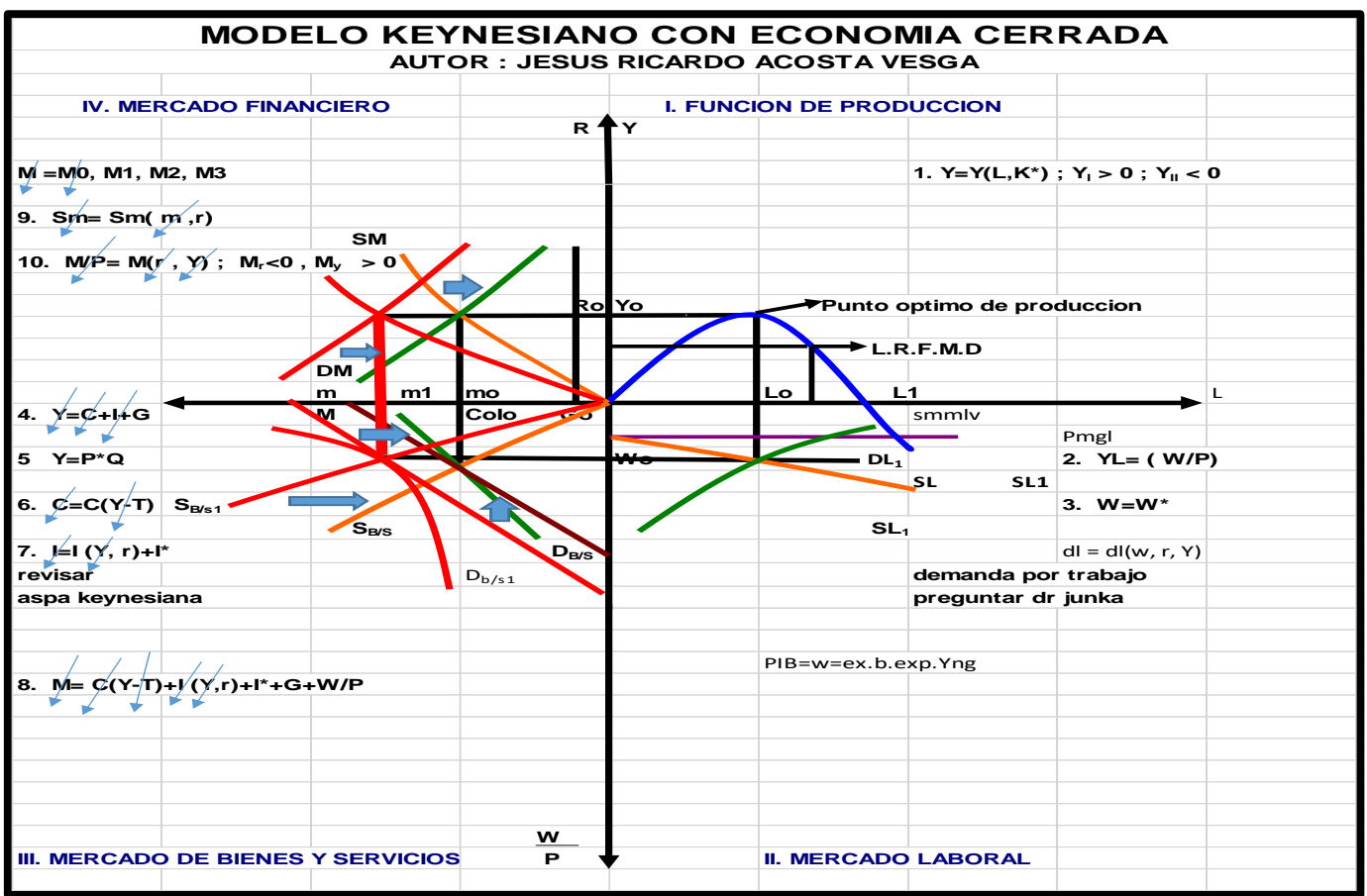

Anexo. Ilustración No. 43. Movimiento de las variables afectadas.

La solución para colocar el modelo en equilibrio es aumentando el gasto para reactivar la economía, con este aumento se produce un aumento en los ingresos y esto reactiva el consumo, la inversión, el presupuesto y a la vez aumentaría la masa monetaria incentivando de nuevo el crédito y así volveríamos al equilibrio.

3. ¿Señor gerente financiero, como se ve afectada su empresa cuando el banco de la república decide aumentar la emisión de dinero?

Al aumentar la emisión primaria de dinero por parte de Banco de la república, va a existir mayor cantidad de dinero en la economía, lo que ocasiona que se incremente la oferta monetaria y esto hace que aumente el consumo de los hogares, la inversión y el gasto y esto hace a la vez que se aumente el ingreso y se reactive la economía. Y la economía puede llegar a presentar un sobre calentamiento 
financiero.

Modelo con movimiento de las variables afectadas

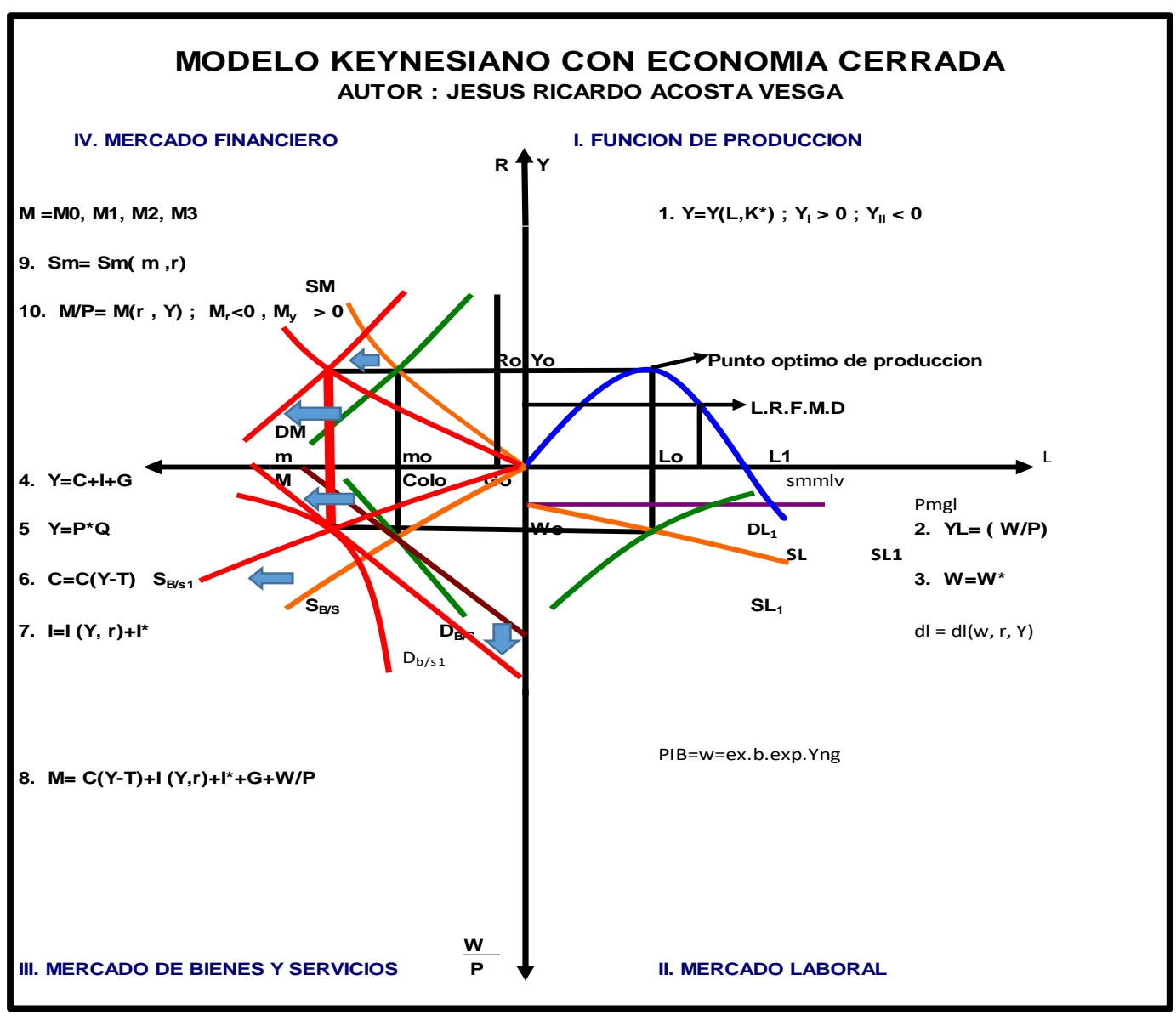

Anexo. Ilustración No. 44. Movimiento de las variables afectadas.

La Solución: Se debe invertir en la planta de producción para aumentar la capacidad productiva, aumentando la producción el número de empleados y así volver al punto de equilibrio inicial.

4. ¿Señor gerente de producción, que pasa cuando el gobierno decide aumentar los instrumentos de política fiscal, como se afectan las variables del modelo?

La solución: Si se incrementan tanto en gasto como los impuestos en el mismo porcentaje, el uno reduce el poder adquisitivo, como son los impuestos y al aumentar el gasto se mejora el poder adquisitivo y se reactiva la economía 
devolviendo todo al punto de equilibrio. Lo que indica que el modelo no se vea afectado.

5. Utilizando el diagrama del modelo Keynesiano cerrado con todas las ecuaciones, analice que pasa cuando disminuye la oferta monetaria.

Si disminuye la oferta monetaria, hace que se suban las tasas de interés, lo que hace que se reduzca la inversión por el costo de los intereses, lo mismo pasa con el consumó, el ingreso se reduce y el gasto también, esto puede producir que se baje la producción y exista una contracción en la economía.

Modelo con movimiento de las variables afectadas

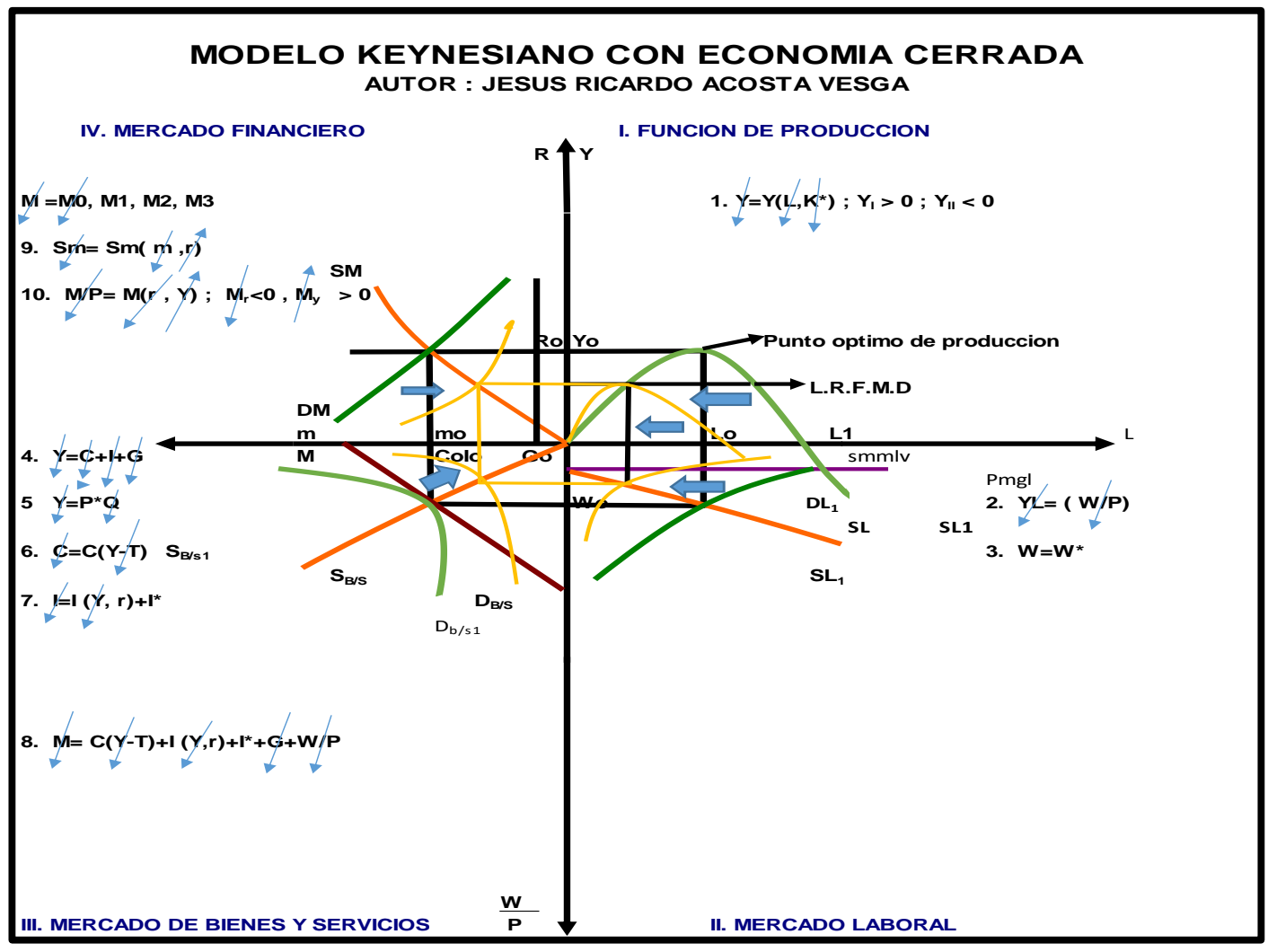

Anexo. Ilustración No. 45. Movimiento de las variables afectadas.

La Solución: Para este caso hay varias respuestas entre ellas una es incrementar el gasto público para reactivar la economía y así volver al punto de equilibrio, otra 
solución sería que el Banco de la Republica, aumentara las emisiones de dinero y así reactivar la economía y volver al punto de equilibrio.

6. Utilizando el diagrama del modelo Keynesiano cerrado con todas las ecuaciones, analice que pasa cuando aumenta el gasto público.

Cuando aumenta el gasto público se reactiva la economía y esto hace que exista una expansión monetaria y hace que la economía crezca.

Modelo con movimiento de las variables afectadas

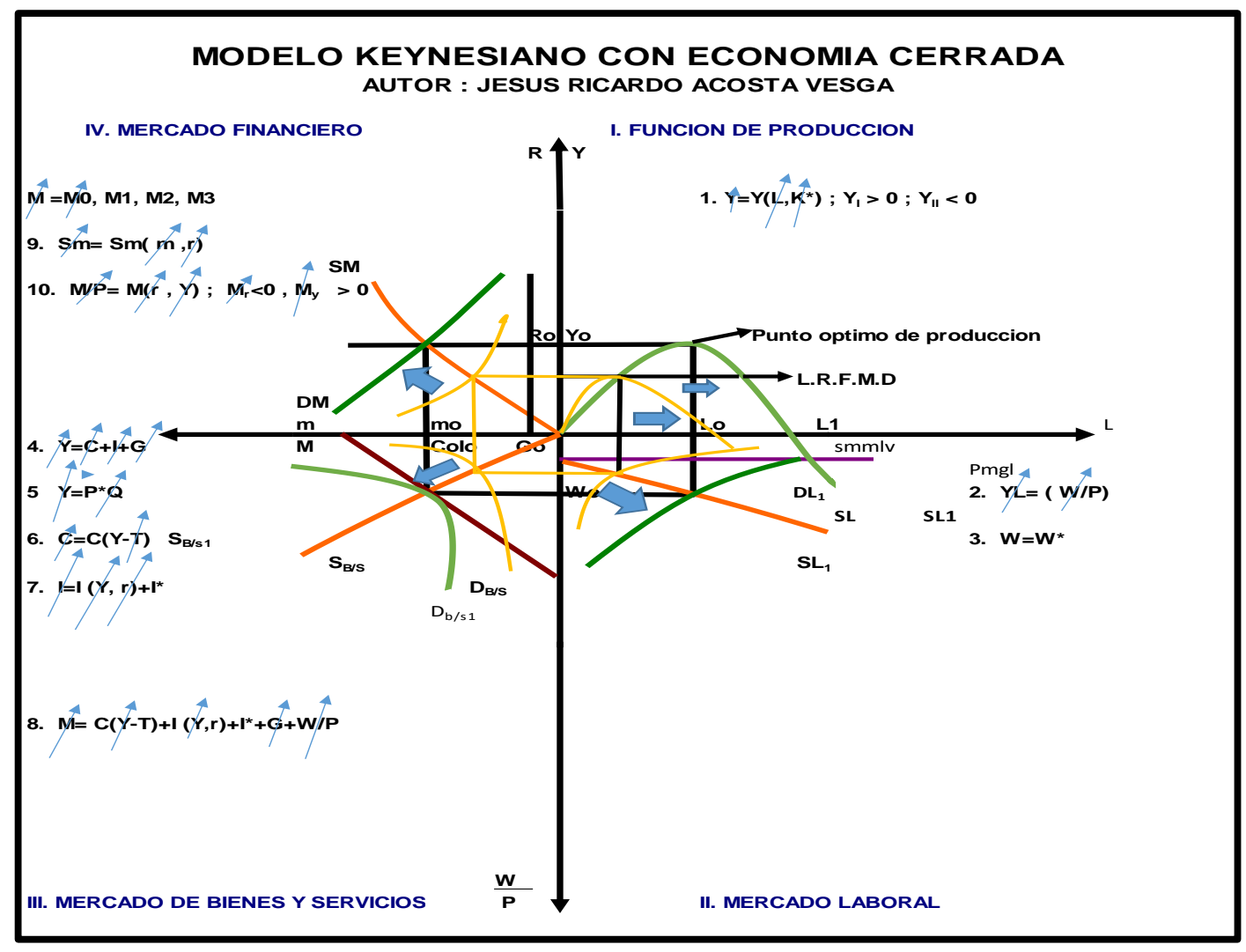

Anexo. Ilustración No. 46. Movimiento de las variables afectadas.

7. Utilizando el diagrama del modelo Keynesiano Cerrado con todas las ecuaciones, analice que pasa cuando aumenta el consumo de los hogares.

Cuando aumenta el consumo indica que aumentaron los ingresos lo que hace que se incrementé la inversión y se haga una expansión monetaria en la economía. 
Modelo con movimiento de las variables afectadas

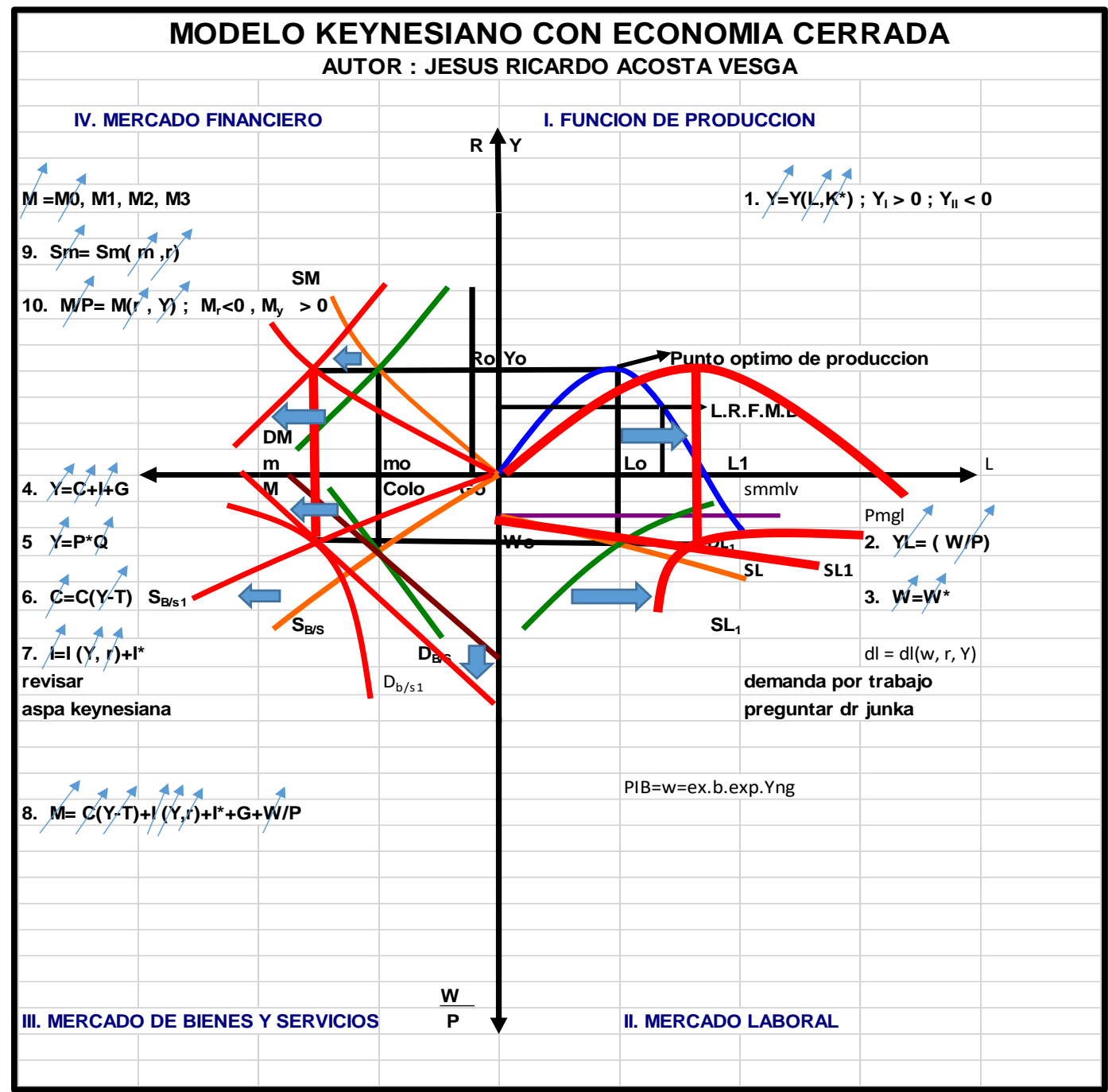

Anexo. Ilustración No. 47. Movimiento de las variables afectadas.

La solución: Para volver 1 punto de equilibrio debemos aumentar los impuestos y con esto reducimos la liquidez qué existe en la economía y así volvemos al punto de equilibrio la economía.

8. Utilizando el diagrama del modelo Keynesiano cerrado con todas las ecuaciones, analice que pasa cuando aumenta la inversión.

Si hay un aumento en la inversión es divido a que se incrementaron los ingresos y esto nos lleva a una expansión monetaria. 
Modelo con movimiento de las variables afectadas

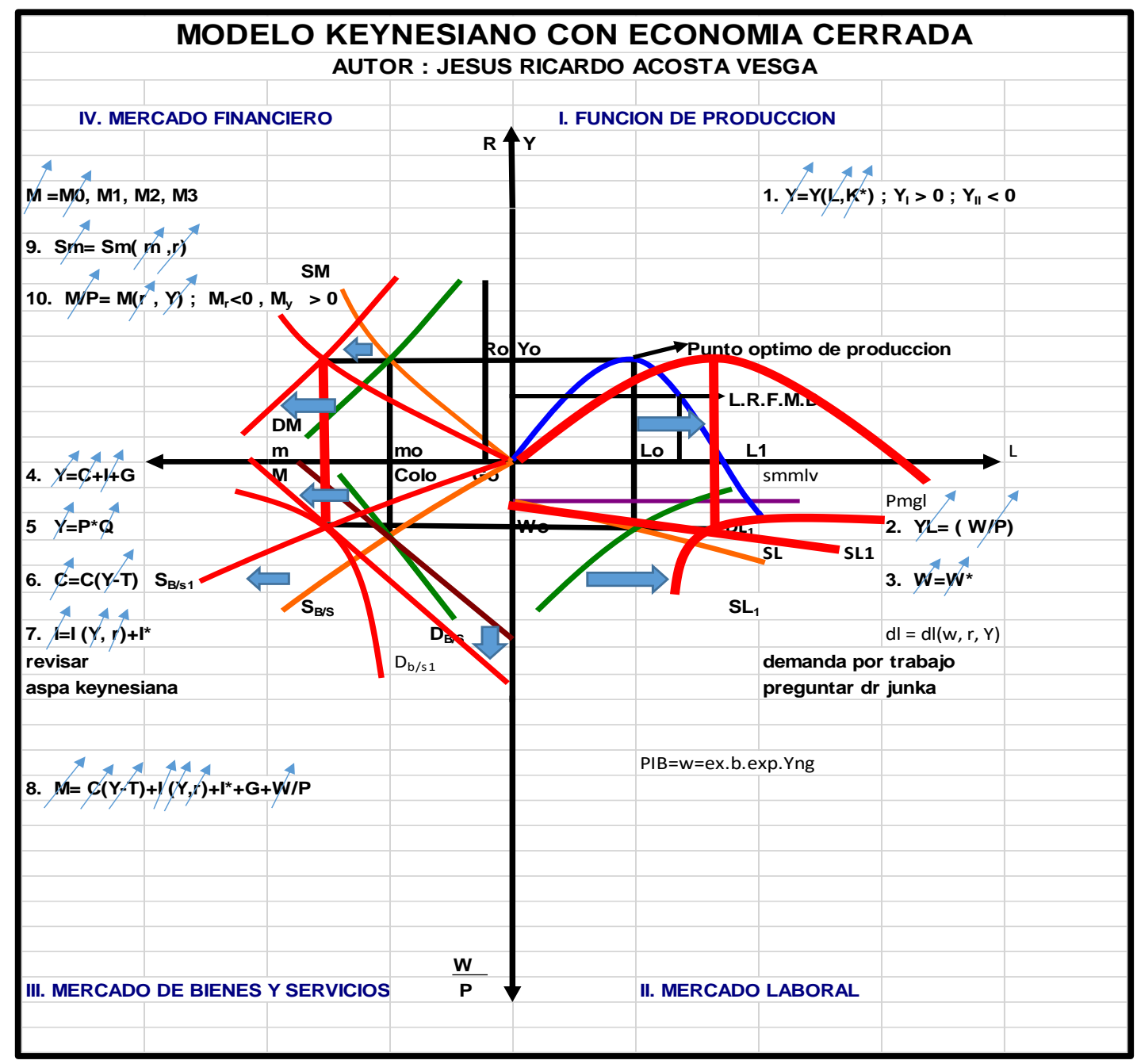

Anexo. Ilustración No. 48. Movimiento de las variables afectadas.

La solución: Para volver 1 punto de equilibrio debemos aumentar los impuestos y con esto reducimos la liquidez qué existe en la economía y así volvemos al punto de equilibrio la economía.

9. Utilizando el diagrama del modelo Keynesiano cerrado con todas las ecuaciones y analice que pasa cuando disminuye la tasa de interés.

Si disminuye la tasa de interés esto ocasiona que la gente demande más dinero porque el costo del dinero es más barato y esto reactiva la economía y origina una 
expansión monetaria.

Modelo con movimiento de las variables afectadas

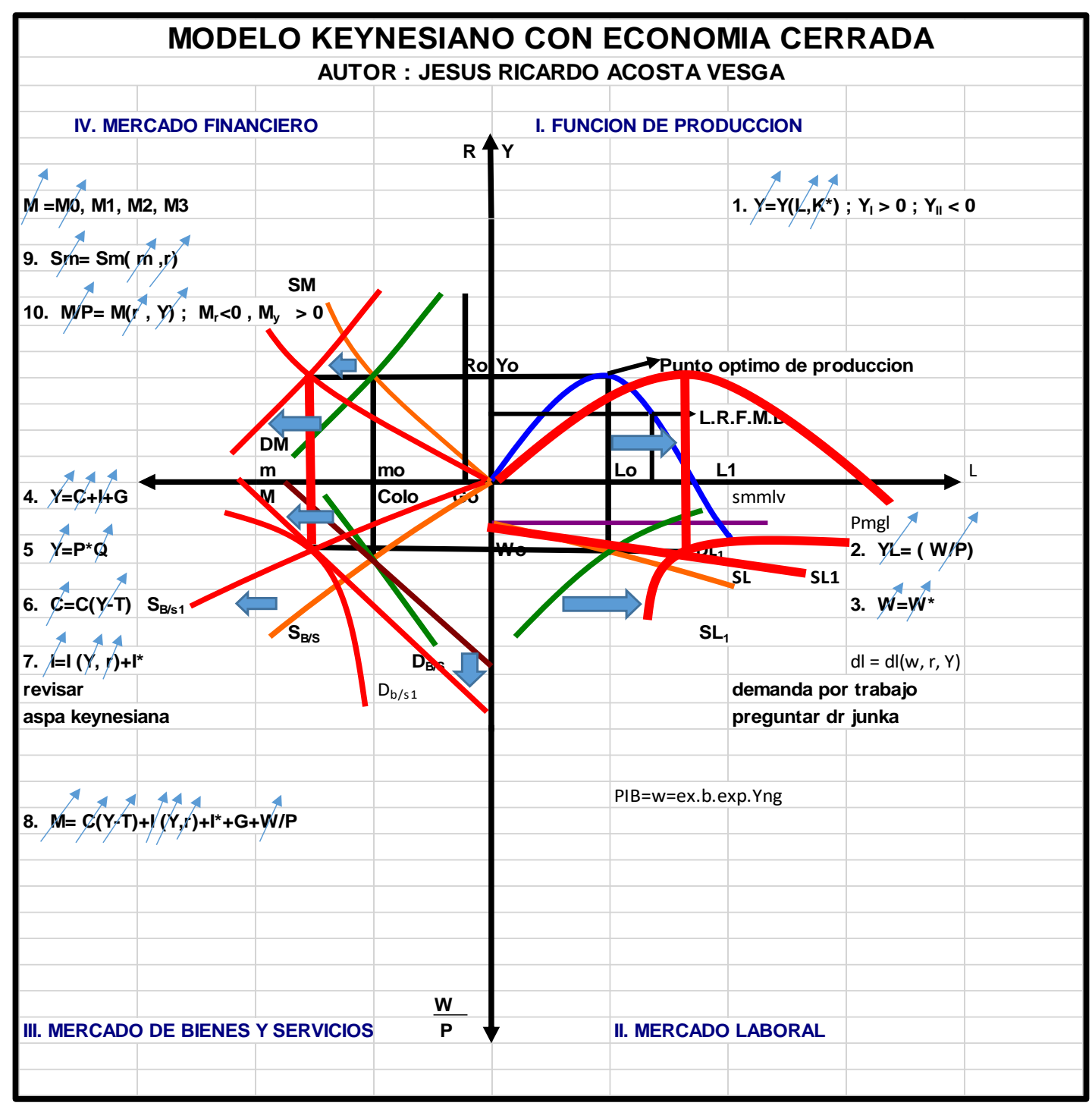

Anexo. Ilustración No. 48. Movimiento de las variables afectadas.

La solución: Para volver al punto de equilibrio debemos aumentar los impuestos y con esto reducimos la liquidez qué existe en la economía y así volvemos al punto de equilibrio la economía. 


\section{Enseñanza Del Modelo Keynesiano Para Estudiantes De \\ Pregrado Una Aproximación Diagramática}

\section{Asignatura Macroeconomía II}

\section{TEST N. 1}

Nombre de estudiante: Nimia Pretel Meneses

Universidad: Fundación Universitaria Monserrate

Programa: Finanzas y negocios Internacionales

Semestre: 9

Fecha: 21/11/2016

A continuación se presentan diez preguntas tipo Saber Pro a las cuales usted les dará solución utilizando el modelo keynesiano de economía cerrada, evidenciando el movimiento de las variables económicas, para lo cual usted tendrá un rol.

1. ¿Señor gerente general, como se ve afectada su empresa cuando el banco de la república decide aumentar la tasa de interés de política monetaria?

Al subir las tasas de interés, aumenta la inversión, aumentan los ingresos, lo que hace que aumente el ingreso disponible a su vez origina un aumento del presupuesto esto origina un aumento en la masa monetaria, luego aumenta la cantidad real de dinero, lo que hizo que aumentara el dinero especulativo y el dinero de transacción todo esto origino una expansión monetaria. 
Modelo con movimiento de las variables afectadas.

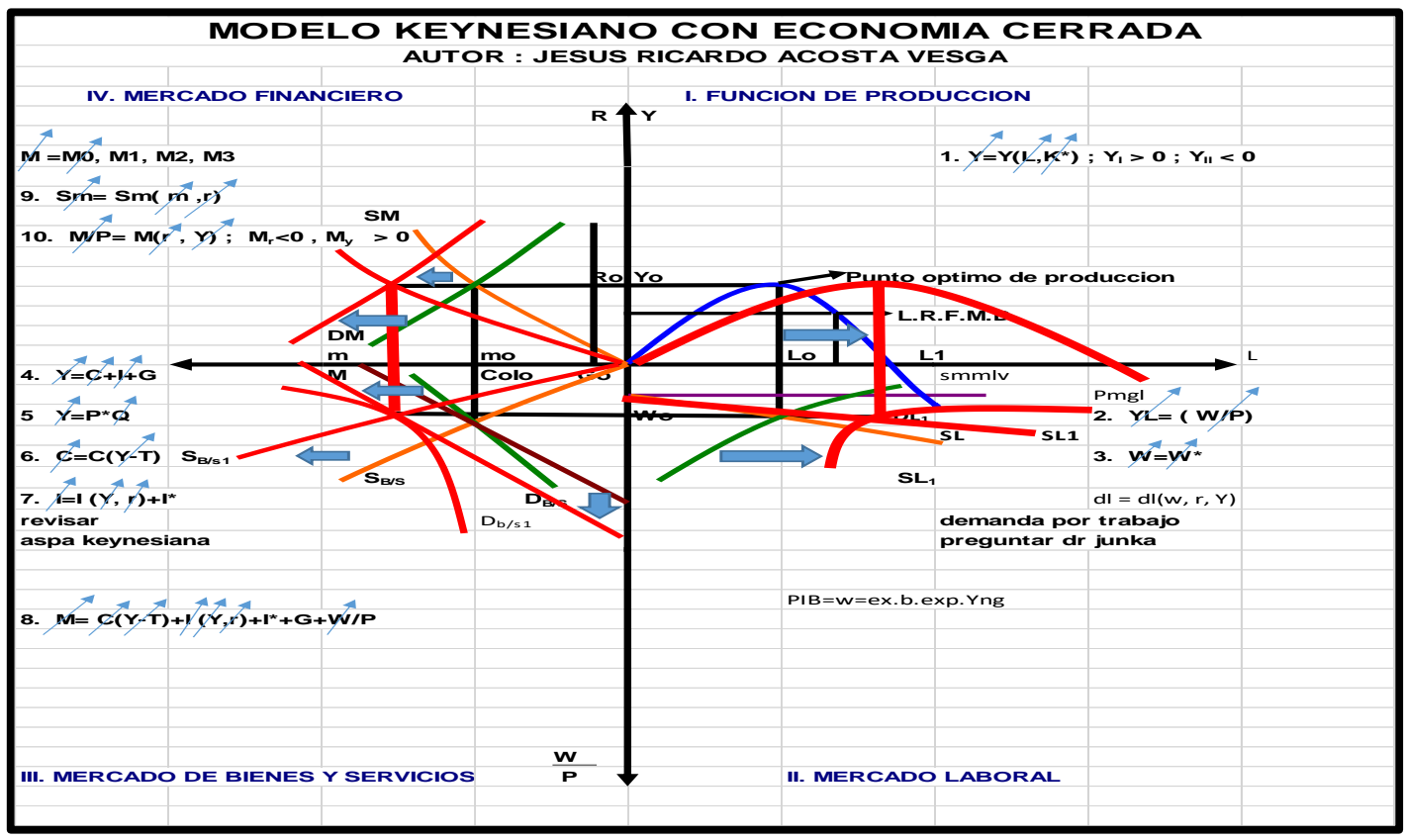

Anexo. Ilustración No. 50. Movimiento de las variables afectadas.

La solución como se observa en el grafico las flechas indican el movimiento de las variables hacia arriba mostrando que aumentaron y crearon una expansión monetaria, como gerente la solución es aumentar la capacidad instalada de la empresa teniendo en cuenta que hay más capital y eso ubica la economía en equilibrio.

2. ¿Señor gerente financiero, como se ve afectada su empresa cuando el banco de la república decide aumentar el encaje bancario?

$\mathrm{Al}$ aumentar el encaje bancario, se reduce el la oferta monetaria, disminuyendo el crédito, lo que hace y se reduce la demanda del dinero especulativo y de transacción, y esto origina una caída en el presupuesto y hace bajar los ingresos de la empresa originando una contracción monetaria, la producción y el número de empleados no se ve afectada en el corto plazo, ni los salarios nominales y por 
supuesto tampoco se afecta el salario real.

Modelo con movimiento de las variables afectadas

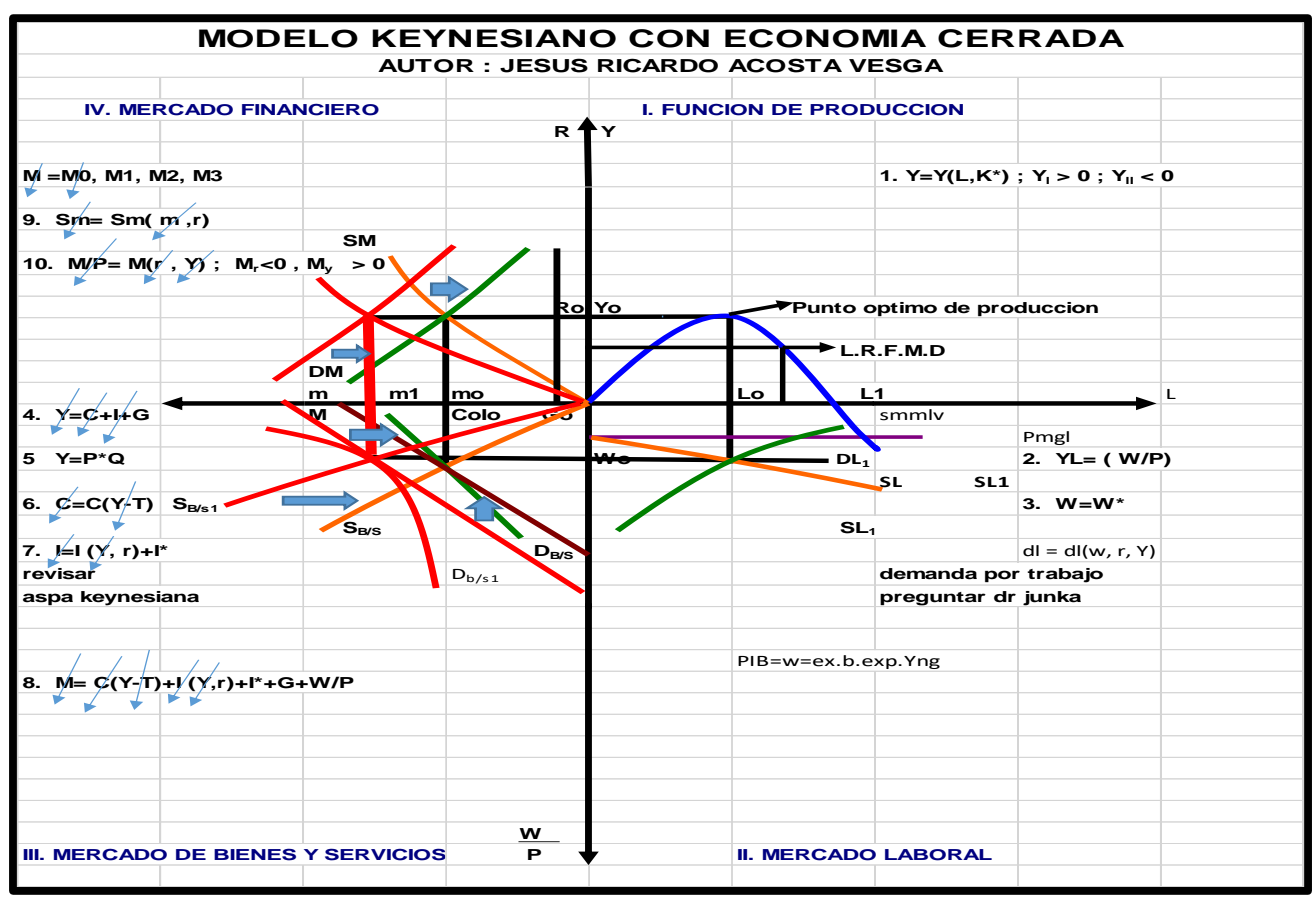

Anexo. Ilustración No. 51. Movimiento de las variables afectadas.

La solución para colocar el modelo en equilibrio es aumentando el gasto para reactivar la economía, con este aumento se produce un aumento en los ingresos y esto reactiva el consumo, la inversión, el presupuesto y a la vez aumentaría la masa monetaria incentivando de nuevo el crédito y así volveríamos al equilibrio.

3. ¿Señor gerente financiero, como se ve afectada su empresa cuando el banco de la república decide aumentar la emisión de dinero?

Al aumentar la emisión primaria de dinero por parte de Banco de la república, va a existir mayor cantidad de dinero en la economía, lo que ocasiona que se incremente la oferta monetaria y esto hace que aumente el consumo de los hogares, la inversión y el gasto y esto hace a la vez que se aumente el ingreso y se reactive la economía. Y la economía puede llegar a presentar un sobre calentamiento 
financiero.

Modelo con movimiento de las variables afectadas

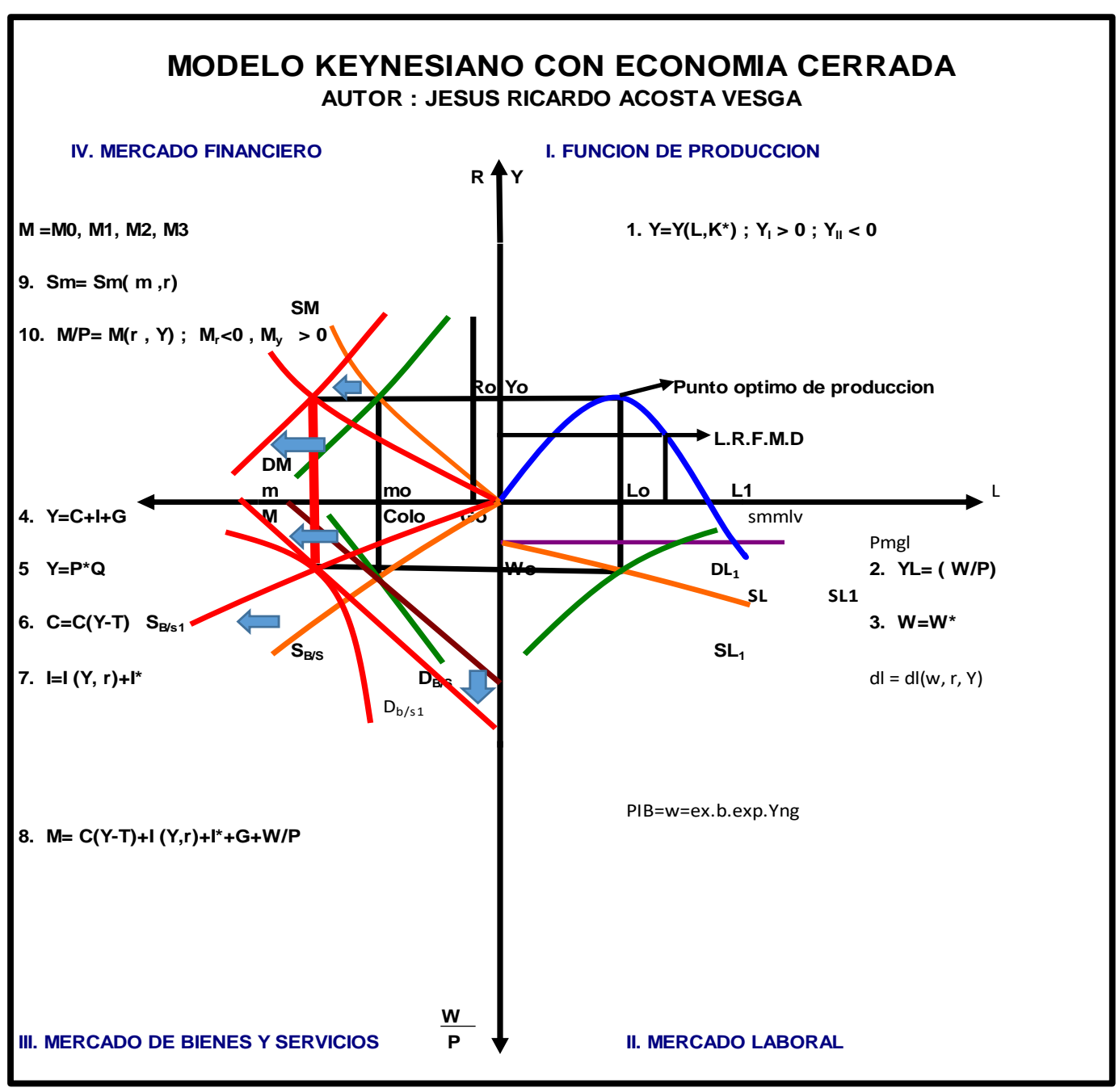

Anexo. Ilustración No. 52. Movimiento de las variables afectadas.

La Solución: Se debe invertir en la planta de producción para aumentar la capacidad productiva, aumentando la producción el número de empleados y así volver al punto de equilibrio inicial.

4. ¿Señor gerente de producción, que pasa cuando el gobierno decide aumentar los instrumentos de política fiscal, como se afectan las variables del modelo?

La solución: Si se incrementan tanto en gasto como los impuestos en el mismo 
porcentaje, el uno reduce el poder adquisitivo, como son los impuestos y al aumentar el gasto se mejora el poder adquisitivo y se reactiva la economía devolviendo todo al punto de equilibrio. Lo que indica que el modelo no se vea afectado.

5. Utilizando el diagrama del modelo Keynesiano cerrado con todas las ecuaciones, analice que pasa cuando disminuye la oferta monetaria.

Si disminuye la oferta monetaria, hace que se suban las tasas de interés, lo que hace que se reduzca la inversión por el costo de los intereses, lo mismo pasa con el consumó, el ingreso se reduce y el gasto también, esto puede producir que se baje la producción y exista una contracción en la economía.

Modelo con movimiento de las variables afectadas

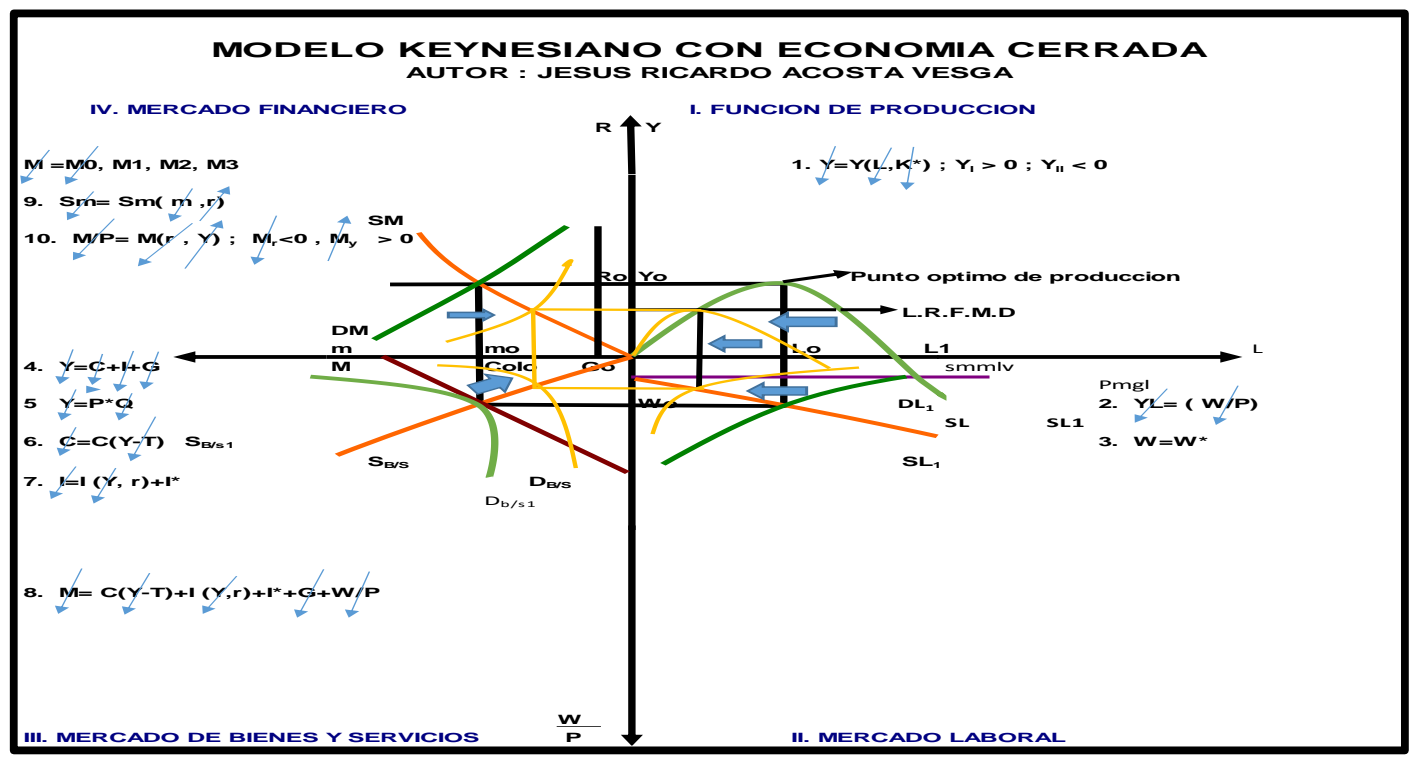

Anexo. Ilustración No. 53. Movimiento de las variables afectadas.

La Solución: Para este caso hay varias respuestas entre ellas una es incrementar el gasto público para reactivar la economía y así volver al punto de equilibrio, otra solución sería que el Banco de la Republica, aumentara las emisiones de dinero y 
así reactivar la economía y volver al punto de equilibrio.

6. Utilizando el diagrama del modelo Keynesiano cerrado con todas las ecuaciones, analice que pasa cuando aumenta el gasto público.

Cuando aumenta el gasto público se reactiva la economía y esto hace que exista una expansión monetaria y hace que la economía crezca.

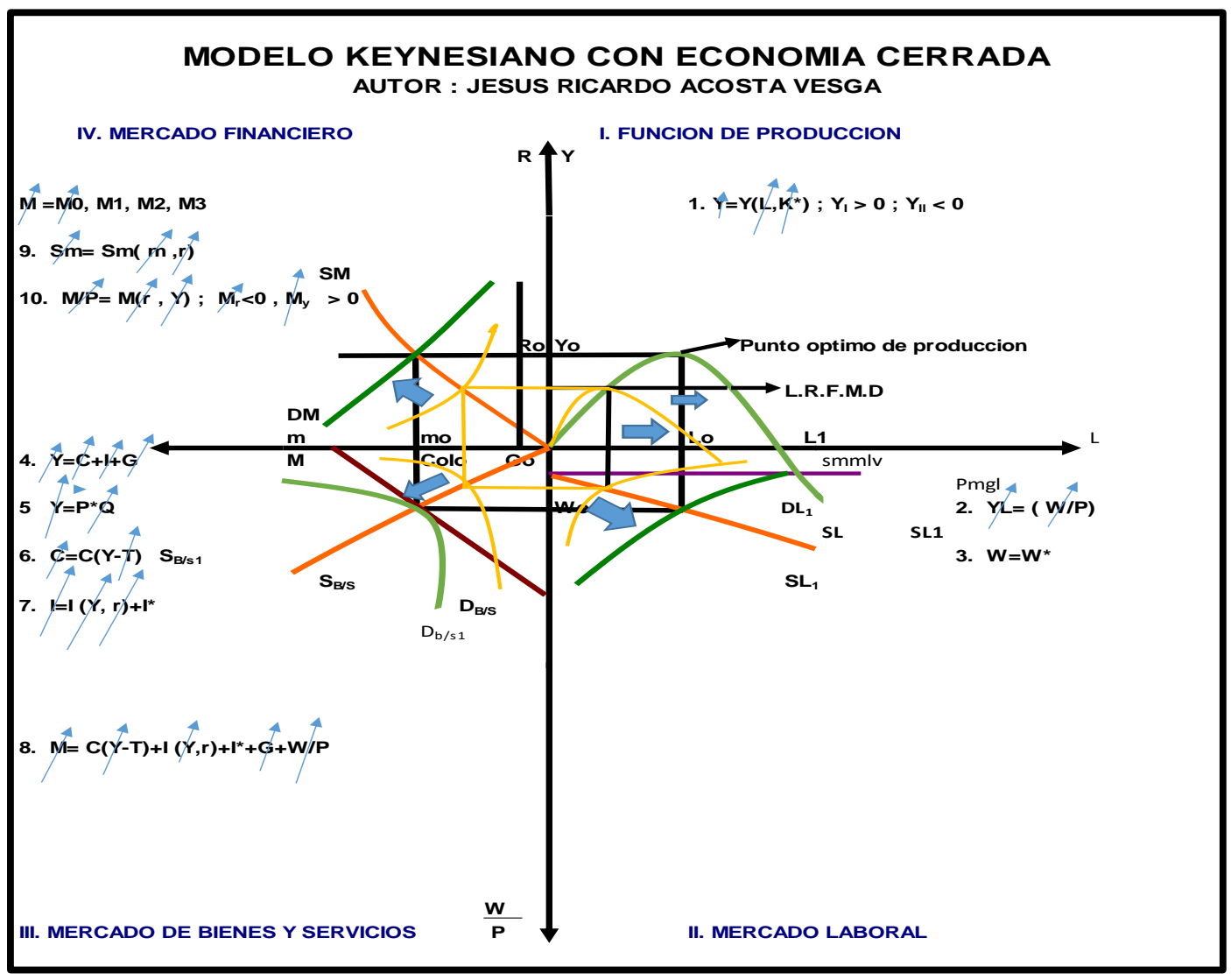

Anexo. Ilustración No. 54. Movimiento de las variables afectadas.

7. Utilizando el diagrama del modelo Keynesiano Cerrado con todas las ecuaciones, analice que pasa cuando aumenta el consumo de los hogares.

Cuando aumenta el consumo indica que aumentaron los ingresos lo que hace que se incrementé la inversión y se haga una expansión monetaria en la economía. 
Modelo con movimiento de las variables afectadas

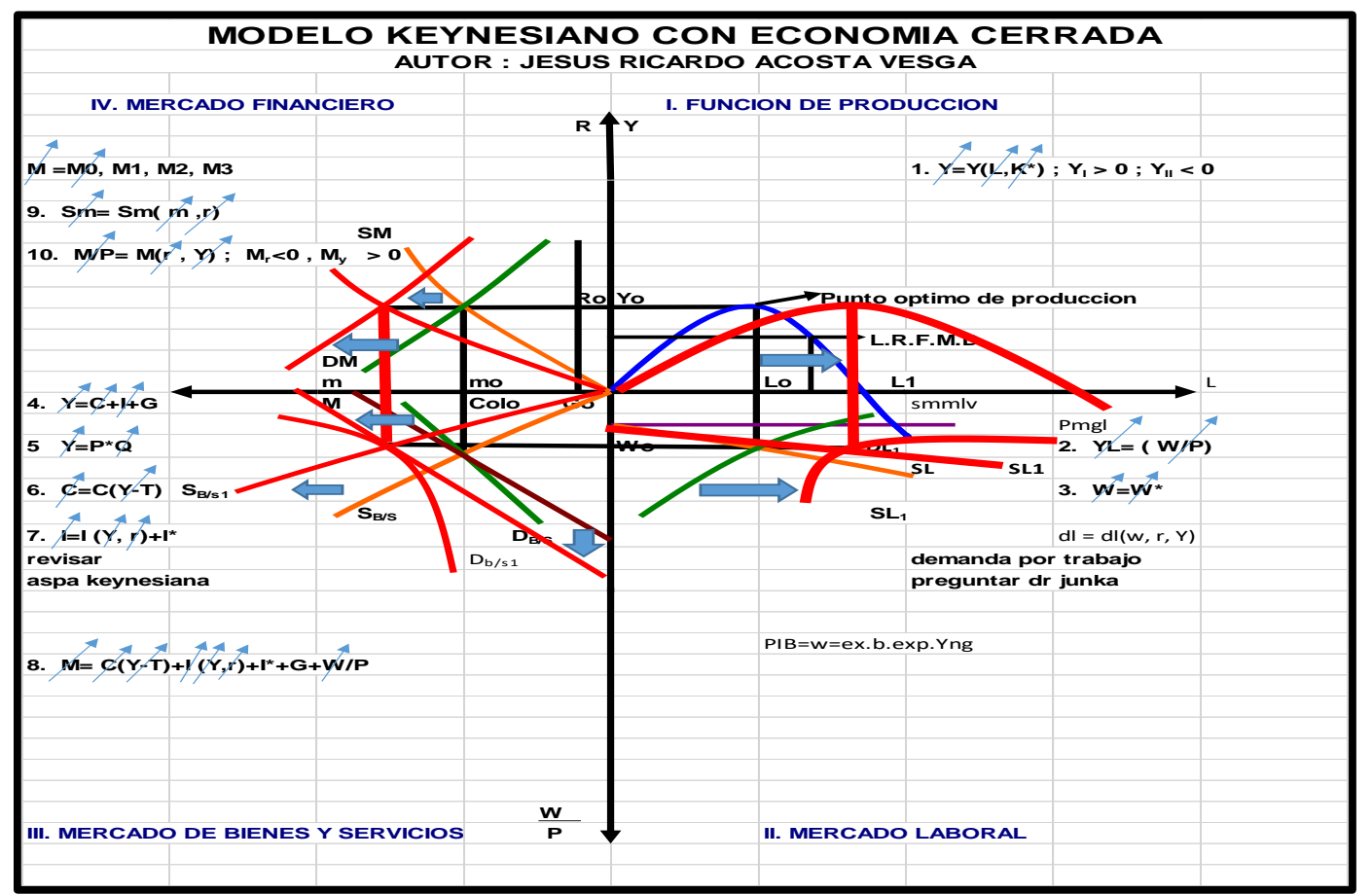

Anexo. Ilustración No. 55. Movimiento de las variables afectadas.

La solución: Para volver 1 punto de equilibrio debemos aumentar los impuestos y con esto reducimos la liquidez qué existe en la economía y así volvemos al punto de equilibrio la economía.

8. Utilizando el diagrama del modelo Keynesiano cerrado con todas las ecuaciones, analice que pasa cuando aumenta la inversión.

Si hay un aumento en la inversión es divido a que se incrementaron los ingresos y esto nos lleva a una expansión monetaria. 
Modelo con movimiento de las variables afectadas

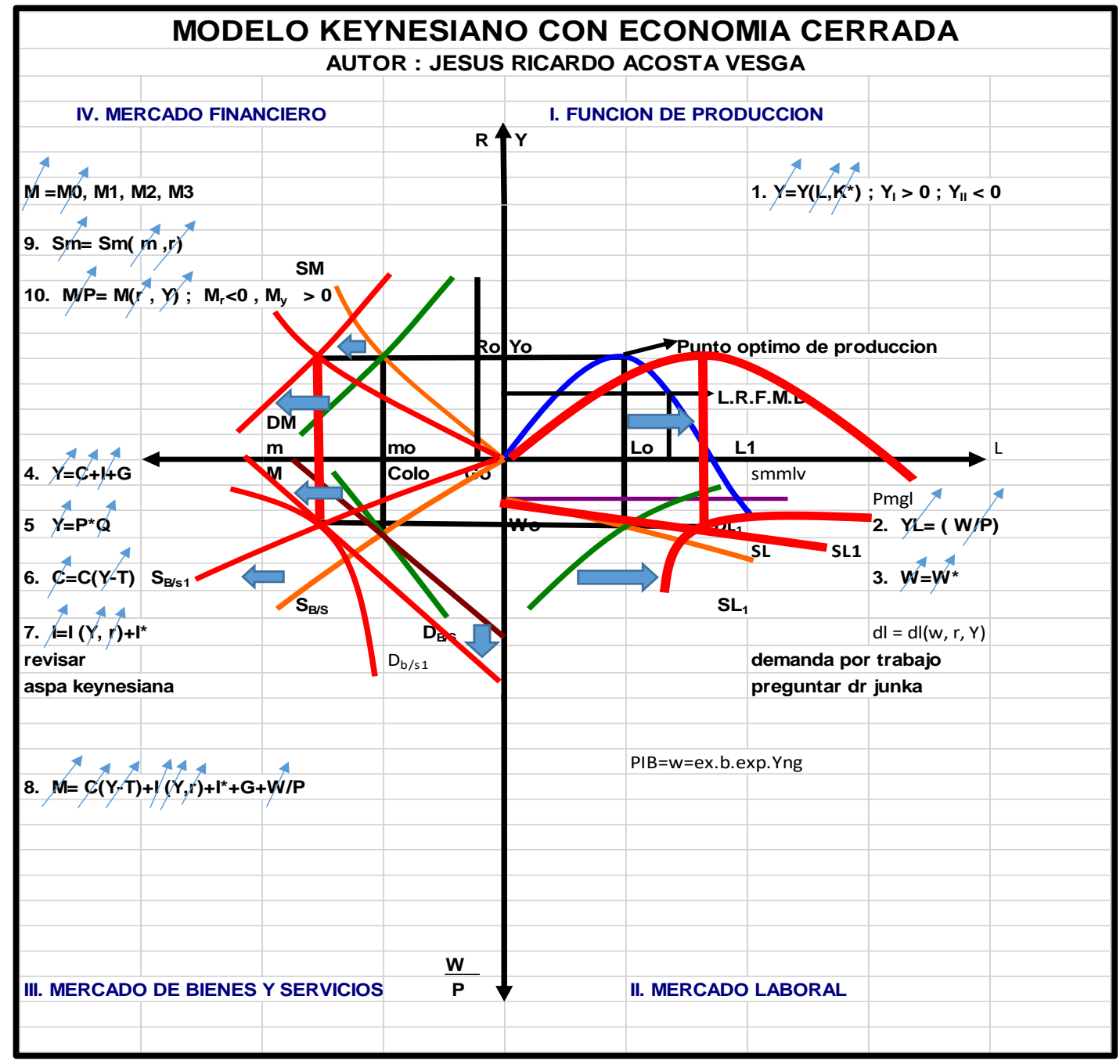

Anexo. Ilustración No. 56. Movimiento de las variables afectadas.

La solución: Para volver 1 punto de equilibrio debemos aumentar los impuestos y con esto reducimos la liquidez qué existe en la economía y así volvemos al punto de equilibrio la economía.

9. Utilizando el diagrama del modelo Keynesiano cerrado con todas las ecuaciones y analice que pasa cuando disminuye la tasa de interés.

Si disminuye la tasa de interés esto ocasiona que la gente demande más dinero porque el costo del dinero es más barato y esto reactiva la economía y origina una 
expansión monetaria.

Modelo con movimiento de las variables afectadas

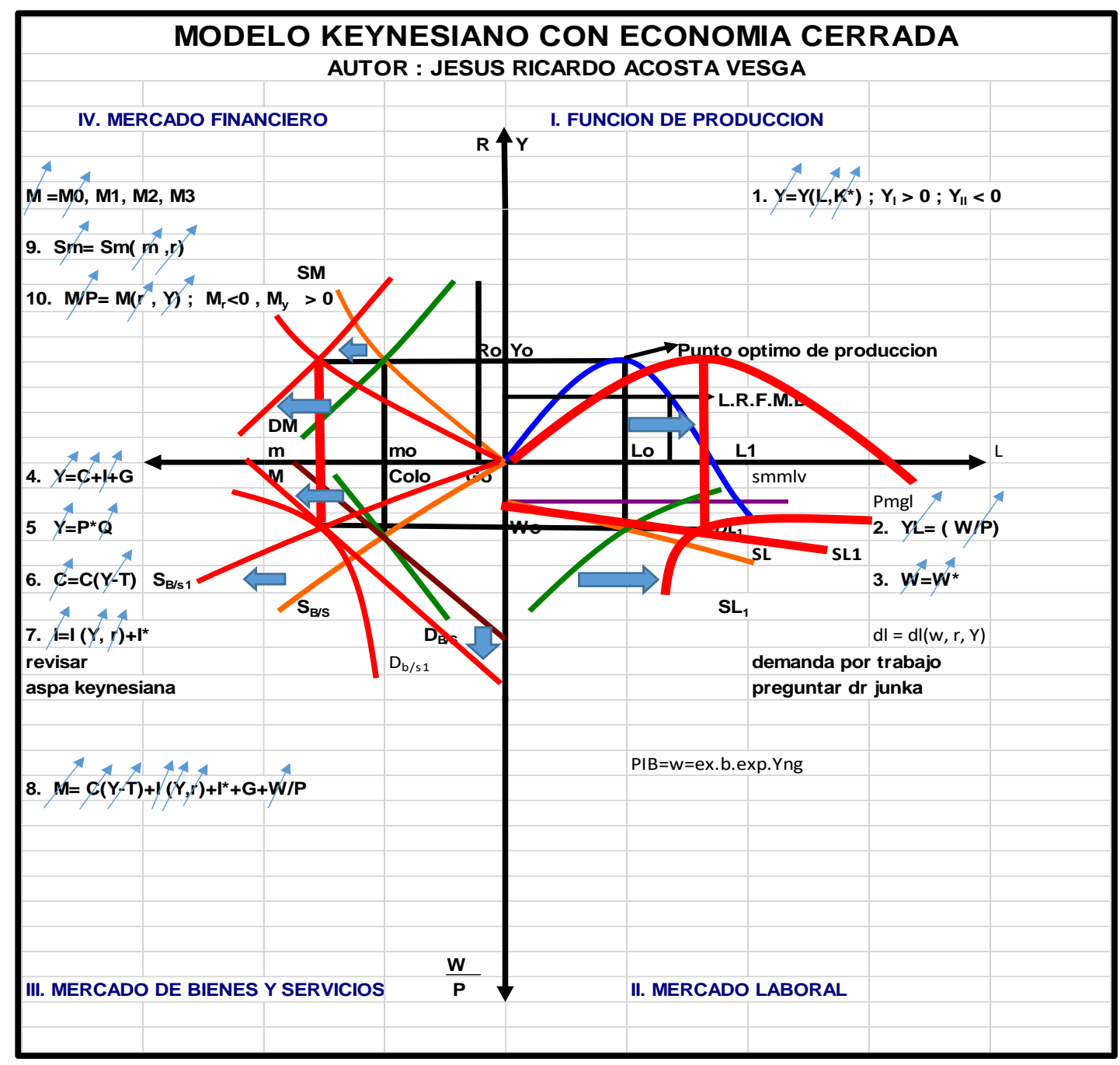

Anexo. Ilustración No. 57. Movimiento de las variables afectadas.

La solución: Para volver al punto de equilibrio debemos aumentar los impuestos y con esto reducimos la liquidez qué existe en la economía y así volvemos al punto de equilibrio la economía.

10. ¿Usted cree que el diagrama del modelo le da las herramientas necesarias para conocer de una forma más sencilla la comprensión de la economía?

Si nos da las herramientas necesarias para comprender la economía de forma 
sencilla y a la vez práctica.

\section{Enseñanza Del Modelo Keynesiano Para Estudiantes De Pregrado Una Aproximación Diagramática}

\section{Asignatura Macroeconomía II}

TEST N. 1

\section{Nombre de estudiante: Leydi Marcela Cortes Alvis}

\section{Universidad: Monserrate}

\section{Programa: Finanzas y Negocios Internacionales Semestre: 8}

\section{Fecha: D. 21 M. Noviembre A. 2016.}

A continuación se presentan diez preguntas tipo Saber Pro a las cuales usted les dará solución utilizando el modelo keynesiano de economía cerrada, evidenciando el movimiento de las variables económicas, para lo cual usted tendrá un rol.

1. ¿Señor gerente general, como se ve afectada su empresa cuando el banco de la república decide aumentar la tasa de interés de política monetaria?

Al subir las tasas de interés, aumenta la inversión, aumentan los ingresos, lo que hace que aumente el ingreso disponible a su vez origina un aumento del presupuesto esto origina un aumento en la masa monetaria, luego aumenta la cantidad real de dinero, lo que hizo que aumentara el dinero especulativo y el dinero de transacción todo esto origino una expansión monetaria.

Modelo con movimiento de las variables afectadas. 


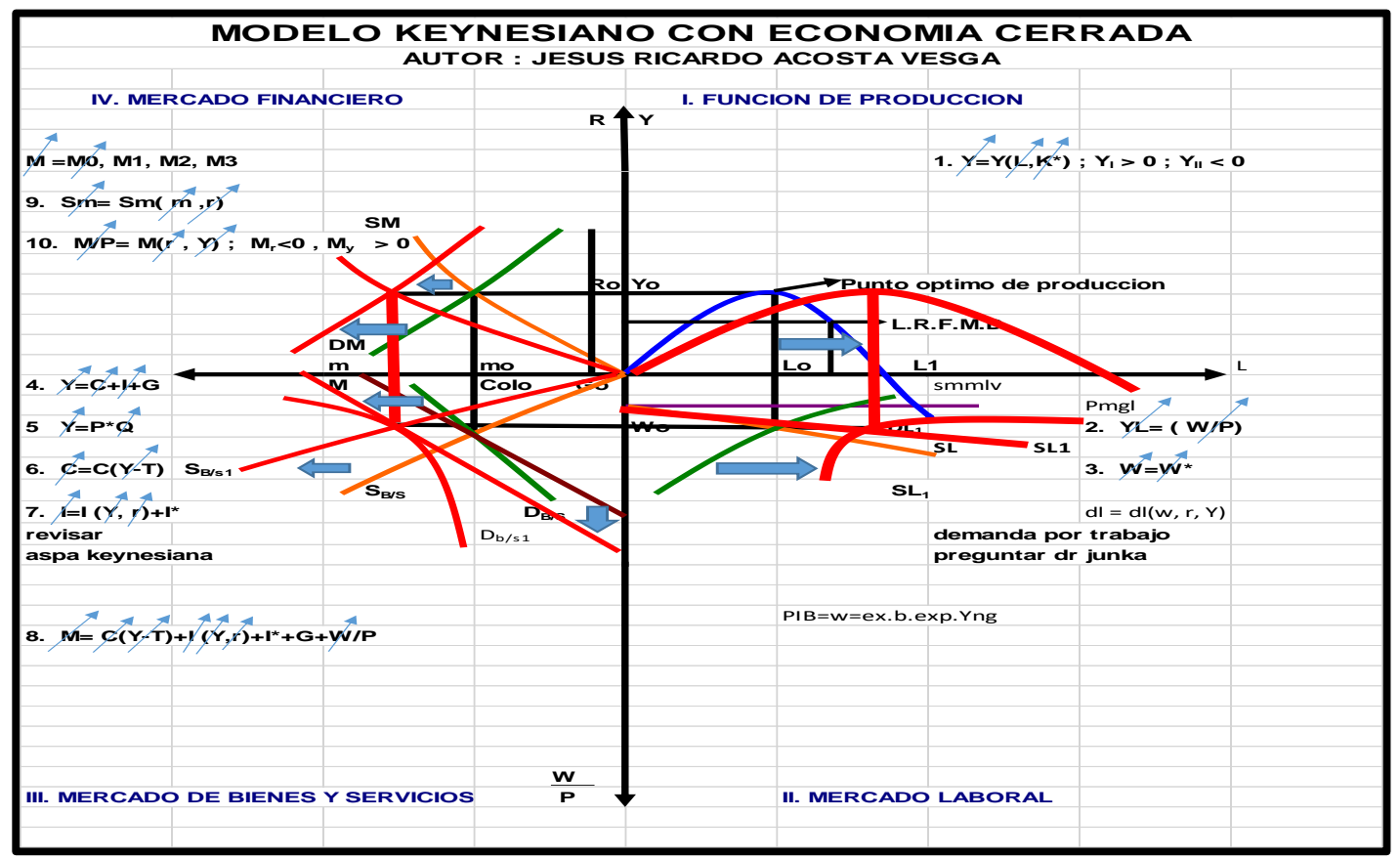

Anexo. Ilustración No. 58. Movimiento de las variables afectadas.

\section{Ilustración N.6. Producción Del Autor}

La solución como se observa en el grafico las flechas indican el movimiento de las variables hacia arriba mostrando que aumentaron y crearon una expansión monetaria, como gerente la solución es aumentar la capacidad instalada de la empresa teniendo en cuenta que hay más capital y eso ubica la economía en equilibrio.

2. ¿Señor gerente financiero, como se ve afectada su empresa cuando el banco de la república decide aumentar el encaje bancario?

Al aumentar el encaje bancario, se reduce el la oferta monetaria, disminuyendo el crédito, lo que hace y se reduce la demanda del dinero especulativo y de transacción, y esto origina una caída en el presupuesto y hace bajar los ingresos de la empresa originando una contracción monetaria, la producción y el número de empleados no se ve afectada en el corto plazo, ni los salarios nominales y por supuesto tampoco se afecta el salario real. 


\section{Modelo con movimiento de las variables afectadas}

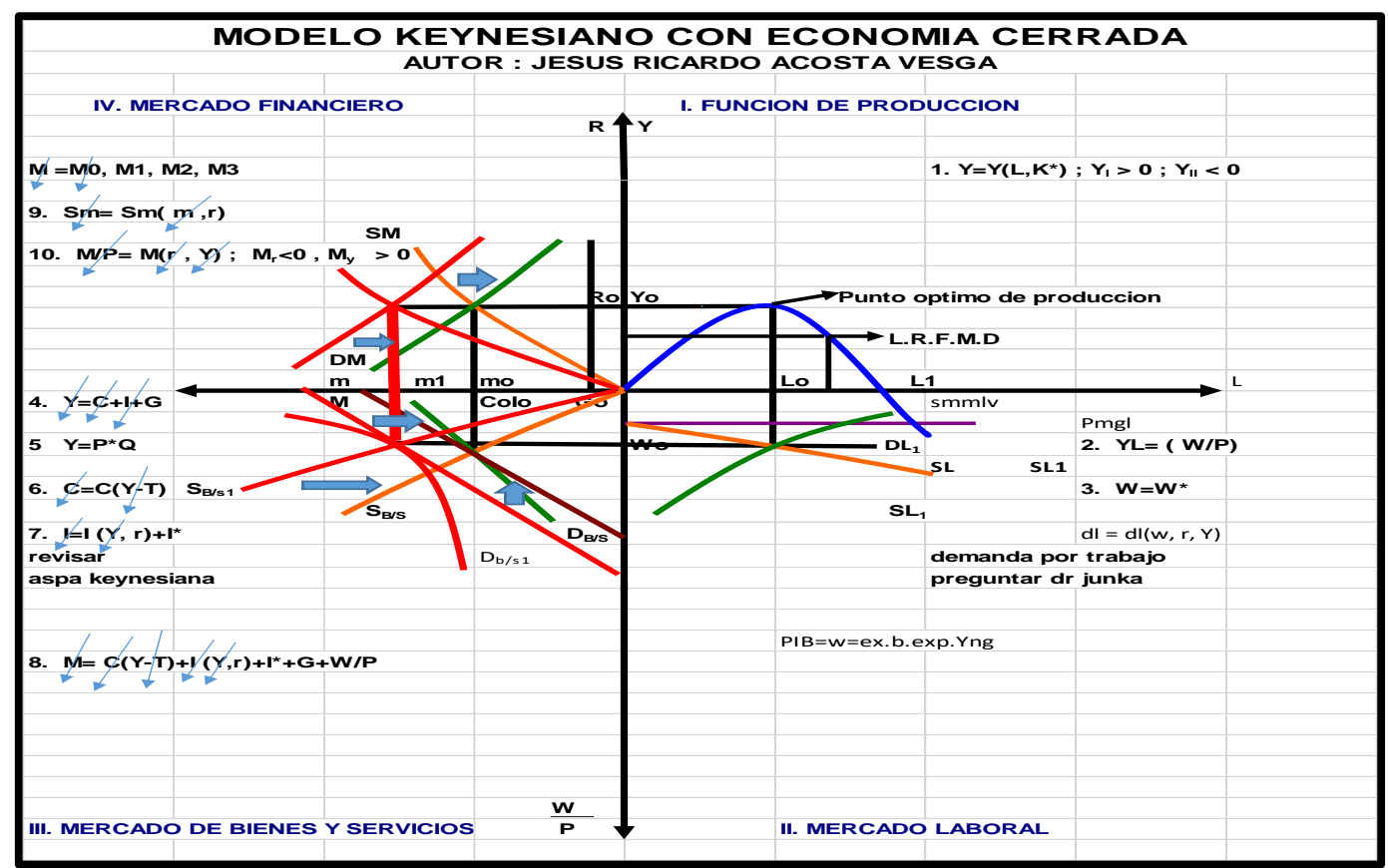

Anexo. Ilustración No. 59. Movimiento de las variables afectadas.

La solución para colocar el modelo en equilibrio es aumentando el gasto para reactivar la economía, con este aumento se produce un aumento en los ingresos y esto reactiva el consumo, la inversión, el presupuesto y a la vez aumentaría la masa monetaria incentivando de nuevo el crédito y así volveríamos al equilibrio.

3. ¿Señor gerente financiero, como se ve afectada su empresa cuando el banco de la república decide aumentar la emisión de dinero?

Al aumentar la emisión primaria de dinero por parte de Banco de la república, va a existir mayor cantidad de dinero en la economía, lo que ocasiona que se incremente la oferta monetaria y esto hace que aumente el consumo de los hogares, la inversión y el gasto y esto hace a la vez que se aumente el ingreso y se reactive la economía. Y la economía puede llegar a presentar un sobre calentamiento financiero. 
Modelo con movimiento de las variables afectadas

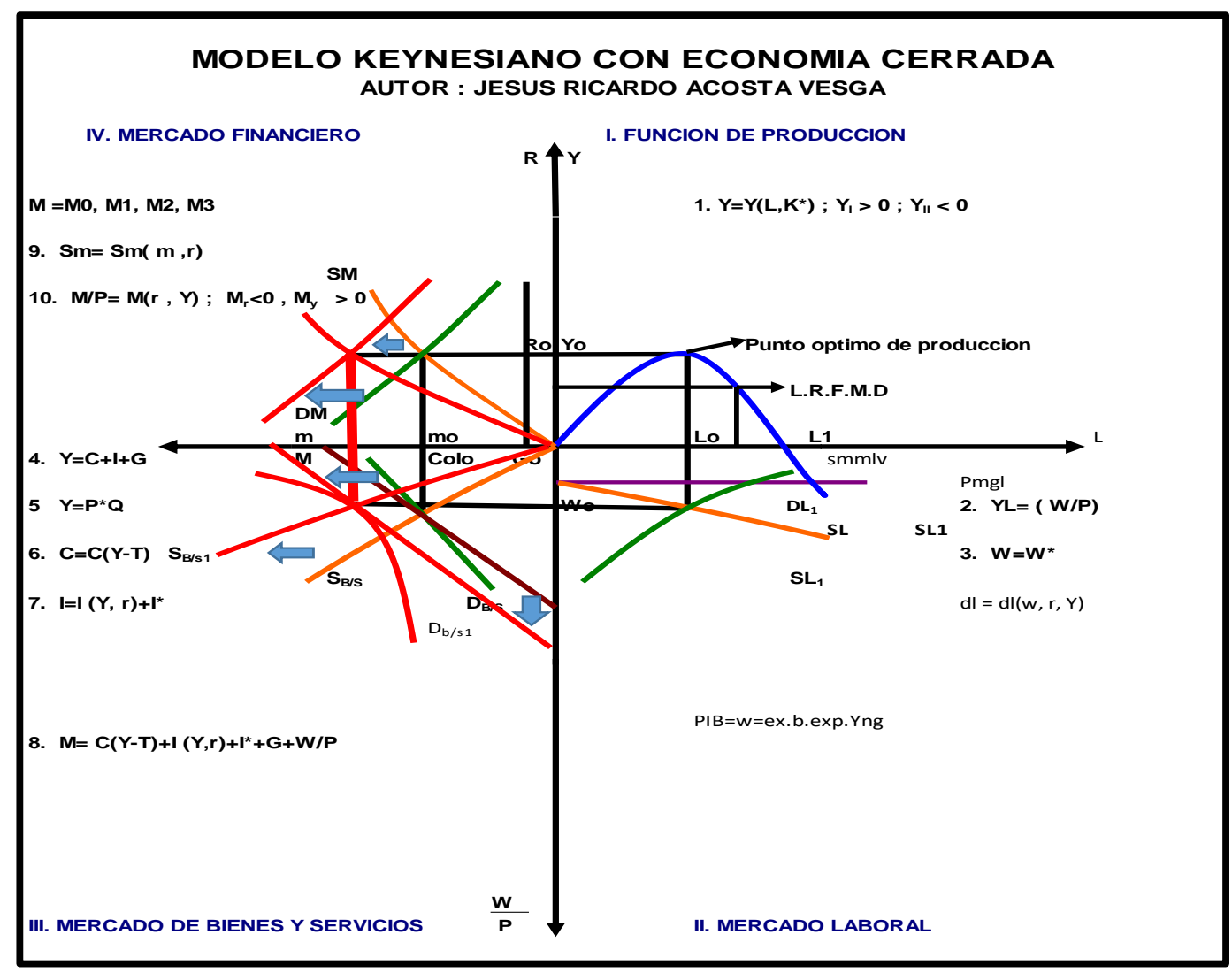

Anexo. Ilustración No. 60. Movimiento de las variables afectadas.

La Solución: Se debe invertir en la planta de producción para aumentar la capacidad productiva, aumentando la producción el número de empleados y así volver al punto de equilibrio inicial.

4. ¿Señor gerente de producción, que pasa cuando el gobierno decide aumentar los instrumentos de política fiscal, como se afectan las variables del modelo?

La solución: Si se incrementan tanto en gasto como los impuestos en el mismo porcentaje, el uno reduce el poder adquisitivo, como son los impuestos y al aumentar el gasto se mejora el poder adquisitivo y se reactiva la economía devolviendo todo al punto de equilibrio. Lo que indica que el modelo no se vea afectado. 
5. Utilizando el diagrama del modelo Keynesiano cerrado con todas las ecuaciones, analice que pasa cuando disminuye la oferta monetaria.

Si disminuye la oferta monetaria, hace que se suban las tasas de interés, lo que hace que se reduzca la inversión por el costo de los intereses, lo mismo pasa con el consumó, el ingreso se reduce y el gasto también, esto puede producir que se baje la producción y exista una contracción en la economía.

\section{Modelo con movimiento de las variables afectadas}

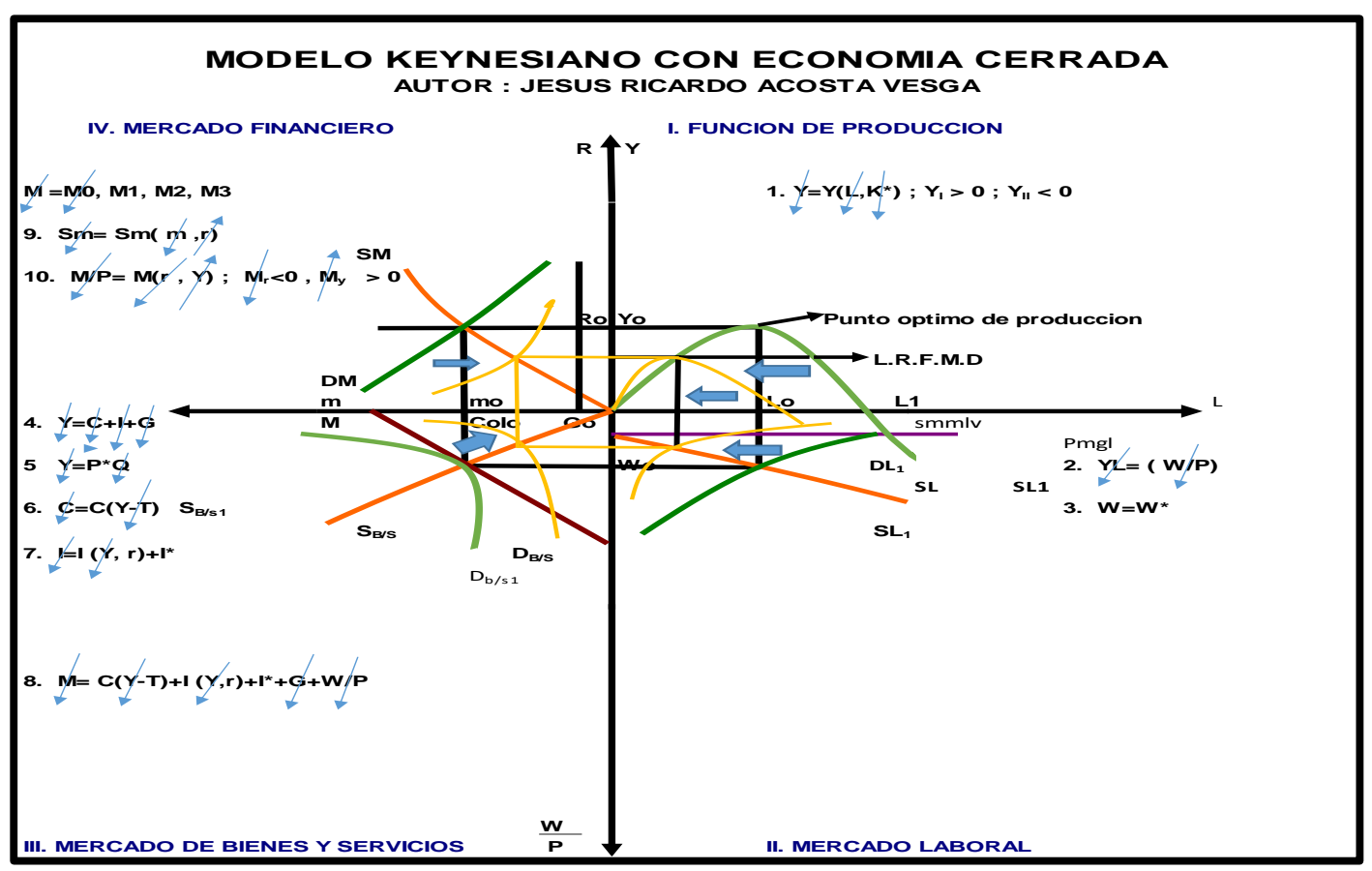

Anexo. Ilustración No. 61. Movimiento de las variables afectadas.

La Solución: Para este caso hay varias respuestas entre ellas una es incrementar el gasto público para reactivar la economía y así volver al punto de equilibrio, otra solución sería que el Banco de la Republica, aumentara las emisiones de dinero y así reactivar la economía y volver al punto de equilibrio.

6. Utilizando el diagrama del modelo Keynesiano cerrado con todas las ecuaciones, analice que pasa cuando aumenta el gasto público. 
Cuando aumenta el gasto público se reactiva la economía y esto hace que exista una expansión monetaria y hace que la economía crezca.

\section{Modelo con movimiento de las variables afectadas}

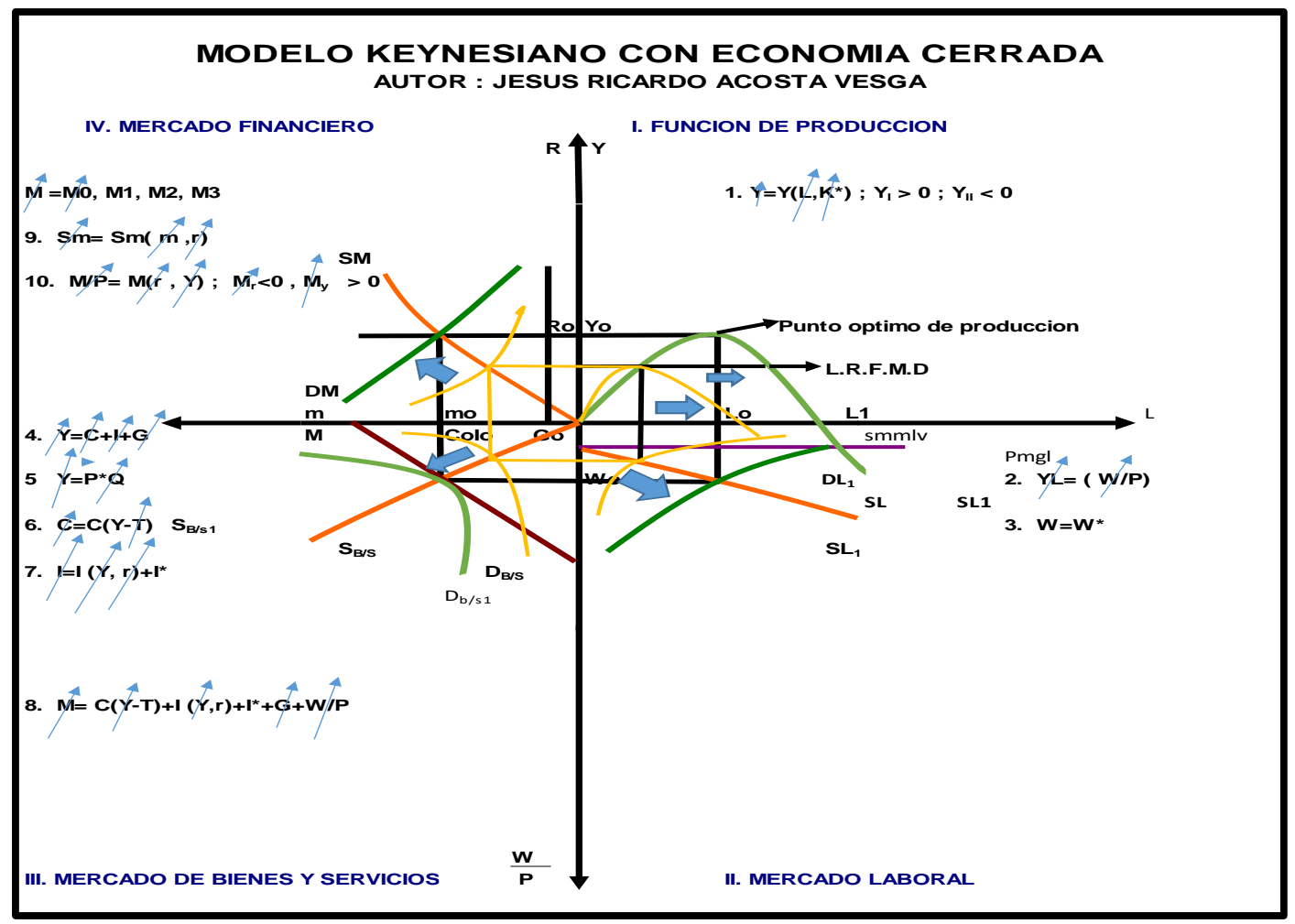

Anexo. Ilustración No. 62. Movimiento de las variables afectadas.

7. Utilizando el diagrama del modelo Keynesiano Cerrado con todas las ecuaciones, analice que pasa cuando aumenta el consumo de los hogares.

Cuando aumenta el consumo indica que aumentaron los ingresos lo que hace que se incrementé la inversión y se haga una expansión monetaria en la economía.

Modelo con movimiento de las variables afectadas 


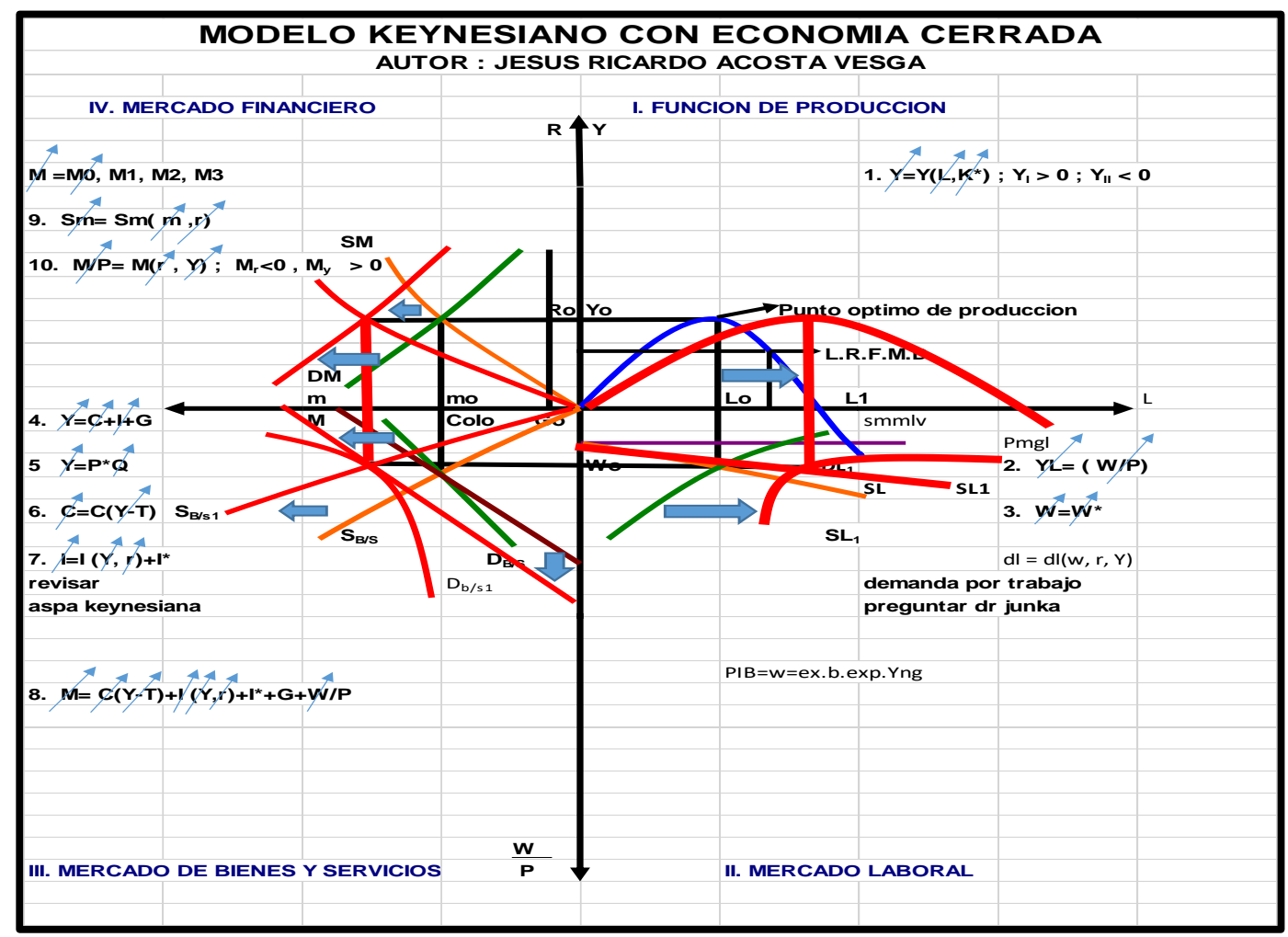

Anexo. Ilustración No. 63. Movimiento de las variables afectadas.

La solución: Para volver 1 punto de equilibrio debemos aumentar los impuestos y con esto reducimos la liquidez qué existe en la economía y así volvemos al punto de equilibrio la economía.

8. Utilizando el diagrama del modelo Keynesiano cerrado con todas las ecuaciones, analice que pasa cuando aumenta la inversión.

Si hay un aumento en la inversión es divido a que se incrementaron los ingresos y esto nos lleva a una expansión monetaria.

Modelo con movimiento de las variables afectadas 


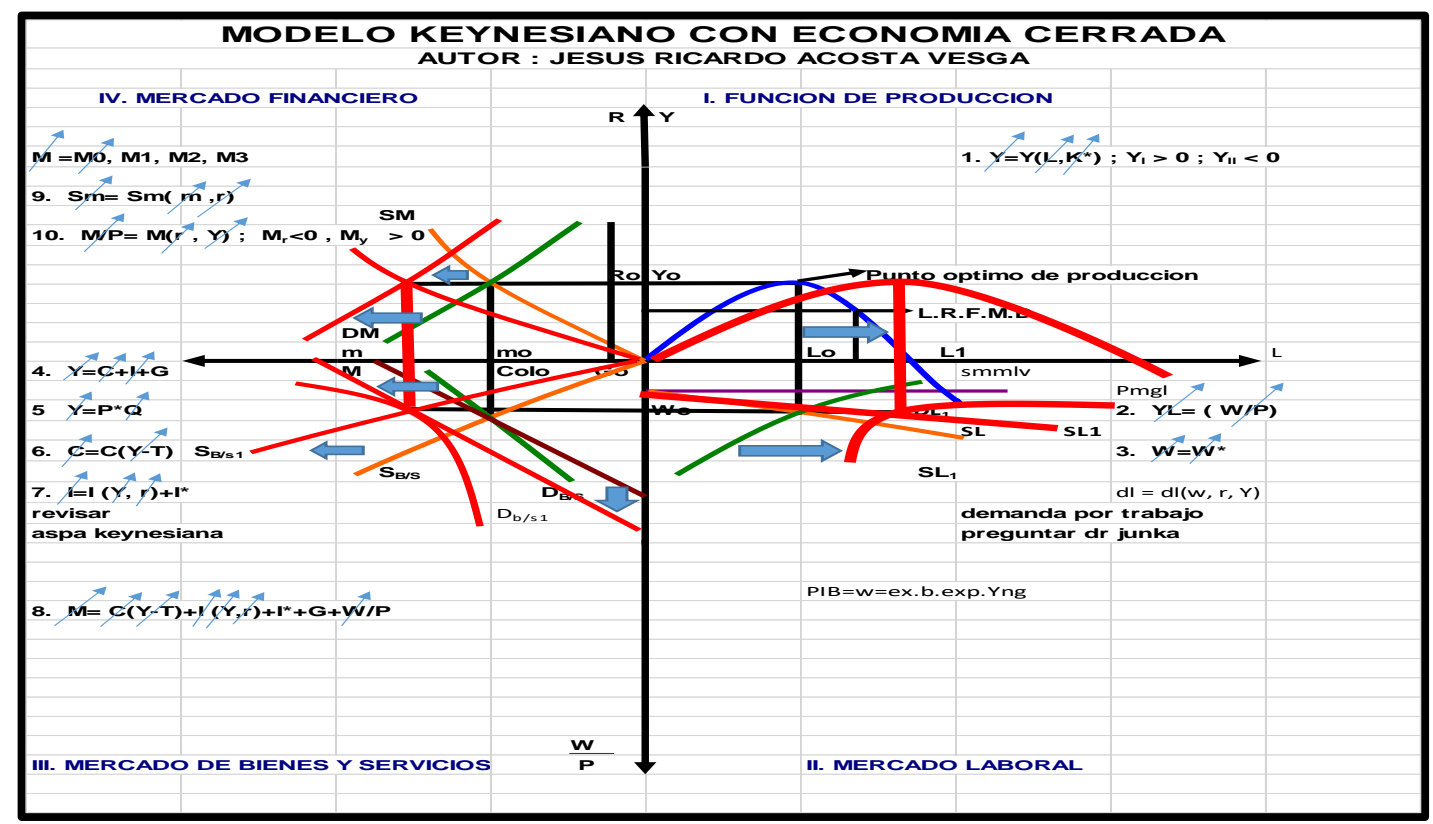

Anexo. Ilustración No. 64. Movimiento de las variables afectadas.

La solución: Para volver 1 punto de equilibrio debemos aumentar los impuestos y con esto reducimos la liquidez qué existe en la economía y así volvemos al punto de equilibrio la economía.

9. Utilizando el diagrama del modelo Keynesiano cerrado con todas las ecuaciones y analice que pasa cuando disminuye la tasa de interés.

Si disminuye la tasa de interés esto ocasiona que la gente demande más dinero porque el costo del dinero es más barato y esto reactiva la economía y origina una expansión monetaria.

Modelo con movimiento de las variables afectadas 


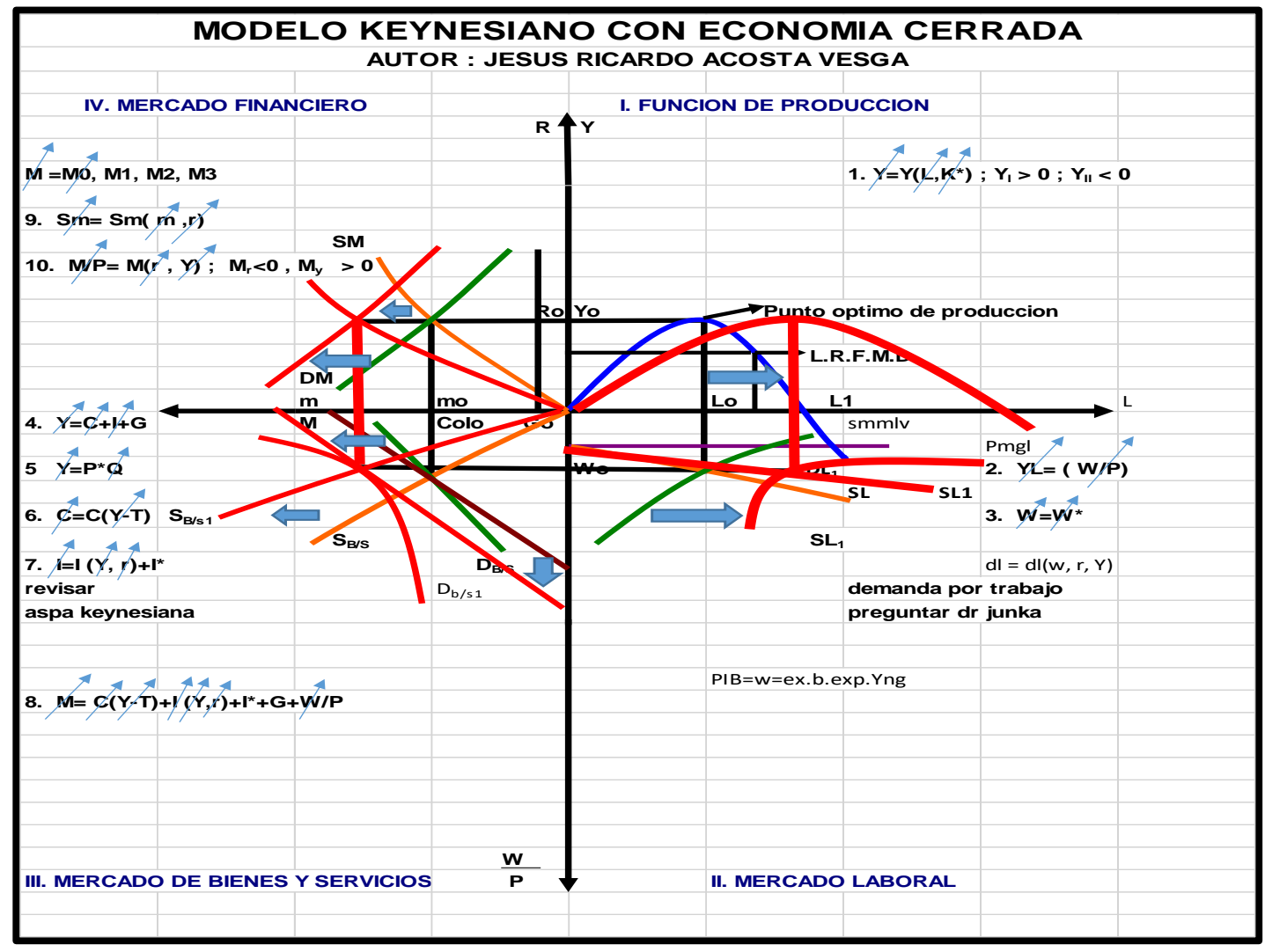

Anexo. Ilustración No. 65. Movimiento de las variables afectadas.

La solución: Para volver al punto de equilibrio debemos aumentar los impuestos y con esto reducimos la liquidez qué existe en la economía y así volvemos al punto de equilibrio la economía.

10. ¿Usted cree que el diagrama del modelo le da las herramientas necesarias para conocer de una forma más sencilla la comprensión de la economía?

Creo que el modelo es una herramienta bastante sólida y concisa donde de una u otra manera podemos entender los modelos básicos de la economía y como puede ser el desplazamiento de sus curvas si alguna de las variables que influyen en la economía llegan a variar y como estas pueden afectarnos directa e indirectamente desde la posición de empresa o simplemente como personas naturales cualquier variable afecta a la sociedad, estado, el mercado etc. Gracias al modelo puedo entender de una manera más 
simplificada y a través de modelos ya que es imposible analizar la realidad del mercado.

\section{Enseñanza del Modelo Keynesiano Para Estudiantes De \\ Pregrado Una Aproximación Diagramática}

Asignatura Macroeconomía II

TEST N. 1

Nombre de estudiante: Juan Sebastián Montañez Ballesteros

Universidad: Unimonserrate

Programa: Finanzas y negocios Internacionales

Semestre: VIII

Fecha: 20 de Noviembre de 2016

A continuación se presentan diez preguntas tipo Saber Pro a las cuales usted les dará solución utilizando el modelo keynesiano de economía cerrada, evidenciando el movimiento de las variables económicas, para lo cual usted tendrá un rol.

1. ¿Señor gerente general, como se ve afectada su empresa cuando el banco de la república decide aumentar la tasa de interés de política monetaria?

2. ¿Señor gerente financiero, como se ve afectada su empresa cuando el banco de la república decide aumentar el encaje bancario?

3. ¿Señor gerente financiero, como se ve afectada su empresa cuando el banco de la república decide aumentar la emisión de dinero?

4. ¿Señor gerente de producción, que pasa cuando el gobierno decide aumentar los instrumentos de política fiscal, como se afectan las variables del modelo?

5. Utilizando el diagrama del modelo Keynesiano cerrado con todas las ecuaciones, analice que pasa cuando disminuye la oferta monetaria. 
6. Utilizando el diagrama del modelo Keynesiano cerrado con todas las ecuaciones, analice que pasa cuando aumenta el gasto público.

7. Utilizando el diagrama del modelo Keynesiano Cerrado con todas las ecuaciones, analice que pasa cuando aumenta el consumo de los hogares.

8. Utilizando el diagrama del modelo Keynesiano cerrado con todas las ecuaciones, analice que pasa cuando aumenta la inversión.

9. Utilizando el diagrama del modelo Keynesiano cerrado con todas las ecuaciones y analice que pasa cuando disminuye la tasa de interés.

10. ¿Usted cree que el diagrama del modelo le da las herramientas necesarias para conocer de una forma más sencilla la comprensión de la economía

\section{Solución:}

1. ¿Señor gerente general, como se ve afectada su empresa cuando el banco de la república decide aumentar la tasa de interés de política monetaria?

Al subir las tasas de interés, aumenta la inversión, aumentan los ingresos, lo que hace que aumente el ingreso disponible a su vez origina un aumento del presupuesto esto origina un aumento en la masa monetaria, luego aumenta la cantidad real de dinero, lo que hizo que aumentara el dinero especulativo y el dinero de transacción todo esto origino una expansión monetaria.

Modelo con movimiento de las variables afectadas. 


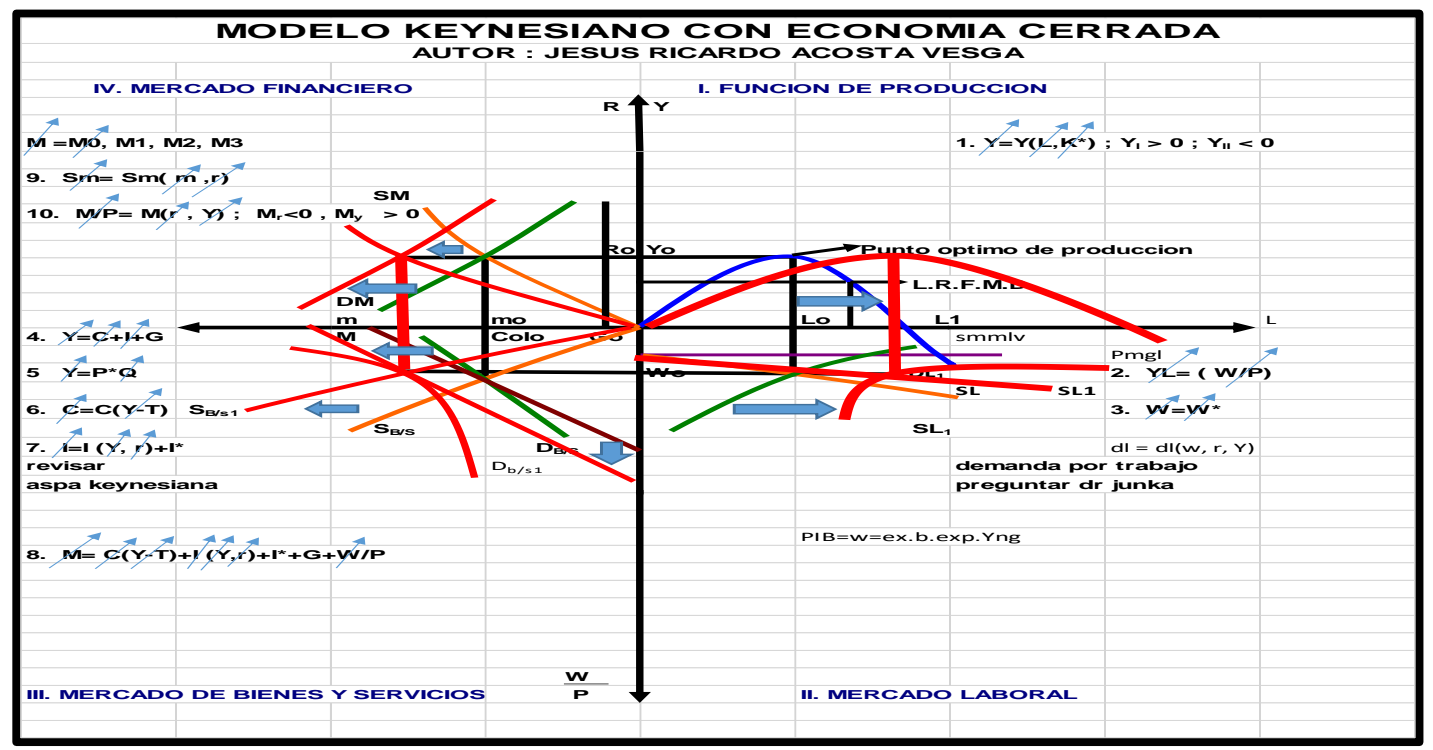

Anexo. Ilustración No. 66. Movimiento de las variables afectadas.

La solución como se observa en el grafico las flechas indican el movimiento de las variables hacia arriba mostrando que aumentaron y crearon una expansión monetaria, como gerente la solución es aumentar la capacidad instalada de la empresa teniendo en cuenta que hay más capital y eso ubica la economía en equilibrio.

2. ¿Señor gerente financiero, como se ve afectada su empresa cuando el banco de la república decide aumentar el encaje bancario?

$\mathrm{Al}$ aumentar el encaje bancario, se reduce el la oferta monetaria, disminuyendo el crédito, lo que hace y se reduce la demanda del dinero especulativo y de transacción, y esto origina una caída en el presupuesto y hace bajar los ingresos de la empresa originando una contracción monetaria, la producción y el número de empleados no se ve afectada en el corto plazo, ni los salarios nominales y por supuesto tampoco se afecta el salario real.

Modelo con movimiento de las variables afectadas 


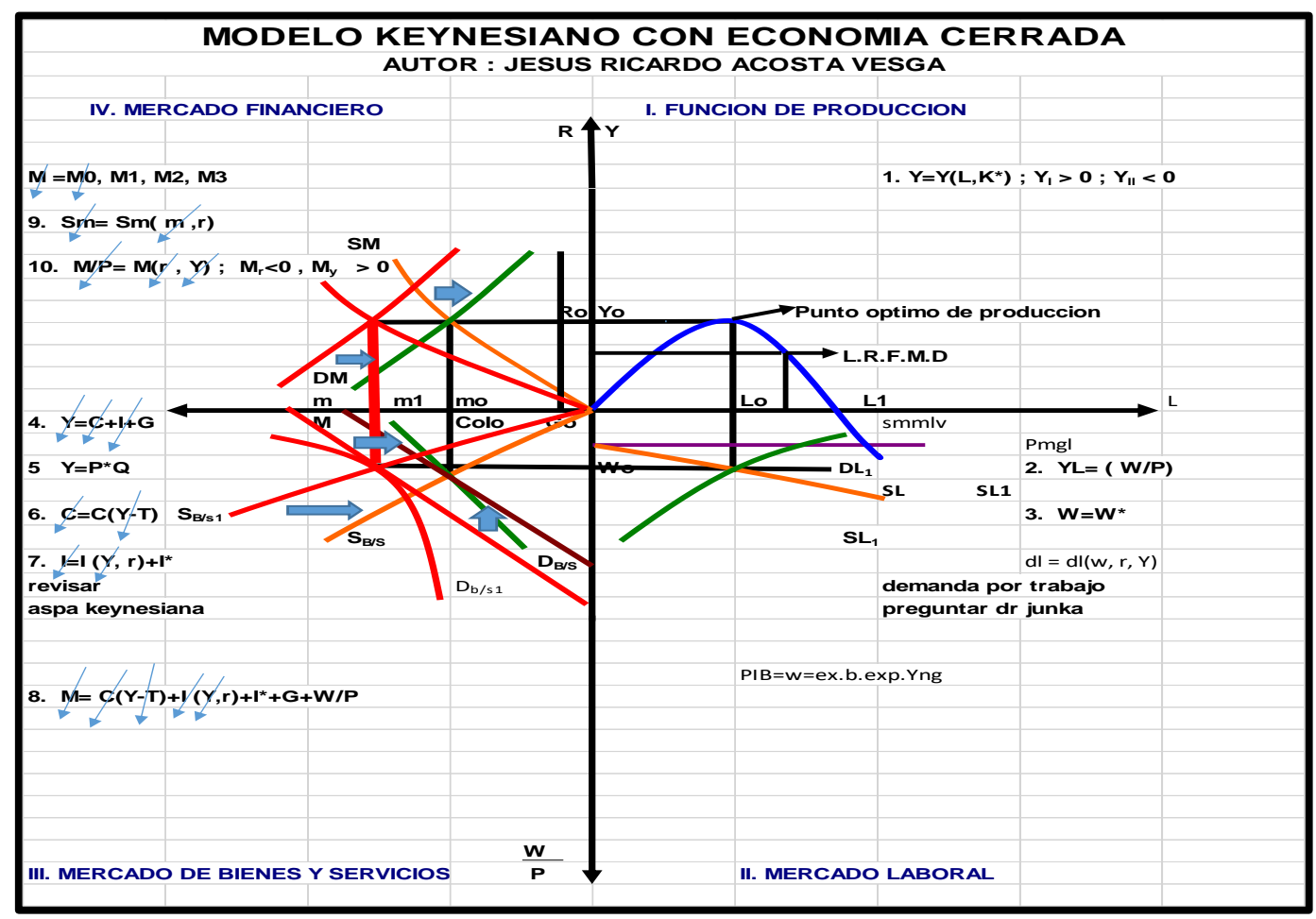

Anexo. Ilustración No. 67. Movimiento de las variables afectadas.

La solución para colocar el modelo en equilibrio es aumentando el gasto para reactivar la economía, con este aumento se produce un aumento en los ingresos y esto reactiva el consumo, la inversión, el presupuesto y a la vez aumentaría la masa monetaria incentivando de nuevo el crédito y así volveríamos al equilibrio.

3. ¿Señor gerente financiero, como se ve afectada su empresa cuando el banco de la república decide aumentar la emisión de dinero?

Al aumentar la emisión primaria de dinero por parte de Banco de la república, va a existir mayor cantidad de dinero en la economía, lo que ocasiona que se incremente la oferta monetaria y esto hace que aumente el consumo de los hogares, la inversión y el gasto y esto hace a la vez que se aumente el ingreso y se reactive la economía. Y la economía puede llegar a presentar un sobre calentamiento financiero. 
Modelo con movimiento de las variables afectadas

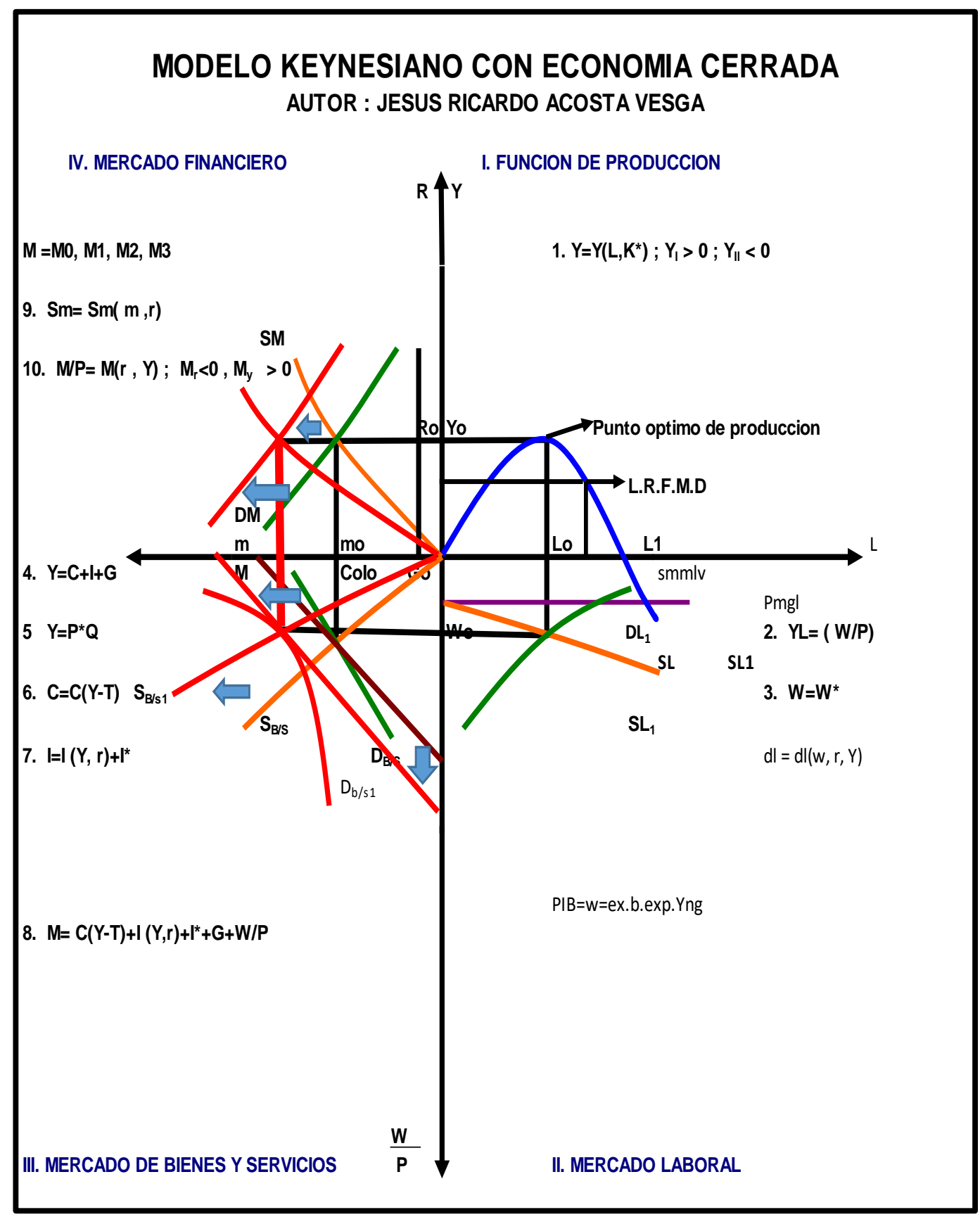

Anexo. Ilustración No. 68. Movimiento de las variables afectadas.

La Solución: Se debe invertir en la planta de producción para aumentar la 
capacidad productiva, aumentando la producción el número de empleados y así volver al punto de equilibrio inicial.

4. ¿Señor gerente de producción, que pasa cuando el gobierno decide aumentar los instrumentos de política fiscal, como se afectan las variables del modelo?

La solución: Si se incrementan tanto en gasto como los impuestos en el mismo porcentaje, el uno reduce el poder adquisitivo, como son los impuestos y al aumentar el gasto se mejora el poder adquisitivo y se reactiva la economía devolviendo todo al punto de equilibrio. Lo que indica que el modelo no se vea afectado.

5. Utilizando el diagrama del modelo Keynesiano cerrado con todas las ecuaciones, analice que pasa cuando disminuye la oferta monetaria.

Si disminuye la oferta monetaria, hace que se suban las tasas de interés, lo que hace que se reduzca la inversión por el costo de los intereses, lo mismo pasa con el consumó, el ingreso se reduce y el gasto también, esto puede producir que se baje la producción y exista una contracción en la economía.

\section{Modelo con movimiento de las variables afectadas}

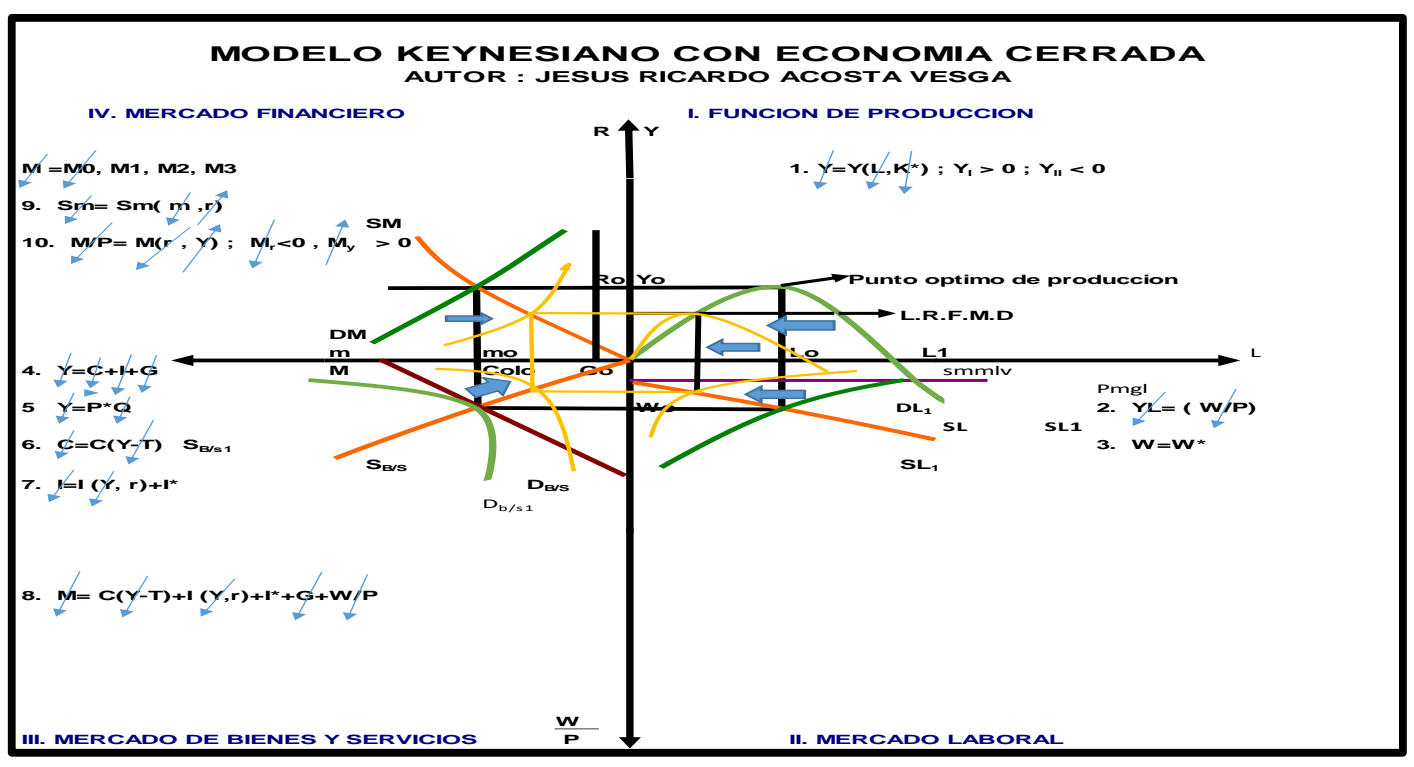


Anexo. Ilustración No. 69. Movimiento de las variables afectadas.

La Solución: Para este caso hay varias respuestas entre ellas una es incrementar el gasto público para reactivar la economía y así volver al punto de equilibrio, otra solución sería que el Banco de la Republica, aumentara las emisiones de dinero y así reactivar la economía y volver al punto de equilibrio.

6. Utilizando el diagrama del modelo Keynesiano cerrado con todas las ecuaciones, analice que pasa cuando aumenta el gasto público.

Cuando aumenta el gasto público se reactiva la economía y esto hace que exista una expansión monetaria y hace que la economía crezca.

\section{Modelo con movimiento de las variables afectadas}

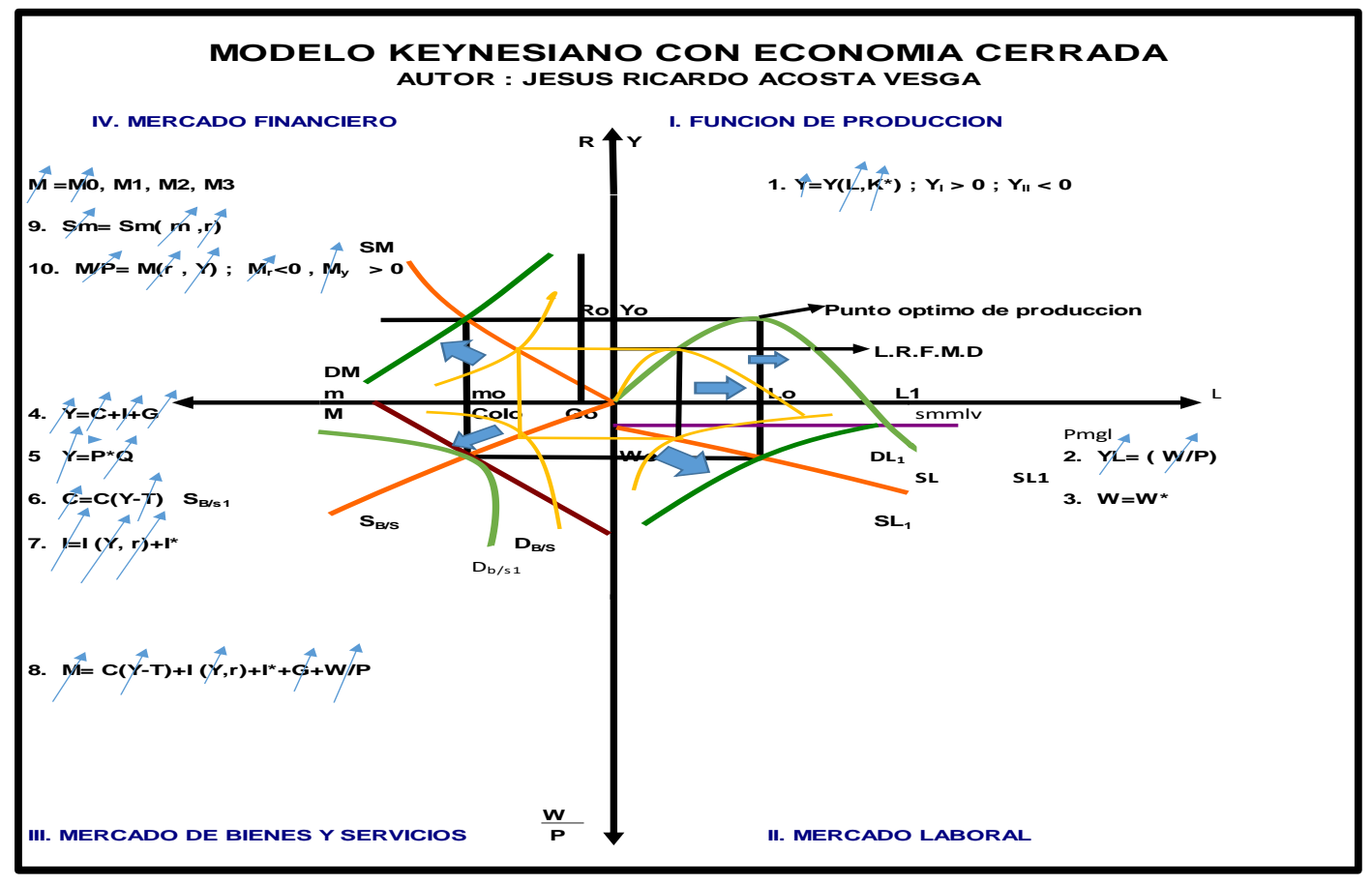

Anexo. Ilustración No. 70. Movimiento de las variables afectadas.

7. Utilizando el diagrama del modelo Keynesiano Cerrado con todas las ecuaciones, analice que pasa cuando aumenta el consumo de los hogares.

Cuando aumenta el consumo indica que aumentaron los ingresos lo que hace que 
se incrementé la inversión y se haga una expansión monetaria en la economía.

Modelo con movimiento de las variables afectadas

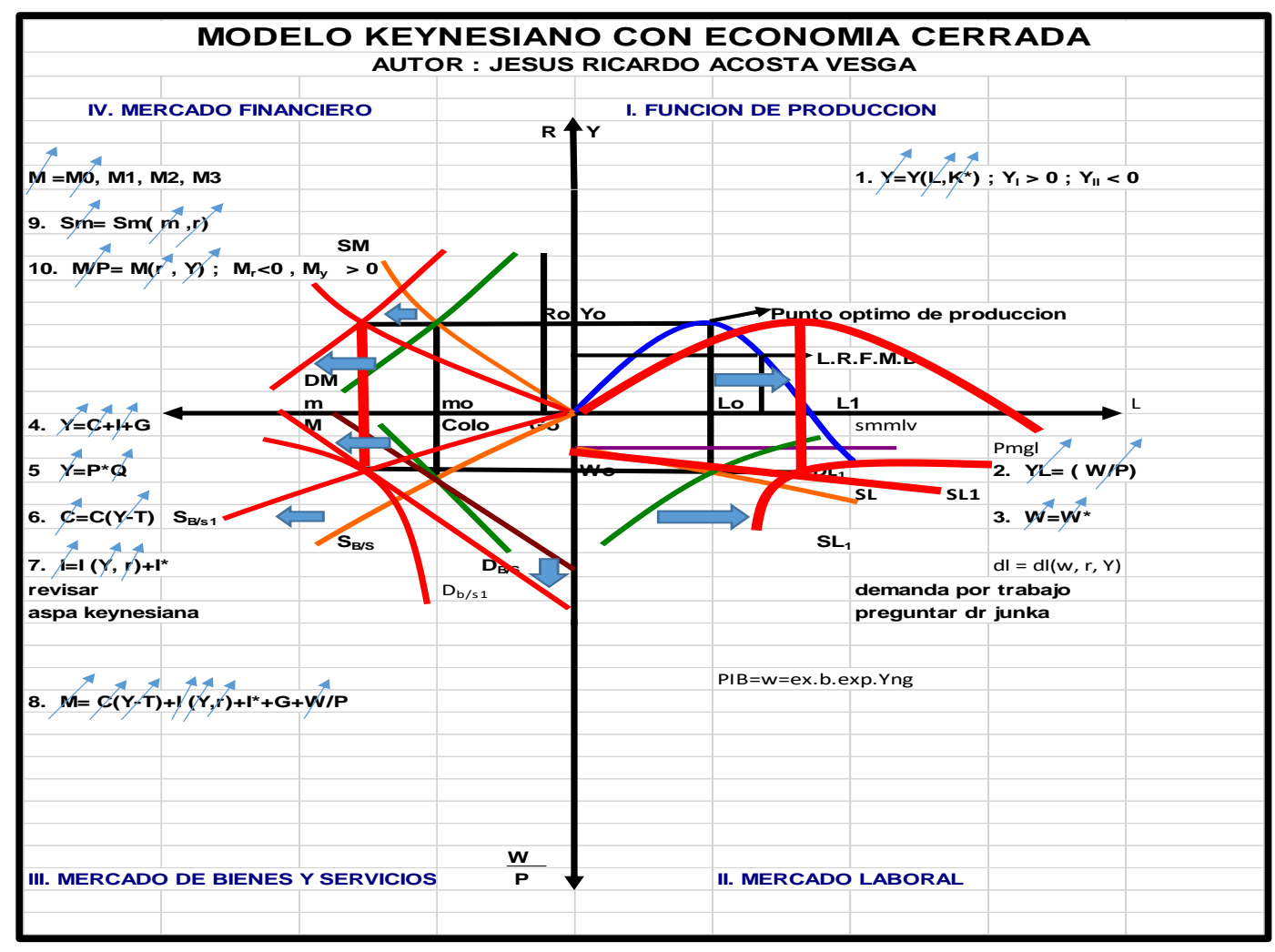

Anexo. Ilustración No. 71. Movimiento de las variables afectadas.

La solución: Para volver 1 punto de equilibrio debemos aumentar los impuestos y con esto reducimos la liquidez qué existe en la economía y así volvemos al punto de equilibrio la economía.

8. Utilizando el diagrama del modelo Keynesiano cerrado con todas las ecuaciones, analice que pasa cuando aumenta la inversión.

Si hay un aumento en la inversión es divido a que se incrementaron los ingresos y esto nos lleva a una expansión monetaria.

Modelo con movimiento de las variables afectadas 


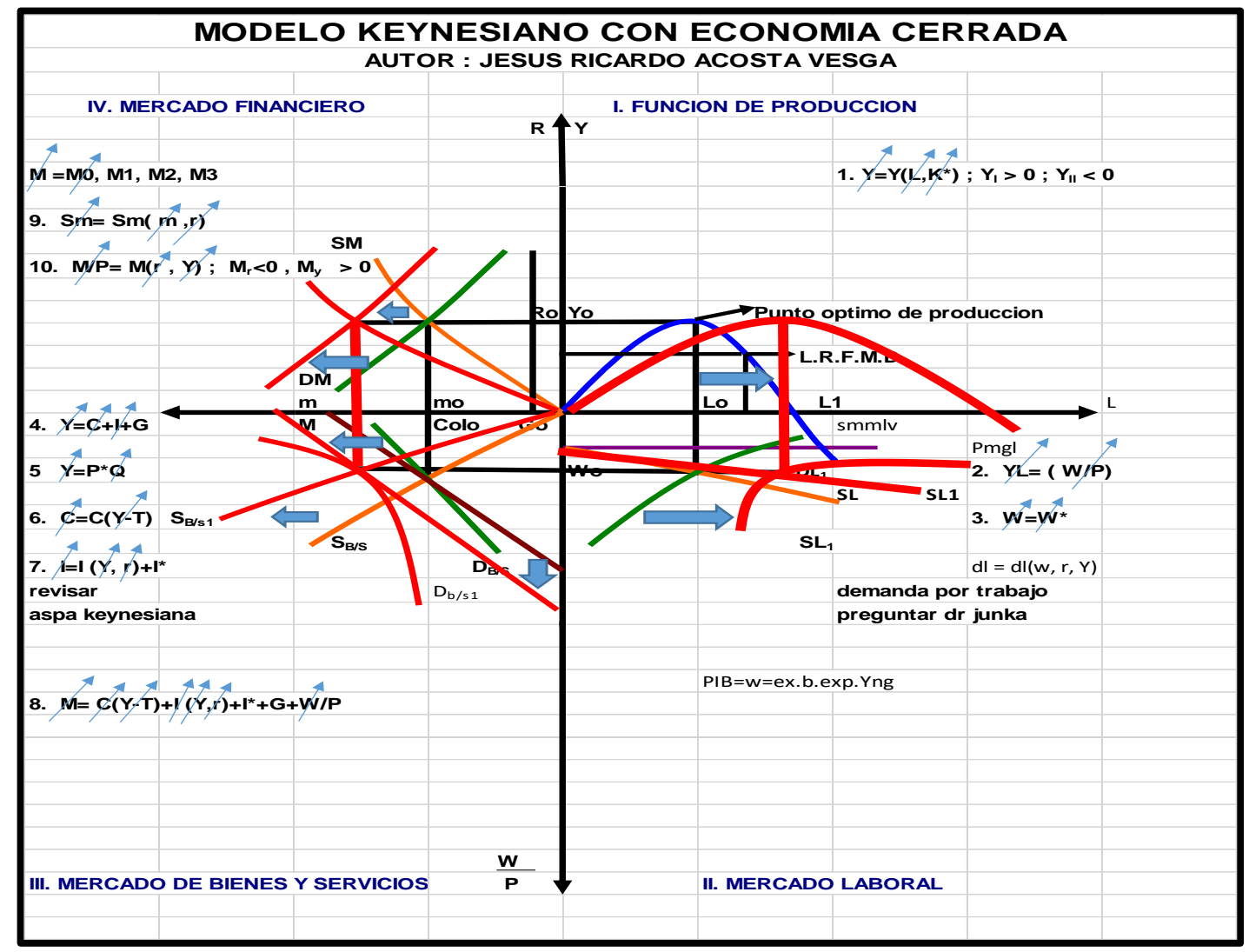

Anexo. Ilustración No. 72. Movimiento de las variables afectadas.

La solución: Para volver 1 punto de equilibrio debemos aumentar los impuestos y con esto reducimos la liquidez qué existe en la economía y así volvemos al punto de equilibrio la economía.

9. Utilizando el diagrama del modelo Keynesiano cerrado con todas las ecuaciones y analice que pasa cuando disminuye la tasa de interés.

Si disminuye la tasa de interés esto ocasiona que la gente demande más dinero porque el costo del dinero es más barato y esto reactiva la economía y origina una expansión monetaria.

Modelo con movimiento de las variables afectadas 


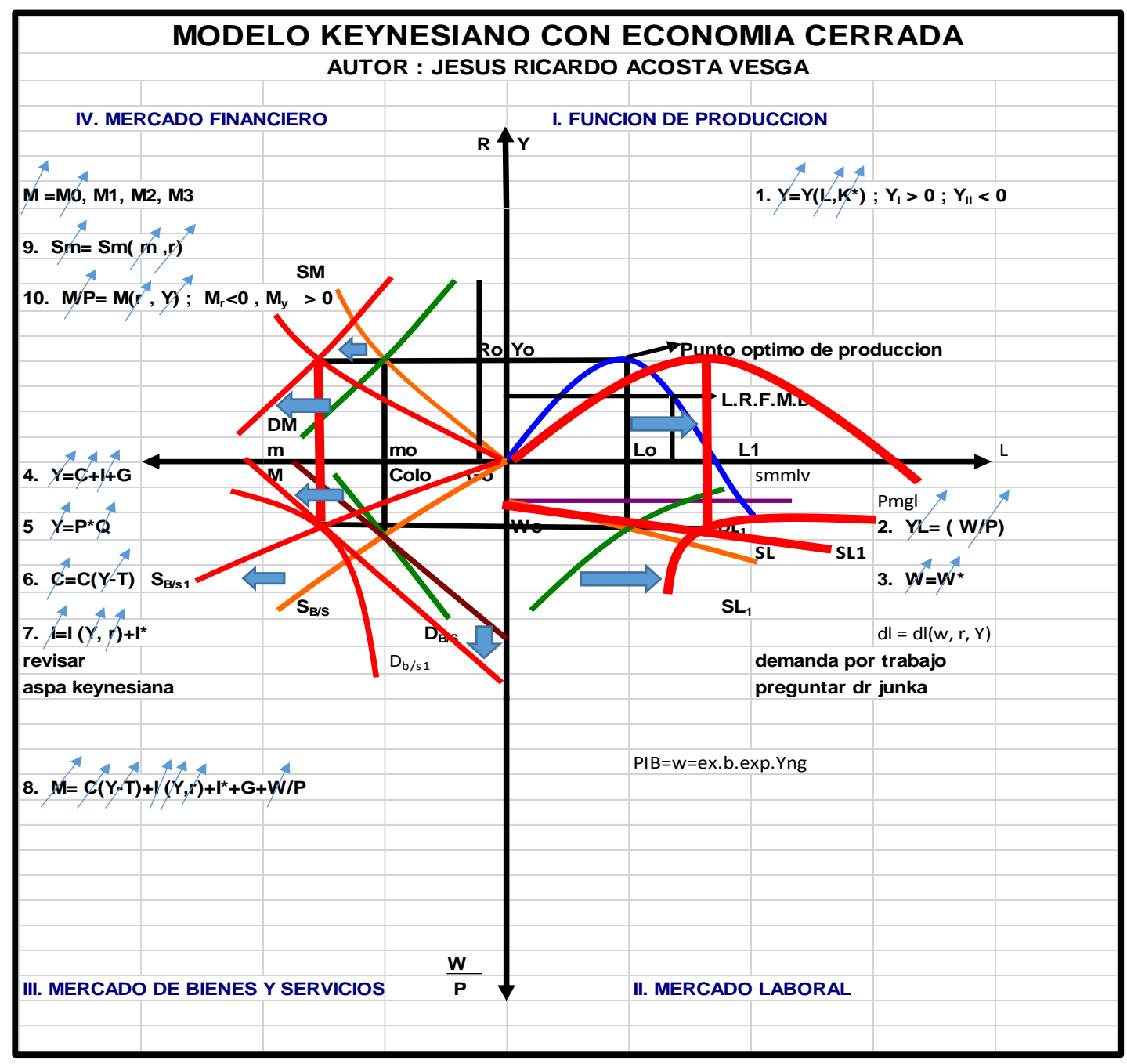

Anexo. Ilustración No. 73. Movimiento de las variables afectadas.

La solución: Para volver al punto de equilibrio debemos aumentar los impuestos y con esto reducimos la liquidez qué existe en la economía y así volvemos al punto de equilibrio la economía.

10. ¿Usted cree que el diagrama del modelo le da las herramientas necesarias para conocer de una forma más sencilla la comprensión de la economía?

Modelo es una herramienta bastante sólida el conocer las variables como afecta al entorno, el mercado etc. 


\section{Enseñanza Del Modelo Keynesiano Para Estudiantes De \\ Pregrado Una Aproximación Diagramática}

\section{Asignatura Macroeconomía II}

TEST N. 1

\section{Nombre de estudiante: SERGIO ACUÑA QUINTERO \\ Universidad: UNIMONSERRATE Programa: FINANZAS Y NEGOCIOS INTERNACIONALES Semestre: 8 VO fecha: D.07 M 11 año 2016}

A continuación se presentan diez preguntas tipo Saber Pro a las cuales usted les dará solución utilizando el modelo keynesiano de economía cerrada, evidenciando el movimiento de las variables económicas, para lo cual usted tendrá un rol.

1. ¿Señor gerente general, como se ve afectada su empresa cuando el banco de la república decide aumentar la tasa de interés de política monetaria?

2. ¿Señor gerente financiero, como se ve afectada su empresa cuando el banco de la república decide aumentar el encaje bancario?

3. ¿Señor gerente financiero, como se ve afectada su empresa cuando el banco de la república decide aumentar la emisión de dinero?

4. ¿Señor gerente de producción, que pasa cuando el gobierno decide aumentar los instrumentos de política fiscal, como se afectan las variables del modelo?

5. Utilizando el diagrama del modelo Keynesiano cerrado con todas las ecuaciones, analice que pasa cuando disminuye la oferta monetaria.

6. Utilizando el diagrama del modelo Keynesiano cerrado con todas las ecuaciones, analice que pasa cuando aumenta el gasto público.

7. Utilizando el diagrama del modelo Keynesiano Cerrado con todas las 
ecuaciones, analice que pasa cuando aumenta el consumo de los hogares.

8. Utilizando el diagrama del modelo Keynesiano cerrado con todas las ecuaciones, analice que pasa cuando aumenta la inversión.

9. Utilizando el diagrama del modelo Keynesiano cerrado con todas las ecuaciones y analice que pasa cuando disminuye la tasa de interés.

10. ¿Usted cree que el diagrama del modelo le da las herramientas necesarias para conocer de una forma más sencilla la comprensión de la economía?

\section{Solución:}

Nota: en la solución solo se exponen las variables de más impacto

1) En cuanto el aumento de las tasas de interés por parte del banco de la republica afectaría en lo siguiente:

Primero hay que destacar que los dos cuadrantes que se verían involucrados serian el del mercado financiero y el mercado de bienes y servicios

Al subir las tasas de interés, aumenta la inversión, aumentan los ingresos, lo que hace que aumente el ingreso disponible a su vez origina un aumento del presupuesto esto origina un aumento en la masa monetaria, luego aumenta la cantidad real de dinero, lo que hizo que aumentara el dinero especulativo y el dinero de transacción todo esto origino una expansión monetaria.

Análisis Lógico. Primero partimos con él modelo en equilibrio como sigue: 


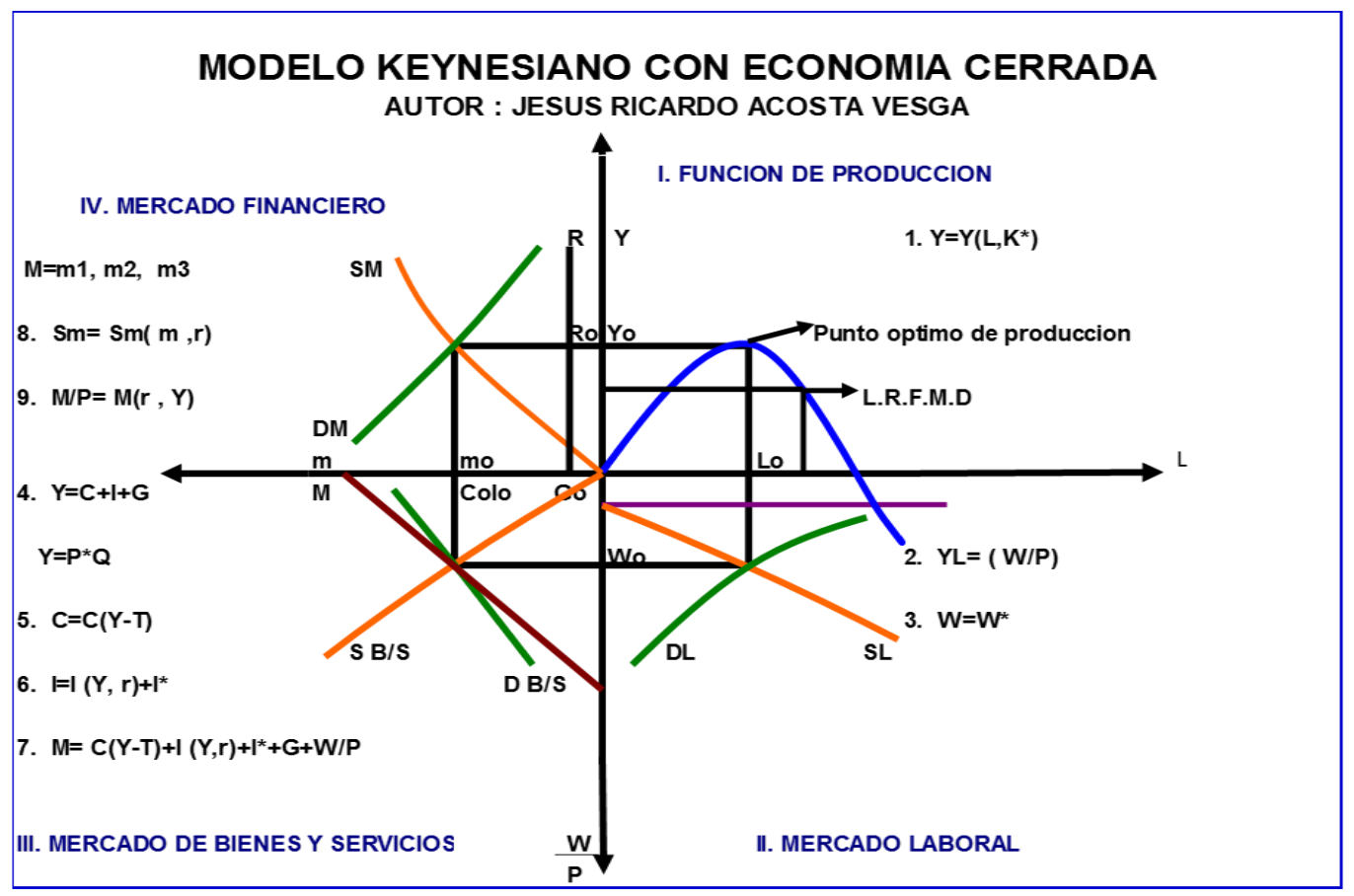

Anexo. Ilustración No. 74. Movimiento de las variables afectadas.

Modelo diagramático keynesiano con movimiento de las variables

afectadas.

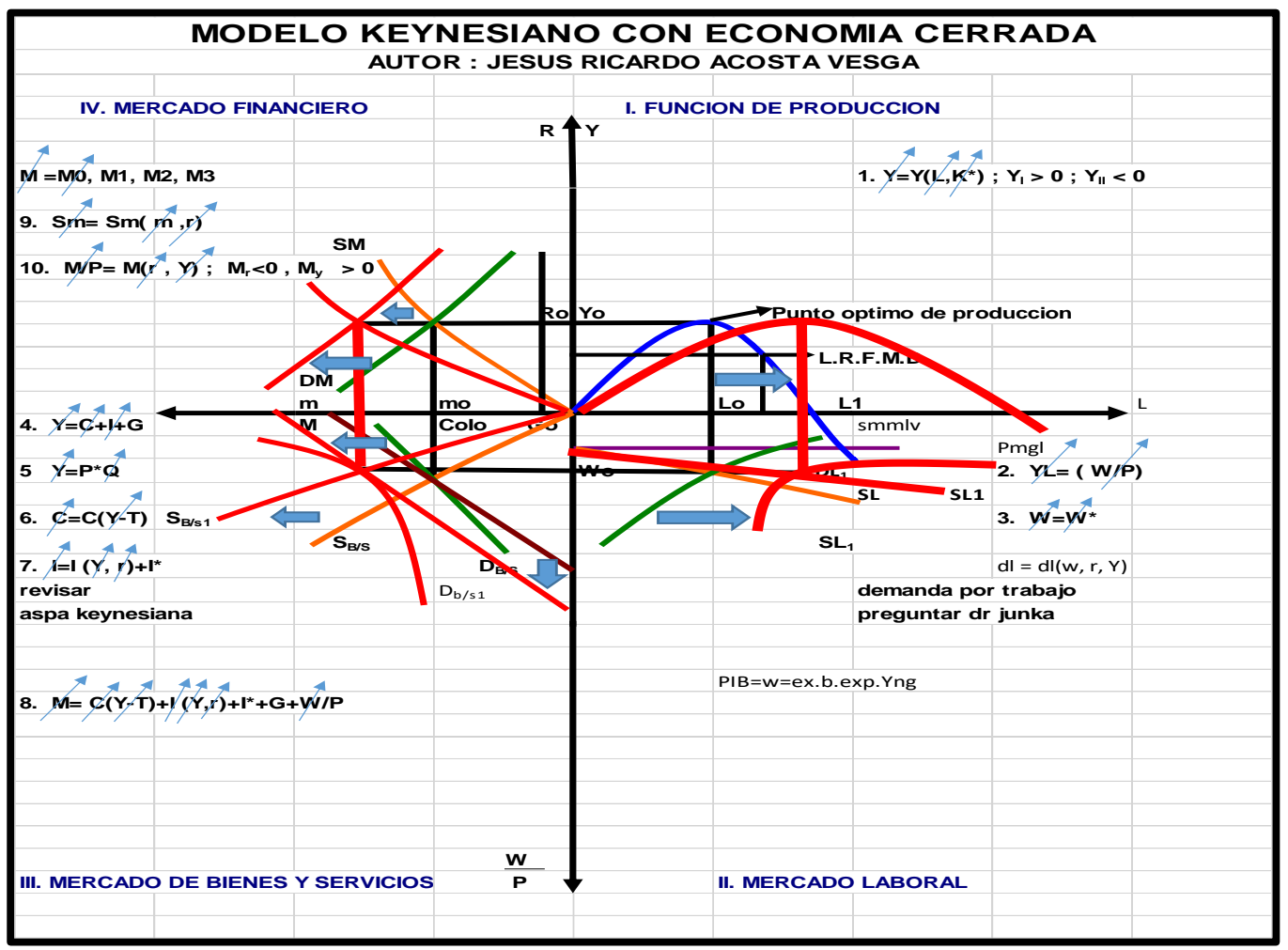


Anexo. Ilustración No. 75. Movimiento de las variables afectadas.

La solución como se observa en el grafico las flechas indican el movimiento de las variables hacia arriba mostrando que aumentaron y crearon una expansión monetaria, como gerente la solución es aumentar (política Fiscal), los impuestos para reducir esa expansión y así volver al equilibrio.

2. ¿Señor gerente financiero, como se ve afectada su empresa cuando el banco de la República decide aumentar el encaje bancario?

Al aumentar el encaje bancario, se reduce el la oferta monetaria, disminuyendo el crédito, lo que hace y se reduce la demanda del dinero especulativo y de transacción, y esto origina una caída en el presupuesto y hace bajar los ingresos de la empresa originando una contracción monetaria, la producción y el número de empleados no se ve afectada en el corto plazo, ni los salarios nominales y por supuesto tampoco se afecta el salario real.

\section{Modelo con movimiento de las variables afectadas}

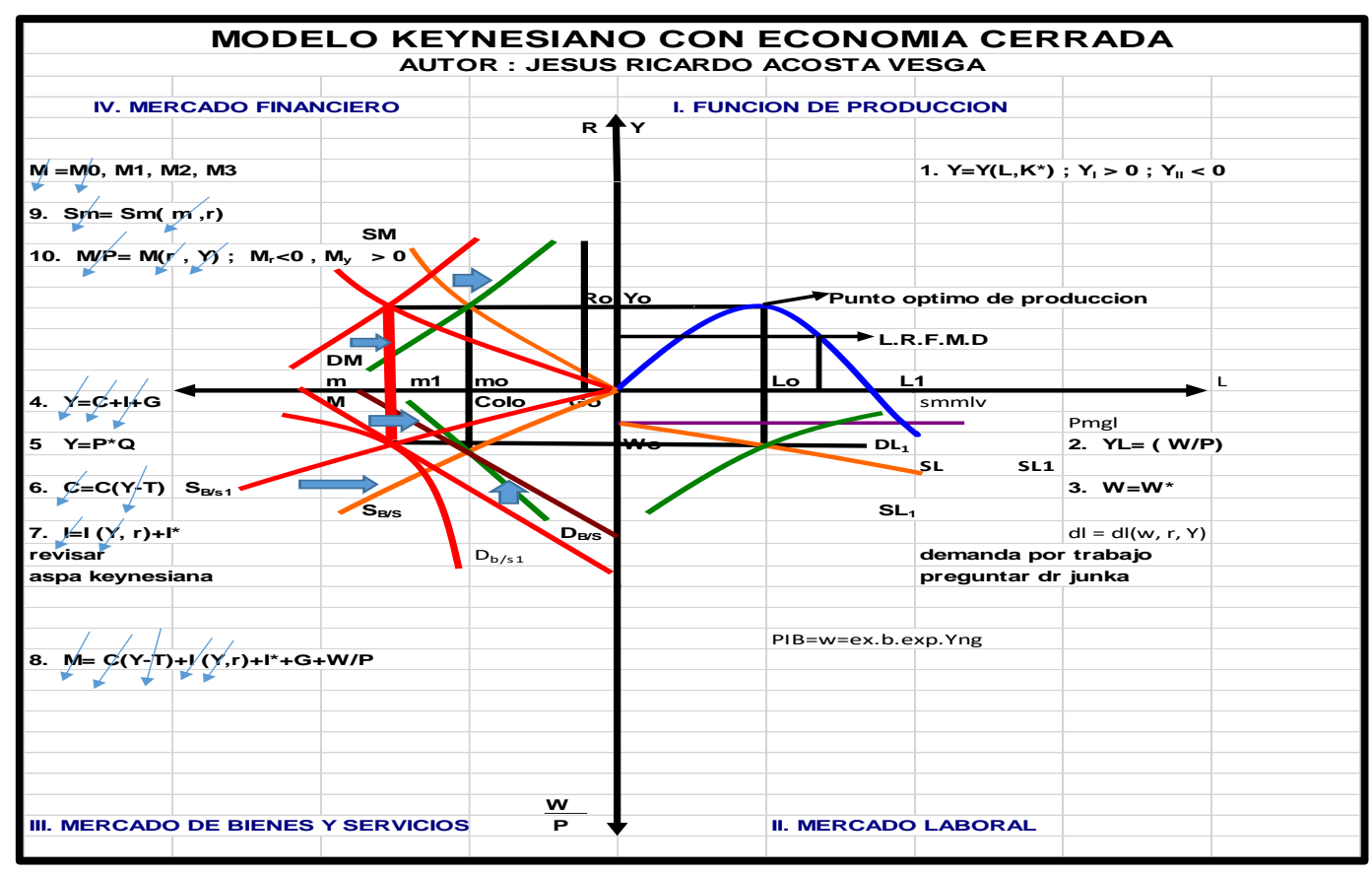


Anexo. Ilustración No. 76. Movimiento de las variables afectadas.

\section{Figura N.9. Producción Del Autor}

La solución para colocar el modelo en equilibrio es aumentando el gasto para reactivar la economía, con este aumento se produce un aumento en los ingresos y esto reactiva el consumo, la inversión, el presupuesto y a la vez aumentaría la masa monetaria incentivando de nuevo el crédito y así volveríamos al equilibrio.

3. ¿Señor gerente financiero, como se ve afectada su empresa cuando el banco de la república decide aumentar la emisión de dinero?

Al aumentar la emisión primaria de dinero por parte de Banco de la república, va a existir mayor cantidad de dinero en la economía, lo que ocasiona que se incremente la oferta monetaria y esto hace que aumente el consumo de los hogares, la inversión y el gasto y esto hace a la vez que se aumente el ingreso y se reactive la economía. Y la economía puede llegar a presentar un sobre calentamiento financiero.

\section{Modelo con movimiento de las variables afectadas}

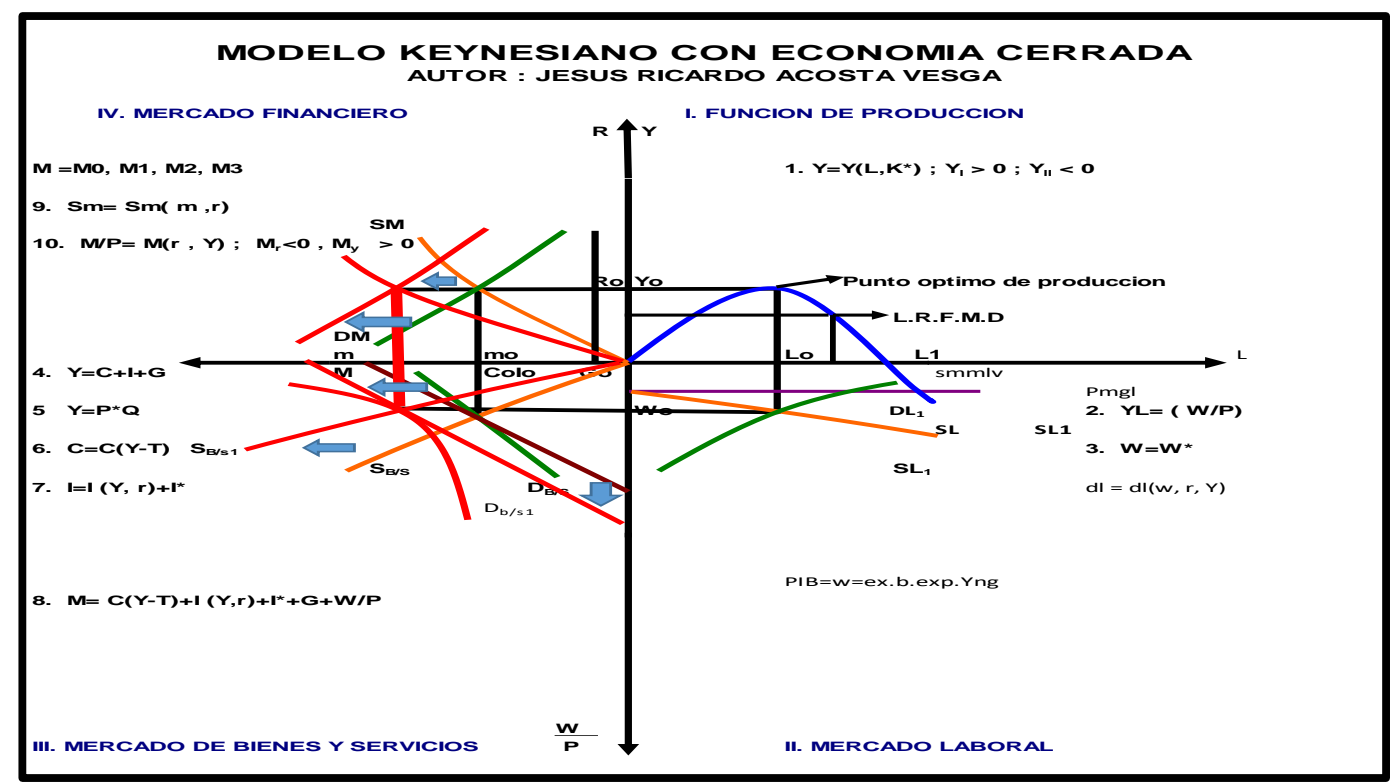

Anexo. Ilustración No.77. Movimiento de las variables afectadas. 
La Solución: Se debe invertir en la planta de producción para aumentar la capacidad productiva, aumentando la producción el número de empleados y así volver al punto de equilibrio inicial.

4. ¿Señor gerente de producción, que pasa cuando el gobierno decide aumentar los instrumentos de política fiscal, como se afectan las variables del modelo?

La solución: Si se incrementan tanto en gasto como los impuestos en el mismo porcentaje, el uno reduce el poder adquisitivo, como son los impuestos y al aumentar el gasto se mejora el poder adquisitivo y se reactiva la economía devolviendo todo al punto de equilibrio. Lo que indica que el modelo no se vea afectado.

5. Utilizando el diagrama del modelo Keynesiano cerrado con todas las ecuaciones, analice que pasa cuando disminuye la oferta monetaria.

Si disminuye la oferta monetaria, hace que se suban las tasas de interés, lo que hace que se reduzca la inversión por el costo de los intereses, lo mismo pasa con el consumó, el ingreso se reduce y el gasto también, esto puede producir que se baje la producción y exista una contracción en la economía.

Modelo con movimiento de las variables afectadas

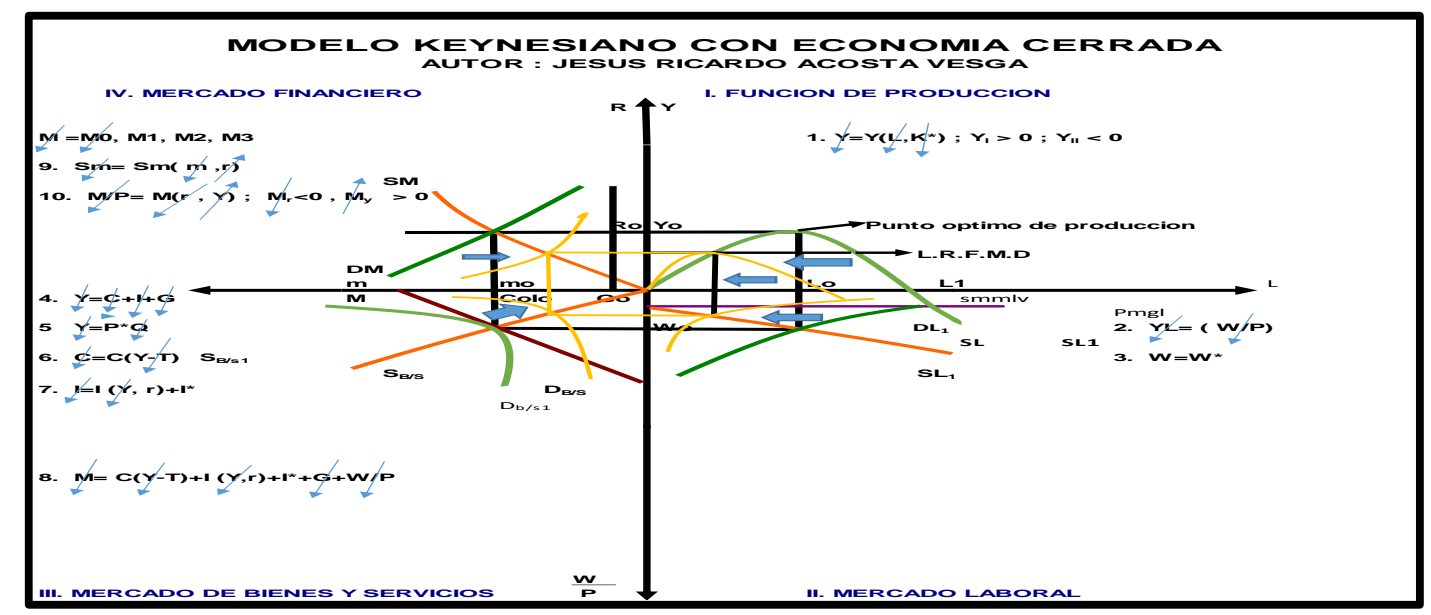

Anexo. Ilustración No. 78. Movimiento de las variables afectadas. 
La Solución: Para este caso hay varias respuestas entre ellas una es incrementar el gasto público para reactivar la economía y así volver al punto de equilibrio, otra solución sería que el Banco de la Republica, aumentara las emisiones de dinero y así reactivar la economía y volver al punto de equilibrio.

6. Utilizando el diagrama del modelo Keynesiano cerrado con todas las ecuaciones, analice que pasa cuando aumenta el gasto público.

Cuando aumenta el gasto público se reactiva la economía y esto hace que exista una expansión monetaria y hace que la economía crezca.

\section{Modelo con movimiento de las variables afectadas}

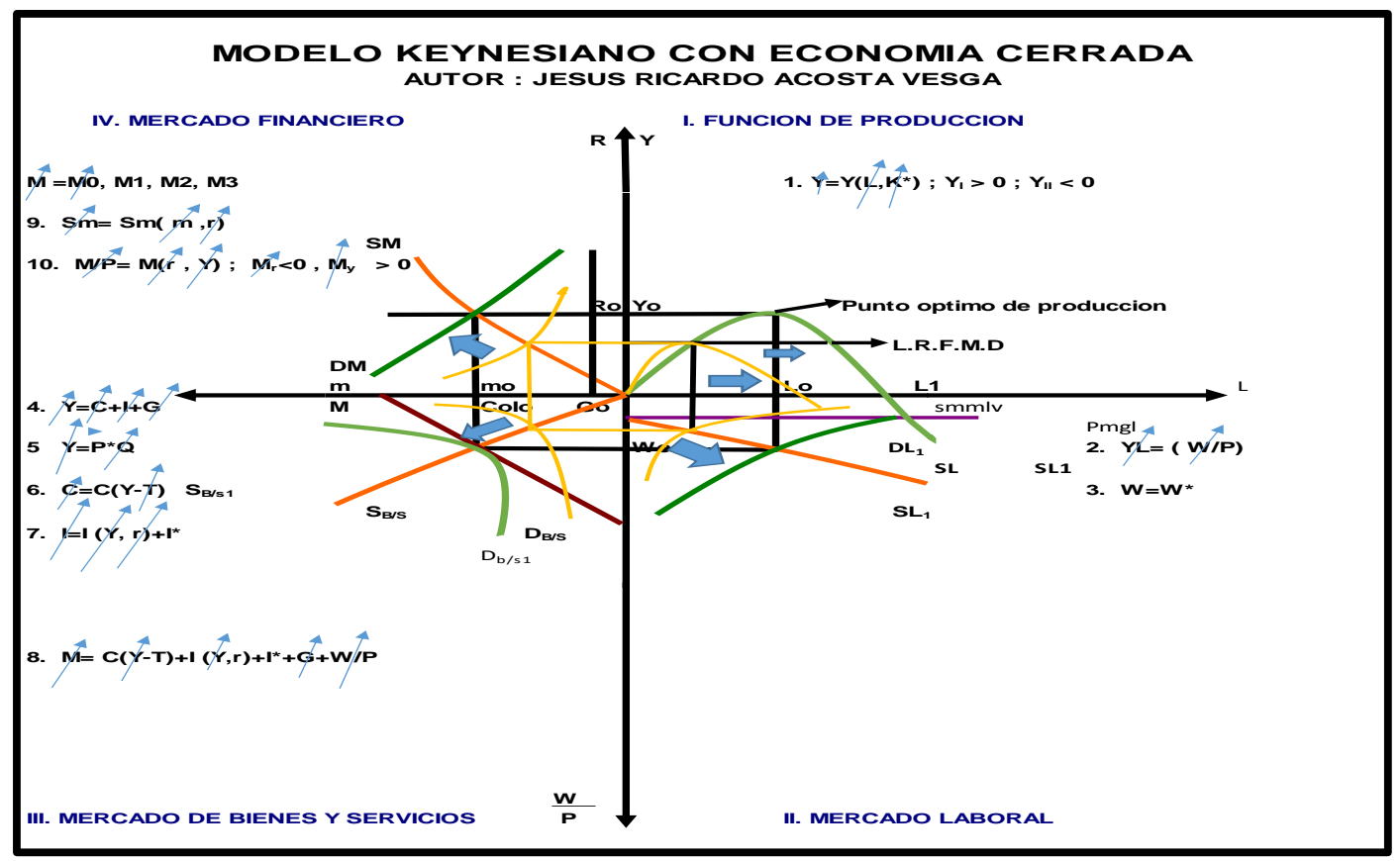

Anexo. Ilustración No. 79. Movimiento de las variables afectadas.

7. Utilizando el diagrama del modelo Keynesiano Cerrado con todas las ecuaciones, analice que pasa cuando aumenta el consumo de los hogares.

Cuando aumenta el consumo indica que aumentaron los ingresos lo que hace que se incrementé la inversión y se haga una expansión monetaria en la economía. 
Modelo con movimiento de las variables afectadas

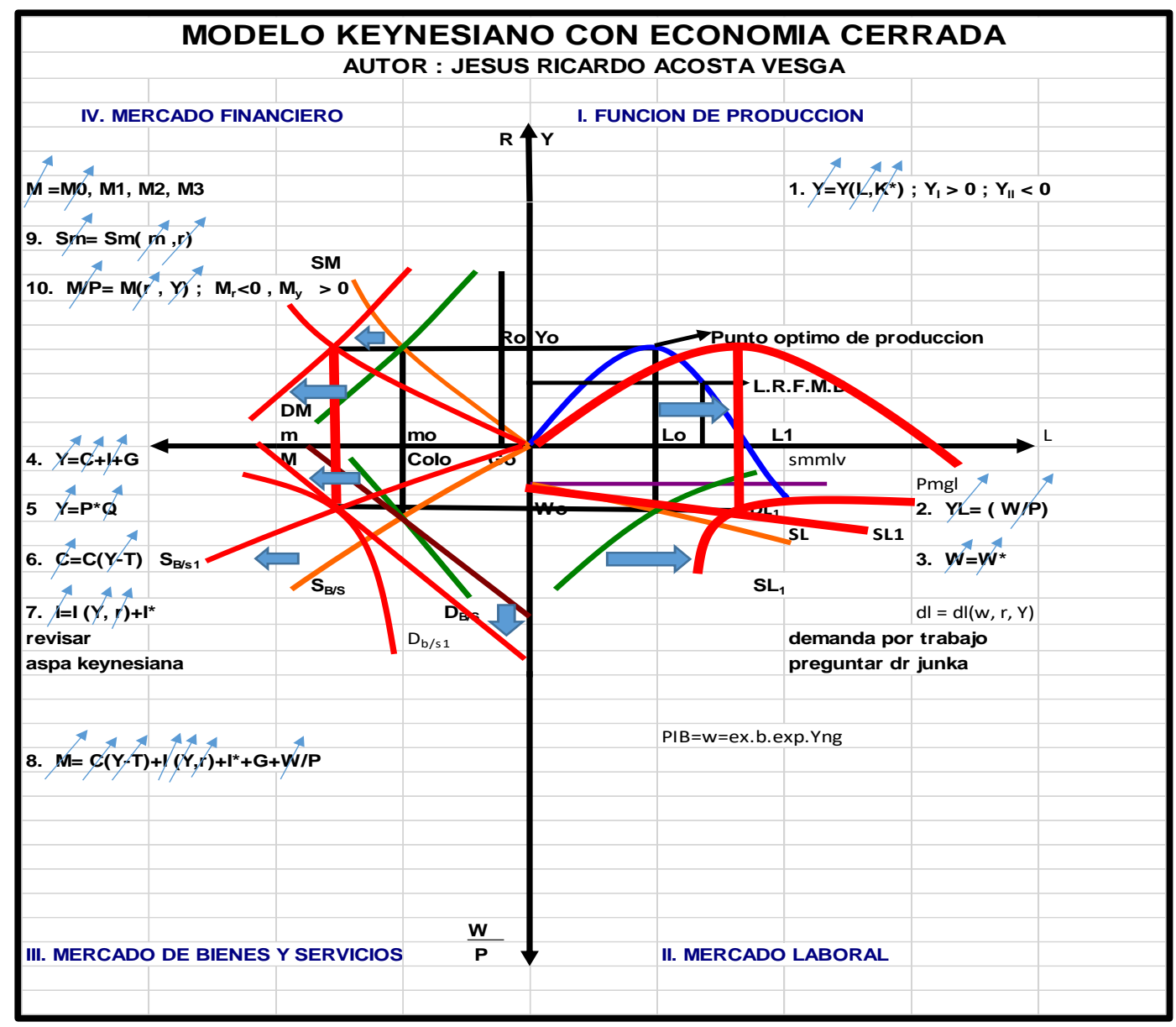

Anexo. Ilustración No. 80. Movimiento de las variables afectadas.

La solución: Para volver 1 punto de equilibrio debemos aumentar los impuestos y con esto reducimos la liquidez qué existe en la economía y así volvemos al punto de equilibrio la economía.

8. Utilizando el diagrama del modelo Keynesiano cerrado con todas las ecuaciones, analice que pasa cuando aumenta la inversión.

Si hay un aumento en la inversión es divido a que se incrementaron los ingresos y esto nos lleva a una expansión monetaria.

Modelo con movimiento de las variables afectadas 


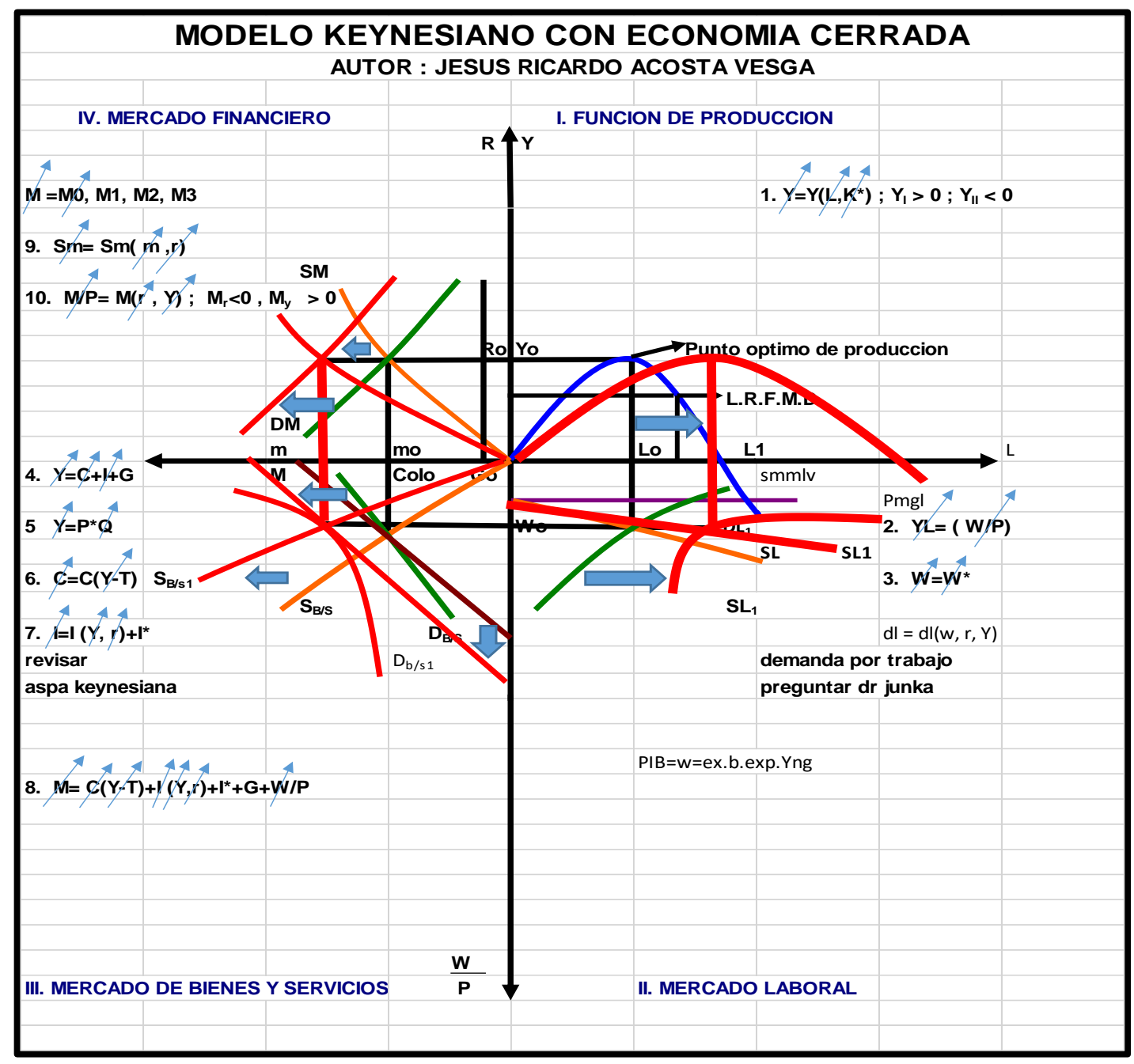

Anexo. Ilustración No. 81. Movimiento de las variables afectadas.

La solución: Para volver 1 punto de equilibrio debemos aumentar los impuestos y con esto reducimos la liquidez qué existe en la economía y así volvemos al punto de equilibrio la economía.

9. Utilizando el diagrama del modelo Keynesiano cerrado con todas las ecuaciones y analice que pasa cuando disminuye la tasa de interés.

Si disminuye la tasa de interés esto ocasiona que la gente demande más dinero porque el costo del dinero es más barato y esto reactiva la economía y origina una expansión monetaria. 
Modelo con movimiento de las variables afectadas

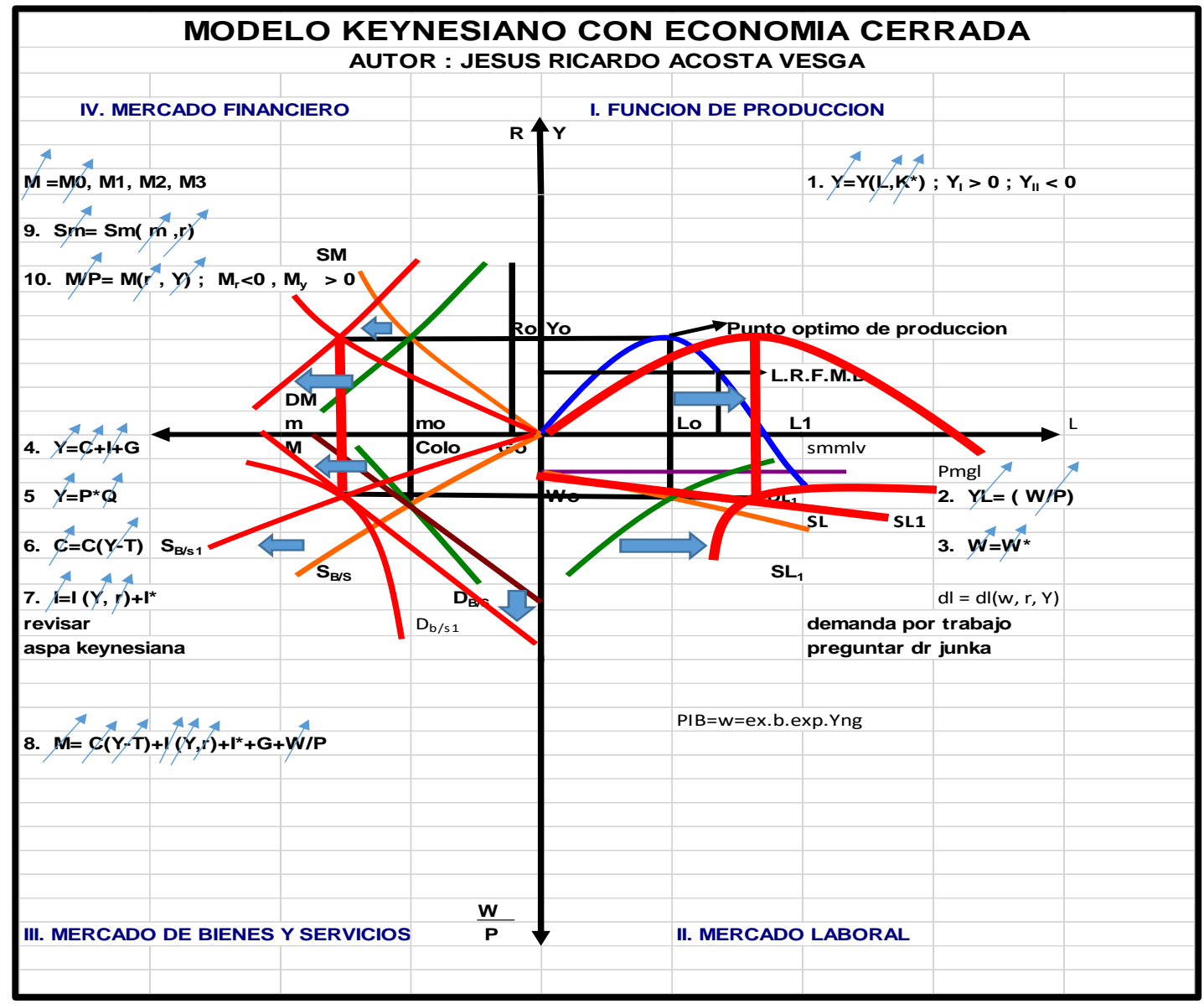

Anexo. Ilustración No. 82. Movimiento de las variables afectadas.

La solución: Para volver al punto de equilibrio debemos aumentar los impuestos y con esto reducimos la liquidez qué existe en la economía y así volvemos al punto de equilibrio la economía.

10. ¿Usted cree que el diagrama del modelo le da las herramientas necesarias para conocer de una forma más sencilla la comprensión de la economía?

Considero que es una herramienta bastante útil para nosotros como estudiantes al momento de analizar no uno sino todos los cuadrantes que están involucrados en este modelo, sin embargo para una mejor comprensión es necesario del conocimiento teórico y la aplicación a ejemplos de la vida real. Pienso que sería una forma más completa de 
entender la economía.

\title{
Enseñanza Del Modelo Keynesiano Para Estudiantes De \\ Pregrado Una Aproximación Diagramática \\ Asignatura Macroeconomía II \\ TEST N. 1
}

\author{
Nombre: Luis Gabriel González Vásquez \\ Universidad: fundación universitaria Monserrate \\ Programa: finanzas y negocios
}

Fecha: 6/11/2016

A continuación se presentan diez preguntas tipo Saber Pro a las cuales usted les dará solución utilizando el modelo keynesiano de economía cerrada, evidenciando el movimiento de las variables económicas, para lo cual usted tendrá un rol.

1. ¿Señor gerente general, como se ve afectada su empresa cuando el banco de la república decide aumentar la tasa de interés de política monetaria?

Respuesta:

1. ¿Señor gerente general, como se ve afectada su empresa cuando el banco de la república decide aumentar la tasa de interés de política monetaria?

Al subir las tasas de interés, aumenta la inversión, aumentan los ingresos, lo que hace que aumente el ingreso disponible a su vez origina un aumento del presupuesto esto origina un aumento en la masa monetaria, luego aumenta la cantidad real de dinero, lo que hizo que aumentara el dinero especulativo y el dinero de transacción todo esto origino una expansión monetaria.

Modelo con movimiento de las variables afectadas. 


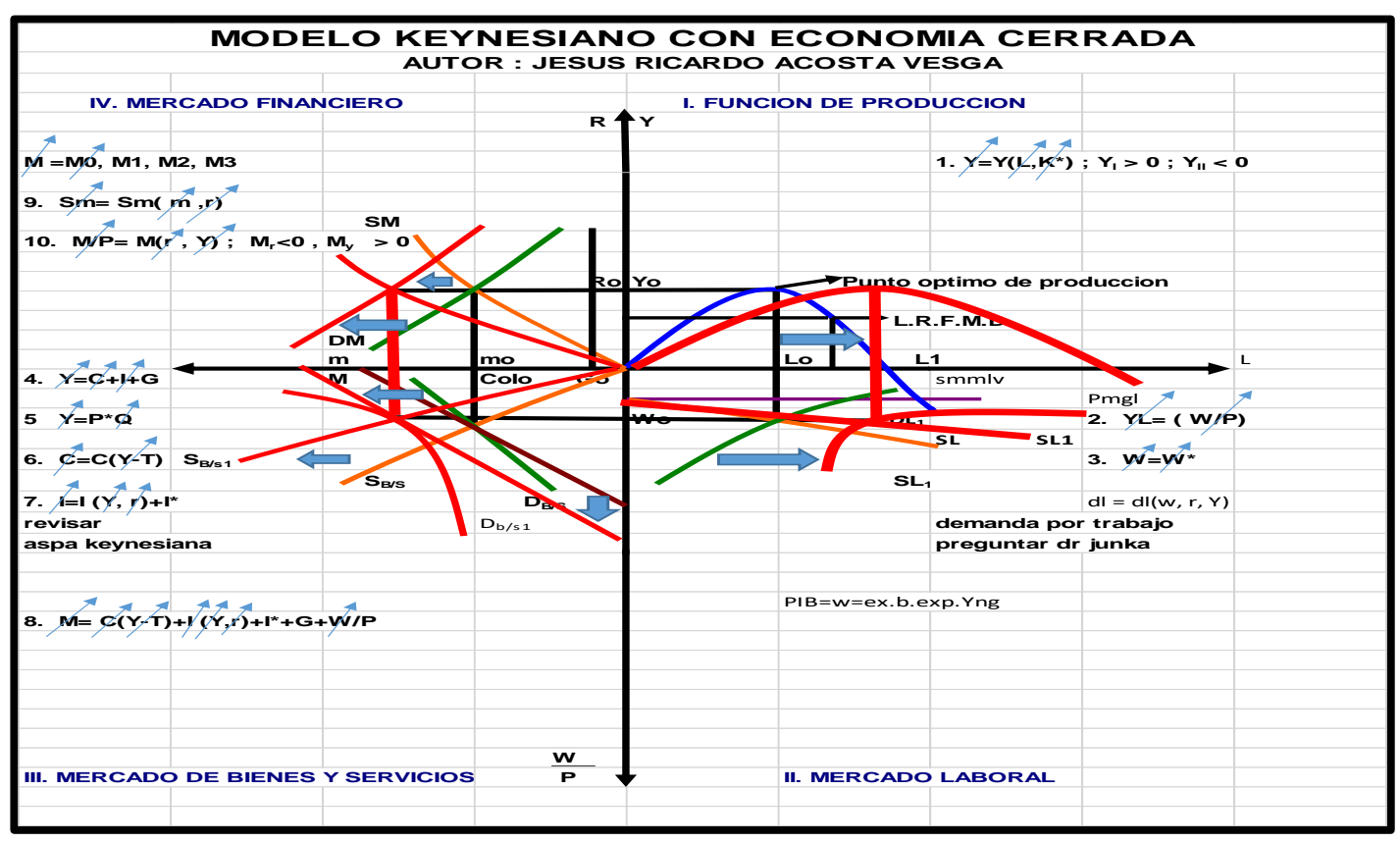

Anexo. Ilustración No. 83. Movimiento de las variables afectadas.

La solución como se observa en el grafico las flechas indican el movimiento de las variables hacia arriba mostrando que aumentaron y crearon una expansión monetaria, como gerente la solución es aumentar la capacidad instalada de la empresa teniendo en cuenta que hay más capital y eso ubica la economía en equilibrio.

2. ¿Señor gerente financiero, como se ve afectada su empresa cuando el banco de la república decide aumentar el encaje bancario?

Al aumentar el encaje bancario, se reduce el la oferta monetaria, disminuyendo el crédito, lo que hace y se reduce la demanda del dinero especulativo y de transacción, y esto origina una caída en el presupuesto y hace bajar los ingresos de la empresa originando una contracción monetaria, la producción y el número de empleados no se ve afectada en el corto plazo, ni los salarios nominales y por supuesto tampoco se afecta el salario real. 
Modelo con movimiento de las variables afectadas

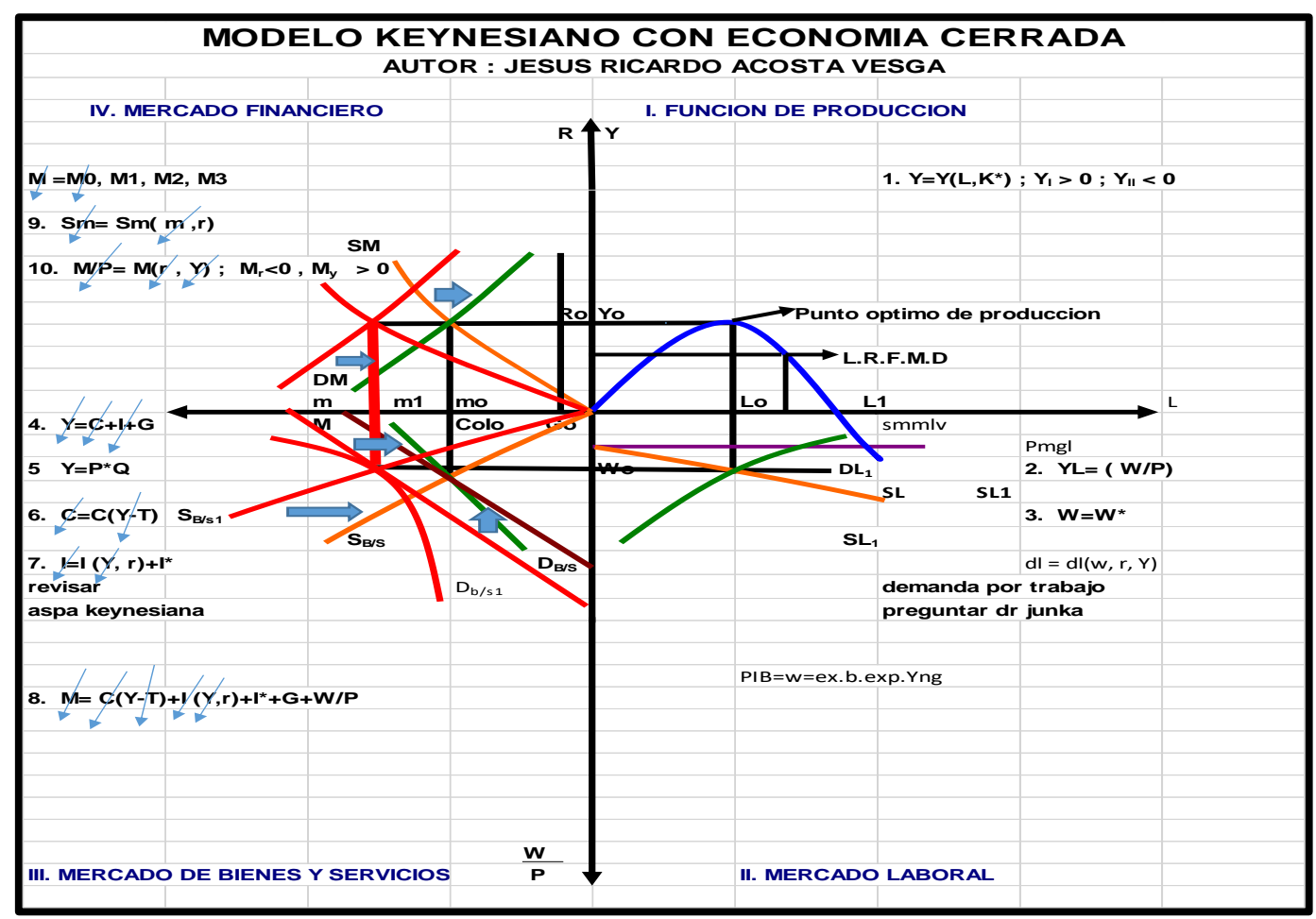

Anexo. Ilustración No. 84. Movimiento de las variables afectadas.

La solución para colocar el modelo en equilibrio es aumentando el gasto para

reactivar la economía, con este aumento se produce un aumento en los ingresos y esto

reactiva el consumo, la inversión, el presupuesto y a la vez aumentaría la masa

monetaria incentivando de nuevo el crédito y así volveríamos al equilibrio.

3. ¿Señor gerente financiero, como se ve afectada su empresa cuando el banco de la república decide aumentar la emisión de dinero?

Al aumentar la emisión primaria de dinero por parte de Banco de la república, va a existir mayor cantidad de dinero en la economía, lo que ocasiona que se incremente la oferta monetaria y esto hace que aumente el consumo de los hogares, la inversión y el gasto y esto hace a la vez que se aumente el ingreso y se reactive la economía. Y la 
economía puede llegar a presentar un sobre calentamiento financiero.

Modelo con movimiento de las variables afectadas

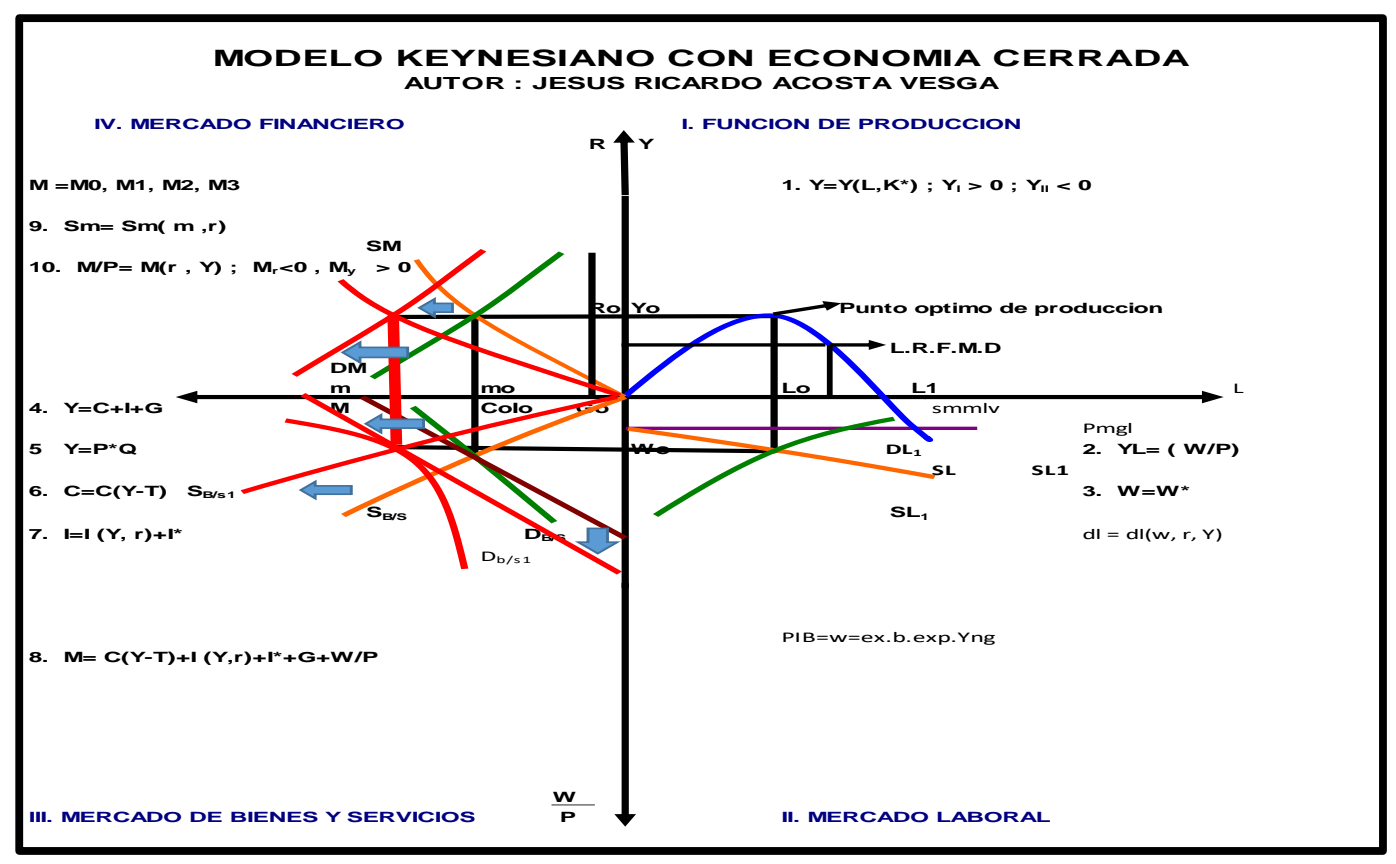

Anexo. Ilustración No. 85. Movimiento de las variables afectadas.

La Solución: Se debe invertir en la planta de producción para aumentar la capacidad productiva, aumentando la producción el número de empleados y así volver al punto de equilibrio inicial.

4. ¿Señor gerente de producción, que pasa cuando el gobierno decide aumentar los instrumentos de política fiscal, como se afectan las variables del modelo?

La solución: Si se incrementan tanto en gasto como los impuestos en el mismo porcentaje, el uno reduce el poder adquisitivo, como son los impuestos y al aumentar el gasto se mejora el poder adquisitivo y se reactiva la economía devolviendo todo al punto de equilibrio. Lo que indica que el modelo no se vea afectado.

5. Utilizando el diagrama del modelo Keynesiano cerrado con todas las ecuaciones, analice que pasa cuando disminuye la oferta monetaria. 
Si disminuye la oferta monetaria, hace que se suban las tasas de interés, lo que hace que se reduzca la inversión por el costo de los intereses, lo mismo pasa con el consumó, el ingreso se reduce y el gasto también, esto puede producir que se baje la producción y exista una contracción en la economía.

\section{Modelo con movimiento de las variables afectadas}

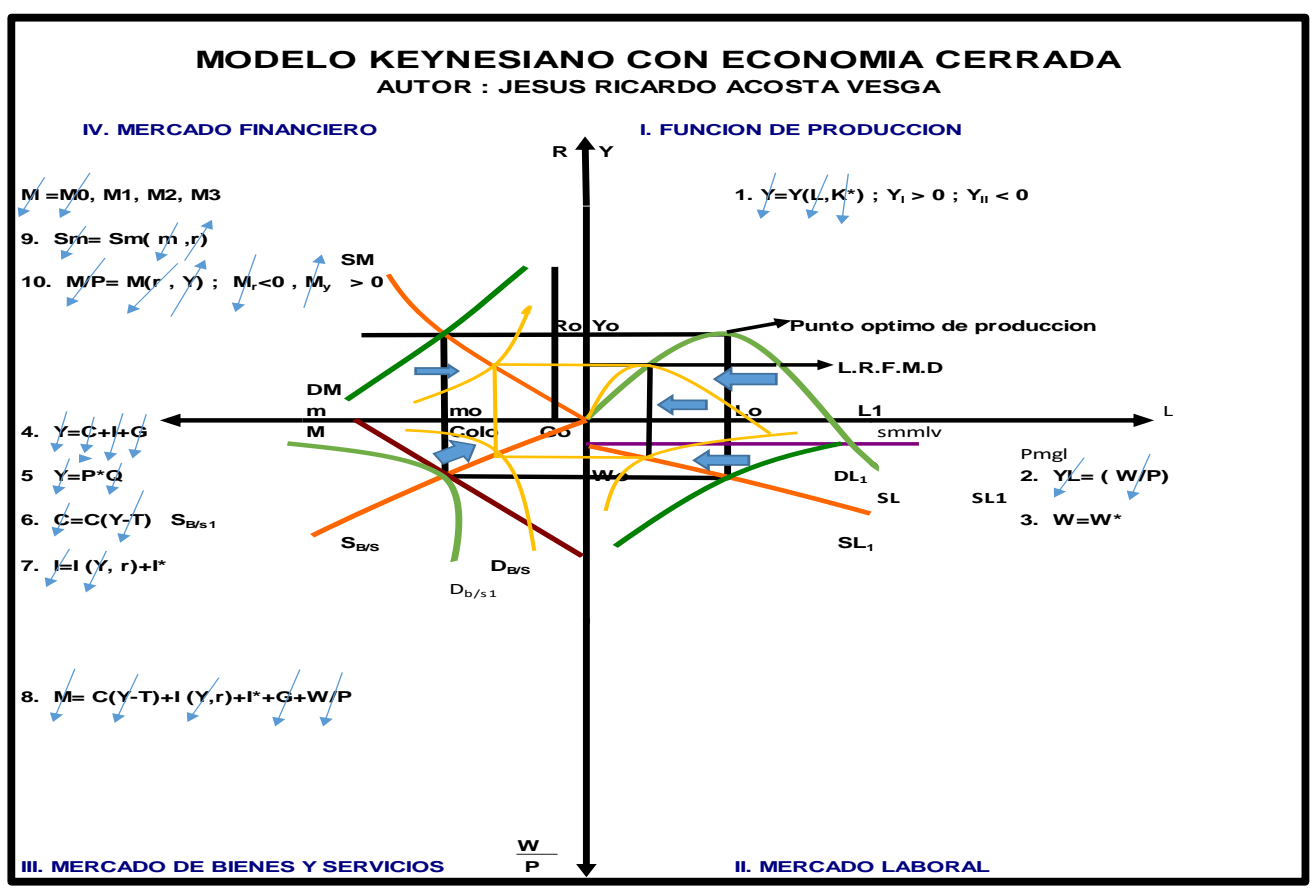

Anexo. Ilustración No. 86. Movimiento de las variables afectadas.

La Solución: Para este caso hay varias respuestas entre ellas una es incrementar el gasto público para reactivar la economía y así volver al punto de equilibrio, otra solución sería que el Banco de la Republica, aumentara las emisiones de dinero y así reactivar la economía y volver al punto de equilibrio.

6. Utilizando el diagrama del modelo Keynesiano cerrado con todas las ecuaciones, analice que pasa cuando aumenta el gasto público.

Cuando aumenta el gasto público se reactiva la economía y esto hace que exista una expansión monetaria y hace que la economía crezca. 
Modelo con movimiento de las variables afectadas

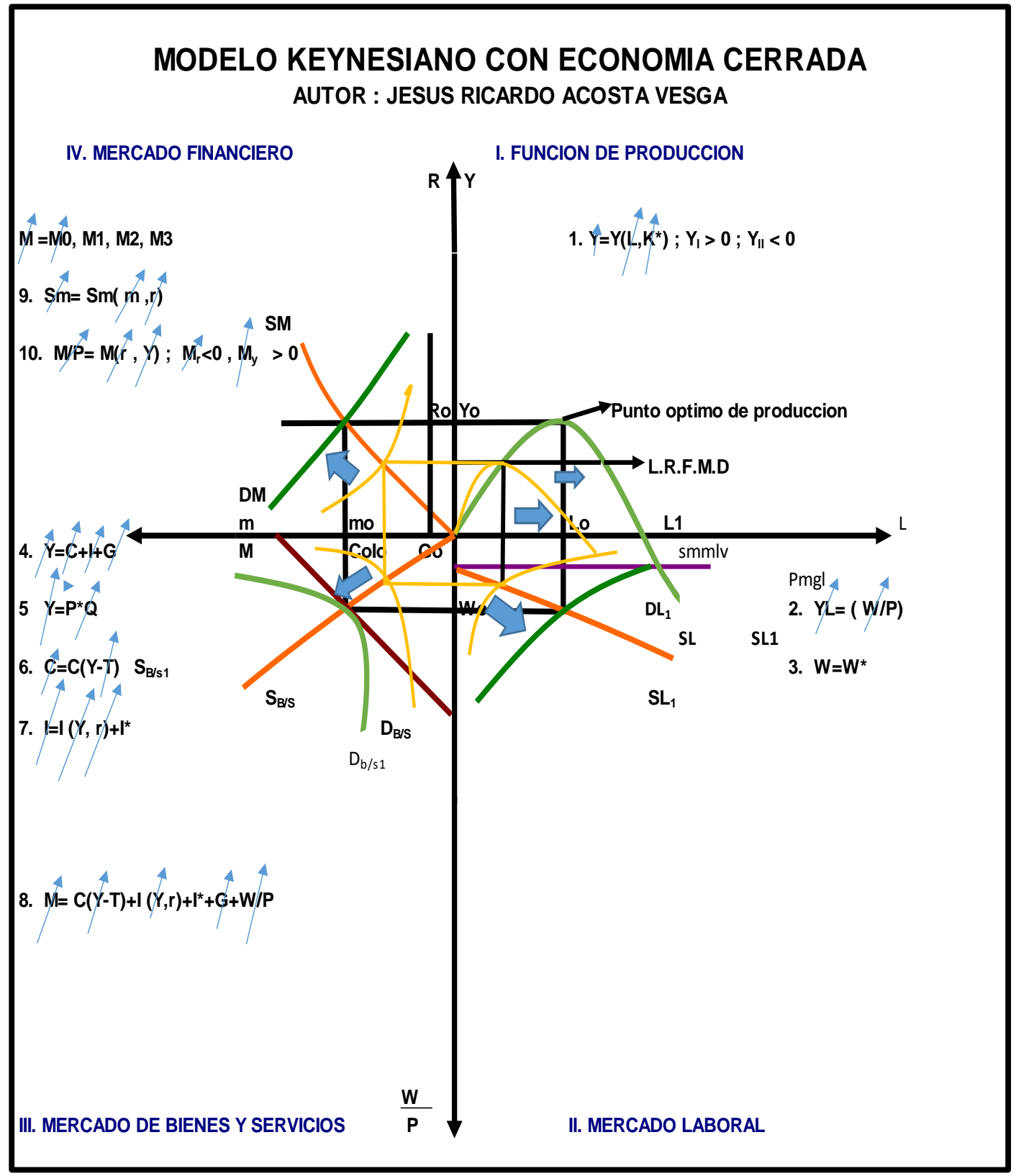

Anexo. Ilustración No. 87. Movimiento de las variables afectadas.

7. Utilizando el diagrama del modelo Keynesiano Cerrado con todas las ecuaciones, analice que pasa cuando aumenta el consumo de los hogares.

Cuando aumenta el consumo indica que aumentaron los ingresos lo que hace que se incrementé la inversión y se haga una expansión monetaria en la economía. 
Modelo con movimiento de las variables afectadas

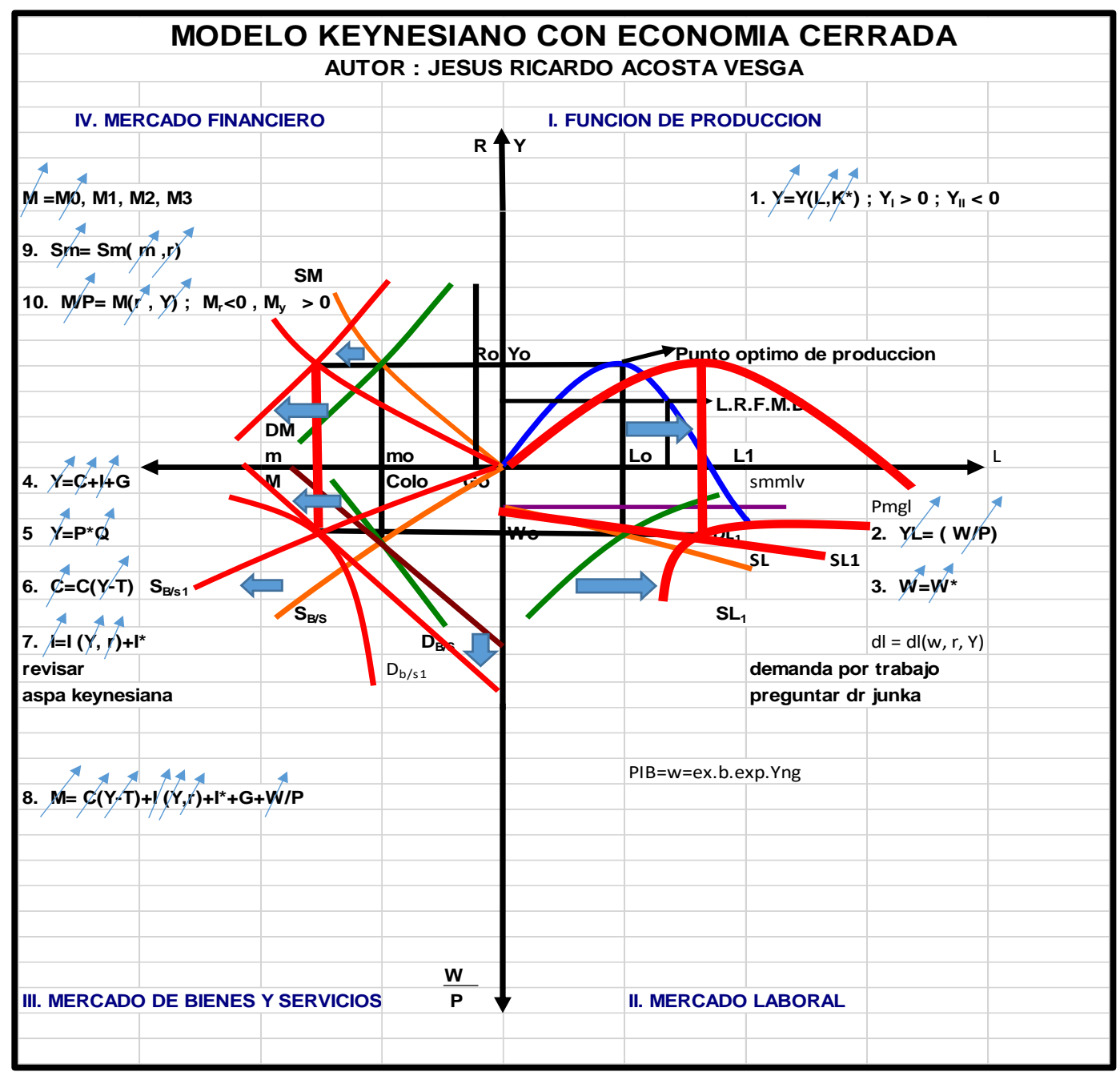

Anexo. Ilustración No. 88. Movimiento de las variables

La solución: Para volver 1 punto de equilibrio debemos aumentar los impuestos y con esto reducimos la liquidez qué existe en la economía y así volvemos al punto de equilibrio la economía.

8. Utilizando el diagrama del modelo Keynesiano cerrado con todas las ecuaciones, analice que pasa cuando aumenta la inversión.

Si hay un aumento en la inversión es divido a que se incrementaron los ingresos y esto nos lleva a una expansión monetaria. 
Modelo con movimiento de las variables afectadas

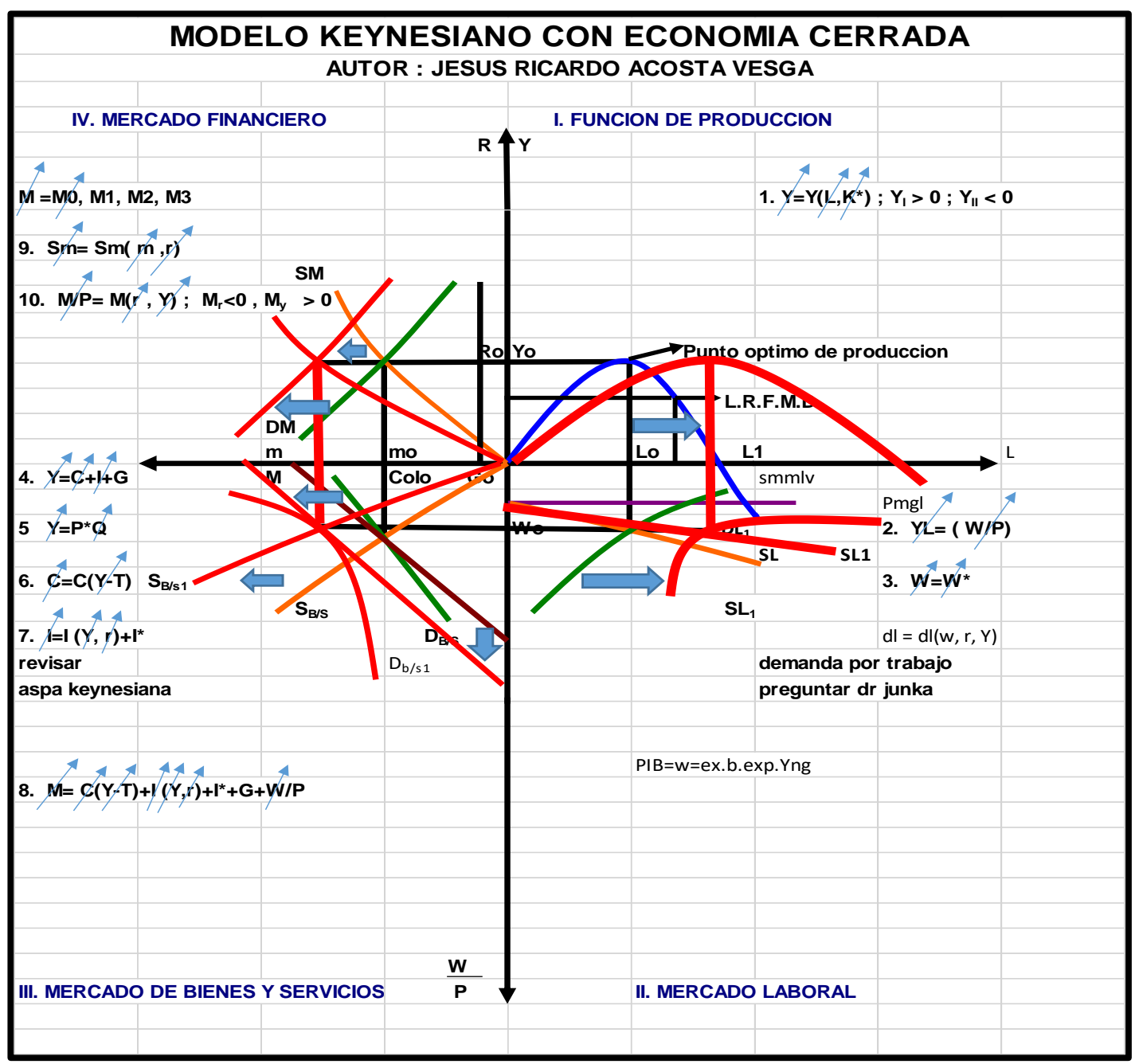

Anexo. Ilustración No. 89. Movimiento de las variables afectadas.

La solución: Para volver 1 punto de equilibrio debemos aumentar los impuestos y con esto reducimos la liquidez qué existe en la economía y así volvemos al punto de equilibrio la economía.

9. Utilizando el diagrama del modelo Keynesiano cerrado con todas las ecuaciones y analice que pasa cuando disminuye la tasa de interés.

Si disminuye la tasa de interés esto ocasiona que la gente demande más dinero porque el costo del dinero es más barato y esto reactiva la economía y origina una 
expansión monetaria.

Modelo con movimiento de las variables afectadas

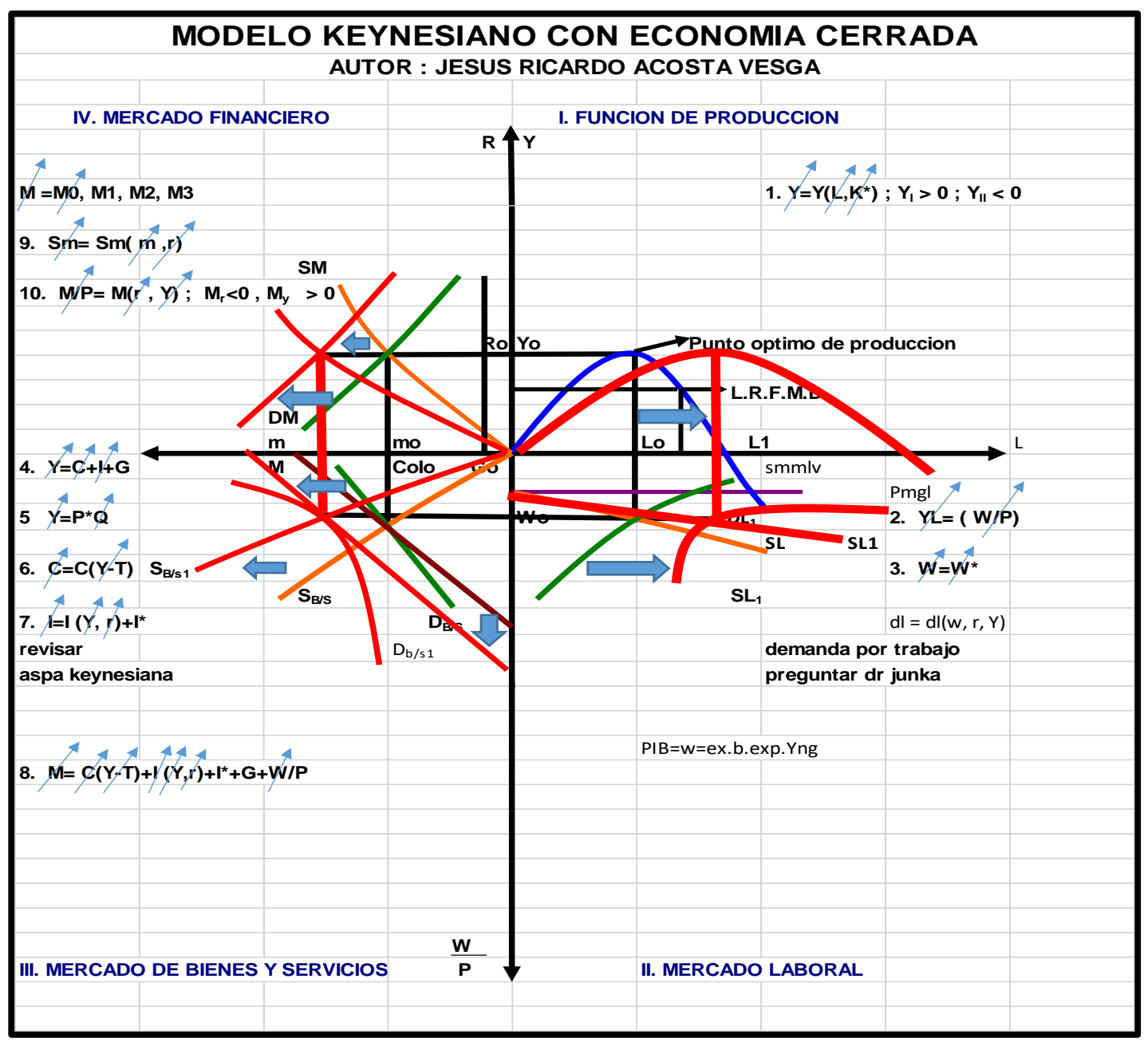

Anexo. Ilustración No. 90. Movimiento de las variables afectadas.

La solución: Para volver al punto de equilibrio debemos aumentar los impuestos y con esto reducimos la liquidez qué existe en la economía y así volvemos al punto de equilibrio la economía.

10. ¿Usted cree que el diagrama del modelo le da las herramientas necesarias para conocer de una forma más sencilla la comprensión de la economía?

El modelo nos brinda una mayor facilidad de comprender y entender las diferentes situaciones económicas mediante las formulas lo que nos facilita saber cómo se comporta 
la economía o el mercado con las diferentes situaciones.

Universidad Monserrate de la facultad de Finanzas y negocios internacionales en la asignatura de Macroeconomía. II. En el sexto semestre en el periodo 2016 - 2.

Ellos vieron economía de forma tradicional.

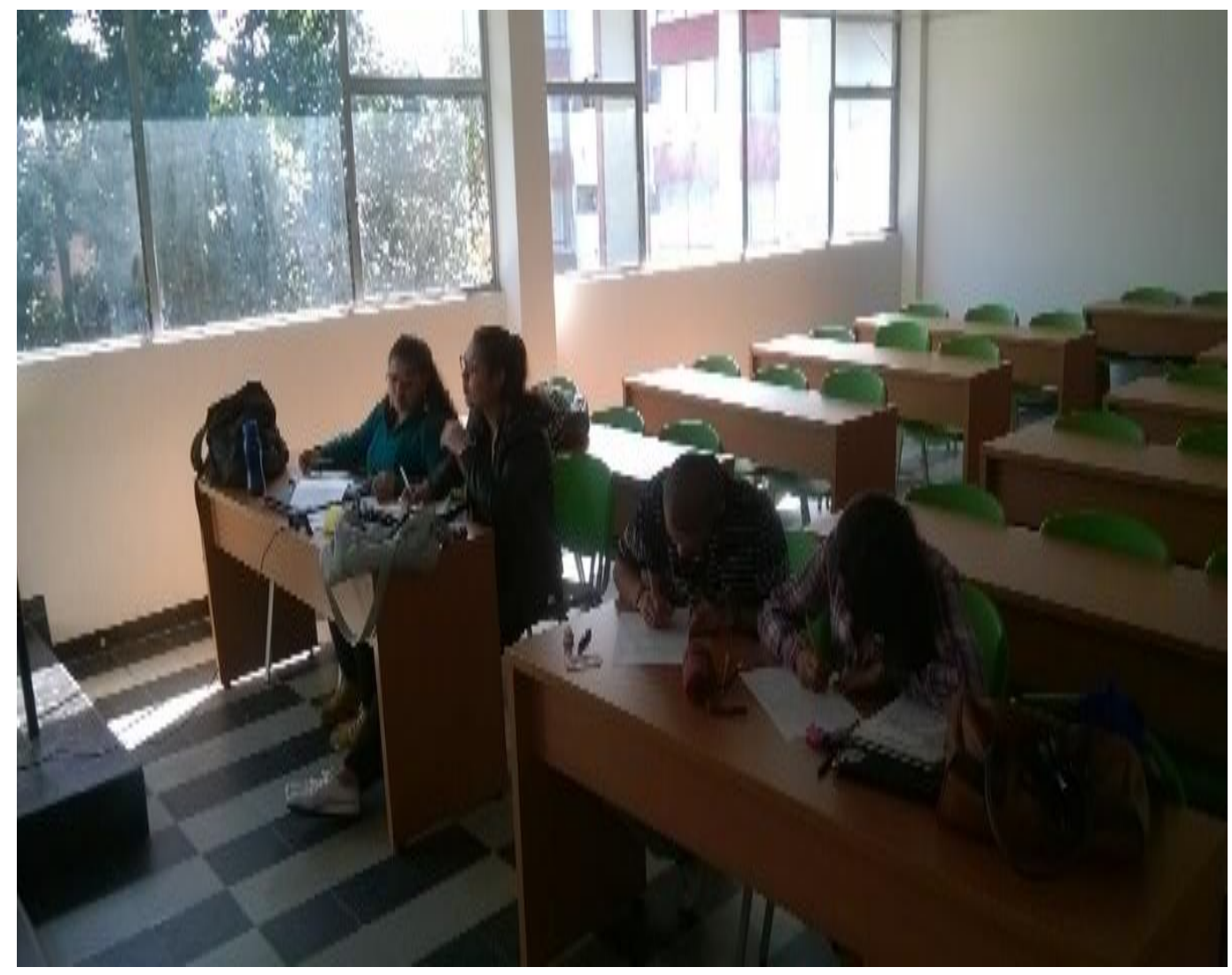

Enseñanza De La Macroeconomía A Estudiantes De Pregrado De La Forma Tradicional A Continuación Se Ve Como Se Debería Responder El Test. 


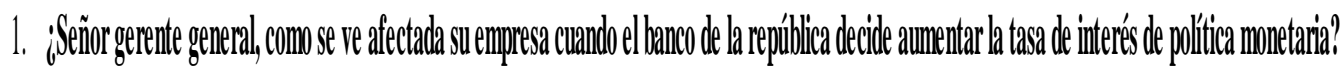
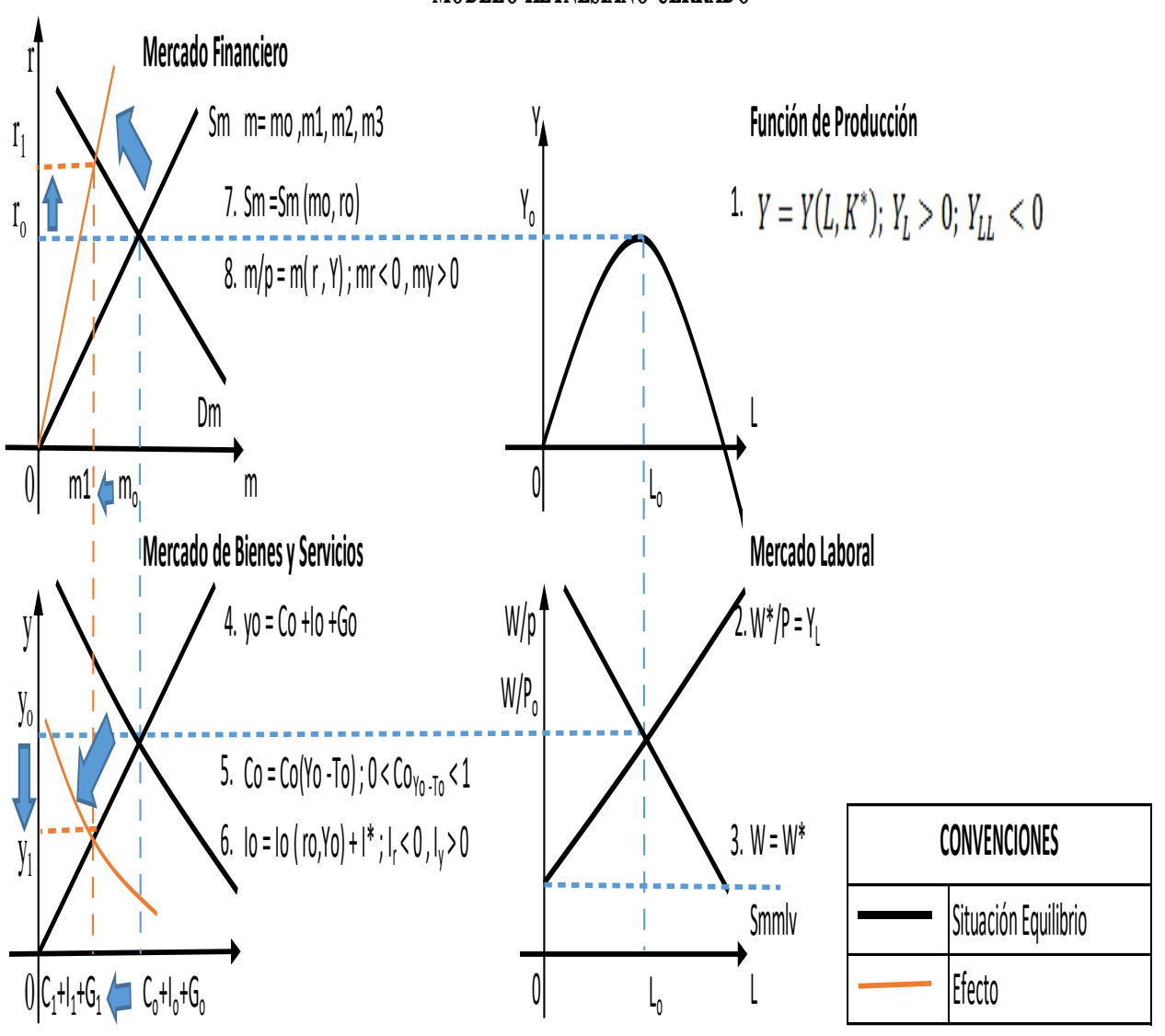

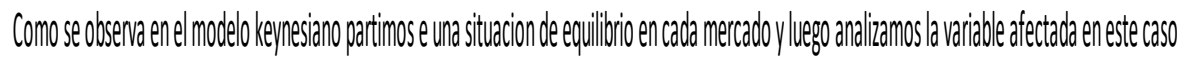

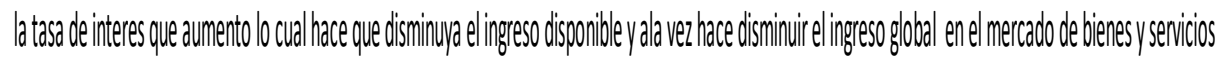

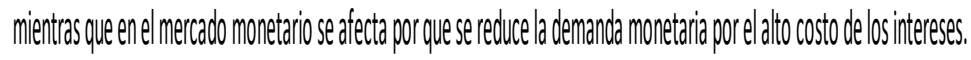

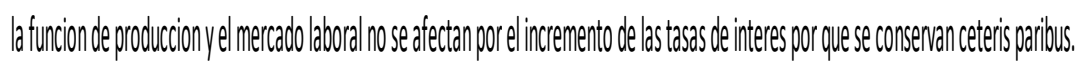

\begin{tabular}{|c|c|c|c|c|c|c|c|c|c|}
\hline$R$ & $\gamma \cdot t$ & $l$ & $\mid$ & $G$ & $m$ & D & $\gamma$ & $l$ & $W / P$ \\
\hline$\uparrow$ & $\Downarrow$ & $\downarrow$ & $\downarrow$ & $\downarrow$ & $\Downarrow$ & $\downarrow$ & $\downarrow$ & $\downarrow$ & $\downarrow$ \\
\hline
\end{tabular}

Ilustración No. 91. Movimiento de las variables afectadas. 


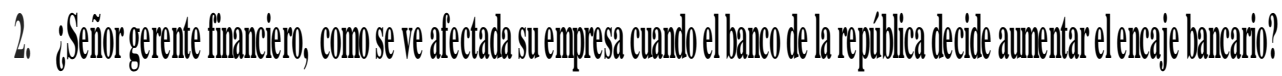
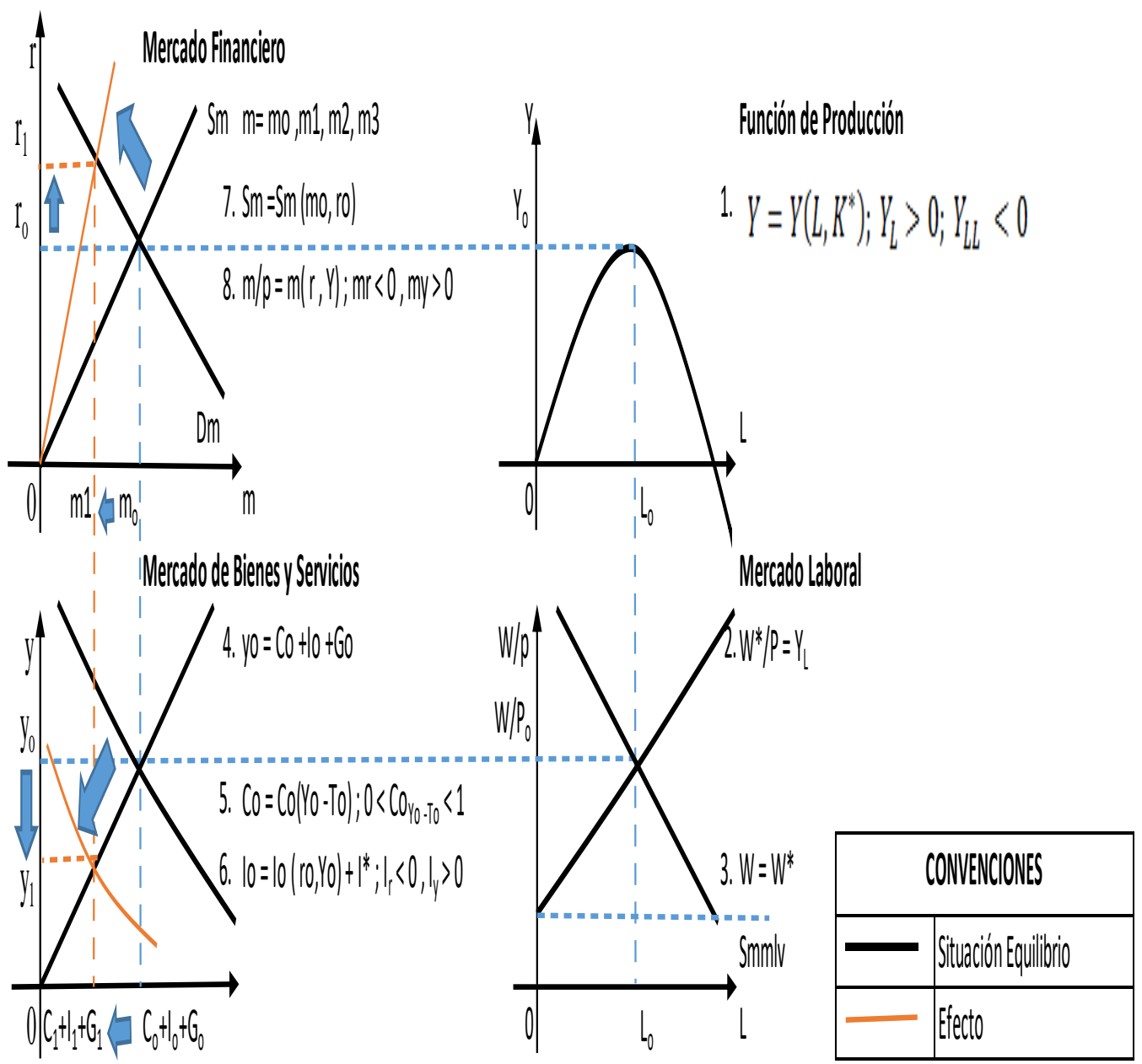

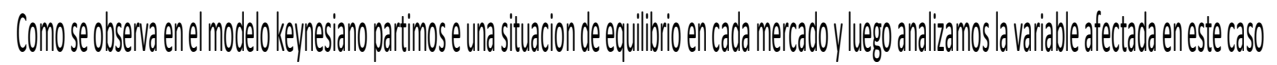

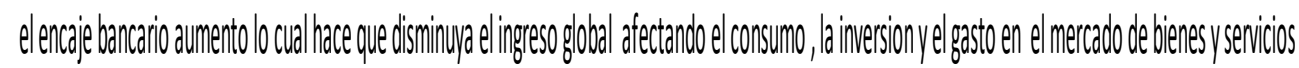

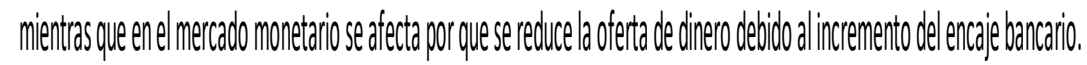

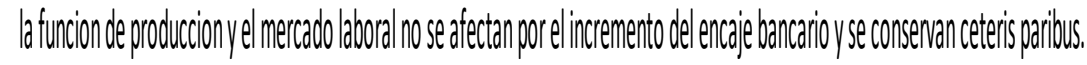

\begin{tabular}{|c|c|c|c|c|c|c|c|c|c|}
\hline$E B$ & $y$ & l & | & $G$ & m & Sm & $\gamma$ & l & $W / P$ \\
\hline$\uparrow$ & $\downarrow$ & $\downarrow$ & $\downarrow$ & $\downarrow$ & $\downarrow$ & $\downarrow$ & $\phi$ & $\phi$ & 4 \\
\hline
\end{tabular}

Ilustración No. 92. Movimiento de las variables afectadas. 


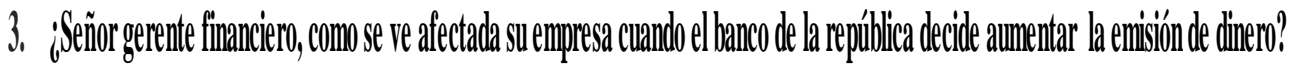

\section{MODELO KENESSANO CERRADO}

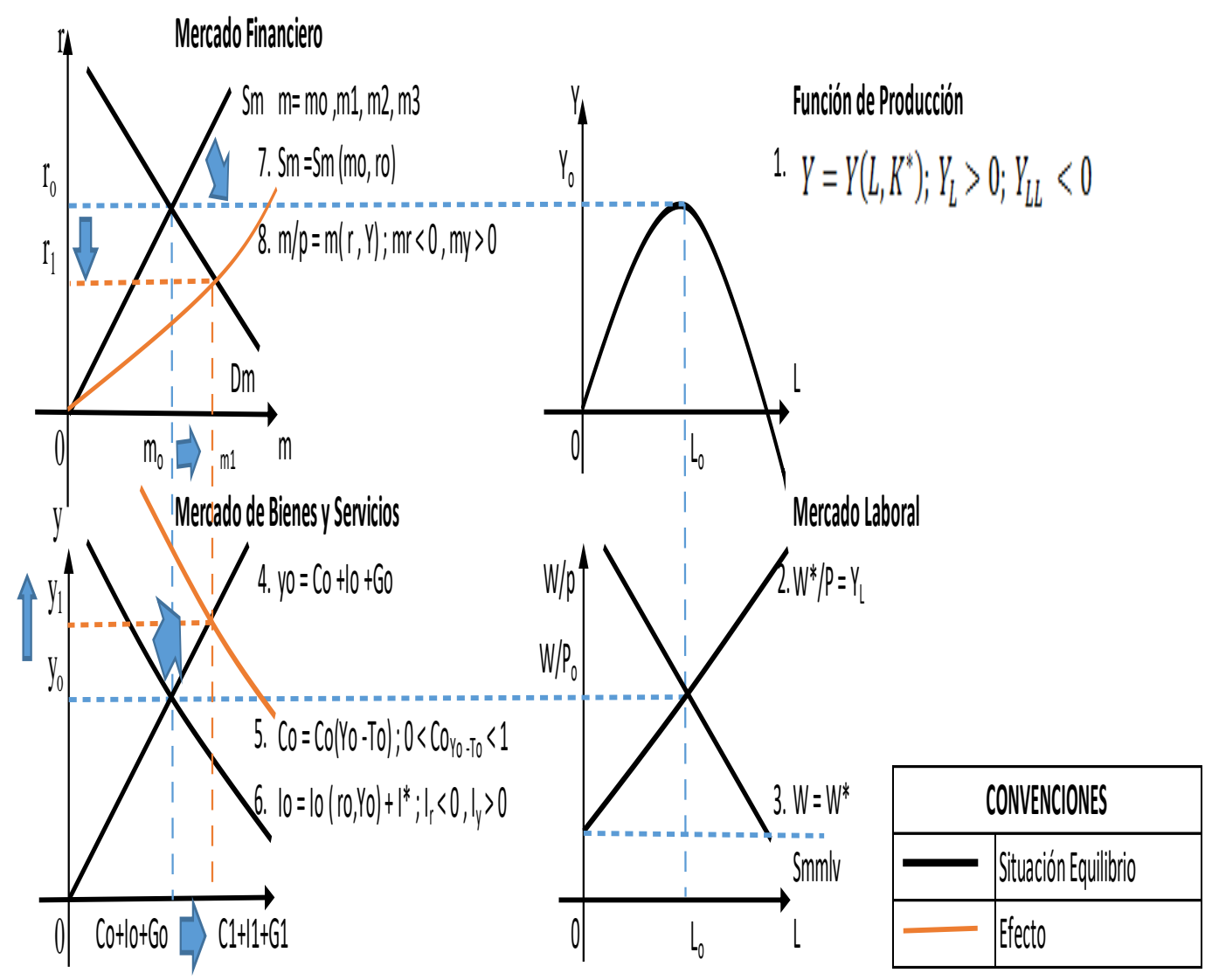

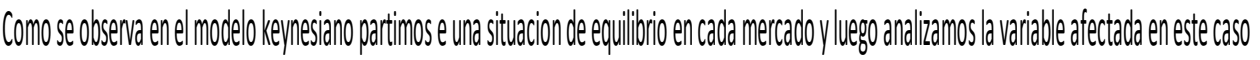

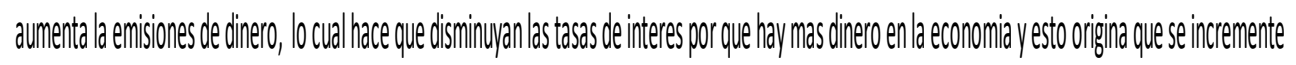

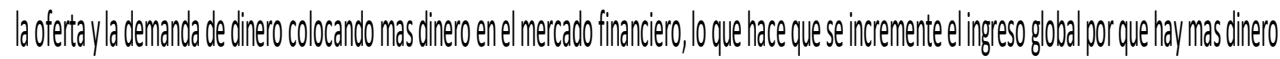
para consumo, inversion y gasso en e mercado de bienes y senvicos. En cuantio a la funcion de produccion ya mercado laboral no se ven decctados yse mantitienen ceteris paribus.

\begin{tabular}{|c|c|c|c|c|c|c|c|c|c|c|}
\hline EmD & $y$ & $c$ & 1 & $G$ & $m$ & Dm & Sm & l & W/P & $Y$ \\
\hline$\uparrow$ & $\uparrow$ & $\uparrow$ & $\uparrow$ & $\uparrow$ & $\uparrow$ & $\uparrow$ & $\uparrow$ & 4 & 4 & 4 \\
\hline
\end{tabular}

Figura Ilustración No. 93. Movimiento de las variables afectadas. 
4. Señor gerente de producción, que pasa cuando el gobierno decide aumentar los instrumentos de política fiscal, como se afectan las variables del modelo? MODELO KEINESIANO CERRADO

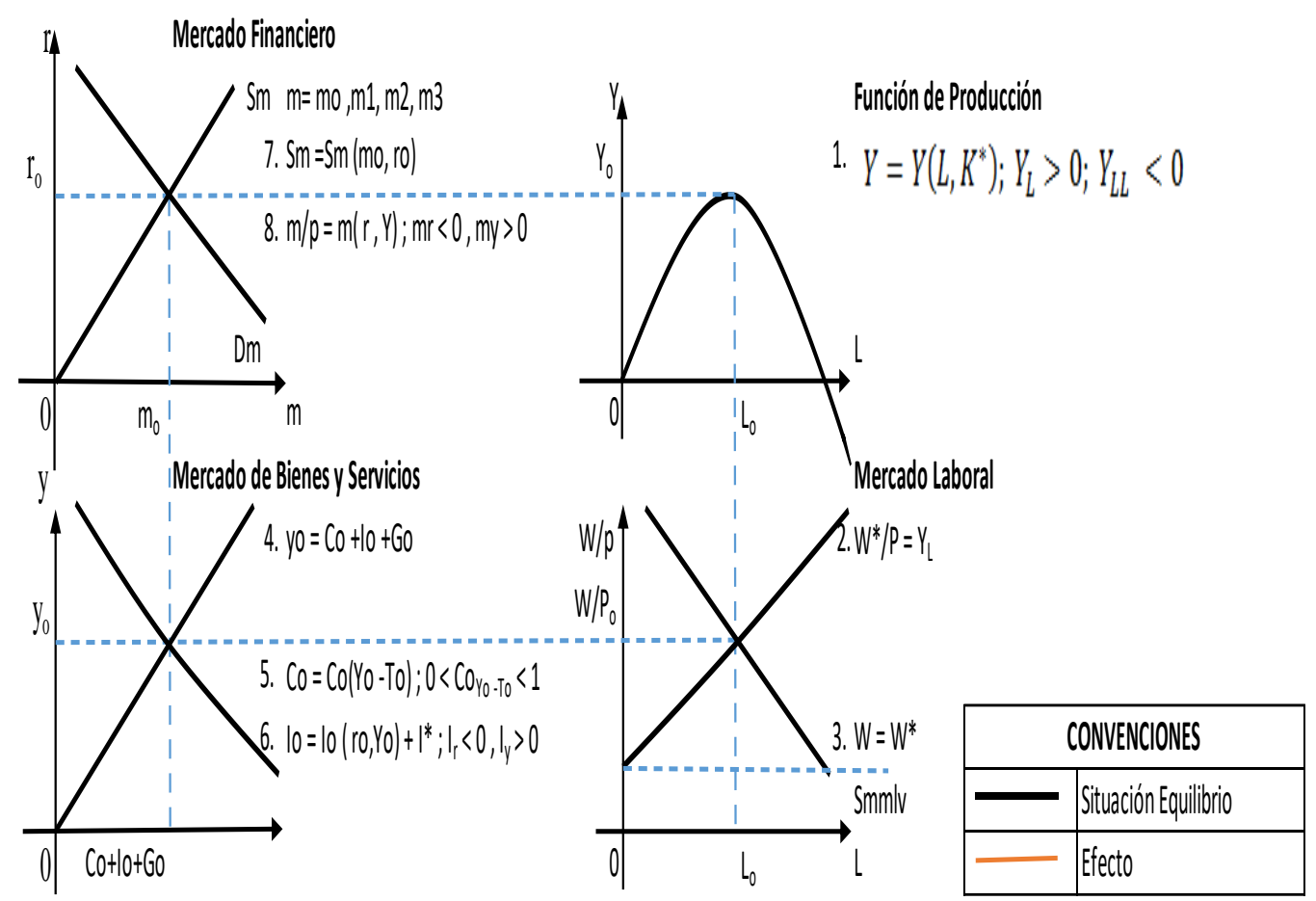

Como se observa en el modelo keynesiano partimos e una situacion de equilibrio en cada mercado y luego analizamos la variable afectada en este caso si el gobierno decide aumentar los instrumentos de politica fiscal, va a incrementar los impuestos yel gasto publico lo que conlleva por un lado a reducir el ingreso disponible, pero por el otro lado al incrementar el gasto aumenta el ingreso global de la economia logrando una mejor redistribucion del ingreso lo cual compensa con el aumento de los impuestos lo que hace que el modelo seequilibrey no se afecte. y por lo tanto no tiene ningun efecto si los cambios son igualmente son igualmente proporcionales.

\begin{tabular}{|c|c|c|c|c|c|c|c|c|c|c|}
\hline$T$ & y & C & | & $G$ & $\mathrm{~m}$ & Dm & Sm & L & $W / P$ & Y \\
\hline 75 & 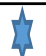 & 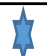 & $\Delta$ & A & is & 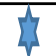 & 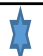 & 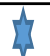 & $\$$ & 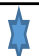 \\
\hline
\end{tabular}

Ilustración No. 94. Movimiento de las variables afectadas. 
5. Utillizando el diagrama del modelo Keynesiano cerrado con todas las ecuaciones, analice que pasa cuando disminuye la oferta monetarila.

\section{VIODELO KENESSANO CERRADO}

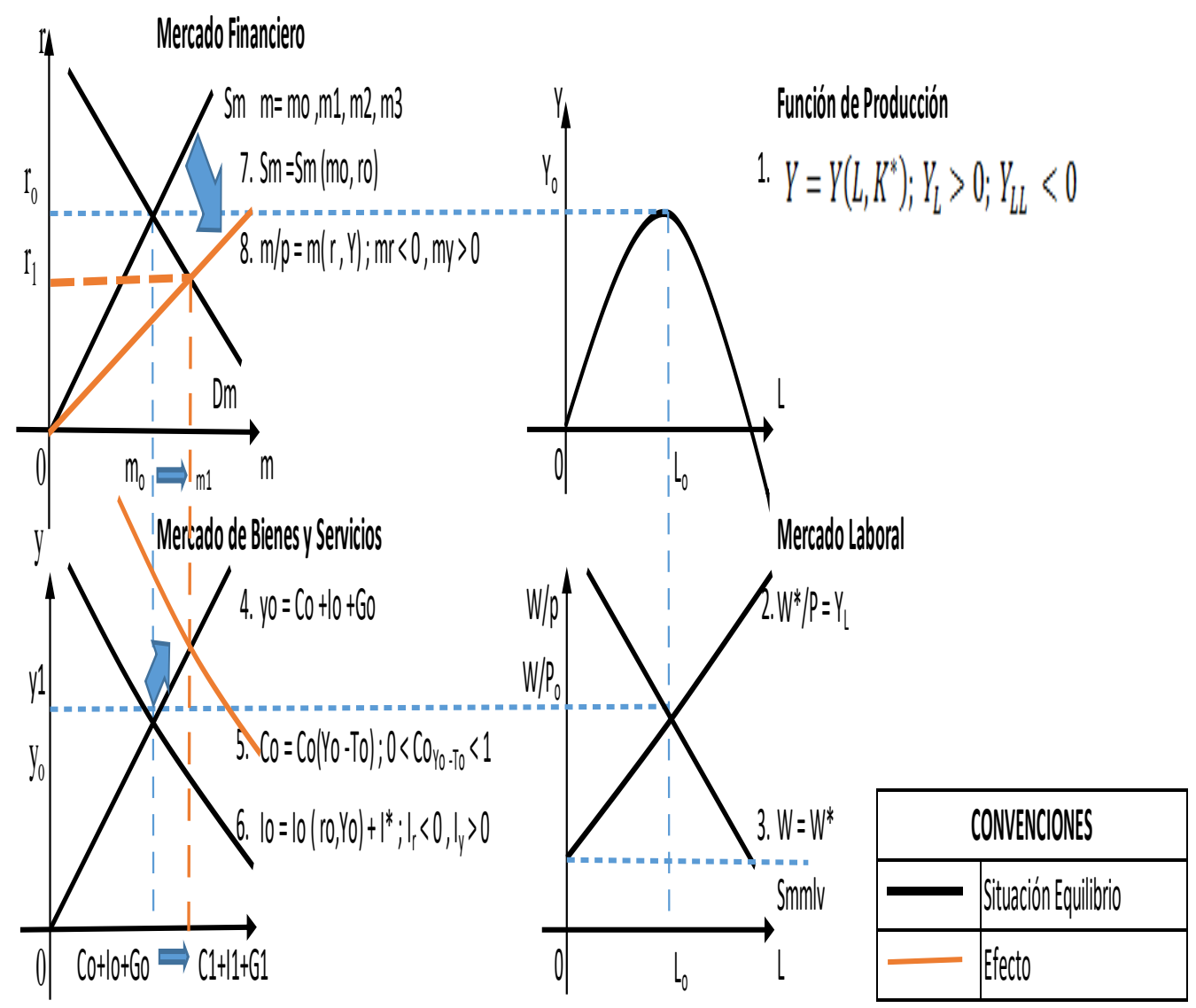

Como se observa en el modelo keynesiano partimos e una situacion de equil brio en cada mercado y luego analizamos la variable afectada en este caso siel gobierno decide aumentar la oferta monetaria, esto hace que las tasas de intereses bajen por que hay mas cantidad de dinero en la economia, por lo tanto tambien auementa la demanda de dinero y hay una expansion monetaria enel mercado financiero en cuanto al mercado de bienes y servicios aumenta e lingresso global y esto origina unamayor inversion, consumo y gasto, en cuento a los cuadrantes de produccion y de mercado laboral no se ven afectados puesto que ellos permanecen ceteris parhbus por que va han sido contratados previamente.

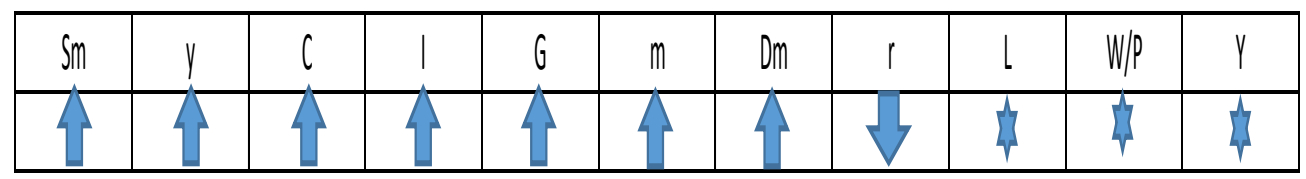

Ilustración No. 95. Movimiento de las variables afectadas. 


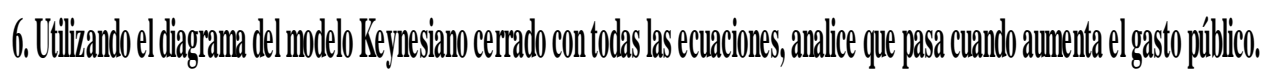

\section{MODELOKENESSHOC CERRADO}

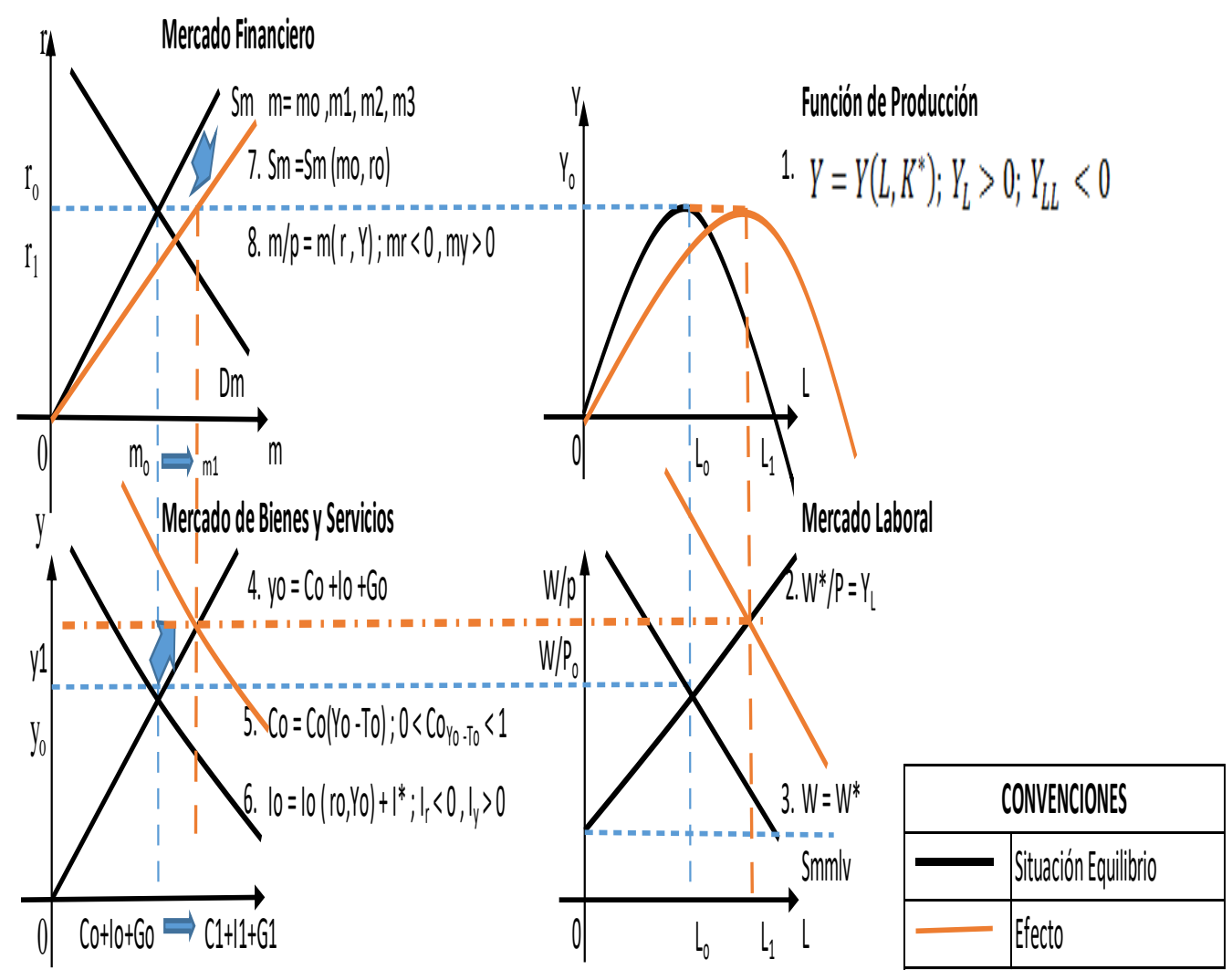

Comose osserva enel modelo keynesiano partimos e una situacion deequilbrio en cadda mercado y luego analizamos la variable afectadda en este caso siel gobiemo decide aumentarele gasto publico esto hace equese incrementel la producción yse contratem mas mano de obra esta decisón se toma para reactivar l a cconomia aumentare e empleo, la canidida de dinero en la economiat,emiendo como efecto una expansion monetaria

\begin{tabular}{|c|c|c|c|c|c|c|c|c|c|c|}
\hline$G$ & y & C & | & $G$ & $m$ & $\mathrm{Dm}$ & r & l & $W / P$ & $\gamma$ \\
\hline 7 & 7 & 7. & 77 & 75 & 7 & 7 & 7. & 1 & 7 & 7 \\
\hline
\end{tabular}

Ilustración No. 96. Movimiento de las variables afectadas. 


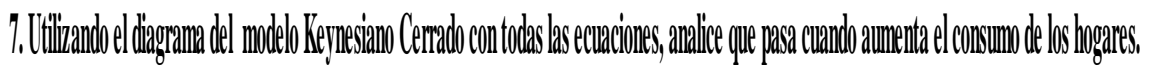

\section{NOODELOKENESEHOCORRRDO}

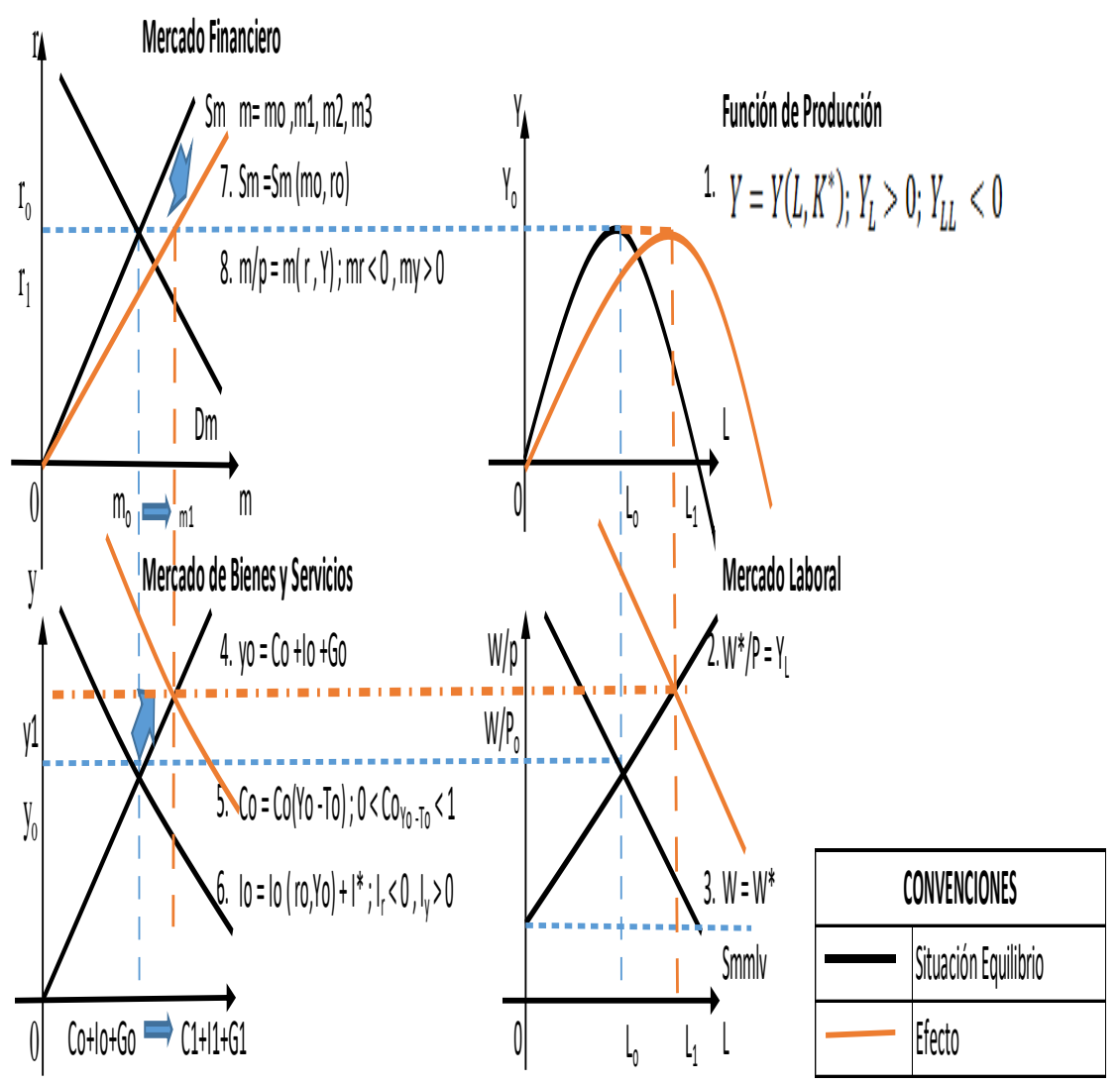

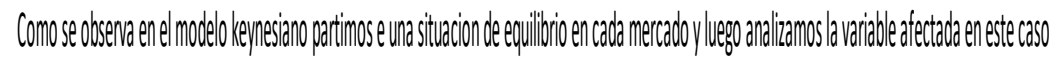

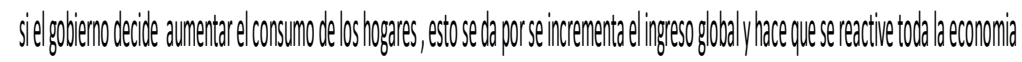

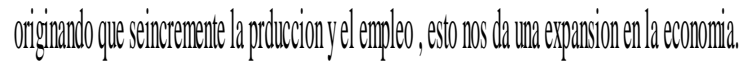

\begin{tabular}{|c|c|c|c|c|c|c|c|c|c|c|}
\hline$G$ & y & $l$ & | & $G$ & m & $\mathrm{Dm}$ & 1 & l & $W / P$ & y \\
\hline 7 & 7 & 1 & 7 & 71 & $\lambda$ & A & 1 & 1 & 1 & 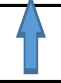 \\
\hline
\end{tabular}

Ilustración No. 97. Movimiento de las variables afectadas. 


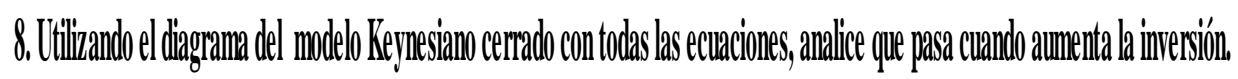

\section{MODELOKEENESHNOCERRADO}

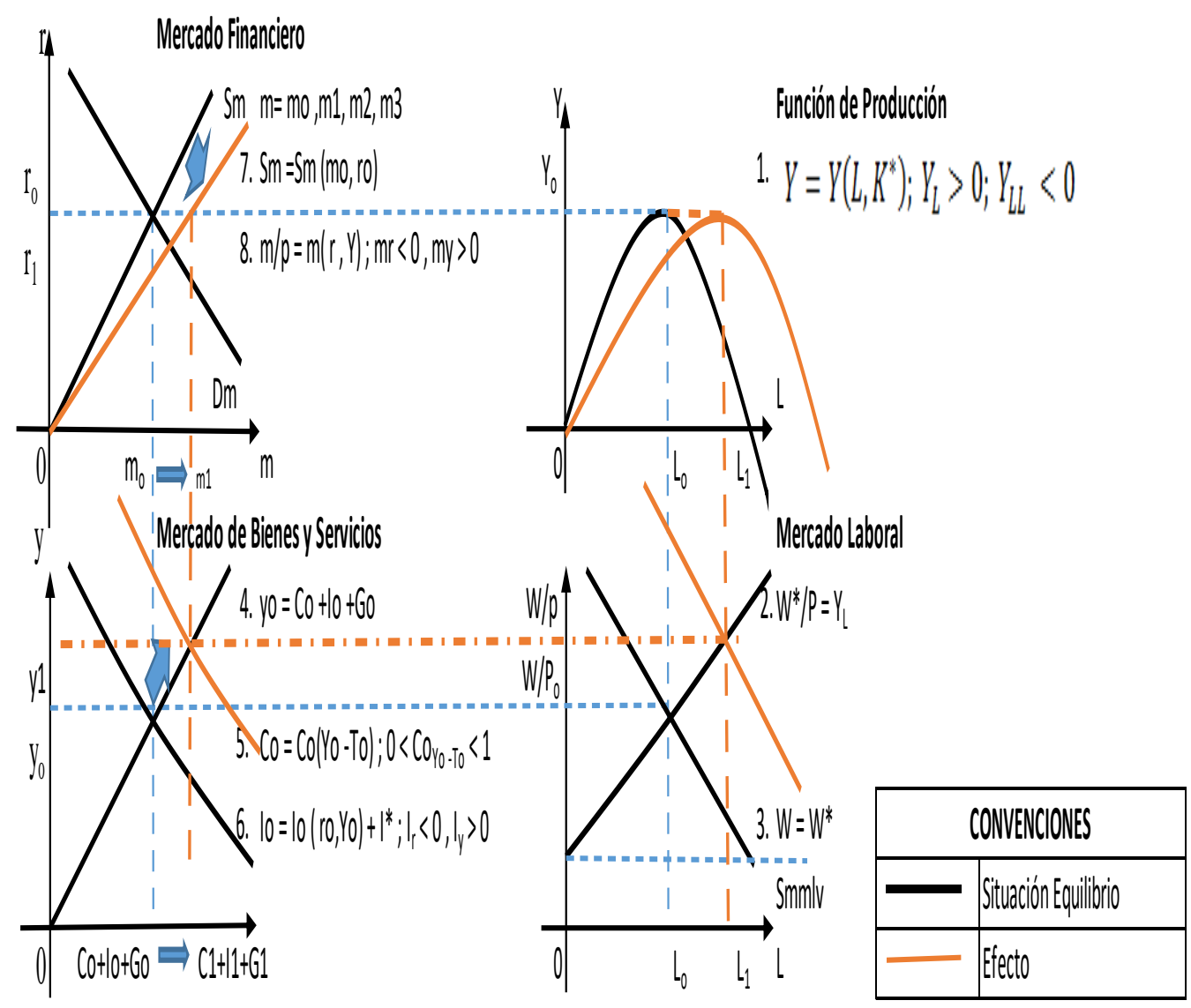

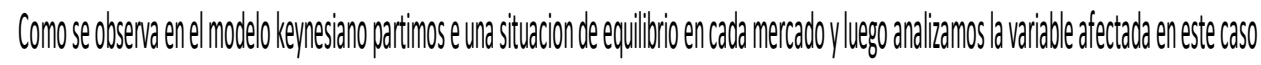

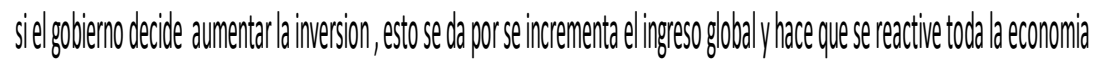

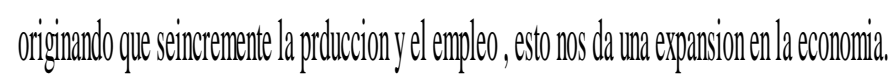

\begin{tabular}{|c|c|c|c|c|c|c|c|c|c|c|}
\hline$G$ & $y$ & c & | & $G$ & $\mathrm{~m}$ & Dm & 1 & l & $W / P$ & Y \\
\hline 7 & 4 & & 7 & & 7 & 7 & 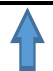 & 4 & 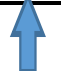 & 7 \\
\hline
\end{tabular}

Ilustración No. 98. Movimiento de las variables afectadas. 


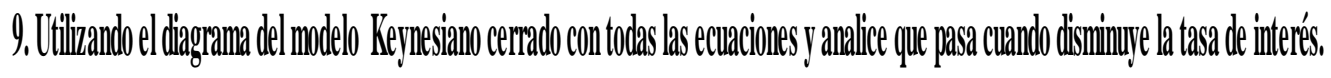

\section{MODELO KENESSANOCERRADO}

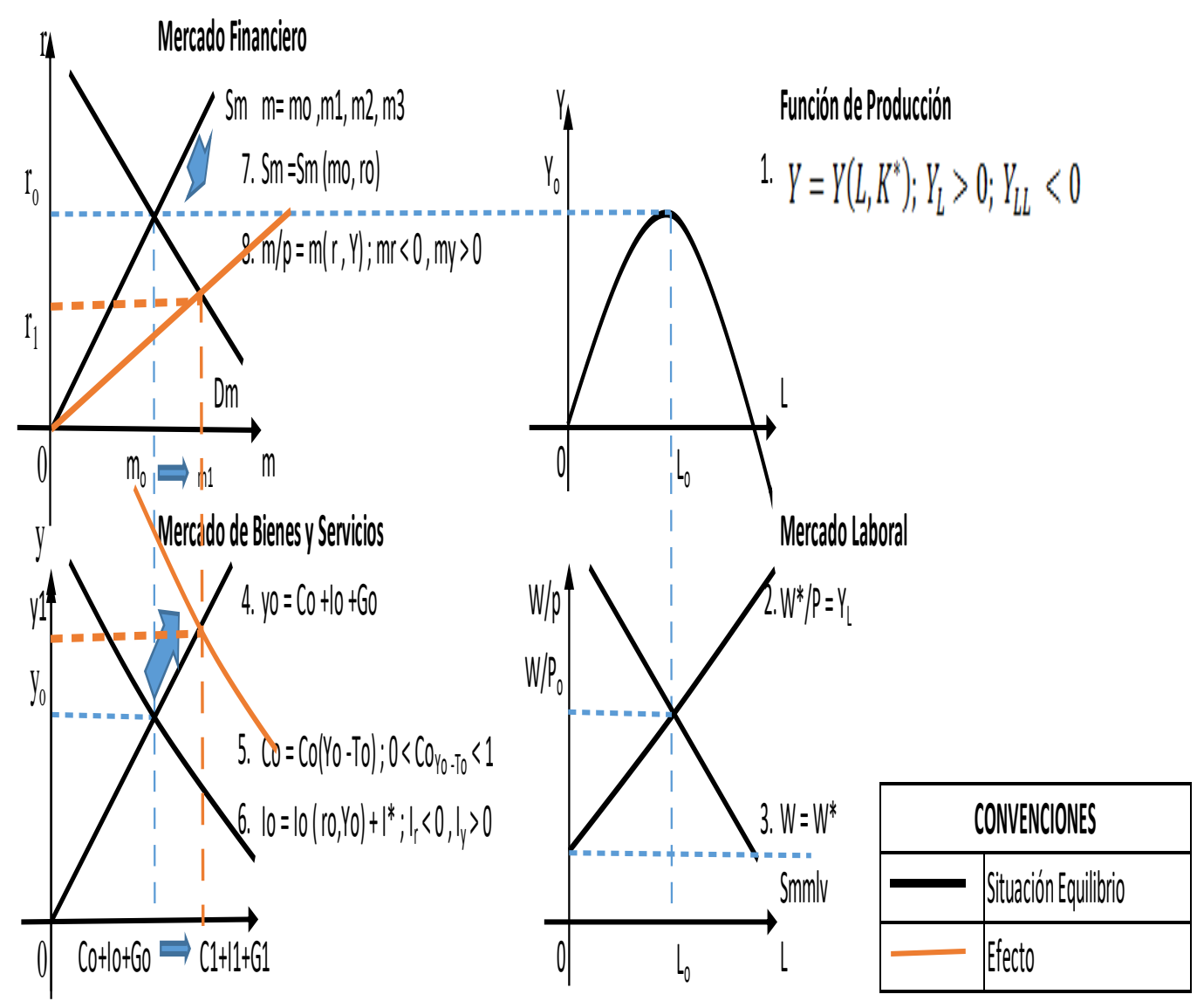

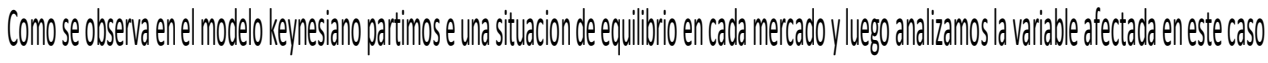

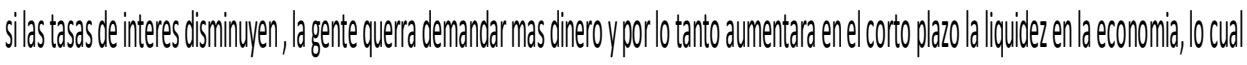
hace que se incremente el ingress global y afeca loa cuadrantes del mercado financiero yel mercado de bienesy servicios, lo oule es la tuncion de produccion yel mercado laboral semantienen ceteris parlibus.

\begin{tabular}{|c|c|c|c|c|c|c|c|c|c|c|}
\hline r & $y$ & C & | & $G$ & $\mathrm{~m}$ & $\mathrm{Dm}$ & $G$ & l & $W / P$ & Y \\
\hline$\sqrt{7}$ & 7 & 7 & 7 & 7 & 4 & 7 & 75 & 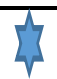 & $\sqrt{1}$ & 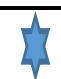 \\
\hline
\end{tabular}

Ilustración No. 99. Movimiento de las variables afectadas.

Nombre: Yesica Alejandra Caicedo 
Universidad: fundación universitaria Monserrate

Programa: finanzas y negocios

Fecha: 17/11/2016

A continuación se presentan diez preguntas tipo Saber Pro a las cuales usted les dará solución.

1. ¿Señor gerente general, como se ve afectada su empresa cuando el banco de la república decide aumentar la tasa de interés de política monetaria?

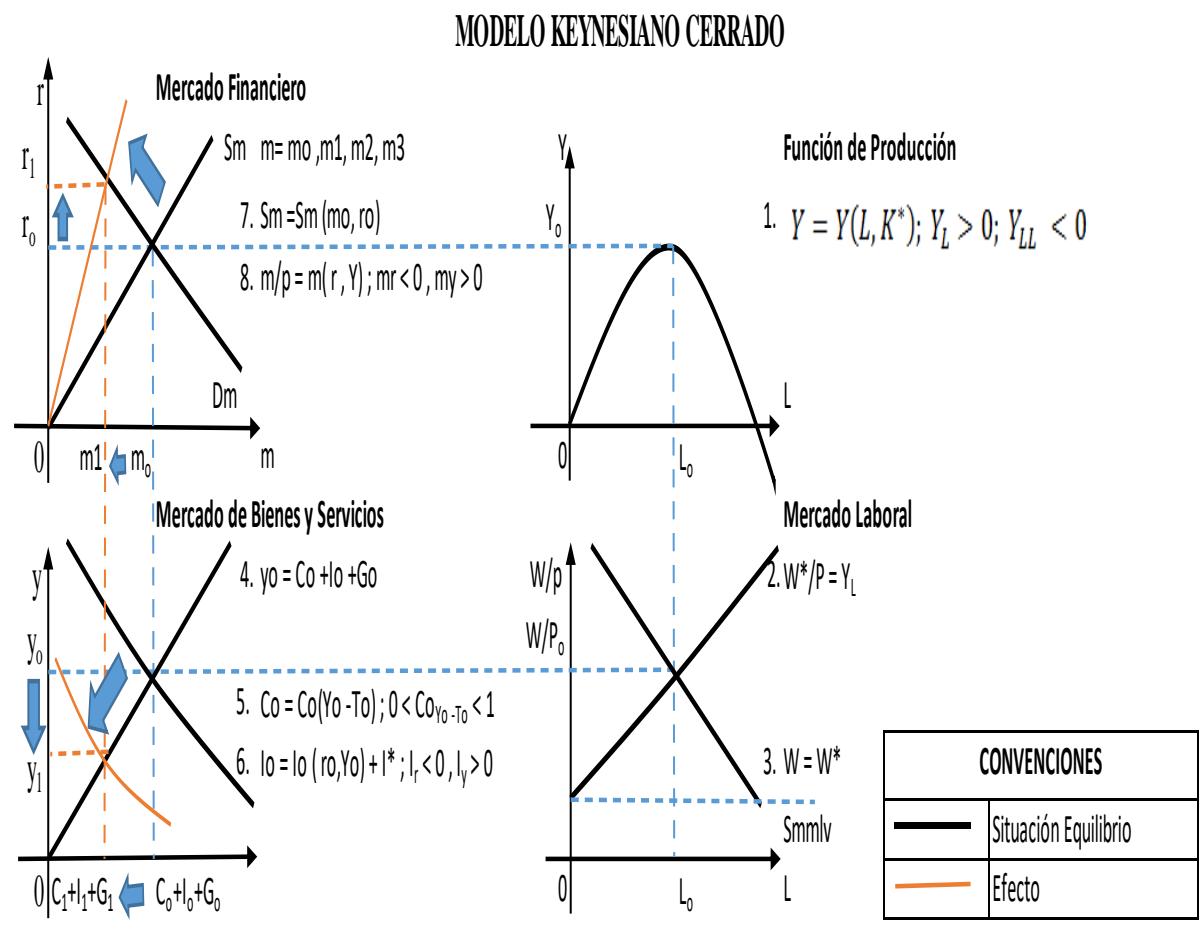

Como se observa ene I modelo kepnesiano partimos e una situacion de equillbrio en cada mercado y luego analizamos la variable afectada en este caso la tasa de interes que aumento lo cual hace que disminuy a el ingreso disponible y ala ver hace disminuire lingresso global en el mercado de bienes y servicios mientras que enel mercado monetario se afecta por que se reduce la demanda monetaria por el atto costo de los intereses. la funcion de produccion yel mercado laboral no se afectan por el incremento de las tasas de interes por que se conservan ceteris paribus.

\begin{tabular}{|c|c|c|c|c|c|c|c|c|c|}
\hline$R$ & $y-t$ & $C$ & | & $G$ & m & Dm & Y & L & $W / P$ \\
\hline 1 & $\downarrow$ & $\downarrow$ & $\downarrow$ & $\downarrow$ & $\downarrow$ & $\downarrow$ & $\$$ & $\$$ & 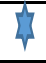 \\
\hline
\end{tabular}

Ilustración No. 100. Movimiento de las variables afectadas. 


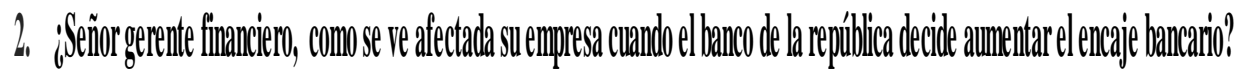

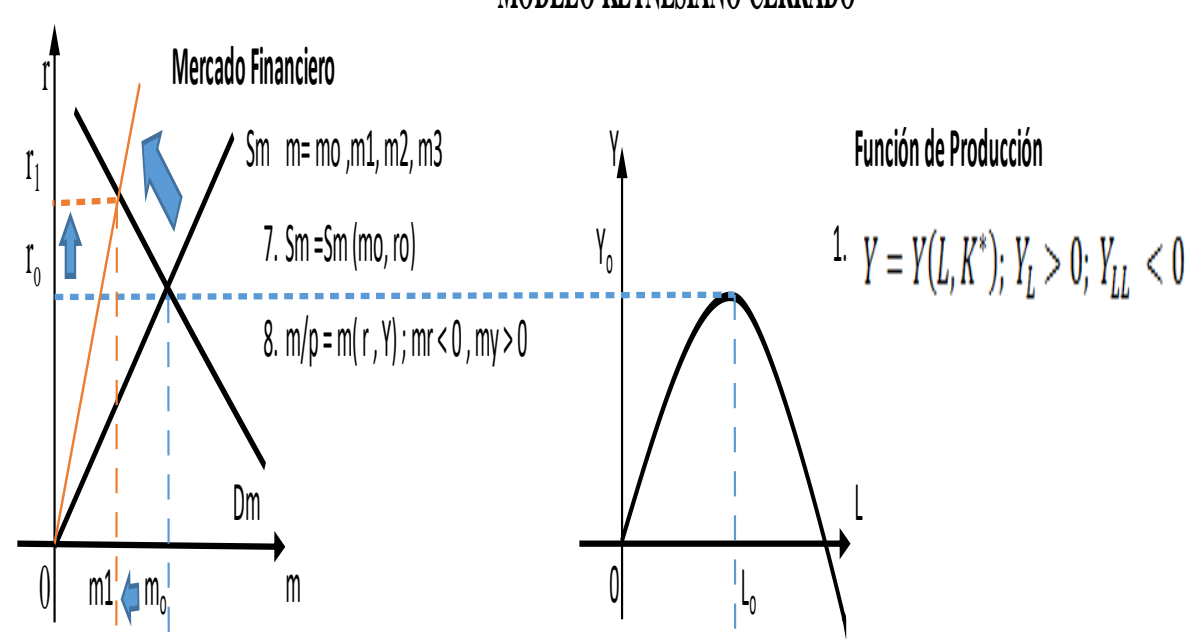

MeradodolebenesyySencios

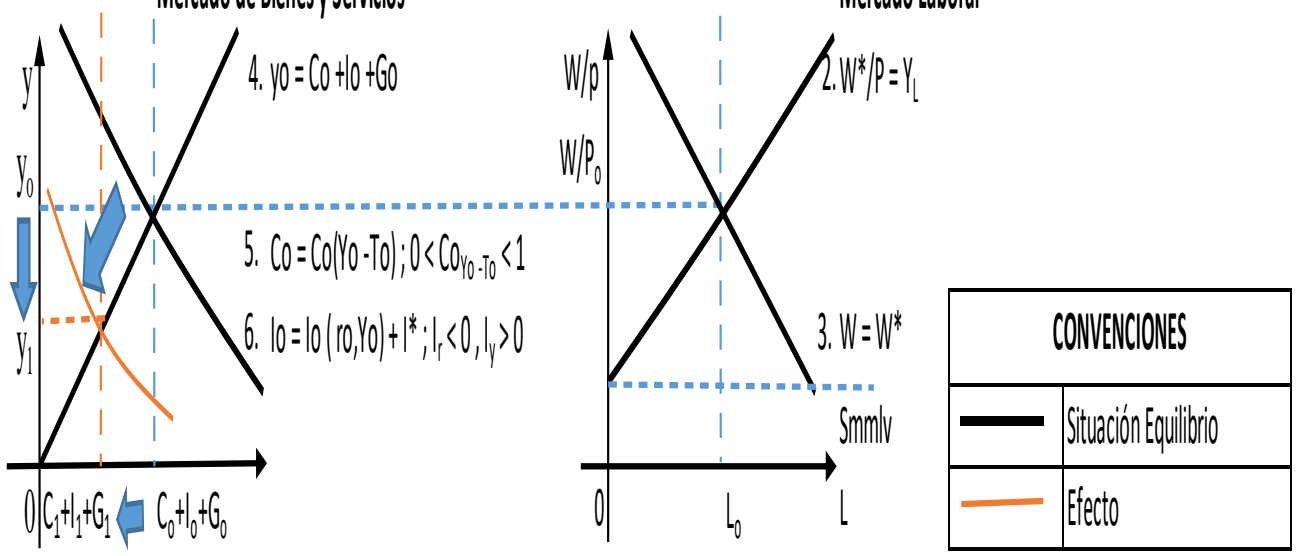

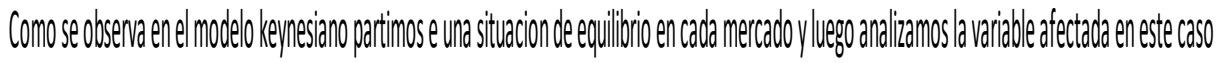

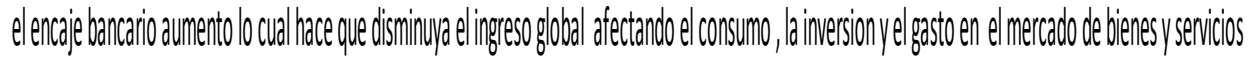

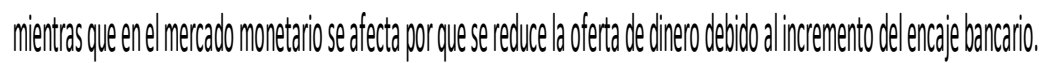

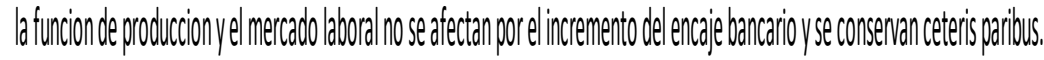

\begin{tabular}{|c|c|c|c|c|c|c|c|c|c|}
\hline$E B$ & $y$ & $l$ & $I$ & $G$ & $m$ & Sm & $\gamma$ & L & W/P \\
\hline$\uparrow$ & $\Downarrow$ & $\downarrow$ & $\downarrow$ & $\Downarrow$ & $\downarrow$ & $\Downarrow$ & $\downarrow$ & $\downarrow$ & $\downarrow$ \\
\hline
\end{tabular}

Ilustración No. 101. Movimiento de las variables afectadas. 


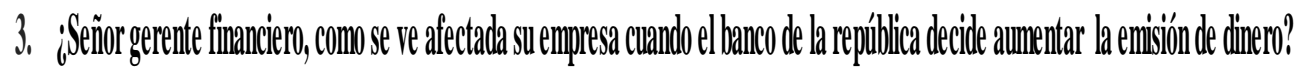

\section{MODELO KEWESSANOCERRADO}

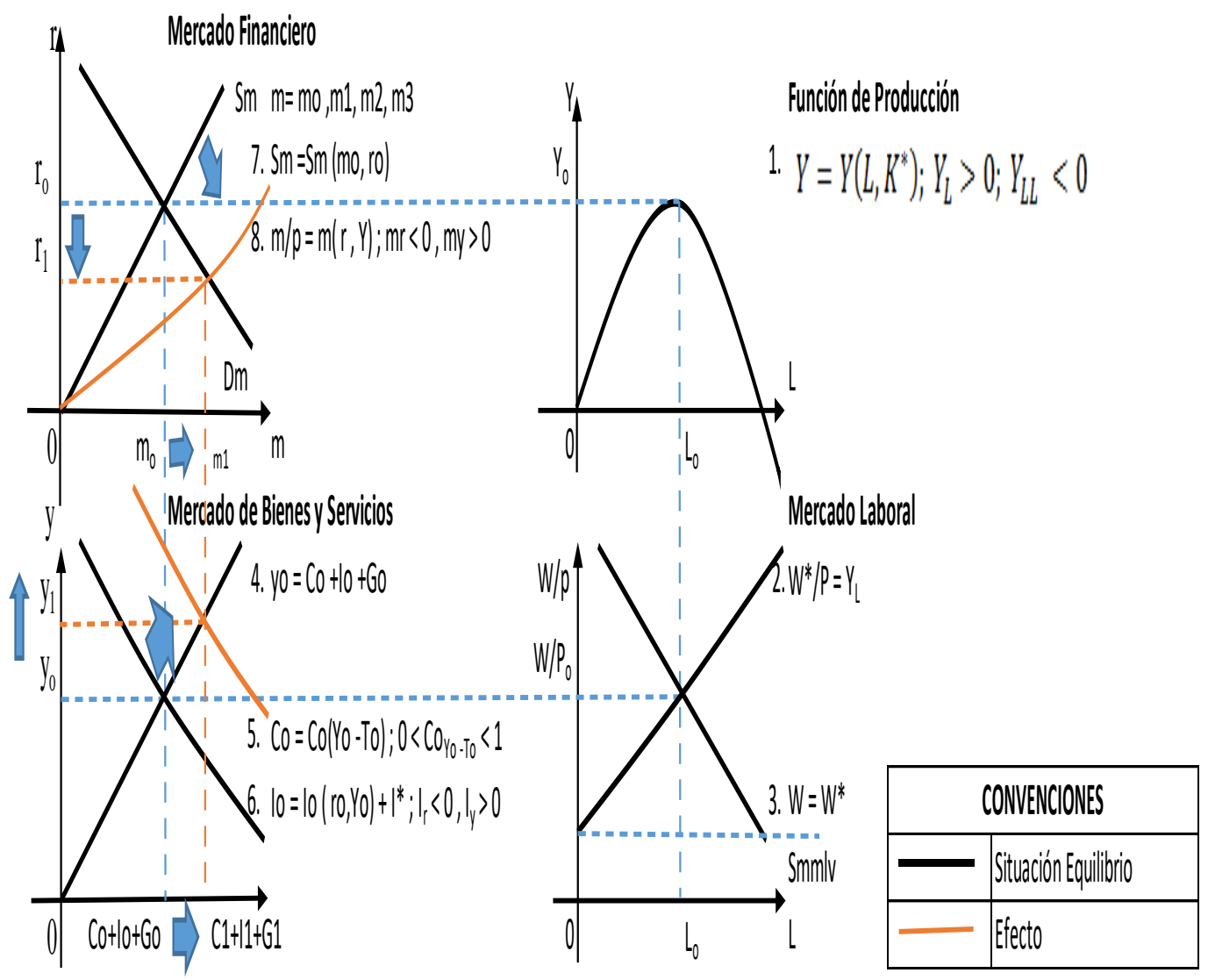

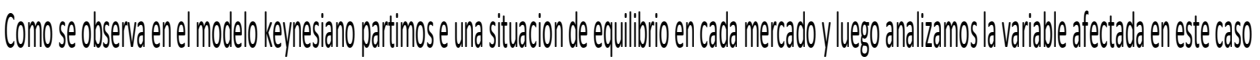

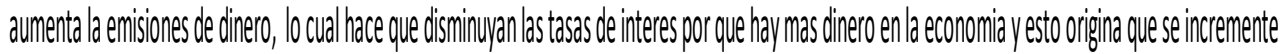

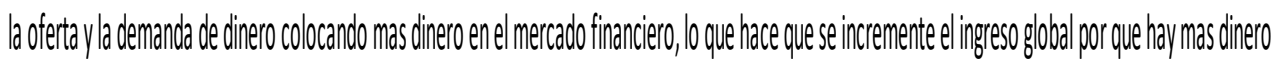
para consumo, inersion ygasto en el mercado de bieness yservicios. En cuantio a la funcion de produccion y a mercado aboora no seven afectados yse mantienen ceteris parbus.

\begin{tabular}{|c|c|c|c|c|c|c|c|c|c|c|}
\hline EmD & $y$ & C & | & $G$ & m & Dm & Sm & L & $W / P$ & Y \\
\hline$\uparrow$ & $\mathrm{T}$ & $\mathrm{A}$ & $\mathrm{A}$ & $\widehat{T}$ & $\Lambda$ & $\uparrow$ & $\pi$ & $\$$ & 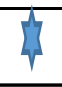 & 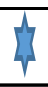 \\
\hline
\end{tabular}

Ilustración No. 102. Movimiento de las variables afectadas. 
4. Señor gerente de producción, que pasa cuando el gobierno decide aumentar los instrumentos de política fiscal, como se afectan las variables del modelo? MODELO KEINESIANO CERRADO

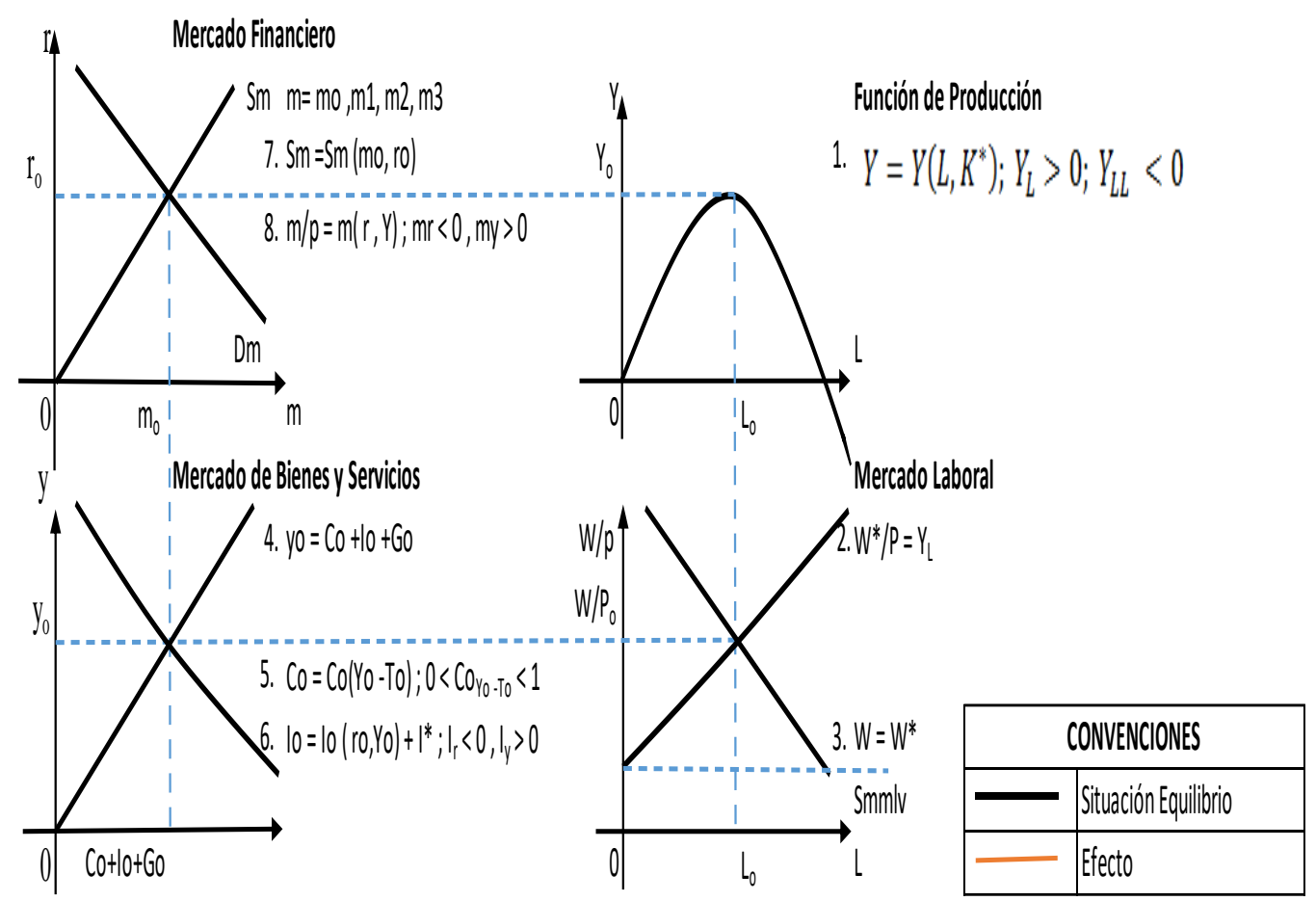

Como se observa en el modelo keynesiano partimos e una situacion de equilibrio en cada mercado y luego analizamos la variable afectada en este caso si el gobierno decide aumentar los instrumentos de politica fiscal, va a incrementar los impuestos yel gasto publico lo que conlleva por un lado a reducir el ingreso disponible, pero por el otro lado al incrementar el gasto aumenta el ingreso global de la economia logrando una mejor redistribucion del ingreso lo cual compensa con el aumento de los impuestos lo que hace que el modelo seequilibrey no se afecte. y por lo tanto no tiene ningun efecto si los cambios son igualmente son igualmente proporcionales.

\begin{tabular}{|c|c|c|c|c|c|c|c|c|c|c|}
\hline$T$ & y & C & | & $G$ & $\mathrm{~m}$ & Dm & Sm & L & $W / P$ & Y \\
\hline 75 & 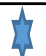 & 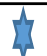 & $\Delta$ & A & is & 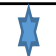 & 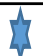 & 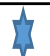 & $\$$ & 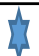 \\
\hline
\end{tabular}

Ilustración No. 103. Movimiento de las variables afectadas. 
5. Utilizando el diagrama del modelo Keynesiano cerrado con todas las ecuaciones, analice que pasa cuando disminuye la oferta monetarila.

\section{YODELO KENESSANO CERRADO}

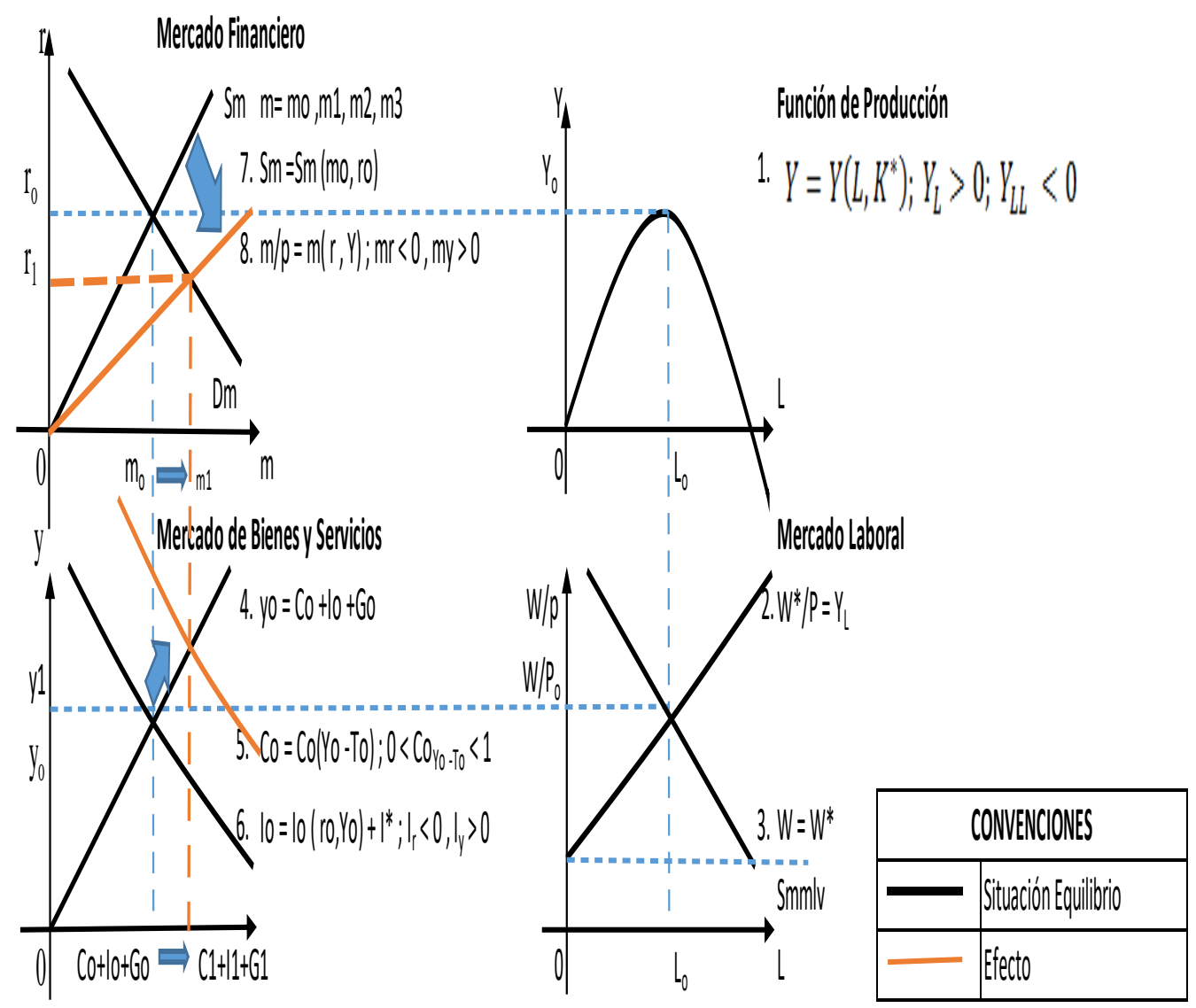

Como se observa en el modelo keynesiano partimos e una situacion de equil brio en cada mercado y luego analizamos la variable afectada en este caso siel gobierno decide aumentar la oferta monetaria, esto hace que las tasas de intereses bajen por que hay mas cantidad de dinero en la economia, por lo tanto tambien auementa la demanda de dinero y hay una expansion monetaria enel mercado financiero en cuanto al mercado de bienes y servicios aumenta e lingresso global y esto origina unamayor inversion, consumo y gasto, en cuento a los cuadrantes de produccion y de merccado laboral no se ven afectados puesto que ellos permanecen ceteris parhbus por que va han sido contratados previamente.

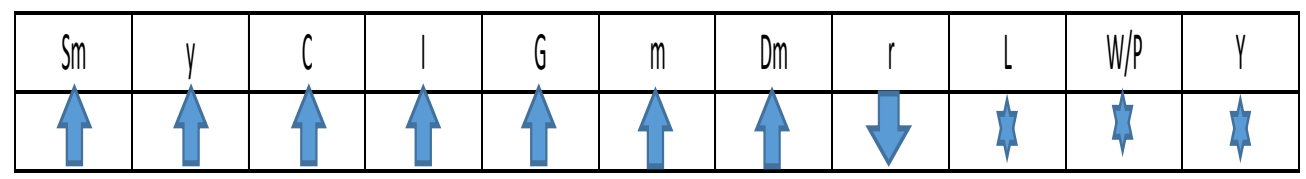

Ilustración No. 104. Movimiento de las variables afectadas. 
6. Itilizando el diagrama del modelo Keynesiano cerrado con todas las cecuaciones, analice que pasa clando aumenta el gasto púbico.

\section{NODELO KENESSANO CERRADO}

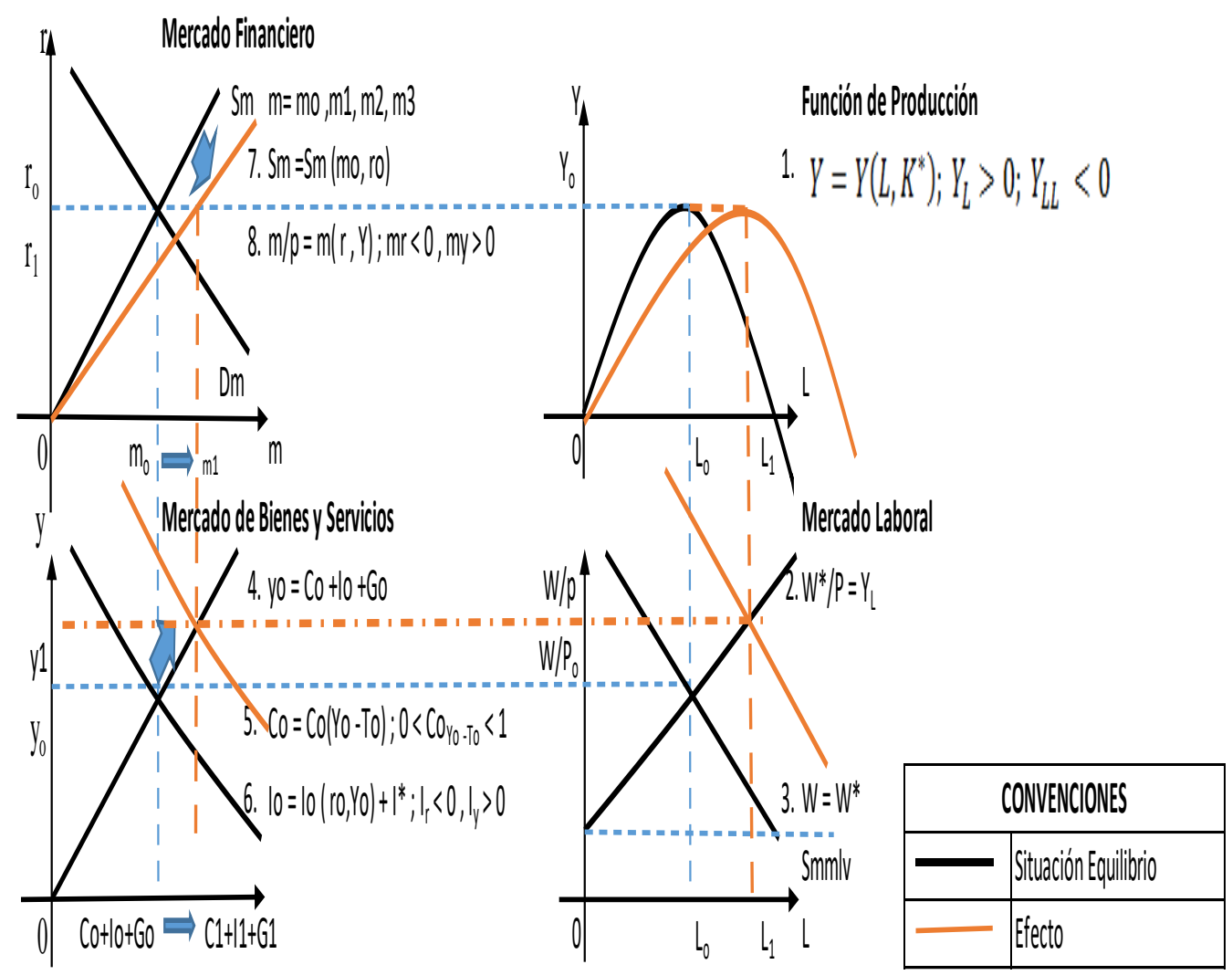

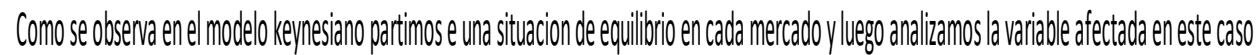
siel gobiemo decide aumentarel gasto publico esto hace equese incrementel a producción yse contratem mas mano de obra esta decision se toma

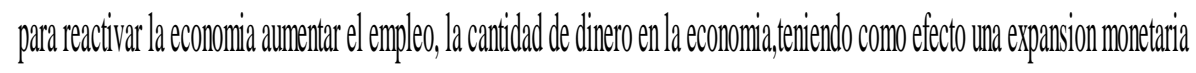

\begin{tabular}{|c|c|c|c|c|c|c|c|c|c|c|}
\hline$G$ & $y$ & C & | & $G$ & m & $\mathrm{Dm}$ & 1 & l & $W / P$ & y \\
\hline 75 & 77 & 71 & 71 & 7 & 77 & 7 & 75 & 7 & 7 & 5 \\
\hline
\end{tabular}

Ilustración No. 105. Movimiento de las variables afectadas. 


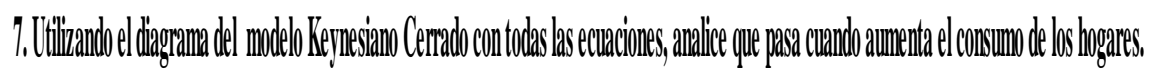

\section{MODELOKENESSHONOCERRDO}

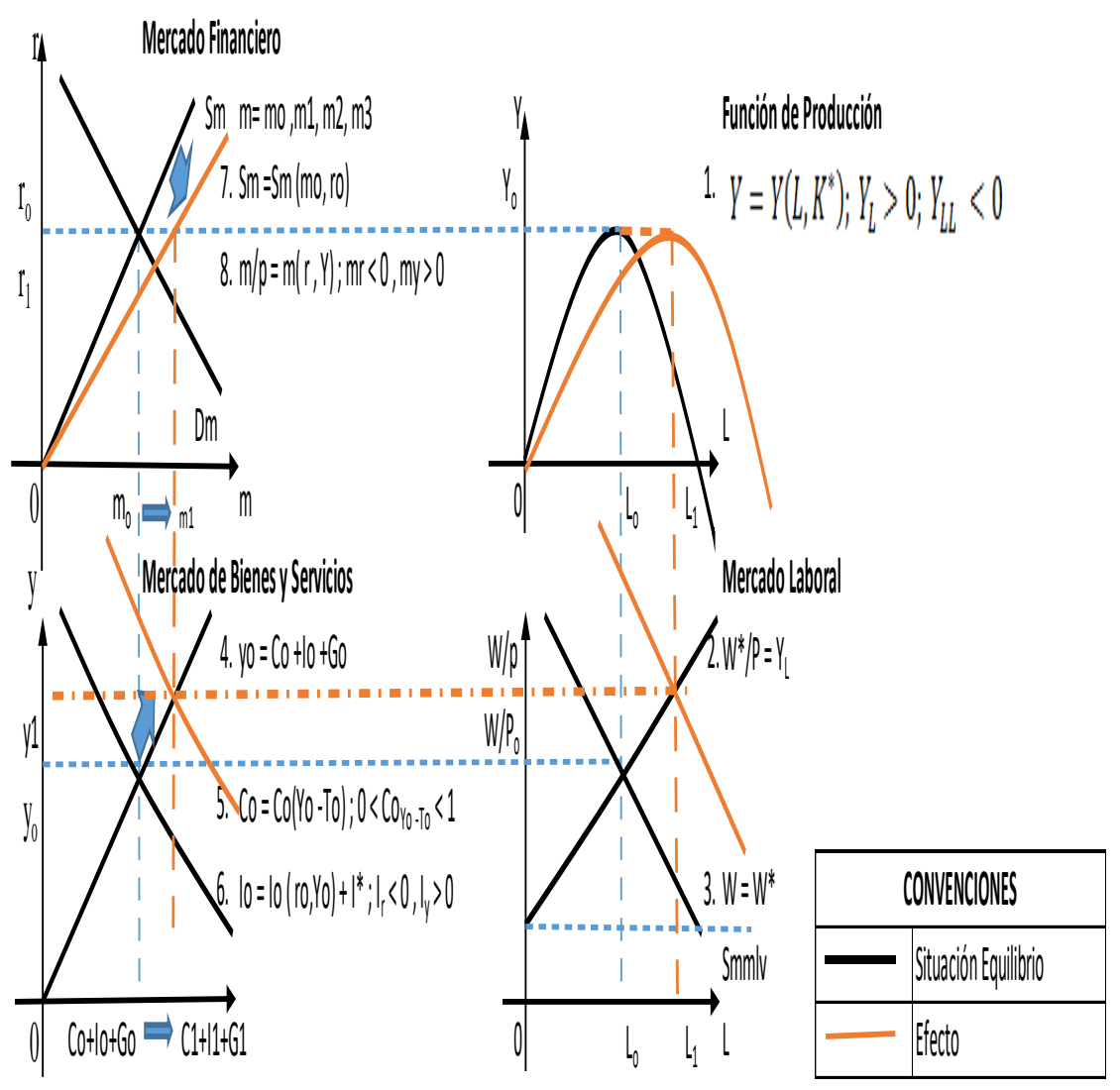

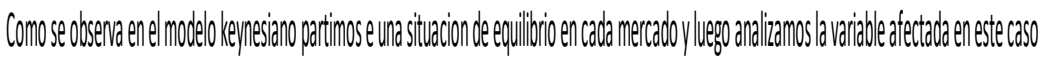

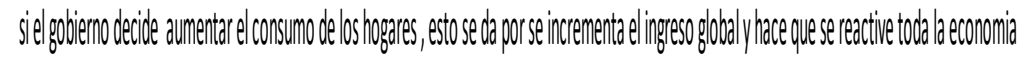

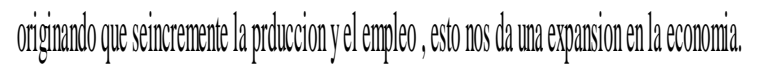

\begin{tabular}{|c|c|c|c|c|c|c|c|c|c|c|}
\hline$G$ & $y$ & l & | & $G$ & m & $\mathrm{Dm}$ & 1 & l & $W / P$ & $\gamma$ \\
\hline 7 & 7 & 78 & 7 & 4 & 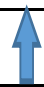 & 7 & 1 & 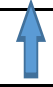 & 1 & 7 \\
\hline
\end{tabular}

Ilustración No. 106. Movimiento de las variables afectadas. 


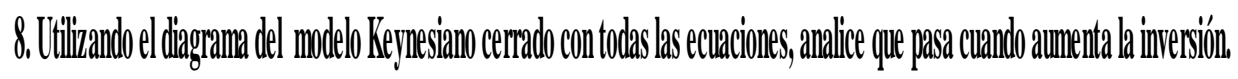

\section{MODELOKENESSHOCERRADO}

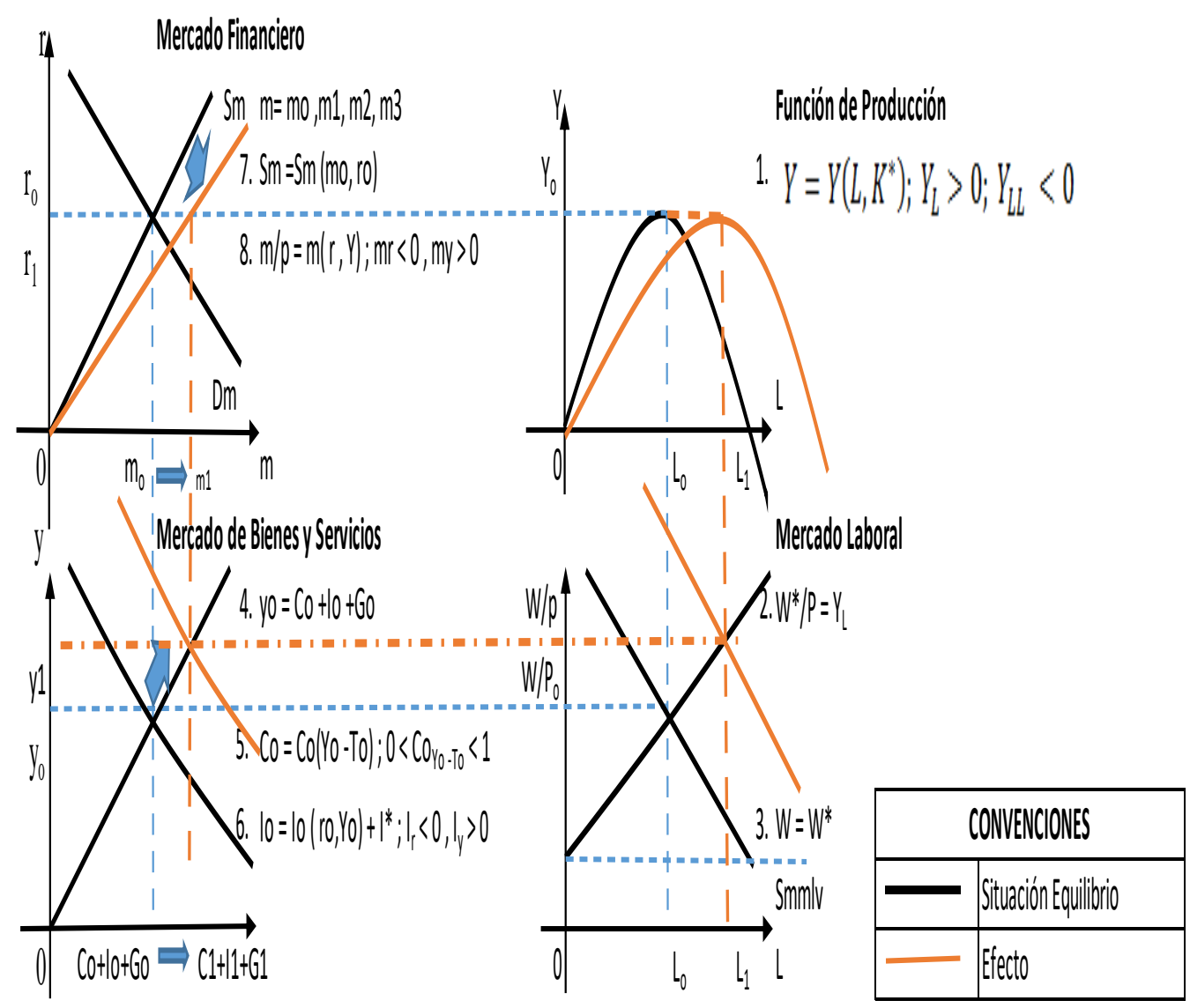

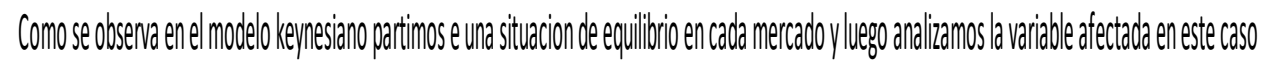

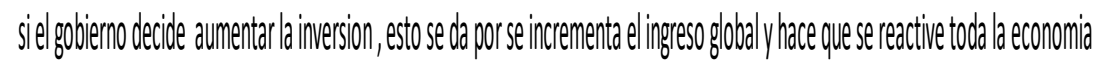
oniginando oque seincrementetel la prouccion yel empleo, esto nos da una expansionen la coconomia.

\begin{tabular}{|c|c|c|c|c|c|c|c|c|c|c|}
\hline$G$ & y & l & | & $G$ & m & $\mathrm{Dm}$ & " & l & $W / P$ & $\gamma$ \\
\hline 7 & & 7 & 7 & $\lambda$ & $\lambda$ & & $\Lambda$ & & 3 & \\
\hline
\end{tabular}

Ilustración No. 107. Movimiento de las variables afectadas. 


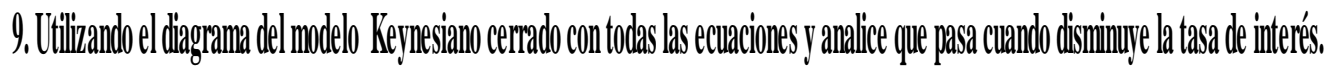

\section{MODELO KENESSINOCERRADO}
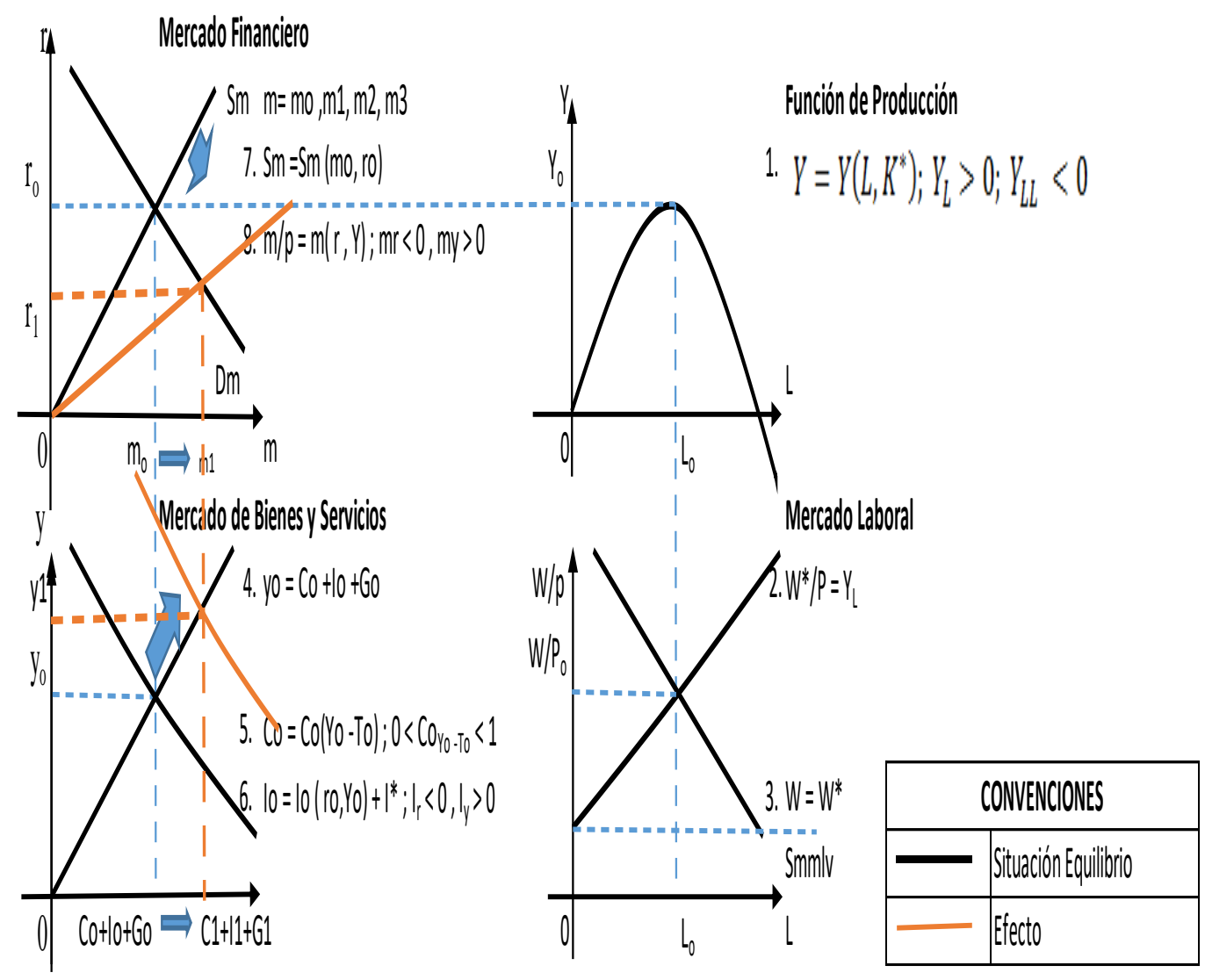

Como se observa en el modelo keynesiano partimos e una situacion de equilibrio en cada mercado y luego analizamos la variable afectada en este caso silas tasas de interes disminuyen, la gente querra demandar mas dinero y por lo tanto aumentara en el corto plazo la liquidez en la economia, Io cual hace que se incremente el ingreso global y afeca loa cuadrantes del mercado financiero y el mercado de bienesy servicios, lo que es la funcion de produccion yel mercado laboral se mantienen ceteris paribus.

\begin{tabular}{|c|c|c|c|c|c|c|c|c|c|c|}
\hline r & y & C & | & $G$ & m & Dm & $G$ & l & $W / P$ & $y$ \\
\hline$\sqrt{7}$ & 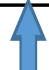 & 1 & 71 & 1 & 7 & 7 & 7. & $\sqrt{1}$ & 1 & 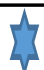 \\
\hline
\end{tabular}

Ilustración No. 108. Movimiento de las variables afectadas.

Enseñanza Del Modelo Keynesiano Para Estudiantes De 


\section{Pregrado Una Aproximación Diagramática}

TEST N. 2

Nombre: Laura Isabel Franco

Universidad: fundación universitaria Monserrate

Programa: finanzas y negocios

Fecha: $17 / 11 / 2016$

A continuación se presentan diez preguntas tipo Saber Pro a las cuales usted les dará solución.

1. ¿Señor gerente general, como se ve afectada su empresa cuando el banco de la república decide aumentar la tasa de interés de política monetaria? MODELO KEYNESIANO CERRADO

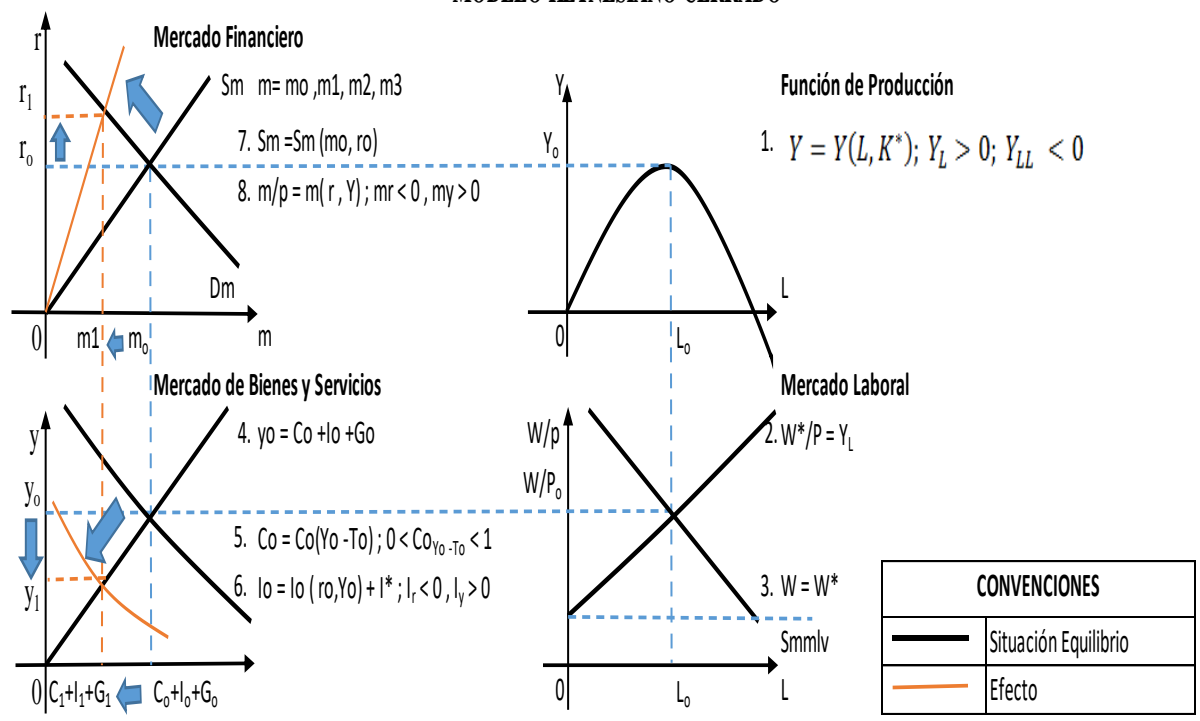

Como se observa en el modelo keynesiano partimos e una situacion de equilibrio en cada mercado y luego analizamos la variable afectada en este caso la tasa de interes que aumento lo cual hace que disminuya el ingreso disponible y ala vez hace disminuir el ingreso global en el mercado de bienes y servicios mientras que en el mercado monetario se afecta por que se reduce la demanda monetaria por el alto costo de los intereses. la funcion de produccion y el mercado laboral no se afectan por el incremento de las tasas de interes por que se conservan ceteris paribus.

\begin{tabular}{|c|c|c|c|c|c|c|c|c|c|}
\hline$R$ & $y-t$ & $C$ & $I$ & $G$ & $m$ & $D m$ & $Y$ & $L$ & $W / P$ \\
\hline$\uparrow$ & $\downarrow$ & $\downarrow$ & $\downarrow$ & $\downarrow$ & $\downarrow$ & $\Downarrow$ & $\downarrow$ & $\downarrow$ & $\$$ \\
\hline
\end{tabular}

Ilustración No. 109. Movimiento de las variables afectadas. 
2. ¿Señor gerente financiero, como se ve afectada su empresa cuando el banco de la república decide aumentar el encaje bancario?

Encaje bancario

Inversión

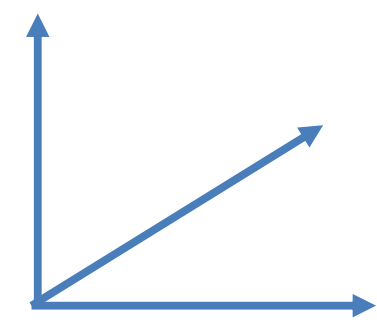

Cuando el banco realiza un mayor porcentaje en el encaje bancario habrá menos, por ende prestara menos y con tasas de interés más altas y se afectara el porcentaje de inversión para mejoras en la producción.

Ilustración No. 110. Movimiento de las variables afectadas.

3. ¿Señor gerente financiero, como se ve afectada su empresa cuando el banco de la república decide aumentar la emisión de dinero?

Emisión dinero

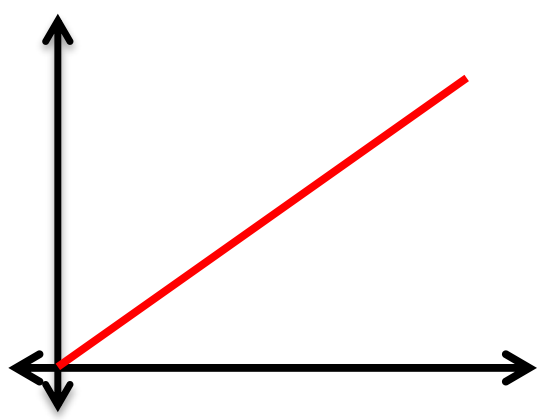

Cuando el banco de la republica accede a aumentar la emisión de dinero, las empresas aprovechan y deciden invertir en mayor porcentaje pero a largo plazo genera repercusiones de pérdida.

Inversión

Ilustración No. 111. Movimiento de las variables afectadas. 
4. ¿Señor gerente de producción, que pasa cuando el gobierno decide aumentar los instrumentos de política fiscal, como se afectan las variables del modelo?

Política fiscal

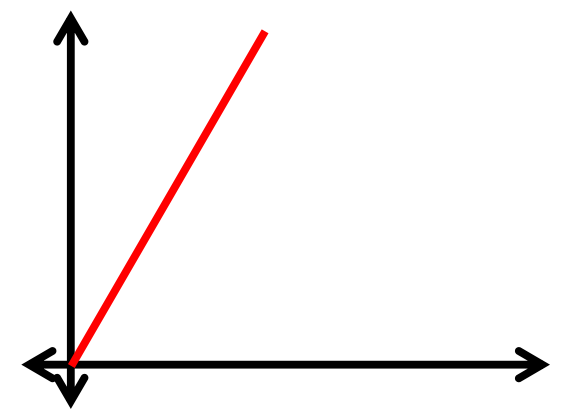

Inversión
Cuando el gobierno decide

aumentar los instrumentos de

política fiscal, las empresas

tienen menos oportunidades de

invertir ya que las tasas de

Ilustración No. 112. Movimiento de las variables afectadas.

5. Utilizando el diagrama del modelo Keynesiano cerrado con todas las ecuaciones, analice que pasa cuando disminuye la oferta monetaria.

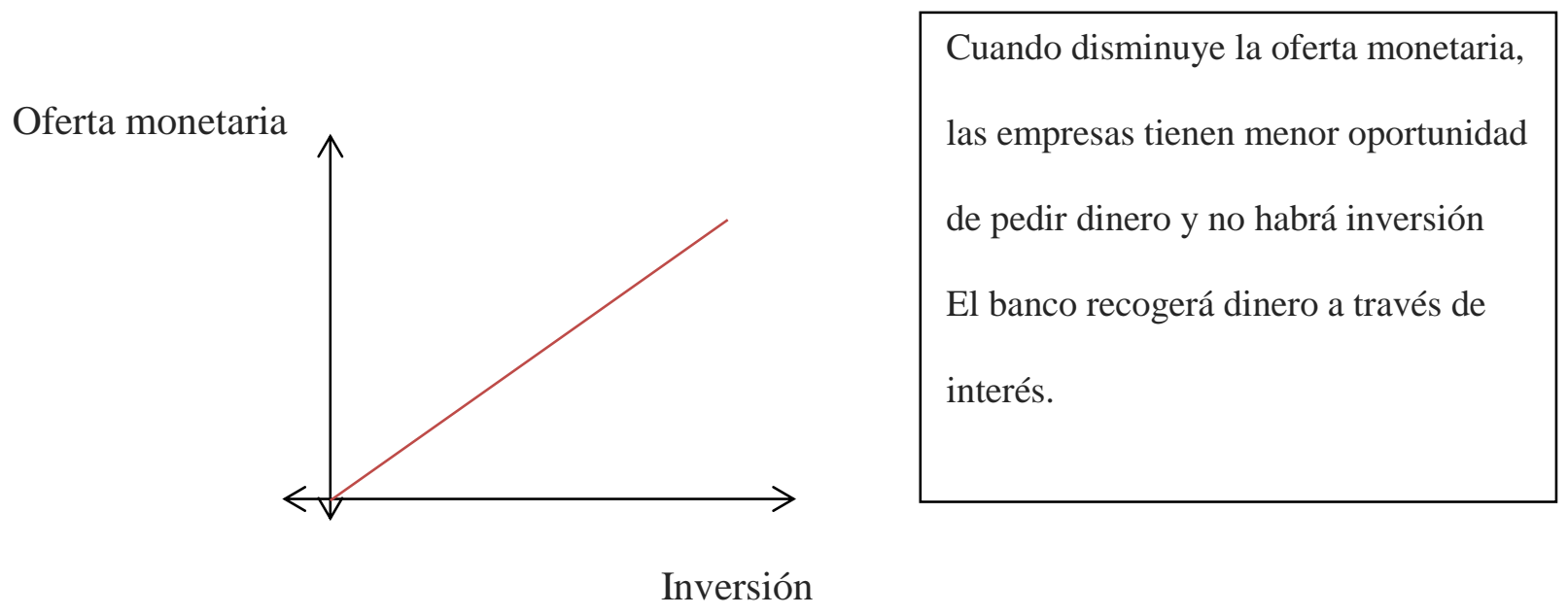

Ilustración No. 113. Movimiento de las variables afectadas. 
6. Utilizando el diagrama del modelo Keynesiano cerrado con todas las ecuaciones, analice que pasa cuando aumenta el gasto público.

Interés

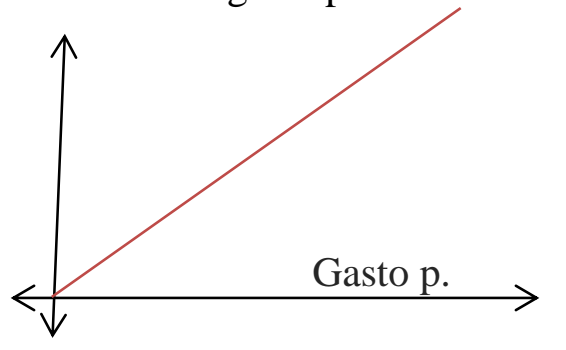

Cuando aumenta el gasto público, el gobierno necesita recoger dinero y para ello realiza un aumento a los intereses.

Ilustración No. 114. Movimiento de las variables afectadas.

7. Utilizando el diagrama del modelo Keynesiano Cerrado con todas las ecuaciones, analice que pasa cuando aumenta el consumo de los hogares.

$$
\begin{aligned}
& y=y(l . K) \\
& E L Y=\left[\begin{array}{cc}
\Delta \% l \\
\Delta \% y
\end{array} \cdot \frac{y}{l}\right]
\end{aligned}
$$

Cuando aumenta el consumo de los hogares se aumenta la producción, por ende aumenta la demanda de mano de obra.

8. Utilizando el diagrama del modelo Keynesiano cerrado con todas las ecuaciones, analice que pasa cuando aumenta la inversión.

$I=I(y \cdot r) \quad \begin{aligned} & \text { Cuando se realiza un aumento en la } \\ & \text { inversión, habrá mayores ingresos y } \\ & \text { mayor producción y generara una mejora } \\ & \text { en el presupuesto de la empresa. }\end{aligned}$

9. Utilizando el diagrama del modelo Keynesiano cerrado con todas las ecuaciones y analice que pasa cuando disminuye la tasa de interés. 
$I=I(y, r)$

Cuando disminuye la tasa de interés, habrá

más oportunidades para invertir en mayor

proporción.

\section{Enseñanza Del Modelo Keynesiano Para Estudiantes De \\ Pregrado Una Aproximación Diagramática}

\section{Test N. 2}

Nombre: Nika Dayana Suarez Feliz

Universidad: fundación universitaria Monserrate

Programa: finanzas y negocios

Fecha: 17/11/2016

A continuación se presentan diez preguntas tipo Saber Pro a las cuales usted les dará solución

1. ¿Señor gerente general, como se ve afectada su empresa cuando el banco de la república decide aumentar la tasa de interés de política monetaria?

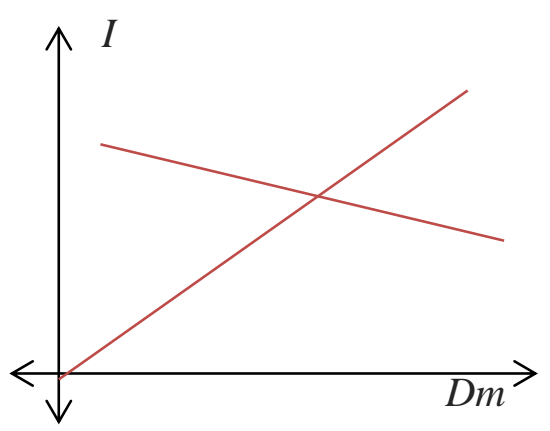

Si en mi empresa se aumenta todas las tasas de interés, puede disminuir mis ingresos, pero si mi empresa decide invertir, recibirá mayores ganancias.

También diría que se verá afectada ya que no podría adquirir préstamos por las tasas de interés tan alta.

Ilustración No.115. Movimiento de las variables afectadas. 
2. ¿Señor gerente financiero, como se ve afectada su empresa cuando el banco de La república decide aumentar el encaje bancario?

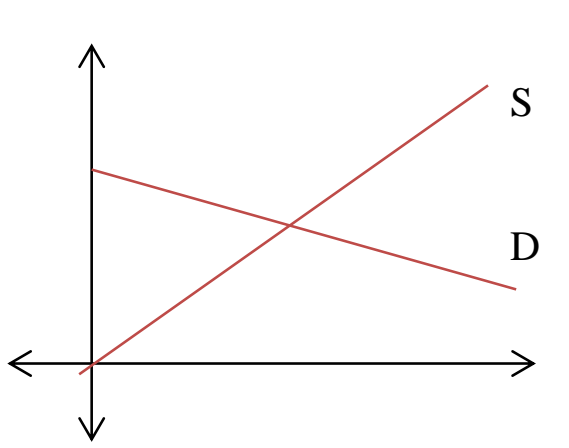

Cuando esto sucede, es porque hay una contratación, así que yo como empresa necesito más dinero pero los bancos no tienen suficiente para prestar, por consiguiente, $\mathrm{mi}$ empresa no puede invertir o realizar las actividades, ya que el dinero que tiene no es suficiente.

\section{Ilustración No. 116. Movimiento de las variables afectadas.}

3. ¿Señor gerente financiero, como se ve afectada su empresa cuando el banco de la república deøde aumentar la emisión de dinero?

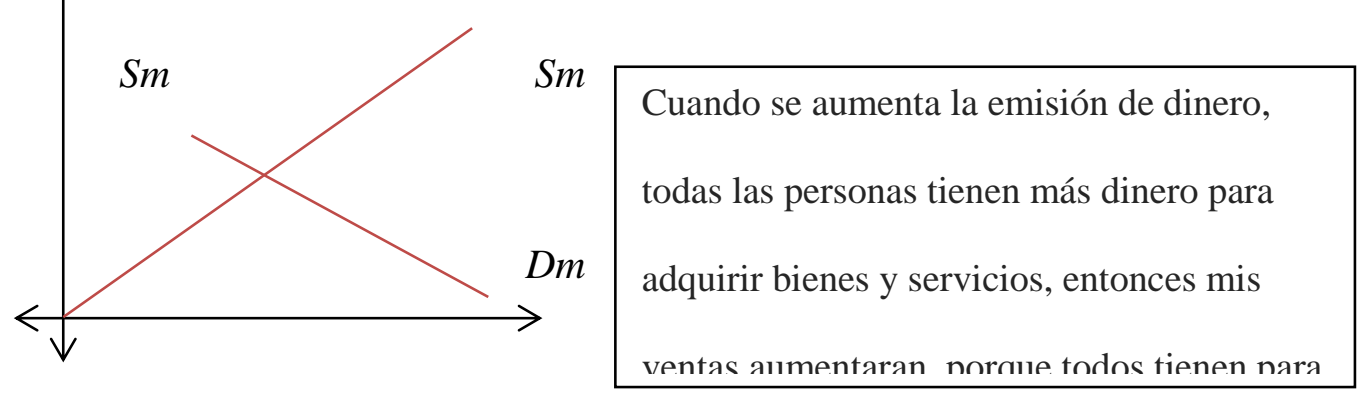

$D m$

Ilustración No. 117. Movimiento de las variables afectadas.

4. ¿Señor gerente de producción, que pasa cuando el gobierno decide aumentar los instrumentos de política fiscal, como se afectan las variables del modelo?

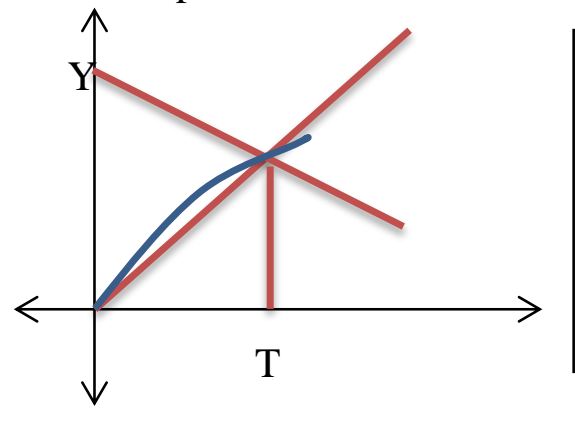

Cuando se aumenta los impuestos, mi empresa se verá obligada a disminuir su producción, por ende se disminuirá la oferta y no habrá productos suficientes,

Ilustración No. 118. Movimiento de las variables afectadas. 
5. Utilizando el diagrama del modelo Keynesiano cerrado con todas las ecuaciones, analice que pasa cuando disminuye la oferta monetaria.

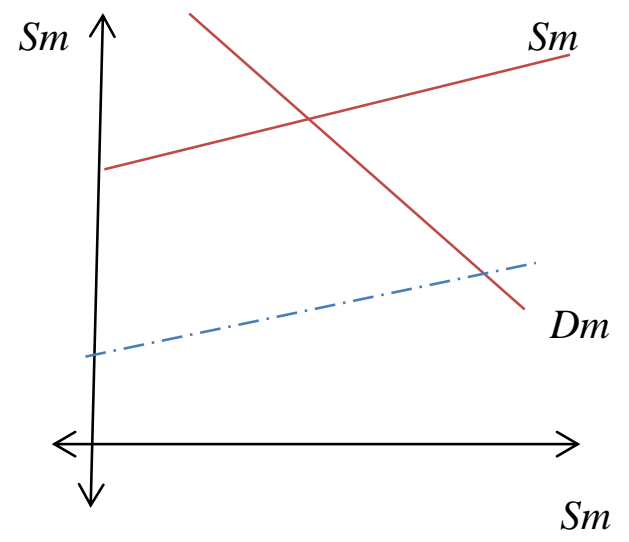

Cuando disminuye la oferta
monetaria, es porque hay una
contracción de la economía por
medio del aumento de tasas de
interés.

Ilustración No. 119. Movimiento de las variables afectadas.

6. Utilizando el diagrama del modelo Keynesiano cerrado con todas las ecuaciones, analice que pasa cuando aumenta el gasto público.

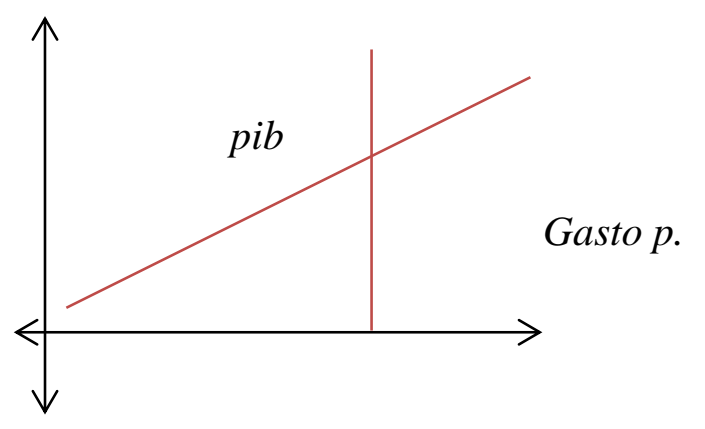

Cuando aumenta el gasto público se ve afectado el nivel de ahorro de la población, además puede generar aumento en los precios al aumentar la demanda de bienes y servicios.

Ilustración No. 120. Movimiento de las variables afectadas. 
7. Utilizando el diagrama del modelo Keynesiano Cerrado con todas las ecuaciones, analice que pasa cuando aumenta el consumo de los hogares.

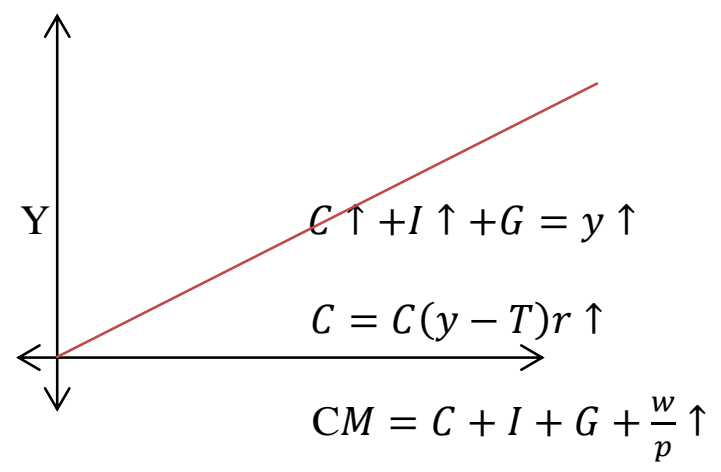

Aumenta el consume, aumentan

los ingresos, y como hay mayor consumo debe aumentar la

producción, así que se debe

Ilustración No.121. Movimiento de las variables afectadas.

8. Utilizando el diagrama del modelo Keynesiano cerrado con todas las ecuaciones, analice que pasa cuando aumenta la inversión.

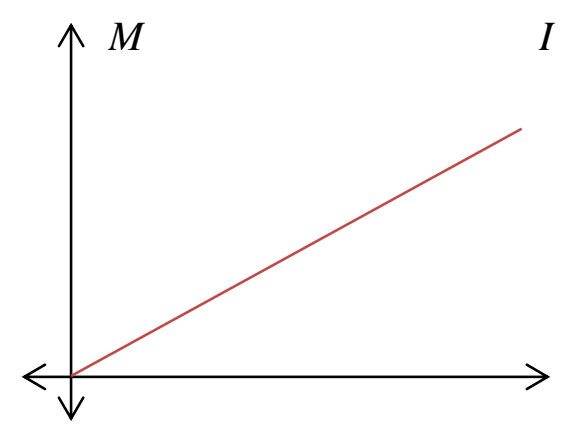

$$
\begin{aligned}
& C+I+G=y \\
& C=c(y-T) \cdot r \\
& M=C+I+G+\frac{w}{p}
\end{aligned}
$$

\section{Ilustración No. 122. Movimiento de las variables afectadas.}

Cuando en mi empresa aumenta la inversión, aumenta los ingresos y el consumo y el presupuesto. 
9. Utilizando el diagrama del modelo Keynesiano cerrado con todas las ecuaciones y analice que pasa cuando disminuye la tasa de interés.

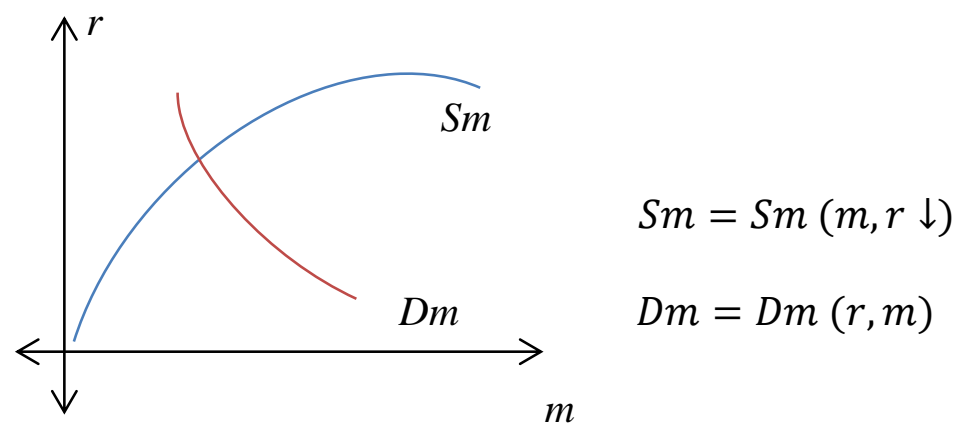

Ilustración No. 123. Movimiento de las variables afectadas.

ENSEÑANZA DEL MODELO KEYNESIANO PARA ESTUDIANTES DE PREGRADO UNA APROXIMACIÓN DIAGRAMATICA

TEST N. 2

Nombre: Oscar David Ayala Gutiérrez

Universidad: fundación universitaria Monserrate

Programa: finanzas y negocios

Fecha: 17/11/2016

A continuación se presentan diez preguntas tipo Saber Pro a las cuales usted les dará solución

1. ¿Señor gerente general, como se ve afectada su empresa cuando el banco de la república decide aumentar la tasa de interés de política monetaria?

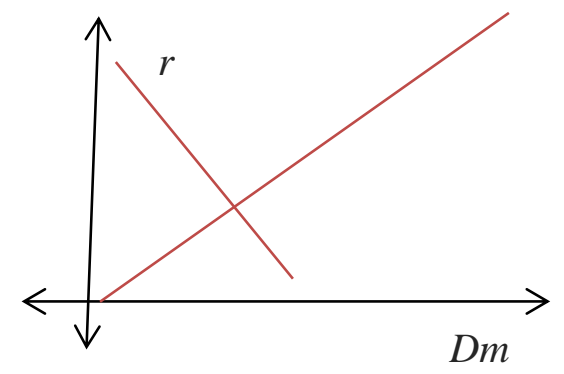

Si el banco de la republica aumenta las tasas de interés, la empresa tendrá menor demanda de crédito porque se verá afectada mi inversión y el crecimiento productivo y económico. 


\section{Ilustración No. 124. Movimiento de las variables afectadas.}

2. ¿Señor gerente financiero, como se ve afectada su empresa cuando el banco de la república decide aumentar el encaje bancario?

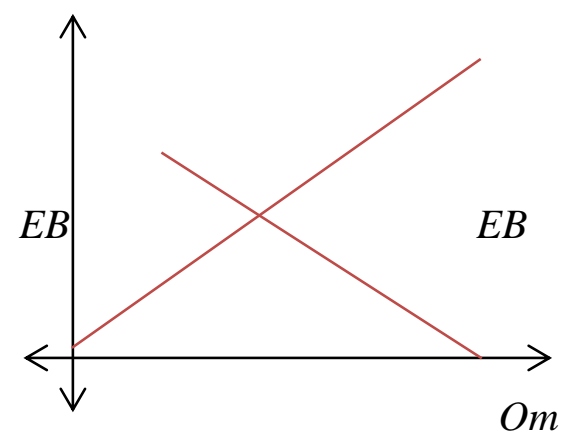

Si el banco de la republica decide aumentar el encaje bancario habrá menos oferta monetaria por parte de los bancos y subirán las tasas de interés, por ende costara más pedir un crédito para invertir en la operación.

\section{Ilustración No. 125. Movimiento de las variables afectadas.}

3. ¿Señor gerente financiero, como se ve afectada su empresa cuando el banco de la república decide aumentar la emisión de dinero?

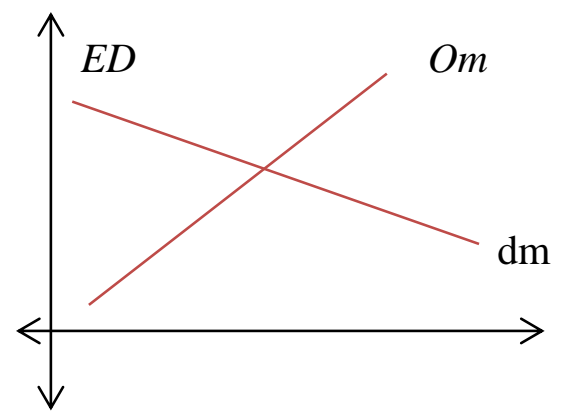
Si el banco de la republica decide aumentar la emisión de dinero, los bancos aumentaran la oferta monetaria y bajaran las tasas de interés, por ende aumenta mi posibilidad de inversión y optimizar mi proceso de producción.

\section{Ilustración No. 126. Movimiento de las variables afectadas.}

4. ¿Señor gerente de producción, que pasa cuando el gobierno decide aumentar los instrumentos de política fiscal, como se afectan las variables del modelo?

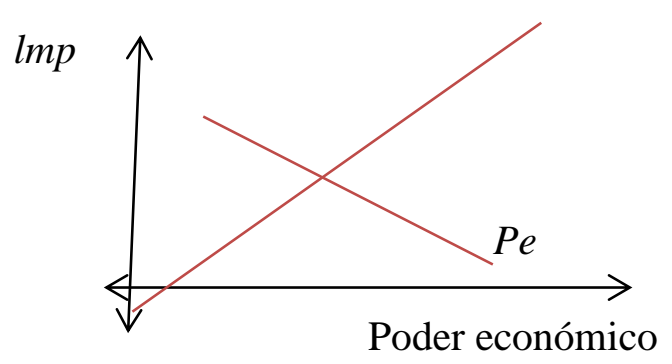
Al aumentar los instrumentos de política fiscal, subirán los impuestos y aumentaran las tasas de interés, por ende disminuye mi poder económico y la capacidad de invertir para aumentar la producción.


Ilustración No. 127. Movimiento de las variables afectadas.

5. Utilizando el diagrama del modelo Keynesiano cerrado con todas las ecuaciones, analice que pasa cuando disminuye la oferta monetaria.

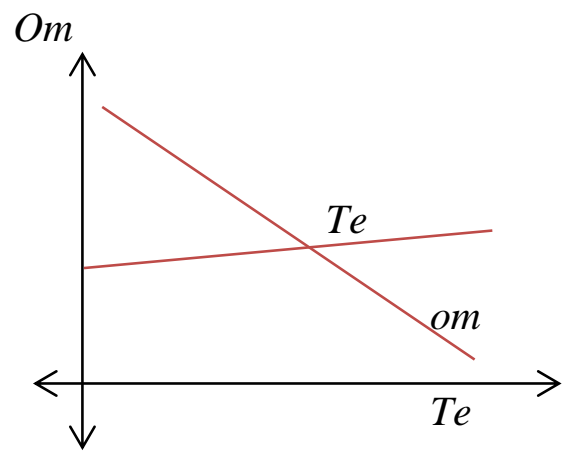

$$
\begin{aligned}
& \text { Cuando disminuye la oferta monetaria, } \\
& \text { aumenta las tasas de interés, disminuye el } \\
& \text { flujo de efectivo y hay una contracción en } \\
& \text { la economía. }
\end{aligned}
$$

Ilustración No. 128. Movimiento de las variables afectadas.

6. Utilizando el diagrama del modelo Keynesiano cerrado con todas las ecuaciones, analice que pasa cuando aumenta el gasto público.

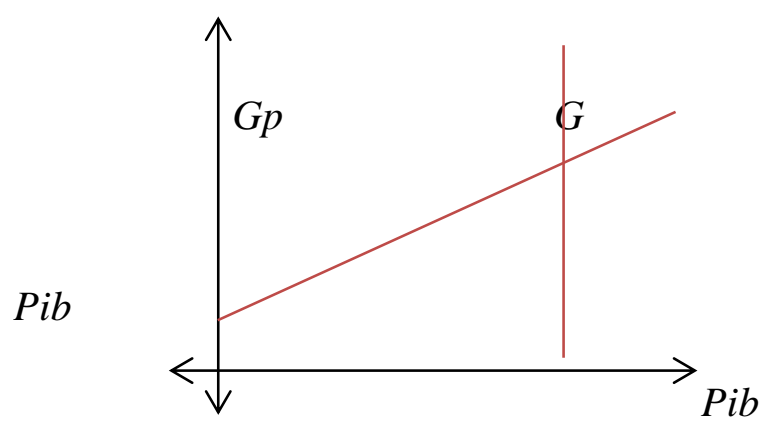
Cuando se aumenta el gasto público, aumenta el ingreso disponible y esto hace que la economía crezca.

Ilustración No. 129. Movimiento de las variables afectadas.

7. Utilizando el diagrama del modelo Keynesiano Cerrado con todas las ecuaciones, analice que pasa cuando aumenta el consumo de los hogares.

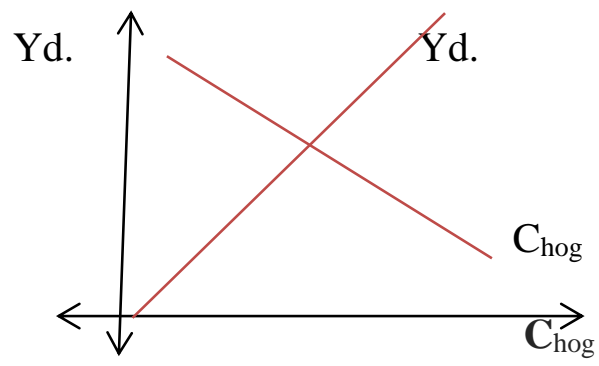

Cuando el consumo de los hogares aumenta significa que ha aumentado el ingreso de las personas, por ende ha aumentado la producción de las empresas. 
Ilustración No. 130. Movimiento de las variables afectadas.

8. Utilizando el diagrama del modelo Keynesiano cerrado con todas las ecuaciones, analice que pasa cuando aumenta la inversión.

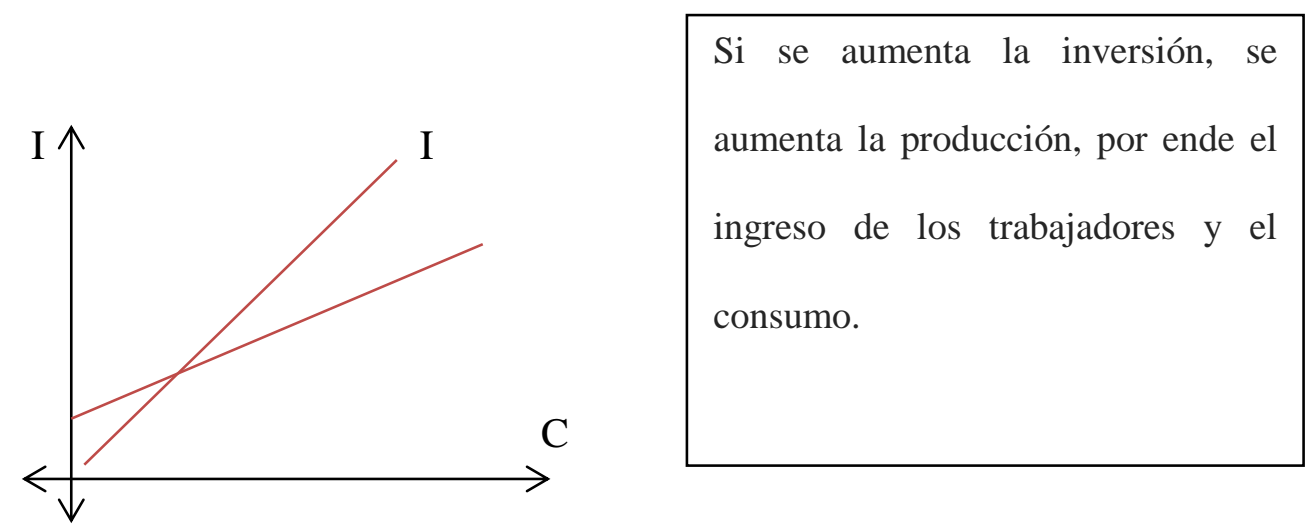

Ilustración No. 131. Movimiento de las variables afectadas.

9. Utilizando el diagrama del modelo Keynesiano cerrado con todas las ecuaciones y analice que pasa cuando disminuye la tasa de interés.

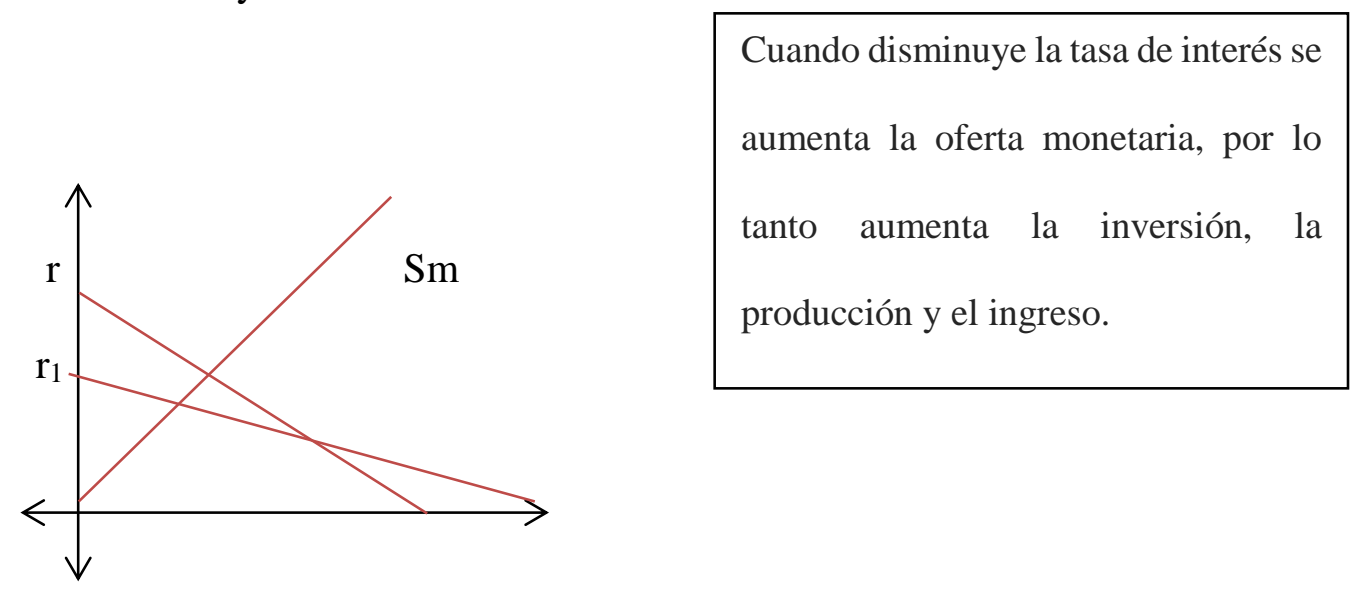

Ilustración No. 132. Movimiento de las variables afectadas. 